\title{
Duct Leakage Modeling in EnergyPlus and Analysis of Energy Savings from Implementing SAV with InCITe ${ }^{\mathrm{TM}}$
}

Craig P. Wray and Max H. Sherman

\author{
Environmental Energy Technologies Division \\ Indoor Environment Department \\ Lawrence Berkeley National Laboratory \\ Berkeley, CA 94720
}

March 2010

This work was supported by the California Energy Commission through the Public Interest Energy Research program under Work Authorization BOA\#78-P-04, Interagency Agreement No. 500-99-013 and by the Assistant Secretary for Energy Efficiency and Renewable Energy, Office of Building Technology, State, and Community Programs, of the U.S. Department of Energy under Contract No. DE-AC02$05 \mathrm{CH} 11231$. 


\section{DISCLAIMER}

This document was prepared as an account of work sponsored by the United States Government. While this document is believed to contain correct information, neither the United States Government nor any agency thereof, nor The Regents of the University of California, nor any of their employees, makes any warranty, express or implied, or assumes any legal responsibility for the accuracy, completeness, or usefulness of any information, apparatus, product, or process disclosed, or represents that its use would not infringe privately owned rights. Reference herein to any specific commercial product, process, or service by its trade name, trademark, manufacturer, or otherwise, does not necessarily constitute or imply its endorsement, recommendation, or favoring by the United States Government or any agency thereof, or The Regents of the University of California. The views and opinions of authors expressed herein do not necessarily state or reflect those of the United States Government or any agency thereof or The Regents of the University of California.

Ernest Orlando Lawrence Berkeley National Laboratory is an equal opportunity employer. 


\section{Table of Contents}

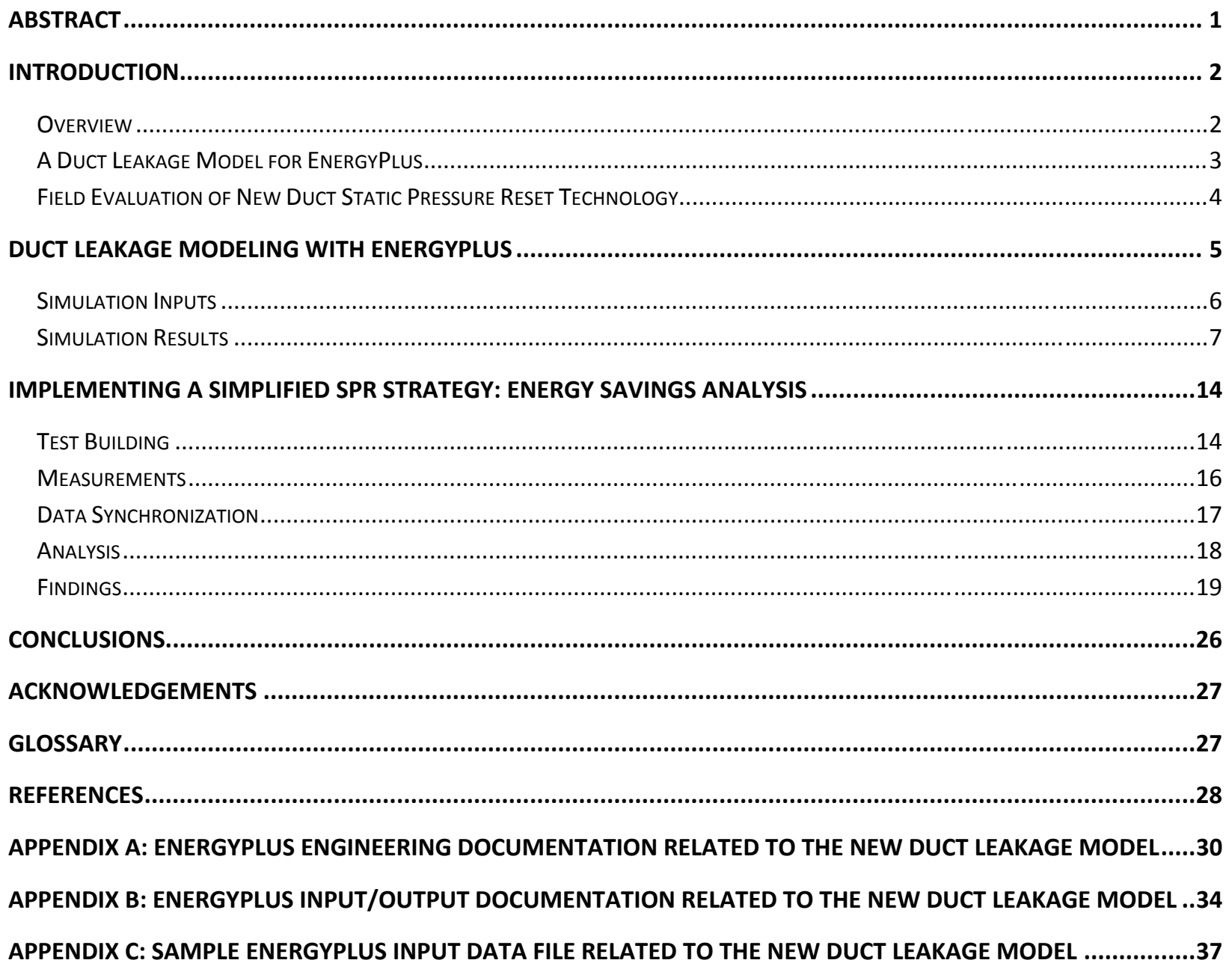




\section{List of Figures}

Figure 1. Supply Fan Power Variation with Leakage and Time .............................................................. 7

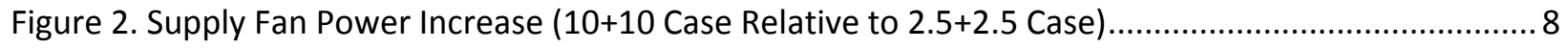

Figure 3. Ceiling Plenum Air Temperature Changes (10+10 Case Relative to $2.5+2.5$ Case)...................... 9

Figure 4. Ceiling Heat Loss Variation with Zone Load Fraction...................................................... 9

Figure 5. Frequency Distribution of Ceiling Heat Loss Relative to Net Zone Load .................................. 10

Figure 6. Cooling Coil Load versus Outdoor Air Temperature ......................................................... 11

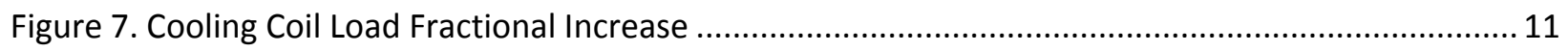

Figure 8. Reheat Coil Load versus Outdoor Air Temperature......................................................... 12

Figure 9. Reheat Coil Load Fractional Increase ........................................................................... 12

Figure 10. Duct Layout for Intervention Floor (control floor duct layout is similar) ............................... 15

Figure 11. Comparison between Supply Fan Airflows and Outdoor Temperature ................................ 18

Figure 12. Duct Static Pressure Set Points - Intervention Floor ......................................................... 20

Figure 13.Measured Duct Static Pressures - Intervention Floor ......................................................... 20

Figure 14. Measured Duct Static Pressures - Control Floor .............................................................. 21

Figure 15. Measured Supply Fan Pressure Rises - Intervention Floor ................................................... 22

Figure 16. Measured Supply Fan Power - Intervention Floor ............................................................. 22

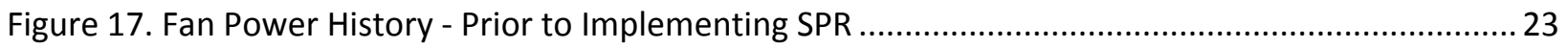

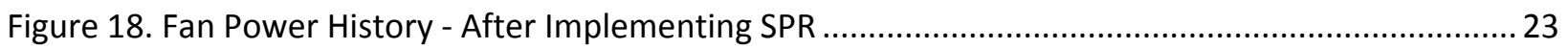

Figure 19. Daily Snapshot - Fan Power History - Prior to Implementing SPR - June 9............................. 24

Figure 20. Daily Snapshot - Fan Power History - After Implementing SPR - July 22 ............................... 24 


\section{List of Tables}

Table 1. Summary of Duct Leakage Impacts on HVAC Site and Source Energy Use ................................13

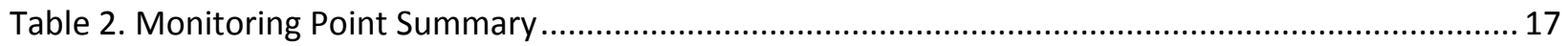

Table 3. Summary of Site Energy Reductions from Implementing SPR - Normal Operation .....................25

Table 4. Summary of Site Energy Reductions from Implementing SPR - Peak Periods ............................ 26 


\section{ABSTRACT}

This project addressed two significant deficiencies in air-handling systems for large commercial building: duct leakage and duct static pressure reset. Both constitute significant energy reduction opportunities for these buildings.

The overall project goal is to bridge the gaps in current duct performance modeling capabilities, and to expand our understanding of air-handling system performance in California large commercial buildings. The purpose of this project is to provide technical support for the implementation of a duct leakage modeling capability in EnergyPlus, to demonstrate the capabilities of the new model, and to carry out analyses of field measurements intended to demonstrate the energy saving potential of the SAV with InCITe ${ }^{\mathrm{TM}}$ duct static pressure reset (SPR) technology.

A new duct leakage model has been successfully implemented in EnergyPlus, which will enable simulation users to assess the impacts of leakage on whole-building energy use and operation in a coupled manner. This feature also provides a foundation to support code change proposals and compliance analyses related to Title 24 where duct leakage is an issue. Our example simulations continue to show that leaky ducts substantially increase fan power: $10 \%$ upstream and $10 \%$ downstream leakage increases supply fan power $30 \%$ on average compared to a tight duct system (2.5\% upstream and 2.5\% downstream leakage). Much of this increase is related to the upstream leakage rather than to the downstream leakage. This does not mean, however, that downstream leakage is unimportant. Our simulations also demonstrate that ceiling heat transfer is a significant effect that needs to be included when assessing the impacts of duct leakage in large commercial buildings. This is not particularly surprising, given that "ceiling regain” issues have already been included in residential analyses as long as a decade ago (e.g., ASHRAE Standard 152); mainstream simulation programs that are used for large commercial building energy analyses have not had this capability until now.

Our analyses of data that we collected during our 2005 tests of the SAV with InCITe ${ }^{\mathrm{TM}}$ duct static pressure reset technology show that this technology can substantially reduce fan power (in this case, by about 25 to 30\%). Tempering this assessment, however, is that cooling and heating coil loads were observed to increase or decrease significantly depending on the time window used. Their impact on cooling and heating plant power needs to be addressed in future studies; without translating the coil loads to plant equipment energy use, it is not possible to judge the net impact of this SPR technology on whole-building energy use. If all of the loads had decreased, such a step would not be as necessary.

Keywords: airflow, buildings, duct, energy, fan, HVAC, power, retrofits, simulation, system 


\section{INTRODUCTION}

\section{Overview}

Typically in North American large commercial buildings, central HVAC systems supply heated or cooled air to conditioned spaces through a complex network of ducts. Fans generate the large pressure rises needed to circulate the air through the typically long duct runs; the associated fan power is a substantial fraction of HVAC energy use. For example, based on Year 2000 energy estimates by the California Energy Commission (Brook 2002), site electricity consumption for commercial buildings in California was 91,800 GWh that year, with a peak demand of 20,200 MW; $27 \%(25,200 \mathrm{GWh})$ of this energy and 50\% (10,200 MW) of this peak demand were related to HVAC equipment operation. The CEC also estimates that $39 \%(9,800 \mathrm{GWh})$ of this HVAC consumption and 21\% (2,100 MW) of this HVAC demand was associated with fan operation; central system supply and return fans represented 56\% (5,500 GWh) of this fanrelated consumption and 48\% (1,000 MW) of this fan-related demand. National energy consumption and peak demand values are on the order of ten times larger.

Although the energy efficiency of many HVAC components in commercial buildings has substantially improved over the past 20 years (e.g., chillers, air-handler drives), there is still a need to make other equally critical components more efficient (e.g., the air handling system itself, which links heating and cooling equipment to occupied spaces). For example, field tests by Lawrence Berkeley National Laboratory (LBNL) in a dozen large commercial buildings suggest that supply duct leakage is widespread and can be as large as 10 to $25 \%$ of air-handler flow (Wray et al. 2005). Measurements by Diamond et al. (2003) in a large commercial building confirmed research-grade simulation results (Franconi 1999; Wray and Matson 2003) that supply duct leakage alone can significantly increase HVAC system energy consumption: adding 15\% leakage (referenced to the average flow through the supply fan during its operation) leads to a fan energy increase of 25 to $35 \%$.

Using a duct-static-pressure reset (SPR) control strategy to reduce duct static pressures (so that at least one terminal box damper is nearly fully open) has the potential to save as much fan energy as does sealing supply duct leaks. For example, recent measurements of duct static pressures by Hydeman et al. (2003) and Federspiel (2005) in three large commercial buildings with variableair-volume (VAV) systems and constant duct-static-pressure set points showed that the set points were 1.3 to 2.0 times what was needed to operate the system, even at maximum load. Assuming a system is oversized about 60\% (EPA 2008) and ignoring other effects on fan pressure rise and efficiency, this suggests that supply fan energy might be reduced by about 25 to $50 \%$ in some cases simply by using SPR control. Implementing fan staging strategies and correcting other fan and duct system deficiencies (e.g., reversed fan rotation, belt slippage, inefficient motors, and restrictive duct entries) offer further opportunities for savings.

California Title 24 (CEC 2008a) is one of the most advanced energy codes in the United States and, like ASHRAE Standard 90.1 (2007), already requires SPR for new buildings with VAV systems that include zone-level direct-digital controls (DDC). However, buildings without zonelevel DDC, which includes at least half of the building stock (Brook 2002), are not required to use SPR. Furthermore, despite the potential for significant energy savings by improving airhandling systems in large commercial buildings, there are no provisions to credit airtight duct systems in these buildings. 
As an example of the possible savings from improving air-handling systems, we crudely estimate that implementing SPR and reducing supply duct leakage airflows has the statewide potential to save about 900 to 2,200 GWh (\$90 to $\$ 220$ million) annually and about 170 to $410 \mathrm{MW}$ in peak demand. Our estimates assume that SPR can be implemented in half of the estimated 8 to $39 \%$ of existing large commercial buildings with VAV systems, that static pressure set points are 1.3 to 2.0 times what is needed to operate the system even at maximum load (assuming that reducing the pressure translates to fan power savings of 25 to 50\%), that three-quarters of existing buildings can benefit from supply duct leakage sealing (Wray et al. 2005), and that the duct leakage that can be eliminated ranges from 10 to $20 \%$ of the nominal design supply airflow in each building (fan power increases associated with this duct leakage are 26 to $70 \%$ respectively; eliminating this duct leakage translates to fan power savings of 21 to 41\%). The lower bounds for savings are based upon LBNL measurements in a Sacramento building; the upper bounds are based upon predictions by Hydeman et al. (2003) and Franconi (1999). Dollar savings assume an electricity price of $\$ 0.10$ per $\mathrm{kWh}$.

There are several reasons for the system deficiencies and absence of code requirements described earlier in this section. One, there is a lack of skilled people and procedures to carry out functional performance tests and efficiently operate buildings (PECI 2004). Second, there are no standardized test methods to characterize fan and duct system performance in these buildings, and testing is widely perceived as too expensive and/or unnecessary. Third, demonstrations of the energy savings potentials of related technology are extremely limited. Fourth, mainstream simulation tools such as EnergyPlus with their simplified fan models and lack of duct system models have been unable to simulate the effects of duct leakage, SPR, or other fan and duct system component improvements, so they cannot be used to demonstrate the energy-saving benefits associated with efficient fan and duct systems.

\section{A Duct Leakage Model for EnergyPlus}

To support new energy-efficiency standards for duct performance, and to improve calibrated simulations for large commercial buildings that might be used in applications such as faultdetection diagnostics or demand-response analyses, there is a need now to add a duct leakage model to programs such as EnergyPlus. Although the Florida Solar Energy Center (FSEC) has already implemented a duct model in EnergyPlus for residential and small commercial buildings, their implementation is not easily extensible to large commercial buildings. One reason is that the FSEC model relies upon detailed airflow versus pressure modeling of the entire duct network. Consequently, modeling a large commercial building's duct system would require a vast number of inputs, and defining all these inputs is not practical for standards compliance analyses. Other reasons are that the duct models themselves are not well developed (e.g., for junctions) and in many cases the inputs are unknowable (e.g., the location and size of each and every duct leak).

The simple "data driven" leakage-fraction-based TRNSYS models that we developed and used in the California Energy Commission’s “High Performance Commercial Buildings” PIER project (Wray 2003, Wray and Matson 2003) are more practical than the FSEC model, because one can actually measure the few parameters needed for inputs. For example, to model a variable-airvolume (VAV) system, the simpler model only requires specifying the leakage flow upstream of terminal boxes and leakage flow fraction downstream of each box (instead of doing very complicated detailed duct network simulations). Inputs for the simpler model can be determined 
using a new diagnostic that LBNL has developed to accurately, rapidly, and inexpensively measure duct leakage flows for entire duct systems (Delporte 2004, Wang and Sherman 2004). This new diagnostic is a simple extension of current test and balance activities (and duct leakage area testing) in large commercial buildings. It will also be useful for verifying duct sealing if credits are claimed in future standards compliance analyses.

\section{Field Evaluation of New Duct Static Pressure Reset Technology}

Over the past several years, with support from the Commission's EISG program, Federspiel Controls developed a simplified method for SPR control of VAV systems. The method is called Static pressure Adjustment from Volume flow (SAV). SAV controls duct static pressure based on a duct pressure-supply fan airflow correlation that is determined using InCITe ${ }^{\mathrm{TM}}$, which is a simple diagnostic procedure and model of system operation. Significant advantages of the new method are that it is potentially more reliable than SPR strategies that rely on zone-level DDCcontrol and VAV box damper position sensing, and it extends the applicability of SPR control to most VAV systems.

To assess the energy savings achievable by the SAV with InCITe ${ }^{\mathrm{TM}}$ method, in 2005, LBNL carried out a DOE-funded SPR intervention study in a 955,000 ft2 office building located in Sacramento. This building is particularly useful because we had already extensively characterized its air-handling systems on Floors 16 and 17 for our 2002 CEC/DOE-funded duct leakage intervention study, and we had validated relevant sensors in the building's Energy Management Control System (EMCS).

In the SPR intervention study, we continuously measured supply fan, VAV box induction fan, and electric reheat coil power on the reference "control" floor (Floor 16, where constant static pressure was maintained in the main duct), and on the "intervention" floor (Floor 17, before and after we changed constant static pressure control to SPR control). For each of the two floors, we also measured the supply fan airflows and, on the intervention floor, the static pressure rises across the supply fans.

In addition to the electrical energy measurements, we also made measurements to assess the impact of static pressure reset on HVAC system thermal performance (e.g., changes in heating and cooling coil loads). Specifically, we also measured air temperatures and relative humidities upstream and downstream of the preheat and cooling coils, and at the air-handler exit (downstream of the supply fan). These measurements allow us to calculate coil loads.

Monitoring was carried out over about a one month period before and one month after the SPR intervention so that we could average out the separate effects of weather-induced thermal loads. Data were recorded once per minute. Until this project, only a preliminary analysis of two days of data had been carried out. The results are encouraging: it appears that the SAV with InCITe ${ }^{\mathrm{TM}}$ strategy saved about one third of the supply fan power. Detailed analyses still need to be completed and the results need to be disseminated. Completion of this work would contribute to the PIER program objective of improving the energy cost and value of California's electricity by demonstrating through measurements how Commission-funded technology (SAV with InCITe ${ }^{\mathrm{TM}}$ ) can save substantial amounts of the HVAC energy in large commercial buildings. We expect that the knowledge gained from this research could be used to craft new requirements for commercial duct system efficiency in future revisions of California's Title 24. 
Goal and Purpose. The overall goal of this project is to bridge the gaps in current duct performance modeling capabilities, and to expand our understanding of air-handling system performance in California large commercial buildings. The purpose of this project is to provide technical support for the implementation of a duct leakage modeling capability in EnergyPlus, to demonstrate the capabilities of the new model, and to carry out analyses of field measurements intended to demonstrate the energy saving potential of the SAV with InCITe ${ }^{\mathrm{TM}}$ technology. We expect that this new capability and information will assist the California building industry in designing better thermal distribution systems for new commercial buildings and in retrofitting existing systems to reduce their energy consumption and peak electrical demand. We also expect that this work will provide a solid foundation for future efforts that address the energy efficiency of large commercial duct systems in Title 24.

Objectives. To address the needs described above, there are three technical objectives in this project:

- Provide technical assistance to the Simulation Research Group (SRG) at LBNL to support implementation of our duct leakage model in EnergyPlus.

- Carry out simulations to demonstrate the utility of the new duct leakage model. This effort provides an opportunity for us to assess the impacts of duct leakage on the heat transfer between the conditioned spaces and ceiling return plenum, which could not be done using the sequential "user hostile” DOE-2/TRNSYS simulation techniques that we used previously.

- Carry out analyses of the measured data to determine the energy savings from implementing the SAV with InCITe ${ }^{\mathrm{TM}}$ SPR control in a large commercial building, and document our findings.

The remainder of this report describes the work carried out to meet these objectives and presents the related results.

\section{DUCT LEAKAGE MODELING WITH ENERGYPLUS}

Energy Performance of Buildings Group staff at LBNL already had documented the simple "data driven" duct leakage model that is now successfully implemented in EnergyPlus, by publishing details about the model in a report for the California Energy Commission's "High Performance Commercial Buildings" PIER project. Originally, the model was not in a form that could be directly inserted into EnergyPlus, nor was the documentation in a format consistent with EnergyPlus engineering and source code documentation requirements. In this task, we worked with Simulation Research Group (SRG) staff at LBNL to translate the model and its documentation into a format that is usable for EnergyPlus. This effort included generating input descriptors for EnergyPlus's Input Data Dictionary (IDD), generating default input values, and identifying appropriate output report parameters. It also included providing technical review of SRG's debugging efforts during initial and detailed programming phases of the model implementation. The model is available in the current release of EnergyPlus.

In particular, the EnergyPlus improvements involved inserting elements of the TRNSYS duct model into EnergyPlus to account for the transfer of air and energy between the ducts and the environment surrounding the ducts (e.g., a ceiling return plenum). EnergyPlus already had models for coils, fans, and the ceiling return plenum, so there was no need to add those capabilities from TRNSYS. The engineering and input/output reference documentation produced 
from these efforts is publicly-available at: http://apps1.eere.energy.gov/buildings/energyplus/, and is also included in Appendices A and B, respectively. The source code related to the new model is provided is available from DOE upon request, subject to license requirements. Because of the size of the modules containing the leakage model (several hundred pages), for practical reasons we have not included them as part of this report. Inserting only the changed lines of code would be meaningless, because the code cannot be read out of context.

\section{Simulation Inputs}

To test the new duct leakage model and to demonstrate its utility, we used the modified version of EnergyPlus with the new duct leakage model (Version 3.1) to simulate a single-duct VAV system in a prototypical large office building, which we used in previous modeling efforts (Wray and Matson 2003). The building represents new construction practice in a Sacramento climate. It is a ten story, 150,000 $\mathrm{ft}^{2}$ office building. Each story has a floor area of $15,000 \mathrm{ft}^{2}$ and is divided into five zones: four 15 -ft wide perimeter zones and one core zone. Each set of five zones has a ceiling plenum above them that serves as the return air plenum. The supply and return fans in the VAV system each have variable-speed-drive control. Although not modeled explicitly, we assumed that the HVAC control system varies the supply fan airflow to maintain a constant duct static pressure upstream of the VAV boxes. A water-cooled hermetic centrifugal chiller supplies chilled water to the air-handling system cooling coil, and rejects heat outdoors using a forceddraft cooling tower. A natural-gas-fired boiler supplies hot water to the VAV box reheat coils. The chiller, boiler, and pumps are located in a below-grade basement.

The five combinations of upstream and downstream duct leakage (fractions referenced to design flows) that we simulated were as follows:

- zero duct leakage (an ideal that is not likely attainable in practice),

- $2.5 \%$ upstream and $2.5 \%$ downstream of the VAV boxes (a realistic tight system),

- $10 \%$ upstream and 2.5\% downstream (a system with leaky main ducts),

- $2.5 \%$ upstream and $10 \%$ downstream (a system with leaky branch ducts, and

- $10 \%$ upstream and $10 \%$ downstream (a system with leakage in all sections).

We simulated only one building and climate combination, because our past analyses showed that climate and building vintage differences do not cause significant variability in duct leakage impacts on fan energy use or on operating cost for leaky duct systems.

The VAV system that we simulated used the same size system and plant equipment for the various duct leakage cases. In particular, the supply (and return) fan design airflow was determined by the high-leakage case $(10+10)$, because the maximum airflow occurs for that case. EnergyPlus "autosizing” was used to determine equipment capacities for this case.

An important step in this task was the translation of the DOE-2 and TRNSYS simulation inputs to create comparable EnergyPlus Input Data Files (IDF). The input data files that we generated in this task are usable as test files for the EnergyPlus test suite, and could be included in the future as part of the minimum conformance test series in the Title 24 Alternative Calculation Method (ACM) Approval Manual. The input file for the last combination of duct leakage is included in Appendix C. 
Upstream and downstream duct leakage is specified simply in the EnergyPlus IDF using the “ZoneHVAC:AirDistributionUnit” object for each above-grade occupied zone. An example for one of the zones that we simulated is as follows:

\begin{tabular}{|c|c|}
\hline \multicolumn{2}{|c|}{ ZoneHVAC:AirDistributionUnit, } \\
\hline PER-1T ATU, & !- Name \\
\hline $\begin{array}{l}\text { PER-1T Supply Inlet, } \\
\text { AirTerminal:SingleDu }\end{array}$ & $\begin{array}{l}\text { !- Air Distribution Unit Outlet Node Name } \\
\text { Ict:VAV:Reheat, !- Air Terminal Object Type }\end{array}$ \\
\hline PER-1T VAV Reheat, & !- Air Terminal Name \\
\hline 0.1 & !- Nominal Upstream Leakage Fraction \\
\hline 0.1 & !- Constant Downstream Leakage Fraction \\
\hline
\end{tabular}

\section{Simulation Results}

We begin by presenting graphical results from our simulations of the leakiest case $(10 \%$ upstream and 10\% downstream) relative to the "tight" case (2.5\% upstream and $2.5 \%$ downstream), followed by a summary of energy impacts for all five leakage cases.

Figure 1 shows that fan power significantly increases with duct leakage, but the increase is not constant over the year. As Figure 2 shows, the most frequent increase is a factor of 1.3 compared to the $2.5+2.5$ case. Ratios of 1.22 to 1.40 also occur in several cases, but much less frequently.

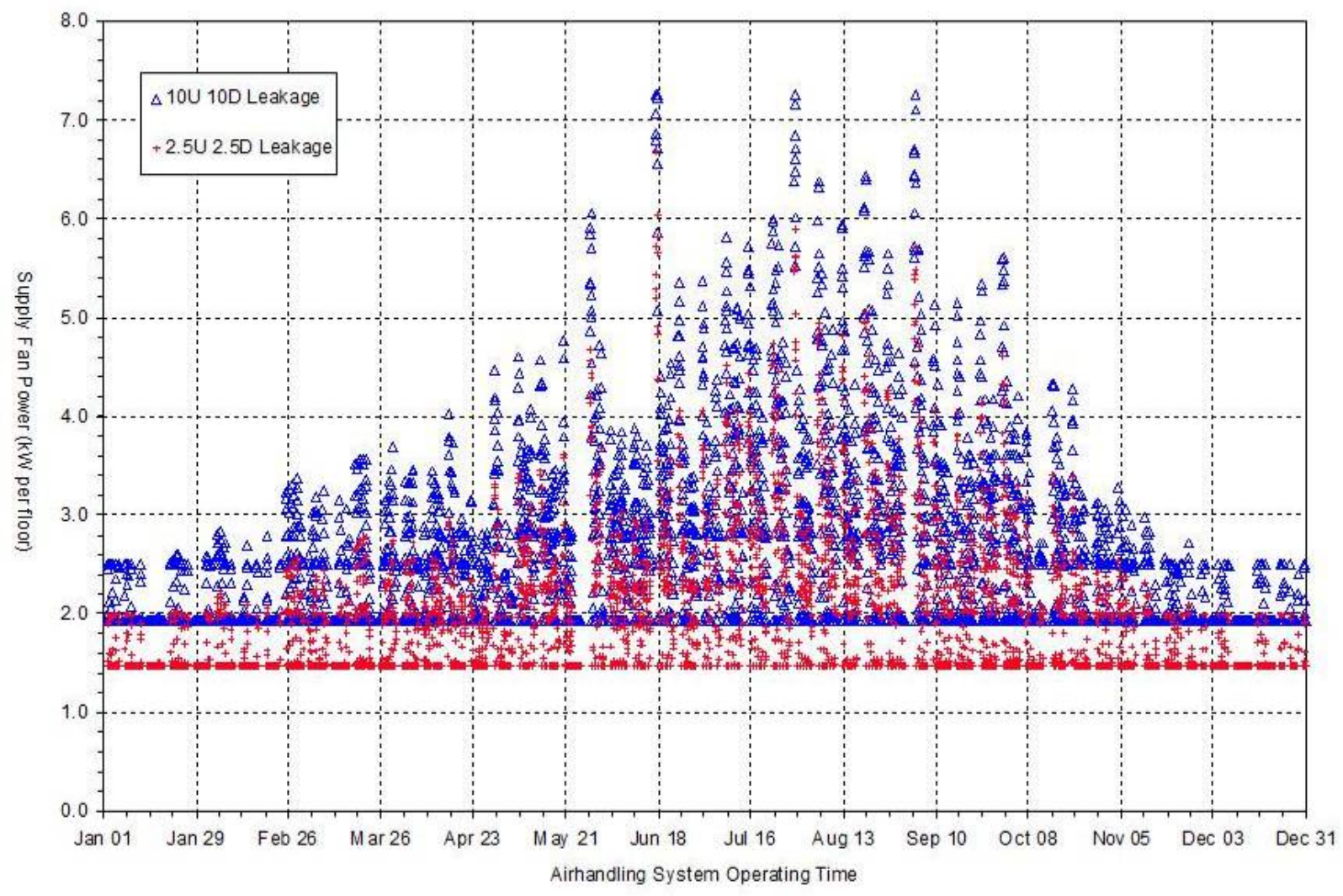

Figure 1. Supply Fan Power Variation with Leakage and Time 


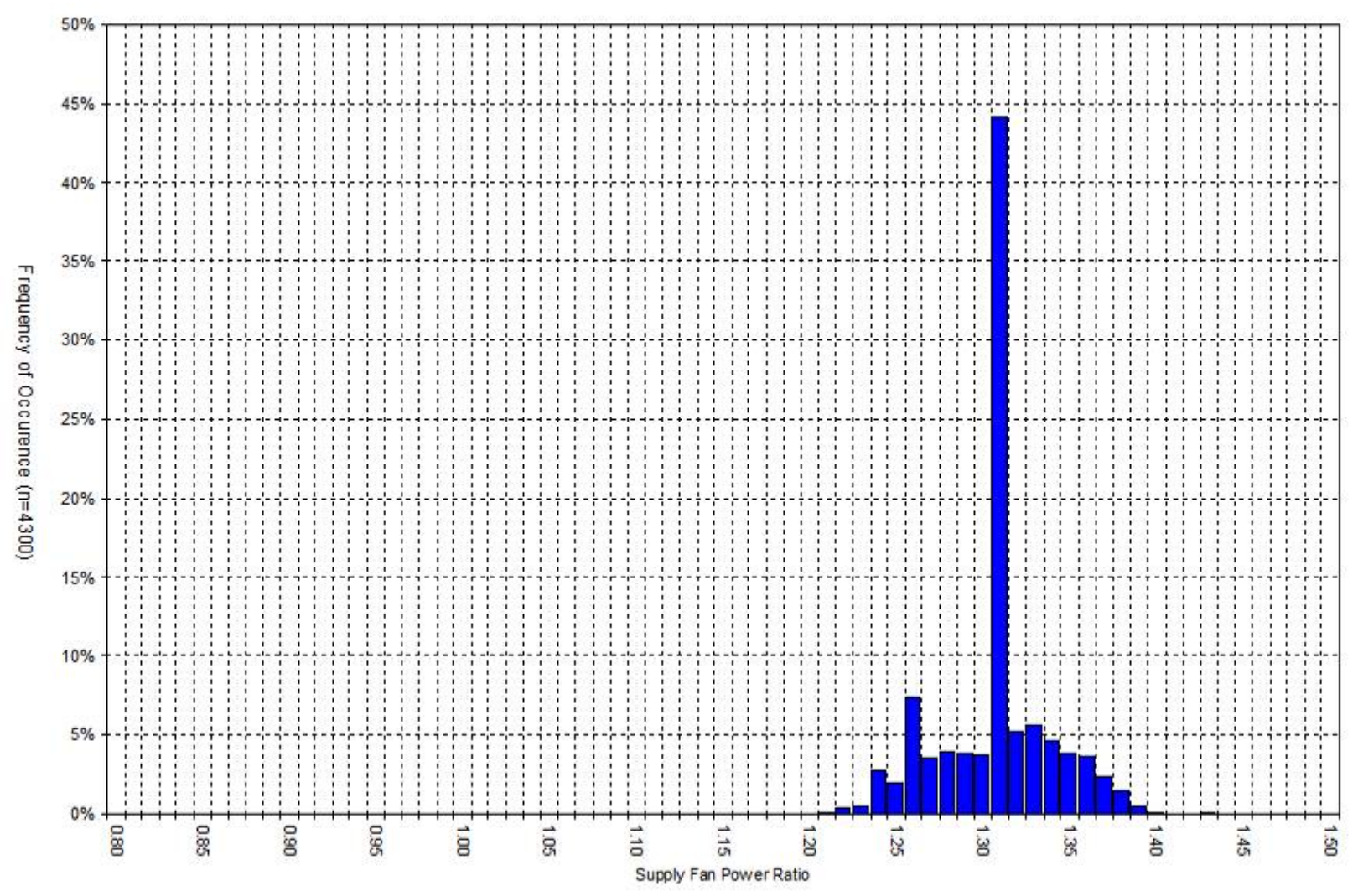

Figure 2. Supply Fan Power Increase (10+10 Case Relative to 2.5+2.5 Case)

These increases are substantially less than had been previously predicted using the hybrid DOE2/TRNSYS simulation approach (ratios of about 1.5 for a similar comparison, Wray and Matson 2003). They agree, however, reasonably well with our field test results (Diamond et al. 2003): factors of 1.25 to 1.35 for similar leakage conditions.

Some of the differences can be explained by the heat transfer between the ceiling plenum and the conditioned spaces. As Figure 3 shows, when cool air leaks from the ducts, it tends to decrease the temperature of the plenum. In a similar manner, when heated air leaks out (from ducts after the VAV box reheat coil), the plenum temperature rises, but this is an infrequent occurrence. Like fan power, the temperature decrease varies throughout the year, and is largest during peak cooling times (e.g., summer). The largest temperature decrease is about $1.1^{\circ} \mathrm{C}$ to $1.4^{\circ} \mathrm{C}$.

The result of the plenum cooling by duct leakage is that the conduction temperature difference across the ceiling increases, and heat is transferred ("lost") from warmer conditioned spaces to the cool plenum. Consequently, the cooler plenum helps to reduce the space cooling load of the conditioned spaces and less air needs to be delivered through the duct system to meet the thermostat call for cooling.

Figure 4 shows the ceiling heat loss and net zone cooling load relative to the maximum net zone load for the entire year's simulation. The zone load fraction varies between -1.0 (maximum heating) and +1.0 (maximum cooling). As discussed above, relative to the $2.5+2.5$ case, the $10+10$ case generally has higher heat loss from the conditioned spaces to the plenum. Because of 
the scatter, however, it is difficult to understand how the heat loss varies with zone load. Figure 5 provides a frequency distribution to simplify the data.

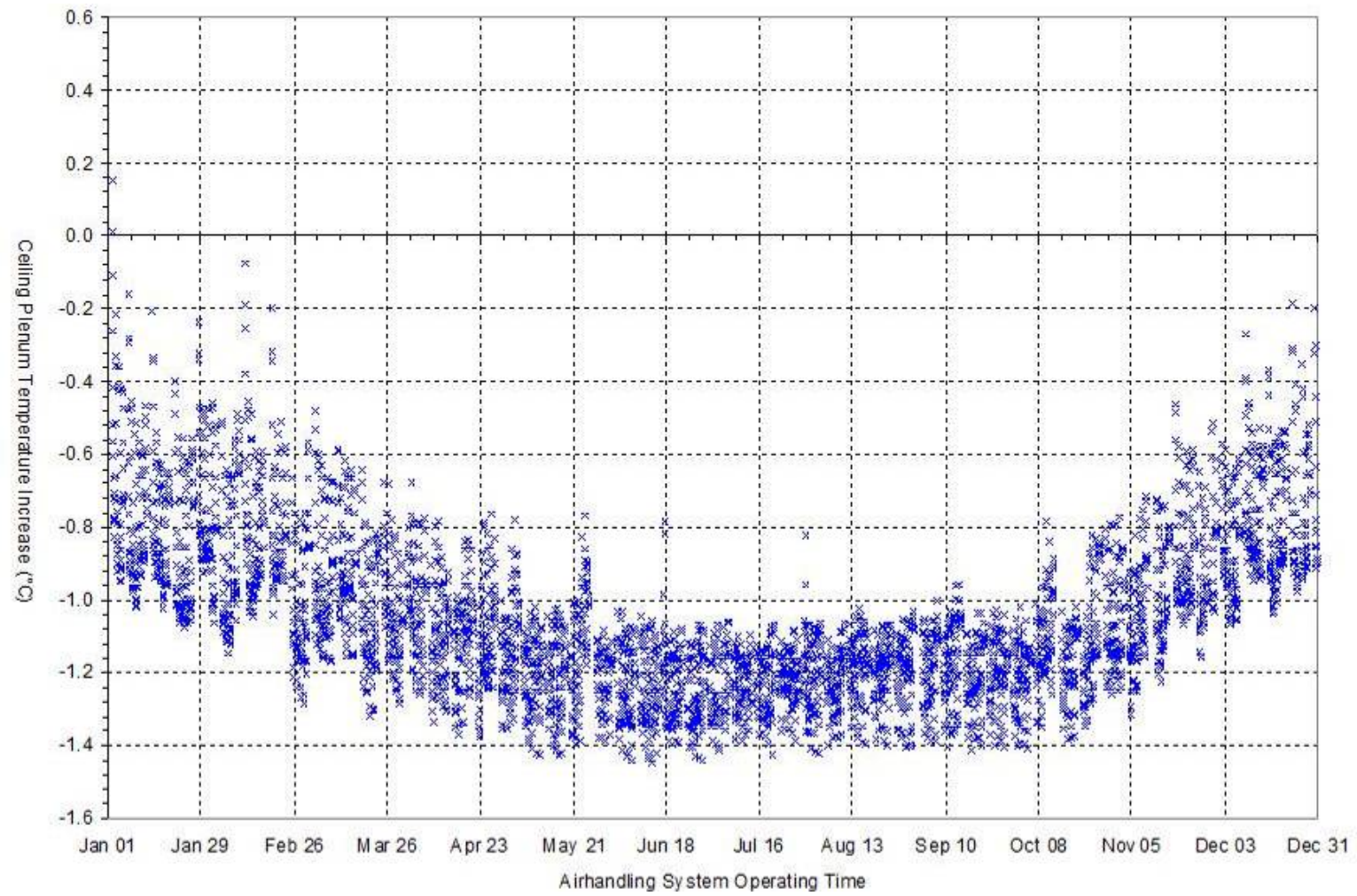

Figure 3. Ceiling Plenum Air Temperature Changes (10+10 Case Relative to $2.5+2.5$ Case)

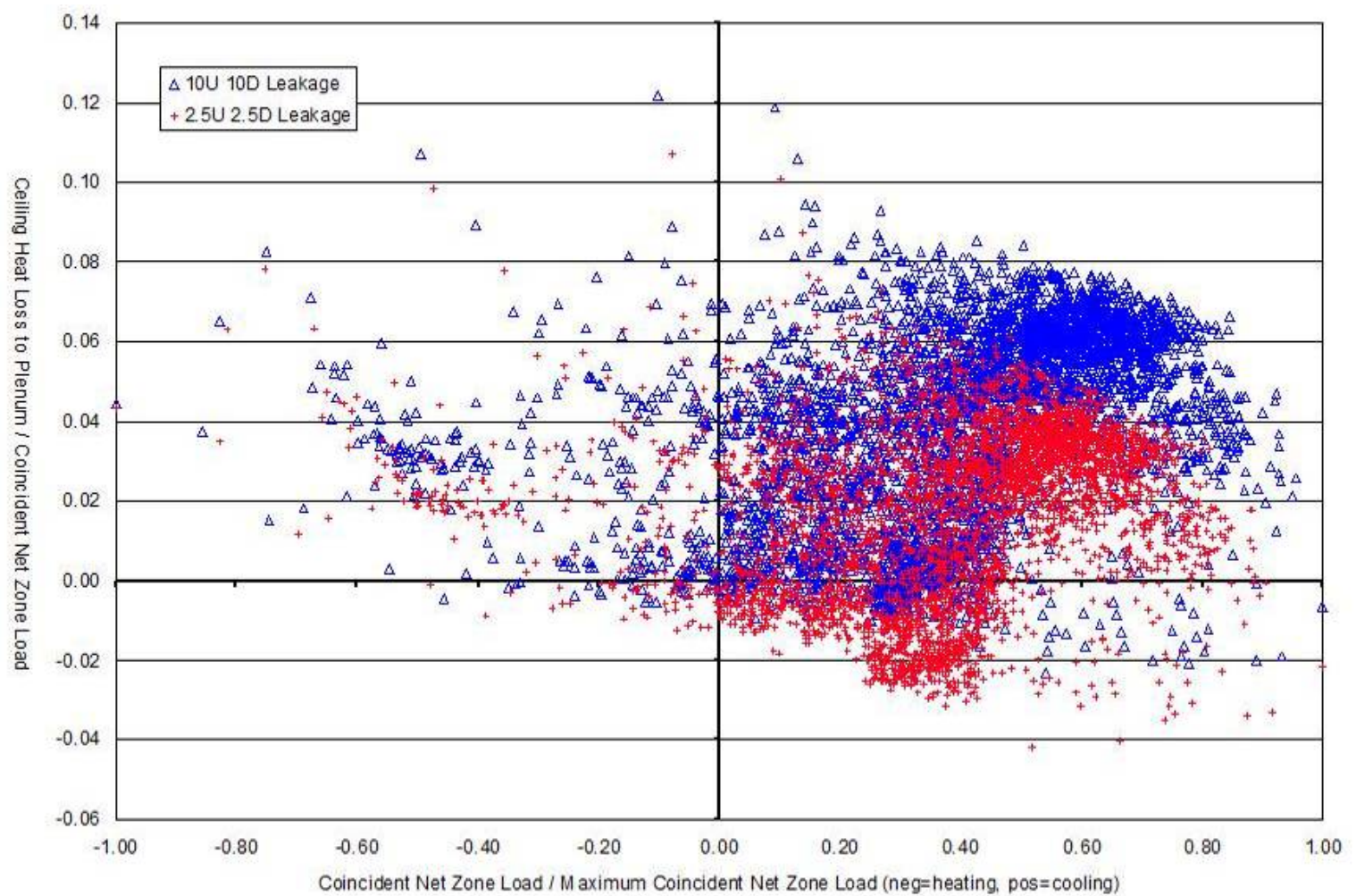

Figure 4. Ceiling Heat Loss Variation with Zone Load Fraction 
In Figure 5, two distributions are shown, which are similar in shape, but are not aligned with load. In particular, the ceiling heat loss fraction for the $2.5+2.5$ case peaks at $+0.035(11.7 \%$ frequency), but has another smaller peak near zero $(-0.005,6.6 \%)$, and varies widely from -0.040 to +0.080 . For this "tight" duct system, heat loss is usually a small fraction of the zone load. For the "leaky" case $(10+10)$, the heat loss fractions are shifted toward higher losses (greater cooling of the plenum and reduced space conditioning load). In this latter case, the largest peak occurs at a fraction of +0.065 ( $11.0 \%$ frequency), and the heat loss fractions range from -0.020 to +0.125 . While still not a large fraction of the zone heat load, not accounting for the impact of the ceiling heat loss and the zone load will lead to overestimates of the effects of duct leakage, as occurred in previous simulations. Because the larger zone loads require more air to be delivered through the VAV boxes and thus by the fan, and because fan power is somewhere between a quadratic and cubic function of airflow, small changes in airflow requirements driven by errors in zone loads can have large impacts on fan power.

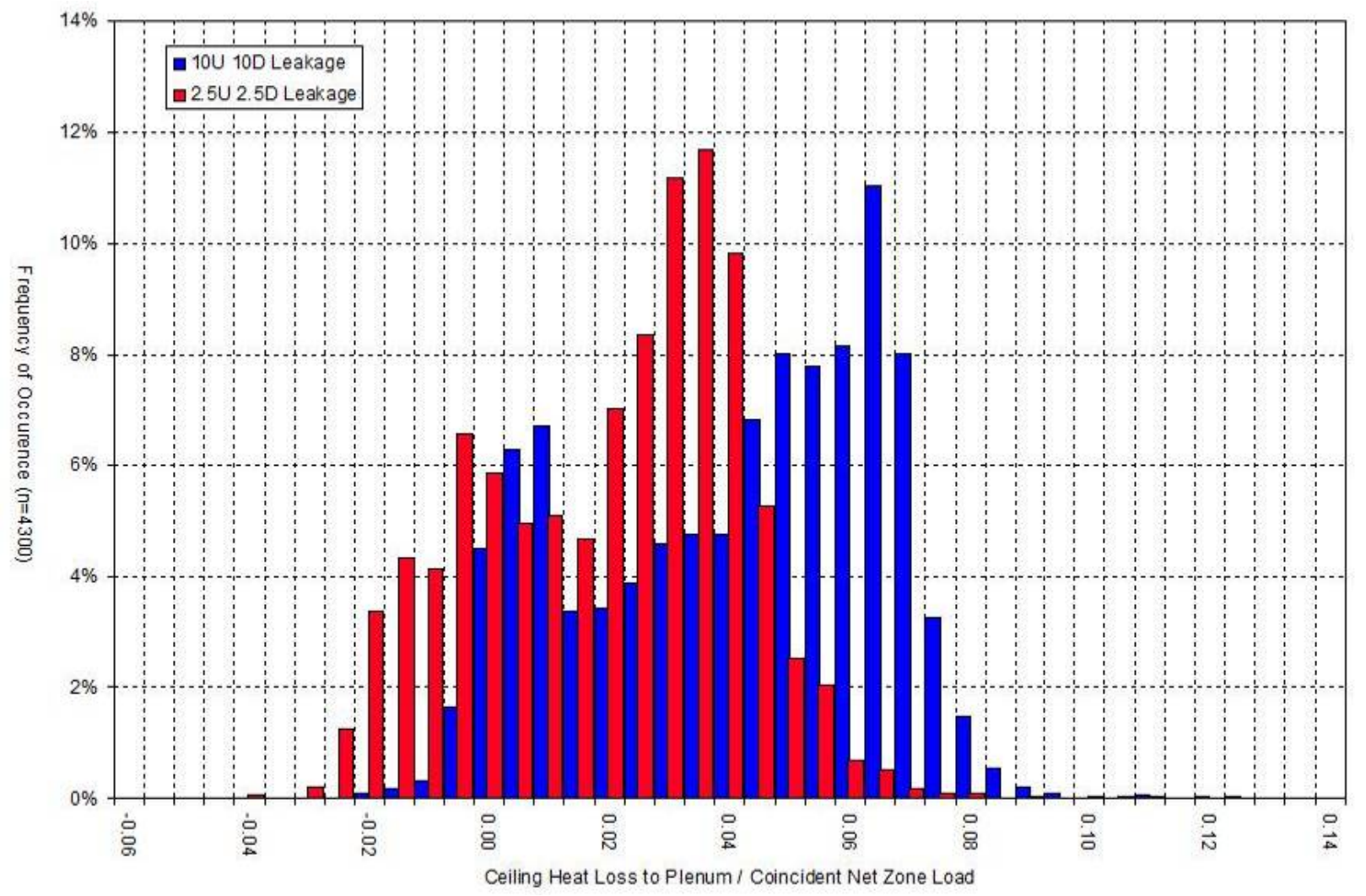

Figure 5. Frequency Distribution of Ceiling Heat Loss Relative to Net Zone Load

Figures 6 through 9 show the effects of increased leakage on cooling and reheat coil loads. These coil loads generally increase only slightly with added leakage. For the cooling coil, most frequently (23.3\%), loads do not increase at all. The distribution of increases ranges from zero up to 0.070 , with most fractional increases above zero centered in the range of +0.025 to +0.035 . For the reheat coils, even more frequently (58.2\%), there is no effect of leakage (zero fractional increase). The distribution, however, in this case ranges from -0.005 to 0.060 . 


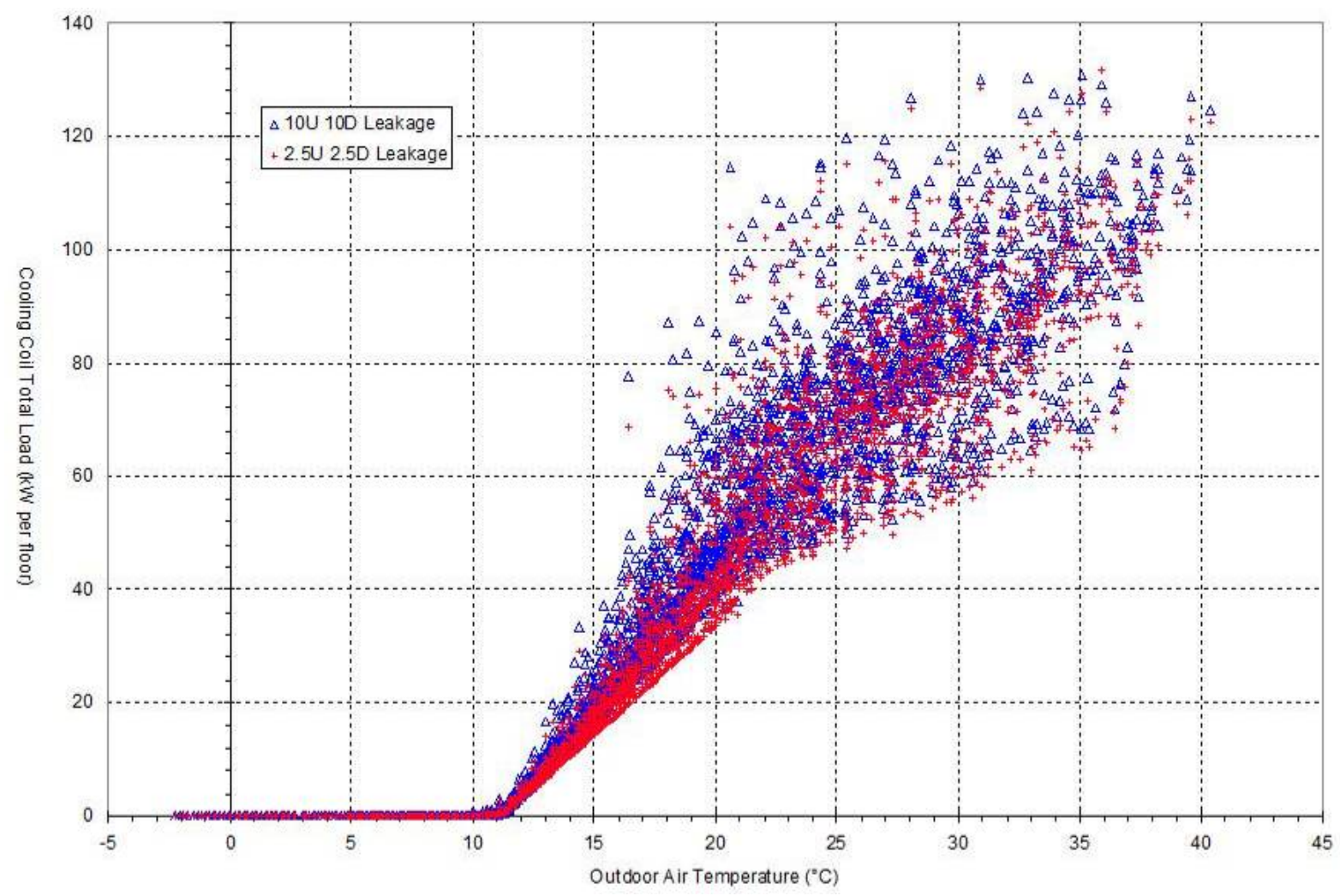

Figure 6. Cooling Coil Load versus Outdoor Air Temperature

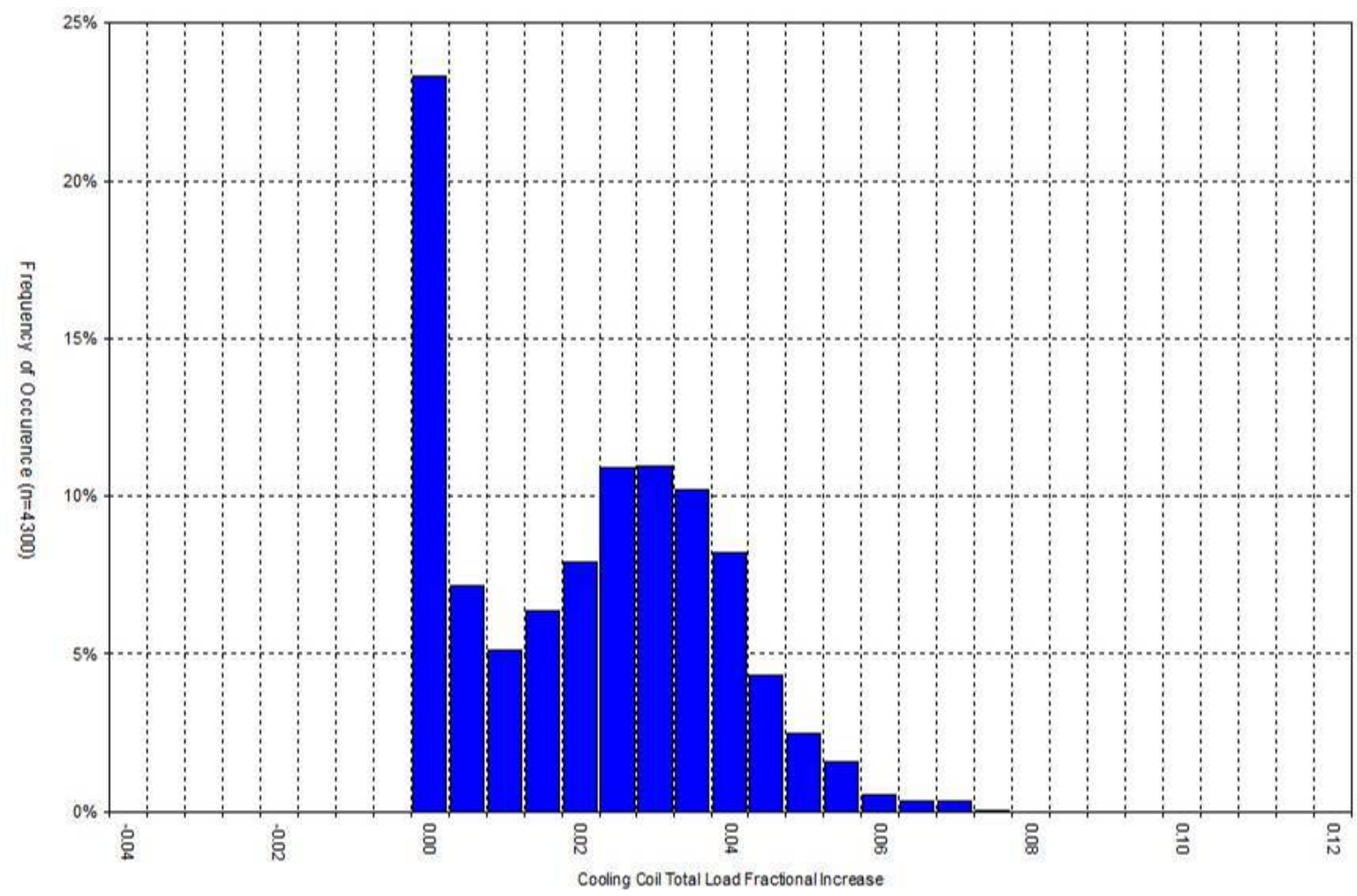

Figure 7. Cooling Coil Load Fractional Increase 


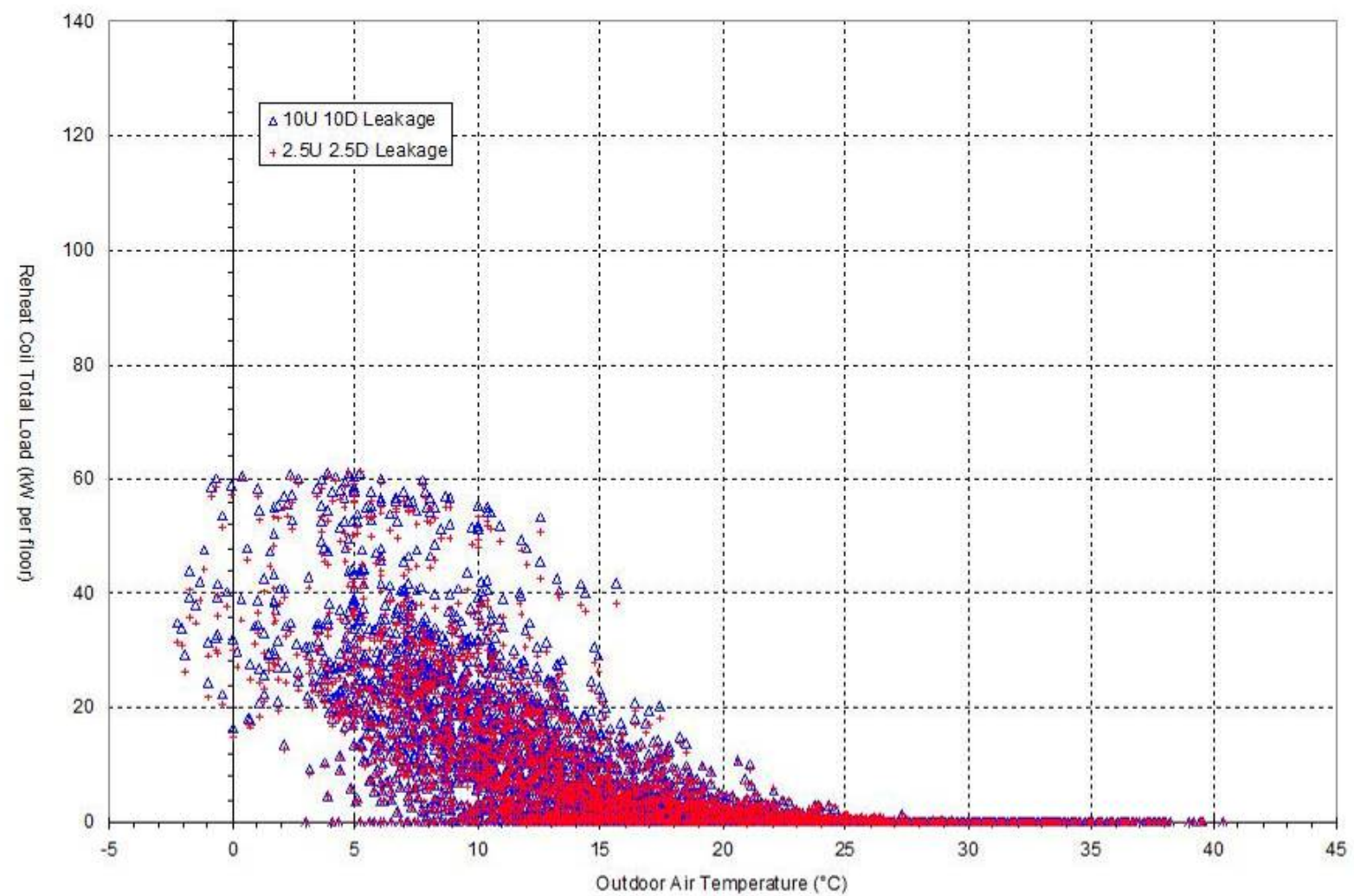

Figure 8. Reheat Coil Load versus Outdoor Air Temperature

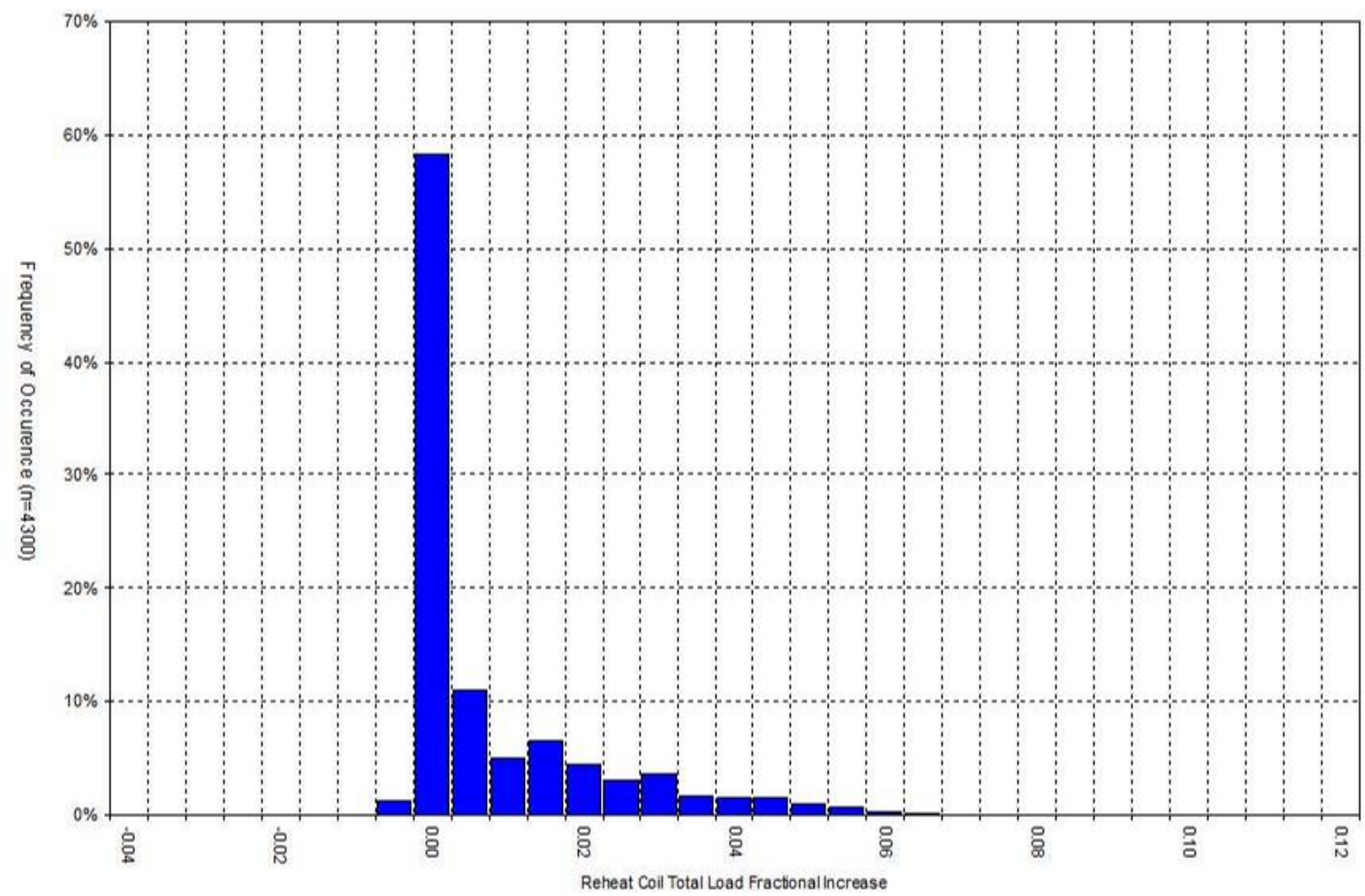

Figure 9. Reheat Coil Load Fractional Increase 
Table 1 summarizes the energy impacts of leakage relative to the "tight" $2.5+2.5$ case. Annual cooling plant energy is the largest energy use component and ranges from 54 to $57 \%$ of the total HVAC system source energy consumption. The fan energy is smaller, but still significant (about 15 to 20\%). The leaky system (10+10) increases total HVAC source energy use about 8.4\%.

Table 1. Summary of Duct Leakage Impacts on HVAC Site and Source Energy Use

\begin{tabular}{|c|c|c|c|c|c|c|c|c|c|c|}
\hline & \multicolumn{10}{|c|}{ Leakage Fraction (\%) } \\
\hline Upstream & 0 & 2.5 & 2.5 & 10 & 10 & 0 & 2.5 & 2.5 & 10 & 10 \\
\hline Downstream & 0 & 2.5 & 10 & 2.5 & 10 & 0 & 2.5 & 10 & 2.5 & 10 \\
\hline & \multicolumn{5}{|c|}{ Site Energy Use (kWh) } & \multicolumn{5}{|c|}{ Site Energy Use Increase (\%) } \\
\hline Supply Fan & 78,282 & 85,524 & 90,041 & 106,685 & 111,269 & -8.5 & 0.0 & 5.3 & 24.7 & 30.1 \\
\hline Return Fan & 26,094 & 28,508 & 30,014 & 35,562 & 37,090 & -8.5 & 0.0 & 5.3 & 24.7 & 30.1 \\
\hline Chiller & 275,713 & 281,334 & 284,941 & 295,112 & 298,103 & -2.0 & 0.0 & 1.3 & 4.9 & 6.0 \\
\hline Tower & 103,918 & 103,898 & 103,964 & 104,324 & 104,305 & 0.0 & 0.0 & 0.1 & 0.4 & 0.4 \\
\hline Boiler Elec & 487 & 502 & 503 & 546 & 548 & -3.1 & 0.0 & 0.2 & 8.7 & 9.2 \\
\hline \multirow[t]{2}{*}{ TOT Elec } & 484,493 & 499,766 & 509,463 & 542,228 & 551,315 & -3.1 & 0.0 & 1.9 & 8.5 & 10.3 \\
\hline & \multicolumn{10}{|c|}{ Leakage Fraction (\%) } \\
\hline Upstream & 0 & 2.5 & 2.5 & 10 & 10 & 0 & 25 & 2.5 & 10 & 10 \\
\hline \multirow[t]{2}{*}{ Downstream } & 0 & 2.5 & 10 & 2.5 & 10 & 0 & 2.5 & 10 & 2.5 & 10 \\
\hline & \multicolumn{5}{|c|}{ Source Energy Use (kWh) } & \multicolumn{5}{|c|}{ Source Energy Use Increase (\%) } \\
\hline Supply Fan & 234,845 & 256,573 & 270,124 & 320,054 & 333,807 & -8.5 & 0.0 & 5.3 & 24.7 & 30.1 \\
\hline Return Fan & 78,282 & 85,524 & 90,041 & 106,685 & 111,269 & -8.5 & 0.0 & 5.3 & 24.7 & 30.1 \\
\hline Chiller & 827,139 & 844,001 & 854,822 & 885,335 & 894,310 & -2.0 & 0.0 & 1.3 & 4.9 & 6.0 \\
\hline Tower & 311,755 & 311,694 & 311,893 & 312,973 & 312,914 & 0.0 & 0.0 & 0.1 & 0.4 & 0.4 \\
\hline Boiler Elec & 1,460 & 1,505 & 1,510 & 1,637 & 1,644 & -3.0 & 0.0 & 0.3 & 8.8 & 9.2 \\
\hline Boiler Fuel & 555,038 & 561,899 & 538,520 & 604,144 & 579,623 & -1.2 & 0.0 & -4.2 & 7.5 & 3.2 \\
\hline TOT & $2,008,518$ & $2,061,197$ & $2,066,909$ & $2,230,829$ & $2,233,567$ & -2.6 & 0.0 & 0.3 & 8.2 & 8.4 \\
\hline
\end{tabular}

\begin{tabular}{|r|ccccc|ccccc|}
\cline { 2 - 11 } \multicolumn{1}{c|}{} & \multicolumn{10}{c|}{ Leakage Fraction (\%) } \\
\hline Upstream & 0 & 2.5 & 2.5 & 10 & 10 & 0 & 2.5 & 2.5 & 10 & 10 \\
Downstream & 0 & 2.5 & 10 & 2.5 & 10 & 0 & 2.5 & 10 & 2.5 & 10 \\
\hline & \multicolumn{10}{c|}{ Source Energy Use (kWh) } \\
\hline Fans & 313,126 & 342,097 & 360,165 & 426,739 & 445,076 & -8.5 & 0.0 & 5.3 & 24.7 & 30.1 \\
Cooling & $1,138,894$ & $1,155,695$ & $1,166,715$ & $1,198,308$ & $1,207,225$ & -1.5 & 0.0 & 1.0 & 3.7 & 4.5 \\
Heating & 556,498 & 563,404 & 540,029 & 605,781 & 581,267 & -1.2 & 0.0 & -4.1 & 7.5 & 3.2 \\
\hline TOTAL & $2,008,518$ & $2,061,196$ & $2,066,909$ & $2,230,829$ & $2,233,567$ & -2.6 & 0.0 & 0.3 & 8.2 & 8.4 \\
\hline
\end{tabular}

\begin{tabular}{|r|ccccc|}
\cline { 2 - 5 } \multicolumn{1}{c|}{} & \multicolumn{5}{c|}{ Leakage Fraction (\%) } \\
\hline Upstream & 0 & 2.5 & 2.5 & 10 & 10 \\
Downstream & 0 & 2.5 & 10 & 2.5 & 10 \\
\hline & \multicolumn{5}{c|}{ Fraction of Total Source energy Use (\%) } \\
\hline Fans & 15.6 & 16.6 & 17.4 & 19.1 & 19.9 \\
Cooling & 56.7 & 56.1 & 56.4 & 53.7 & 54.0 \\
Heating & 27.7 & 27.3 & 26.1 & 27.2 & 26.0 \\
\hline
\end{tabular}

Interestingly, downstream leakage has a smaller impact than upstream leakage. In the 10+2.5 case (leaky main ducts), supply fan energy increases $24.7 \%$. In the $2.5+10$ case (leaky branch ducts), the increase is only 5.3\%. The reason for this behavior needs further investigation, but we speculate that leaks downstream of the VAV boxes "look" like supply grilles to the box airflow controller and fan. Consequently, dampers will not modulate to increase box flows when there is downstream leakage, unless the zone temperature deviates from the thermostat set point. Even if the damper does not modulate, the fan energy still increases, however, in the downstream leakage case because insufficient air is delivered to zones (the fan runs longer to deliver enough cooling or heating to meet the load) and because of changes to zone loads caused by related 
changes in plenum air temperatures. Previous simulations could not account for the zone coupling effects.

\section{IMPLEMENTING A SIMPLIFIED SPR STRATEGY: ENERGY SAVINGS ANALYSIS}

This project analyzed data that resulted from implementing a new duct static pressure reset strategy in an actual large commercial building. The SPR technology was developed with support from the CEC’s Energy Innovations Small Grant Program. In particular, Federspiel Controls developed a simple diagnostic procedure and model of system operation that linearly correlates duct static pressure and supply fan airflow (Federspiel 2004, 2005). The diagnostic method simply involves measuring the velocity pressure near the fan inlet (represents fan flow) and the duct static pressure at multiple points over the fan's operating range, while the VAV box dampers attempt to control flow in response to a nominally constant thermostat set point. The goal is to define the characteristics of the linear region where all VAV boxes are in control (dampers modulating). In this model, the linear correlation between $P_{s m}$ and $Q_{f a n}$ that is used to determine the duct static pressure set point is as follows:

$$
P_{s m}=P_{s m, \text { min }}+\left(P_{s m, \text { max }}-P_{s m, \text { min }}\right) * \frac{\left(Q_{f a n}-Q_{f a n, \text { min }}\right)}{\left(Q_{f a n, \text { max }}-Q_{f a n, \min }\right)}=C_{1}+C_{2} * \frac{\left(Q_{f a n}-Q_{f a n, \text { min }}\right)}{\left(Q_{f a n, \max }-Q_{f a n, \min }\right)}
$$

where $P_{s m}$ is the duct static pressure set point and $Q_{f a n}$ is the airflow through the supply fan at standard conditions. In a separate project funded by DOE, work is currently underway to implement this strategy in EnergyPlus, along with a fan system component model (fan, belt, motor, and variable-frequency-drive), and a duct system model (to determine fan pressure rise).

Energy Performance of Buildings Group staff at LBNL carried out analyses of the data that we measured in 2005 to determine the energy savings from implementing SAV with InCITe ${ }^{\mathrm{TM}}$. This effort included:

- synchronizing the data that we collected from approximately 250 sensors, each of which recorded time separately,

- normalizing the post-intervention performance data using the pre-intervention data as a reference to account for weather and operational differences between monitoring periods, and

- calculating the fan, preheat and reheat coil, and cooling coil energy savings relative to the pre-intervention period.

The following describes the test building, our measurements, the analysis, and our findings regarding the energy savings from implementing SAV with $\operatorname{InCITe}^{\mathrm{TM}}$.

\section{Test Building}

Diamond et al. (2003) describe the office building in Sacramento where we implemented the SPR strategy. In summary, the building was first occupied in 2001, has 25 stories, and a total floor area of $955,000 \mathrm{ft}^{2}$. Our study focused on two floors with similar occupancy and use (each approximately 29,000 $\mathrm{ft}^{2}$ ). We had already extensively characterized the HVAC system operation on the intervention $\left(17^{\text {th }}\right)$ floor in our past efforts to study the impacts of duct leakage; this is where we installed the SPR technology. We used the $16^{\text {th }}$ floor as a control (i.e., no changes to the HVAC system) for comparison to the intervention floor. 
Each floor has four separate air-handlers, with two nominal 15,000 cfm, 15 hp supply airhandlers per floor and two nominal 10,000 cfm, $5 \mathrm{hp}$ relief air-handlers per floor. Each pair of supply and relief air-handlers is located in a separate mechanical room at the northeast and northwest corners of each floor, and each air-handler uses an EMCS-controlled variablefrequency-drive. Each supply air-handler is a draw-through packaged unit that is equipped with an air mixing chamber, a filter section, a hot-water air preheat coil, a chilled-water air cooling coil, and a backward-curved plug fan. Each relief air-handler uses a backward-curved tube-axial centrifugal fan. A central plant with boilers and chillers supplies the appropriate air-handler coils with cold and hot water.

Together, the two supply air-handlers on each floor serve a single-duct VAV system supply loop that in turn serves $34 \mathrm{VAV}$ boxes on the intervention floor and 38 boxes on the control floor (see Figure 10). The difference between the numbers of zones on the two floors is due to slight changes in room configuration, and does not affect our findings. A single duct-static-pressuresensor in each loop is located at the farthest point from the air-handlers. The 13 perimeter VAV boxes on the intervention floor and the 14 perimeter boxes on the control floor have discharge electric reheat coils (750 to 2,500 W, staged) and are parallel-fan-powered (1/6 and 1/4 hp induction fans), with the fans drawing their induction air from the ceiling plenum return through a pleated filter and discharging into the primary air section of the box through an adjustable fixed-stop gravity backdraft damper. The core VAV boxes have no reheat and no induction fans. Each VAV box inlet has a flow grid located immediately upstream of its EMCS-controlled primary air damper.

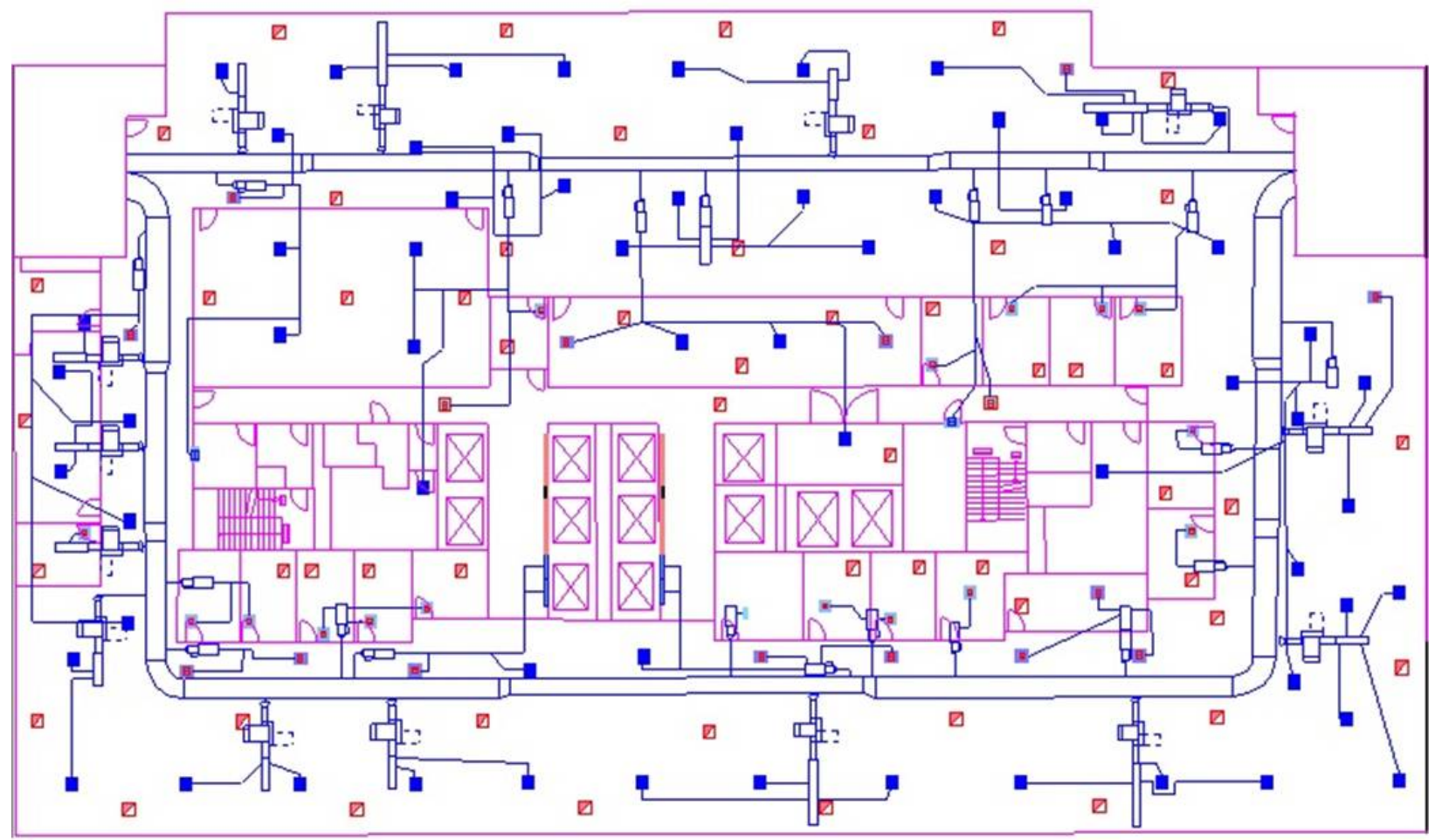

Figure 10. Duct Layout for Intervention Floor (control floor duct layout is similar)

In total, the VAV boxes on the intervention floor serve 103 supply grilles, each with a manual volume damper located near the branch takeoff. Most supply grilles use 2' x 2' perforated-face 
grilles and discharge in multiple directions; exceptions are the wall grilles in the two electrical rooms, a discharge with no grille in the communications equipment room, and the linear slot diffusers in the two main elevator lobbies. The 2' x 2' grilles sit in the ceiling between T-bar sections, with a small gap between the grille edges and the T-bar sections.

With the exception of the elevator lobbies (portions of the slot diffusers also serve as return grilles), ceiling returns are 2' x 2' perforated-face grilles. The mechanical rooms are each connected to the ceiling space through a short return transfer duct, and serve as a large plenum from which the supply air-handler draws its return air through EMCS-controlled return dampers.

Using duct leakage airflow diagnostics, we previously determined that the actual airflow through the duct leaks is small (about 5\% of total air-handler supply airflow at operating conditions). The test building showed every indication of a "tight" thermal distribution system: good application of mastic, metal bands at joints, and overall high quality.

Outdoor air is ducted to each supply air-handler mixing box from a wall louver and through two parallel EMCS-controlled dampers: a minimum outdoor air damper and a larger economizer damper. Return air is exhausted directly from each mechanical room to outdoors by the relief airhandler, as needed to control indoor-outdoor pressure difference for the floor. The indoor pressure appears to be referenced to the outdoor pressure at the building roof.

The building operated in cooling mode during our SPR intervention study. If pre-cooling is not needed, the HVAC systems are put into occupied mode around 5:00 a.m. and the systems run to maintain zone temperature conditions until 6:00 p.m. If pre-cooling is needed (dictated by building and outdoor temperatures measured at midnight), the corresponding HVAC system is put into economizer mode (outdoor air dampers fully open) and the air-handler supply fans are operated for pre-cooling. The relief fans run as needed to maintain building pressures.

During the occupied mode, the discharge duct temperature measured at the outlet of the supply air-handlers is used to control the heating and cooling valves serving the coils upstream of the air handler supply fan. A supply air temperature reset strategy is used. In particular, on each floor, the EMCS monitors about a dozen zone thermostats to identify the temperature of the warmest zone. Using that temperature, supply air temperature is linearly reset: a supply air temperature of $60^{\circ} \mathrm{F}$ corresponds to a zone temperature of $78^{\circ} \mathrm{F}$; a supply air temperature of $70^{\circ} \mathrm{F}$ corresponds to a zone temperature of $74^{\circ} \mathrm{F}$.

\section{Measurements}

We extensively monitored the intervention and control floors to characterize HVAC system operation and to determine the impact of SPR on fan and coil energy consumption. The monitoring occurred over the period from early June 2005 to early August 2005. Results from past monitoring during 2001 to 2003 were useful to troubleshoot the operation of our monitoring equipment and to validate the data being collected using the building's Energy Management Control System (EMCS). Our monitoring using the EMCS involved recording data for 310 measurement points. In addition, we installed 44 temperature, relative humidity, pressure, and power monitoring points. Table 2 summarizes these 354 points. 
Table 2. Monitoring Point Summary

\begin{tabular}{|c|c|c|}
\hline & EMCS Monitoring & LBNL Installed Monitoring \\
\hline Supply Fans & & $\begin{array}{l}\text { Electricity consumption, fan pressure } \\
\text { rise, fan airflow }\end{array}$ \\
\hline Relief Fans & & Electricity consumption \\
\hline Outdoor Air Supply & $\begin{array}{l}\text { Minimum outdoor airflow; economizer } \\
\text { damper position }\end{array}$ & Air temperature; relative humidity \\
\hline Return Air & $\begin{array}{l}\text { Damper position; air temperature; } \\
\text { relative humidity }\end{array}$ & $\begin{array}{l}\text { Airflow, air temperature; relative } \\
\text { humidity }\end{array}$ \\
\hline Air Handler Cabinet & Supply air temperature (after fan) & $\begin{array}{l}\text { Supply air temperature and relative } \\
\text { humidity (after supply fan and before } \\
\text { preheat coil); air temperature between } \\
\text { cooling coil and supply fan }\end{array}$ \\
\hline Zones (All) & Zone air temperature, primary airflow & \\
\hline $\begin{array}{l}\text { Zones (All with Induction } \\
\text { Fans and Heaters) }\end{array}$ & $\begin{array}{l}\text { Induction fan status (off / on); box reheat } \\
\text { status (off / } 1^{\text {st }} \text { stage / } 2^{\text {nd }} \text { stage) }\end{array}$ & \\
\hline Zones (Selected) & & $\begin{array}{l}\text { Supply air temperature at the farthest } \\
\text { grille from each of six selected VAV } \\
\text { boxes }\end{array}$ \\
\hline Outdoor Conditions & Air temperature; relative humidity & Air temperature; relative humidity \\
\hline $\begin{array}{l}\text { Miscellaneous } \\
\text { Temperatures and } \\
\text { Pressures }\end{array}$ & $\begin{array}{l}\text { Static pressure in supply loop (one } \\
\text { location per floor); indoor-outdoor static } \\
\text { pressure difference }\end{array}$ & $\begin{array}{l}\text { Static pressure in middle of each supply } \\
\text { loop section (east, south, west, and } \\
\text { north); ceiling plenum air temperature } \\
\text { (four locations, intervention floor) }\end{array}$ \\
\hline
\end{tabular}

Duct static pressures that we measured were sampled using approximately $1 \mathrm{~mm}$ diameter holes drilled into the middle of each of four duct walls. The holes were each covered with a magnet that had a pressure tap attached using epoxy. The four taps were connected together with tubing to provide one "average" duct static pressure signal for each location. All single-ended measured pressures (e.g., duct static pressure) were referenced to the ceiling plenum.

On the zone level, for the VAV boxes with induction fans, the EMCS recorded induction fan status (on / off) and box heater status (off / stage 1 / stage 2). In our previous tests, we had already measured the induction fan power as a function of VAV box primary airflow reported by the EMCS. The EMCS primary airflow and fan status data were then used to calculate induction fan energy over the test period. We also used previously measured data for the heater power for each powered VAV box to calculate reheat coil power.

\section{Data Synchronization}

We used the duct static pressure signal to synchronize data. Our data were recorded at 1 minute intervals; EMCS data were recorded at 5 minute intervals. We interpolated to estimate missing values. For longer time periods (up to 60 observations once or twice a week during EMCS data download by building staff), we interpolated based on two values: the average of the observations in the hour before the missing data and the average of the observations in the hour after the missing data. This approach did not change the results significantly. We used the factory calibration for the power transducers and used previously calibrated airflow and pressure measuring equipment as discussed by Diamond et al. (2003). 


\section{Analysis}

We selected two approximately two-week periods for our analysis: June 8 to June 21 and July 20 to August 3. These periods had the most continuous sets of data from our monitoring period. Synchronized data were imported into Excel for graphing and energy saving calculations. A separate psychrometric calculator coded in Excel by LBNL staff, based on ASHRAE algorithms (1996), was used to generate humidity ratio, air density, and specific enthalpy values corresponding to each air temperature and relative humidity measurement. We found that the calculated humidity ratios, however, were inconsistent through the air-handlers. In many cases, humidity ratios increased from before the coils to after the fan, which should not happen unless water is added to the air-stream, which it was not. Consequently, because the humidity-based data were unreliable, our analyses of coil loads focused on sensible loads and not total loads.

Figure 11 shows a comparison between supply fan flow and outdoor air temperature. There is no apparent correlation visible. Consequently, it is not possible to scale parameters with outdoor temperature, as is sometimes done in savings analyses.

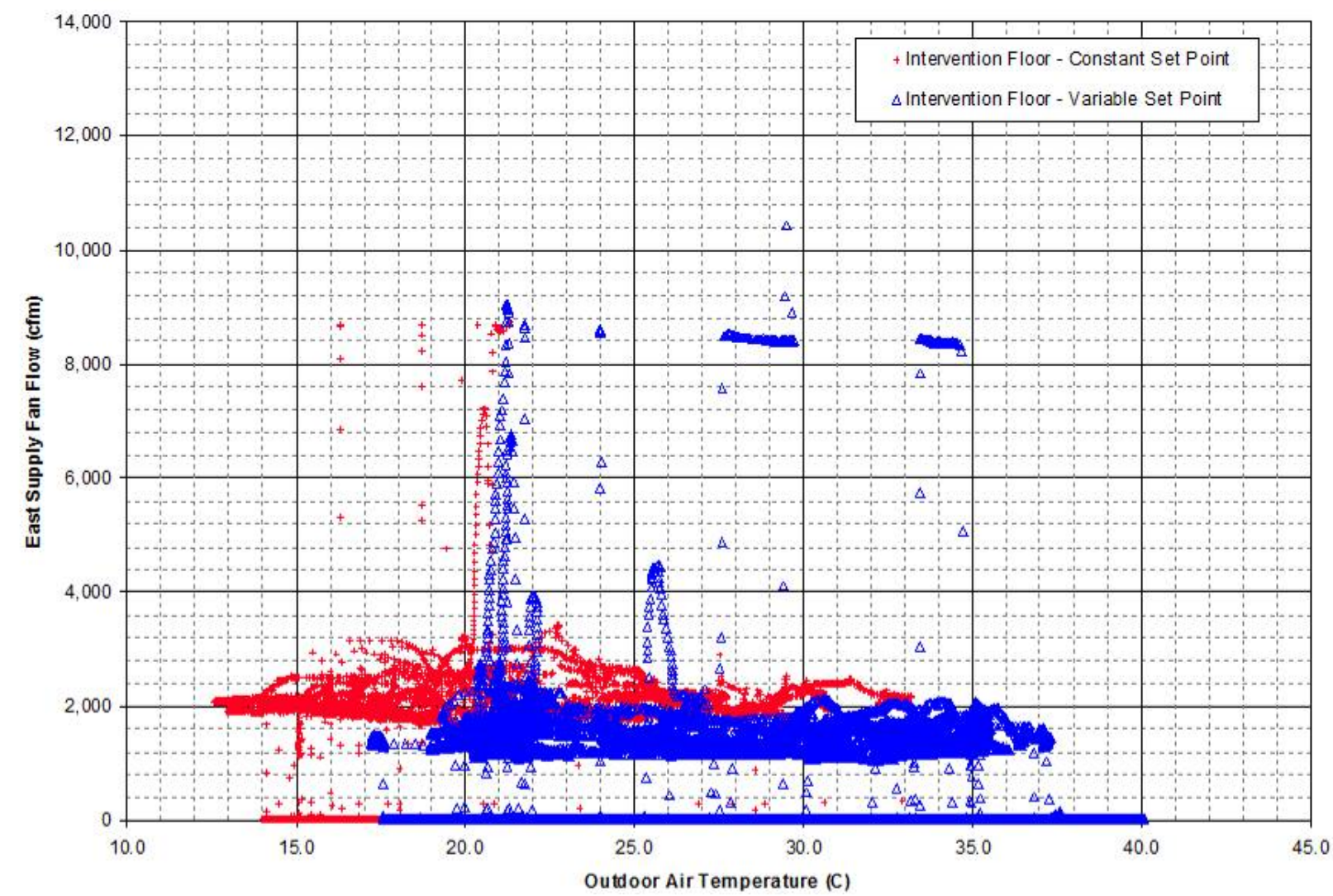

Figure 11. Comparison between Supply Fan Airflows and Outdoor Temperature

To take temperature differences and corresponding operational differences into account for different periods, a normalization procedure was used to adjust the airflows (or other variable such as power) measured on the intervention floor during the pre-SPR period to what would be measured during the SPR period if SPR had not been implemented, assuming that changes on the intervention floor occur in the same proportion as on the control floor. The adjusted value of interest is calculated as follows: 


$$
\bar{X}_{I, \text { adjusted }}=\bar{X}_{I B} \times \frac{\bar{X}_{C S}}{\bar{X}_{C B}}
$$

where

$\mathrm{X}=$ the variable being studied for the time period specified,

IB = measured value for intervention floor, base case time period,

$\mathrm{CS}=$ measured value for control floor, SPR time period, and

$\mathrm{CB}=$ measured value for control floor, base case time period.

The fractional change in the parameter of interest is:

$$
\text { FractionalChange }=1-\frac{\bar{X}_{I S}}{\bar{X}_{I, \text { adjusted }}}
$$

where

IS $=$ measured value for intervention floor, SPR time period.

A positive fractional change represents a reduction in energy use. Conversely, a negative value represents an increase.

Unless otherwise noted, these equations were used to calculate the normalized changes due to SPR for two time periods: 5:00a to 6:00p and 2:00p to 6:00p (peak). In order to compare a variable for the same time period for both the control and intervention floor, we included only those observations when both control and intervention floor air-handler supply fans were on.

\section{Findings}

Figure 12 shows the duct static pressure set point strategies, before and after SAV with InCITe ${ }^{\mathrm{TM}}$ was implemented. Prior to implementation, the duct static pressure set point was constant at about $250 \mathrm{~Pa}$ (1 in.w.c.). After implementation, as expected, the set point varies with flow: from about $250 \mathrm{~Pa}$ at maximum flow to about $100 \mathrm{~Pa}$ at 4,000 $\mathrm{cfm}$ and below. It is unclear why some of the post-implementation set points deviate from the linear function of flow, but in general there are few instances where this occurs. The majority of the data are located between about $2,700 \mathrm{cfm}$ and $6,400 \mathrm{cfm}$, well below the maximum flow of about 13,000 $\mathrm{cfm}$. This means that the fan is operating at low part-loads. Without knowing more about the fan characteristics, however, it is not clear whether the part-load operation results in reduced efficiency or surge.

The actual response to the set points for the intervention floor is shown in Figure 13. Figure 14 shows the actual response for the control floor, where the set point remained constant at about $250 \mathrm{~Pa}$ throughout the tests. There are several instances when the measured pressure does not match the set point on the intervention floor. It is likely that many of these differences correspond to times when the fan is speeding up or slowing down. The points near zero are for times when the fan is off. The reason for the cluster of points at about $150 \mathrm{~Pa}$ and high flows is unknown. One possibility is that it corresponds to times when VAV box and other dampers are opened for pre-cooling and the system is unable to maintain its set point due to the low system resistance. It is unclear why similar behavior does not occur on the control floor. 


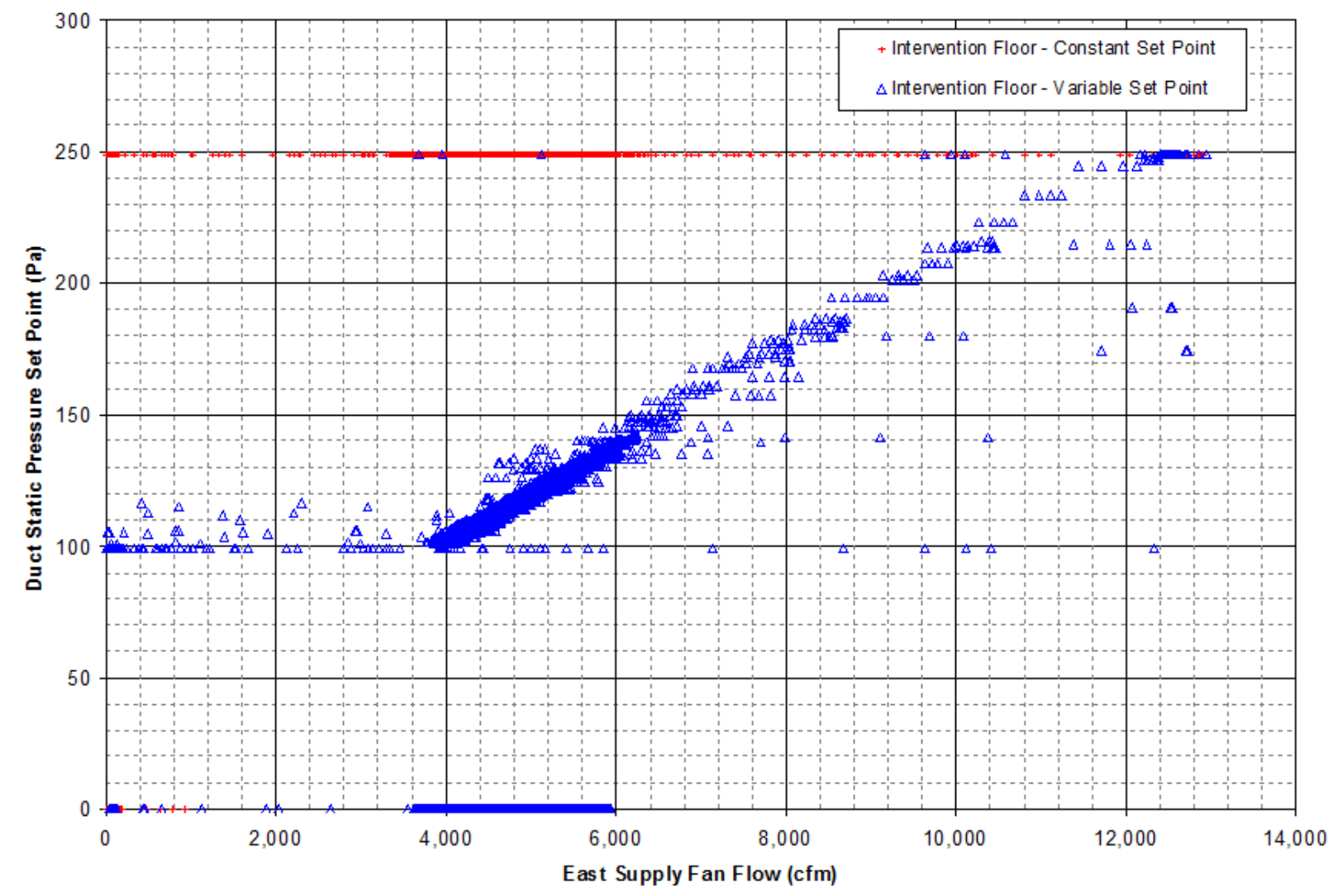

Figure 12. Duct Static Pressure Set Points - Intervention Floor

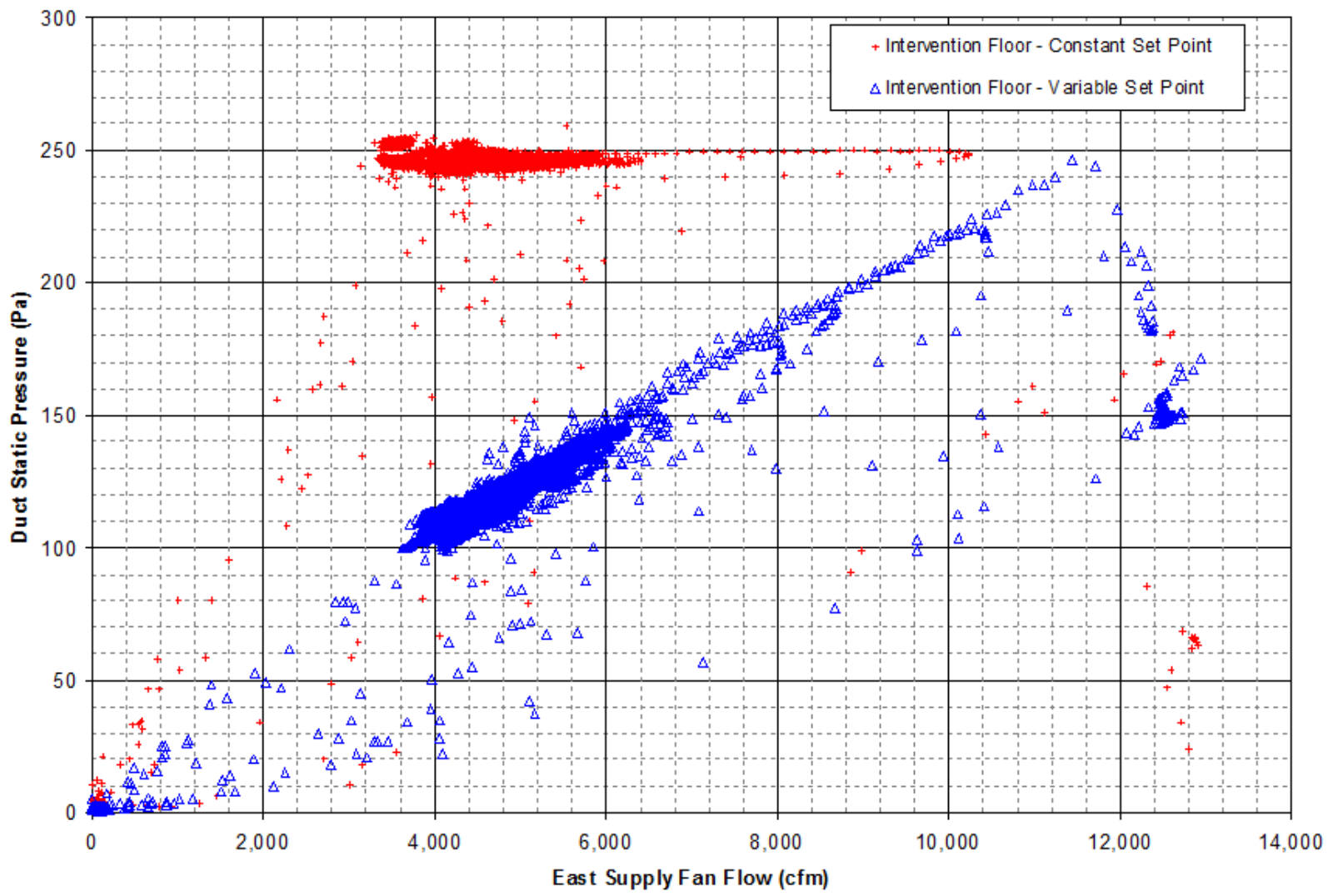

Figure 13.Measured Duct Static Pressures - Intervention Floor 


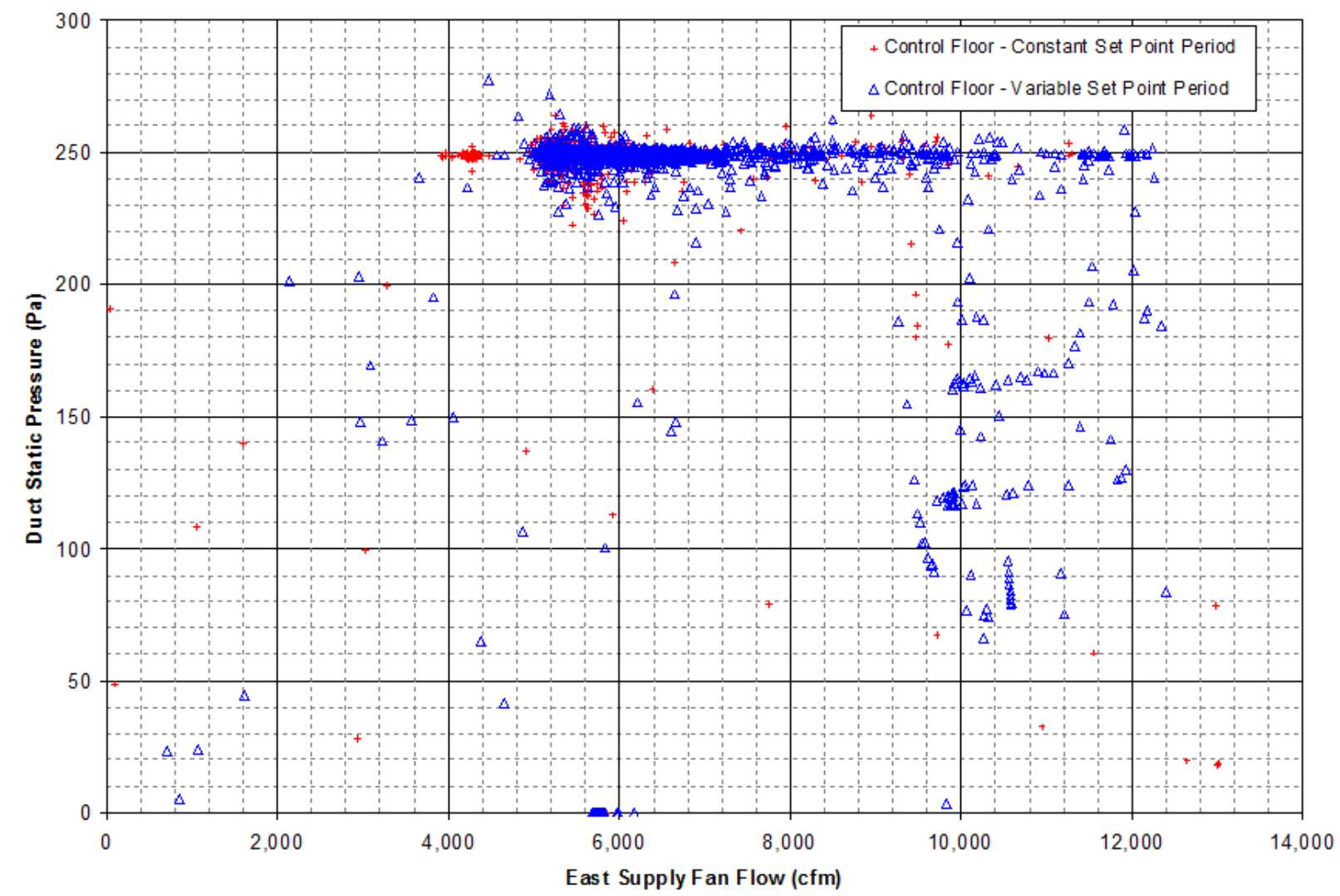

Figure 14. Measured Duct Static Pressures - Control Floor

Figure 15 shows the fan pressure rise for one of the fans on the intervention floor before and after SPR is implemented. As expected, the system curves differ substantially, because the duct static pressure set point changed significantly. In general, we expect that "system curves" for VAV systems with modulating VAV box dampers and duct static pressure control will be a quadratic function of flow $\left(\Delta P_{f a n}=\alpha Q_{f a n}{ }^{2}+\beta Q_{f a n}+P_{s m}\right)$, such as is observed in Figure 15 for flows above about $4,000 \mathrm{cfm}$. Ignoring times when the fan is off or speeding up or slowing down, the fan pressure rise as the flow approaches zero will be near the duct static pressure set point (assuming that the system can maintain control at low flow, especially in the presence of leaky ducts).

Fan power variation with flow for one fan on the intervention floor before and after SPR is implemented is shown in Figure 16. The variation in fan power is substantial at lower flows and near zero at high flows. This means that SPR will have the greatest effect if the system operates at reduced load, such as is observed for this system. Systems that operate near maximum flow most of the time will benefit less from implementing SPR. However, because high flows correspond to high power, small changes in fan pressure rise due to SPR might still result in significant energy savings at less than maximum flow.

Figures 17 and 18 show the fan power history for the two monitoring periods of interest. In particular, Figure 17 shows that fan power on the control and intervention floors is quite similar before implementing SPR. After implementing SPR, Figure 18 shows a substantial reduction in supply fan power for the intervention floor compared to the control floor. Figures 19 and 20 show the fan power variations for sample days, before and after implementing SPR, respectively. 


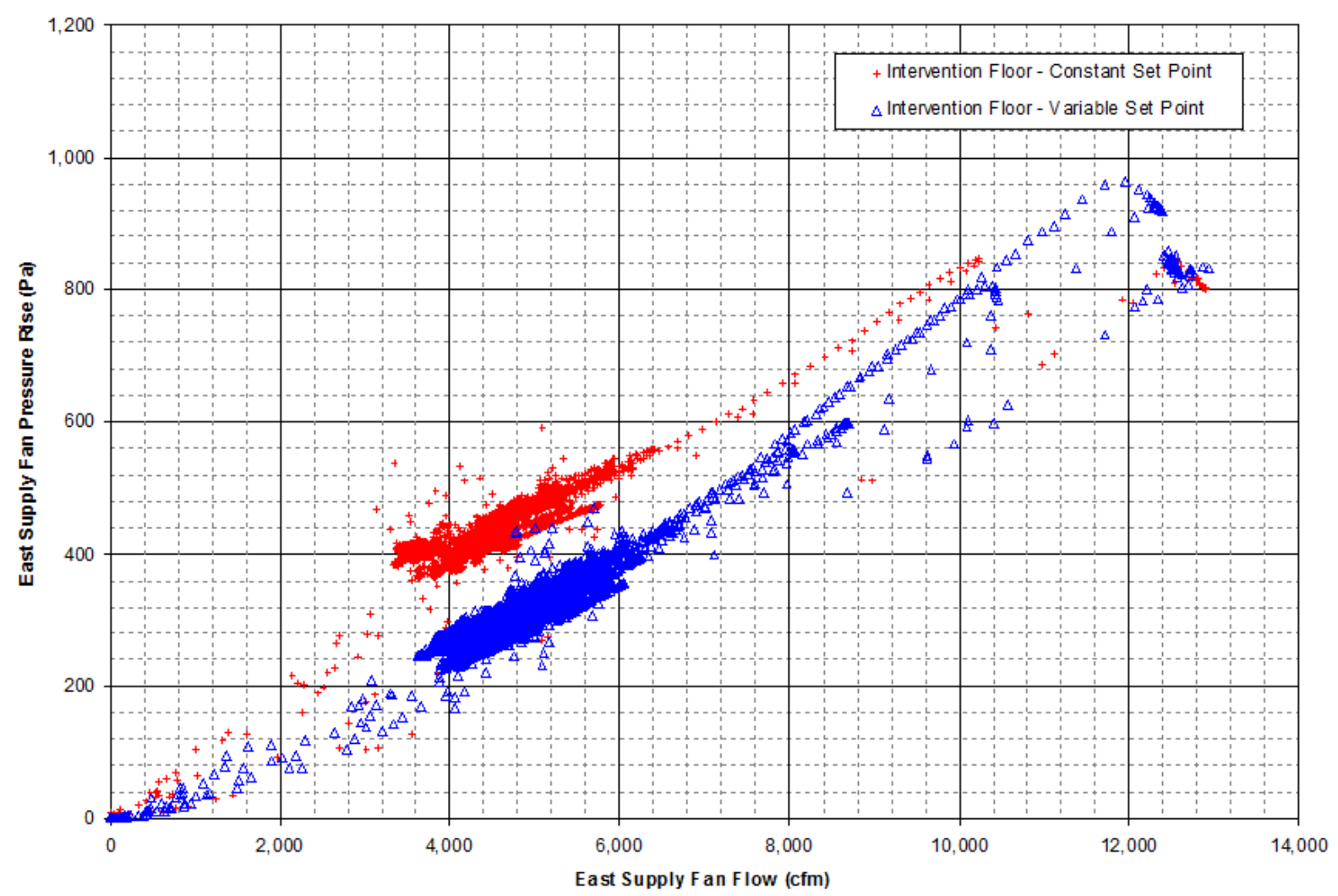

Figure 15. Measured Supply Fan Pressure Rises - Intervention Floor

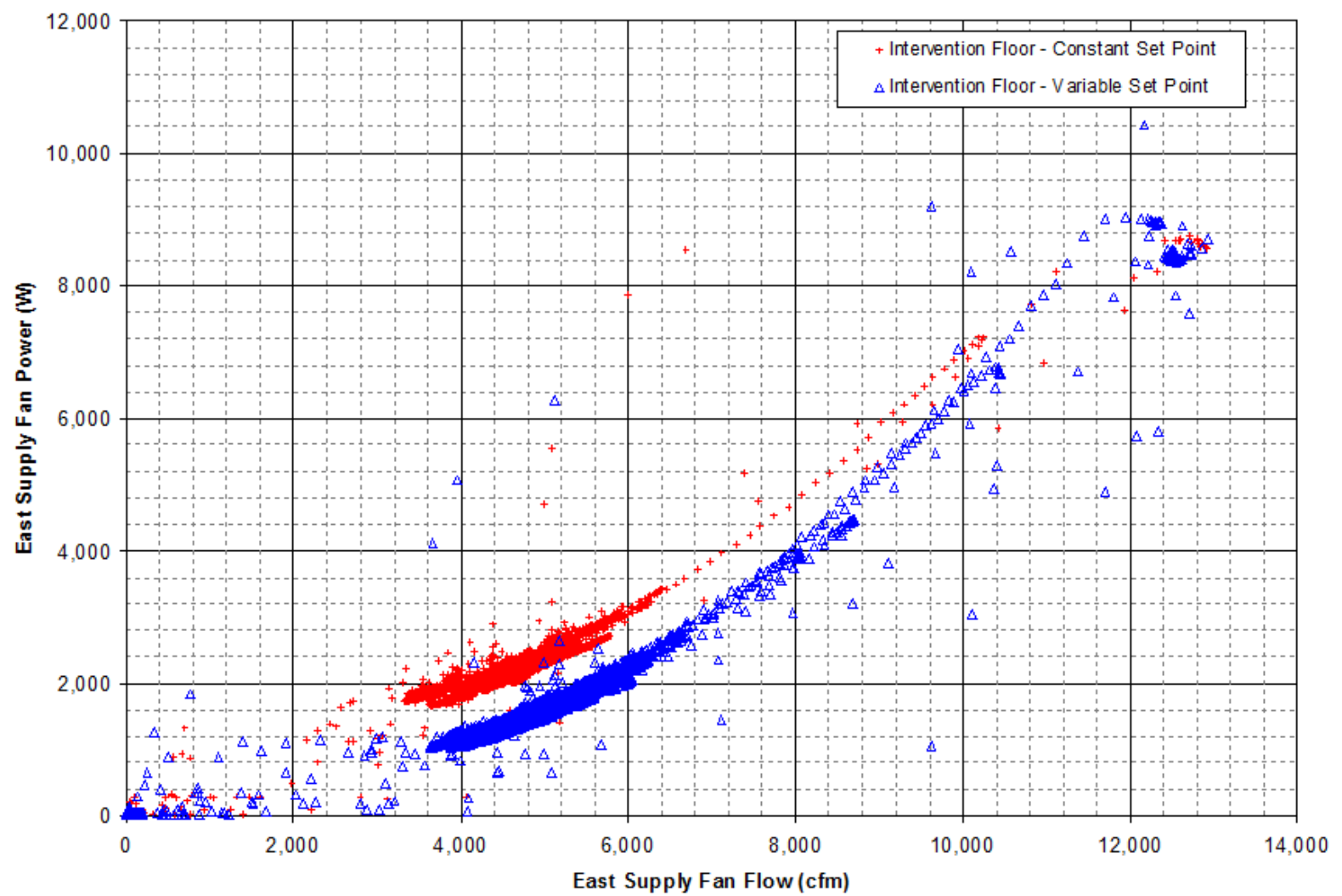

Figure 16. Measured Supply Fan Power - Intervention Floor 


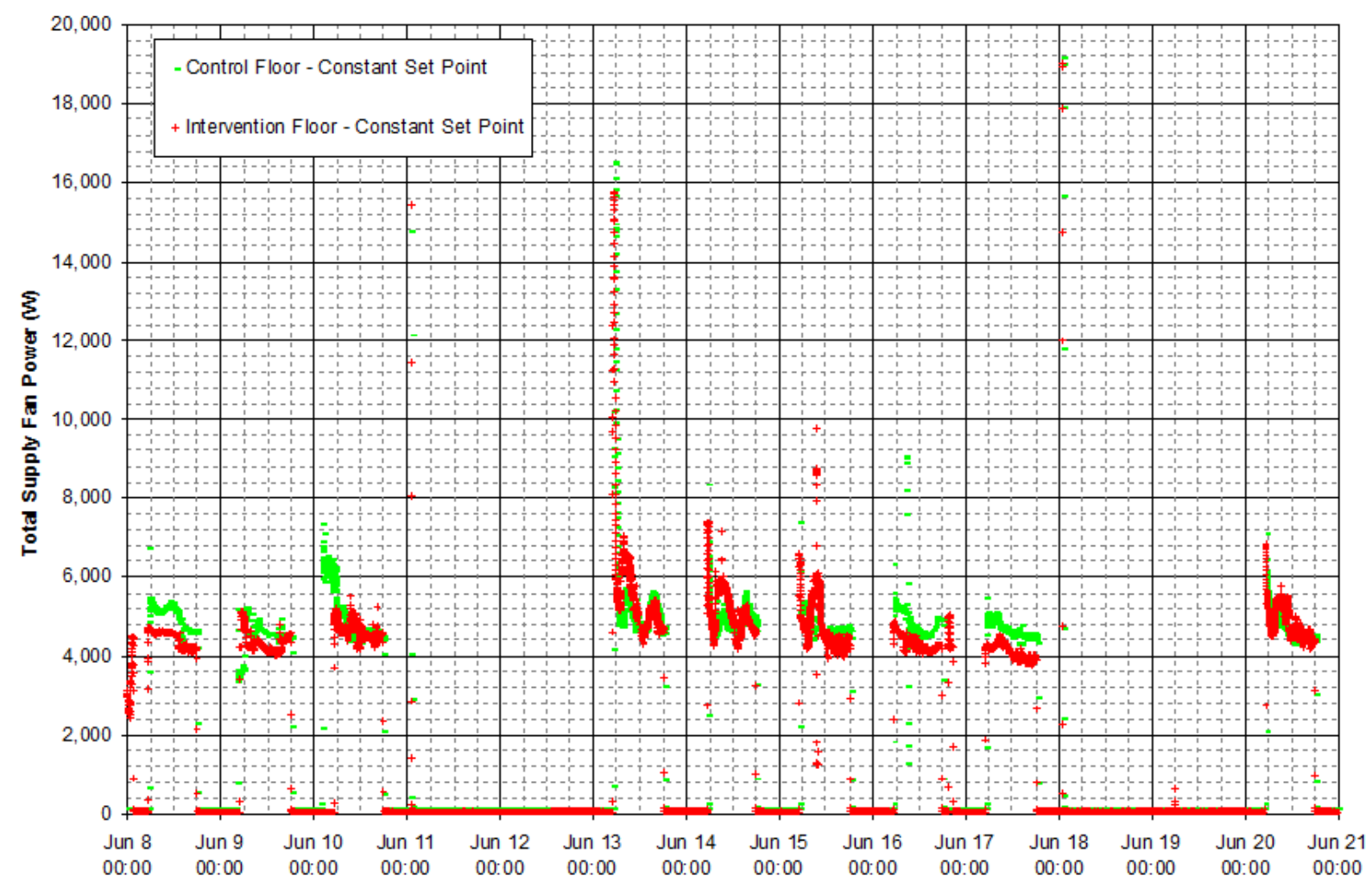

Figure 17. Fan Power History - Prior to Implementing SPR

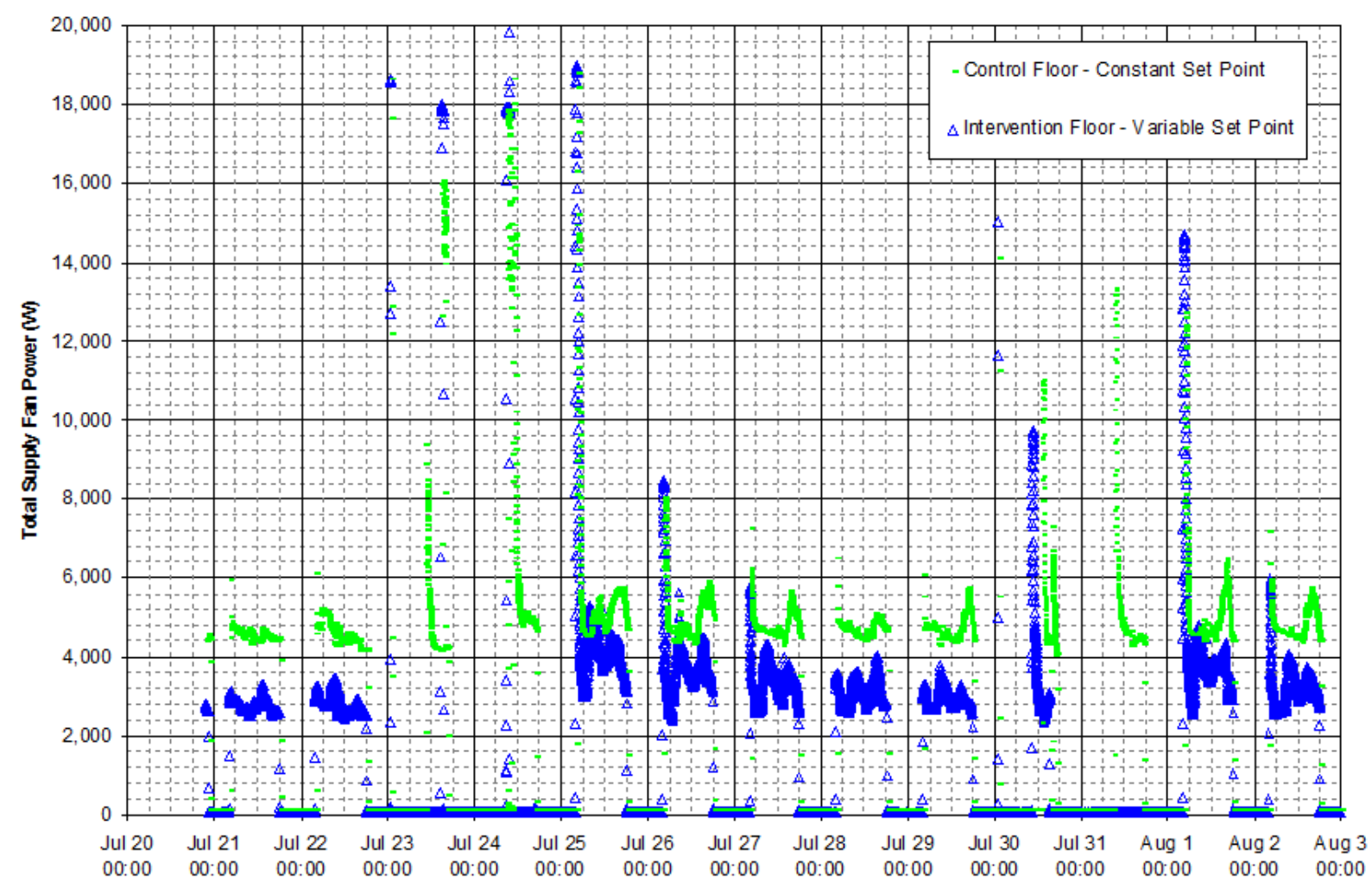

Figure 18. Fan Power History - After Implementing SPR 


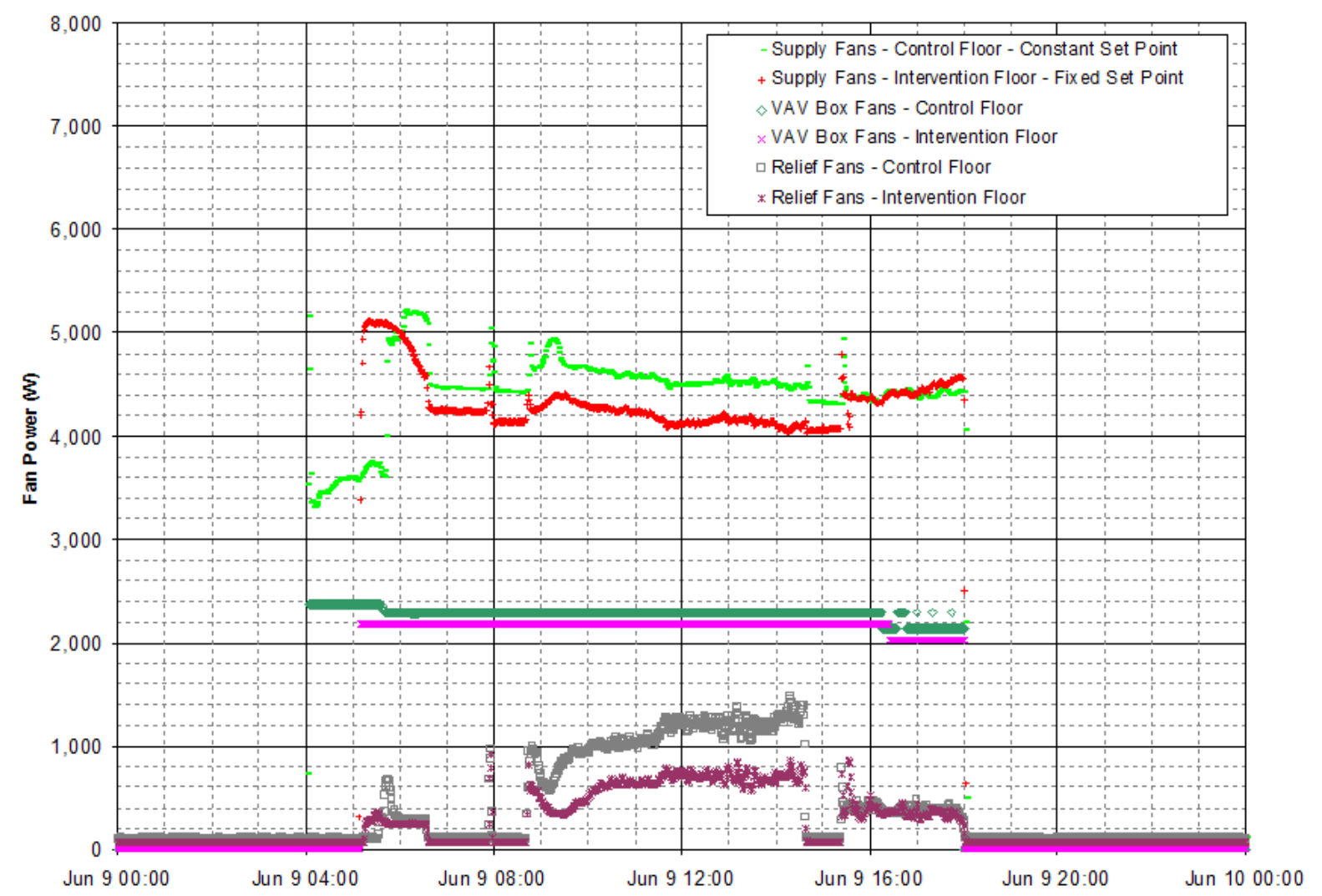

Figure 19. Daily Snapshot - Fan Power History - Prior to Implementing SPR - June 9

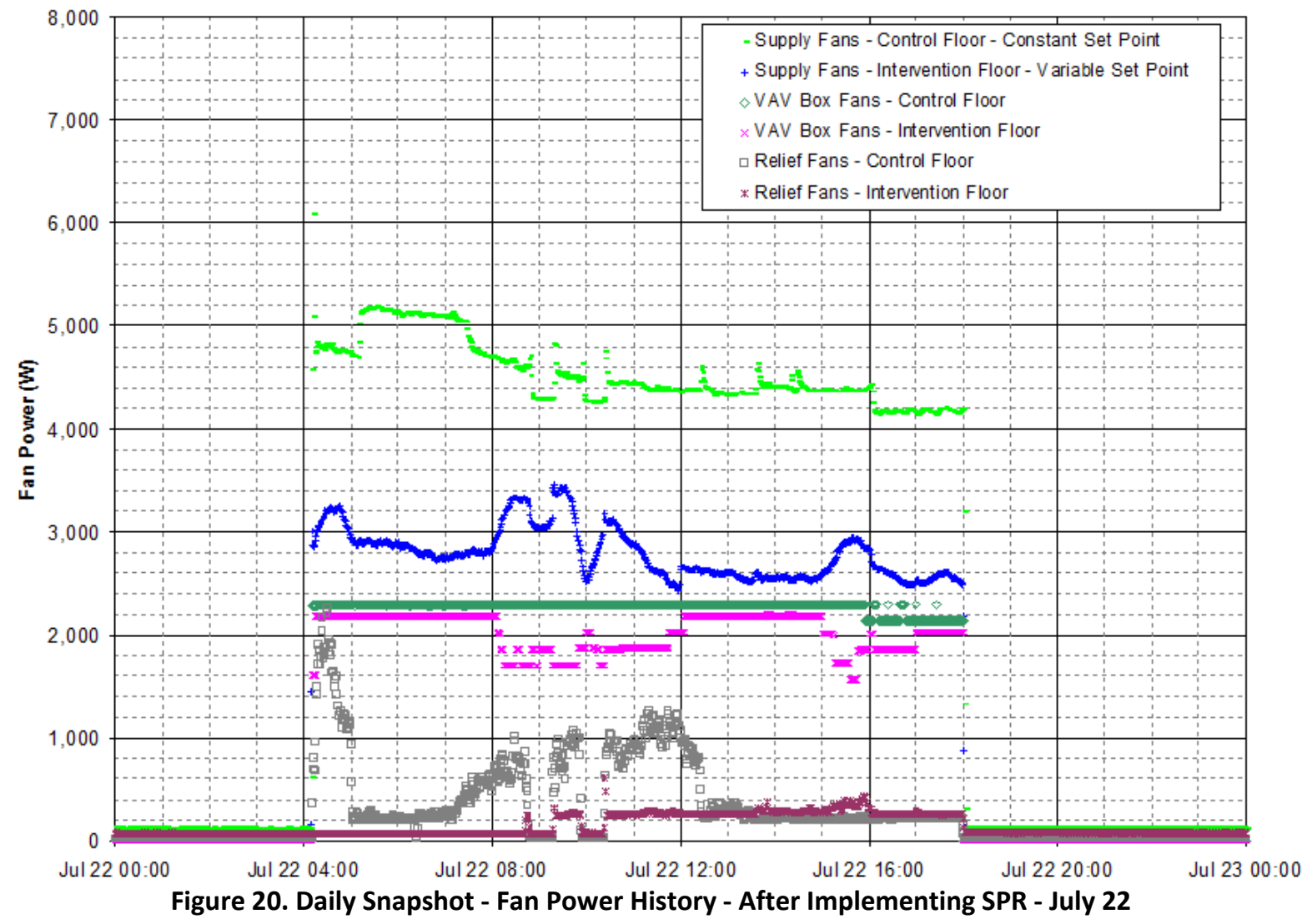


Figure 20 shows that not only is supply fan power reduced significantly, but so also is relief fan power and VAV box fan power. Table 3 summarizes the power and load reductions associated with implementing SPR in the test building during normal fan operating hours (5:00a to 6:00p).

Table 3. Summary of Site Energy Reductions from Implementing SPR - Normal Operation

\begin{tabular}{|c|c|c|c|c|c|c|c|c|}
\hline & & \multicolumn{2}{|c|}{ Pre-SPR } & \multirow{2}{*}{\begin{tabular}{|l|} 
Post-SPR \\
M easured \\
\end{tabular}} & \multirow{2}{*}{$\begin{array}{c}\text { Post/Pre } \\
\text { Ratio }\end{array}$} & \multicolumn{2}{|c|}{ Reduction } & \multirow[b]{2}{*}{ Units } \\
\hline & Floor & M easured & Adjusted & & & Difference & Fraction & \\
\hline Supply Fan & Control & 5,543 & & 5,748 & 1.0370 & \multirow[b]{2}{*}{-158} & \multirow[b]{2}{*}{$3.5 \%$} & \multirow[b]{2}{*}{$\mathrm{cfm}$} \\
\hline Flow (East) & Intervention & 4,373 & 4,535 & 4,693 & & & & \\
\hline \multirow{2}{*}{$\begin{array}{r}\text { Supply Fan } \\
\text { Flow (W est) }\end{array}$} & Control & 6,068 & & 6,099 & 1.0052 & \multirow[b]{2}{*}{-24} & \multirow[b]{2}{*}{$-0.4 \%$} & \multirow[b]{2}{*}{$\mathrm{cfm}$} \\
\hline & Intervention & 5,616 & 5,646 & 5,670 & & & & \\
\hline \multirow{2}{*}{$\begin{array}{r}\text { Supply Fan } \\
\text { Flow (East+W est) }\end{array}$} & Control & 11,610 & & 11,847 & 1.0204 & \multirow[b]{2}{*}{-169} & \multirow[b]{2}{*}{$-1.7 \%$} & \multirow[b]{2}{*}{$\mathrm{cfm}$} \\
\hline & Intervention & 9,990 & 10,194 & 10,363 & & & & \\
\hline \multirow{2}{*}{$\begin{array}{r}\text { Supply Fan } \\
\text { Power (East+W est) } \\
\end{array}$} & Control & 4,760 & & 4,738 & 0.9953 & \multirow[b]{2}{*}{1,377} & \multirow[b]{2}{*}{$29.8 \%$} & \multirow[b]{2}{*}{ W } \\
\hline & Intervention & 4,639 & 4,617 & 3,240 & & & & \\
\hline \multirow{2}{*}{$\begin{array}{r}\text { Return Fan } \\
\text { Power (East+W est) } \\
\end{array}$} & Control & 518 & & 513 & 0.9897 & \multirow[b]{2}{*}{209} & \multirow[b]{2}{*}{$42.6 \%$} & \multirow[b]{2}{*}{ W } \\
\hline & Intervention & 497 & 492 & 282 & & & & \\
\hline \multirow{2}{*}{$\begin{array}{l}\text { VAV Box Fan } \\
\text { Power (Total) }\end{array}$} & Control & 2,135 & & 2,077 & 0.9730 & \multirow[b]{2}{*}{167} & \multirow[b]{2}{*}{$11.4 \%$} & \multirow[b]{2}{*}{ W } \\
\hline & Intervention & 1,924 & 1,872 & 1,705 & & & & \\
\hline \multirow{2}{*}{$\begin{array}{r}\text { Total Fan } \\
\text { Power (Total) }\end{array}$} & Control & 7,413 & & 7,327 & 0.9885 & \multirow[b]{2}{*}{1,748} & \multirow[b]{2}{*}{$25.9 \%$} & \multirow[b]{2}{*}{ W } \\
\hline & \begin{tabular}{|l|} 
Intervention \\
\end{tabular} & 7,060 & 6,978 & 5,230 & & & & \\
\hline \multirow{2}{*}{$\begin{array}{r}\text { Cooling Coil Sensible } \\
\text { Load (East+W est) }\end{array}$} & Control & 39,851 & & 56,517 & 1.4182 & & & \\
\hline & Intervention & 39,305 & 55,744 & 51,950 & & 3,794 & $6.8 \%$ & W \\
\hline Preheat Coil Sensible & Control & $-5,988$ & & $-3,665$ & 0.6121 & & & \\
\hline Load (East+W est) & Intervention & $-3,766$ & $-2,305$ & $-3,968$ & & $-1,663$ & $-72.1 \%$ & $\mathrm{~W}$ \\
\hline VAV Box Reheat Coil & Control & 55 & & 0 & 0.0000 & & & \\
\hline Power (Total) & Intervention & 0 & 0 & 0 & & 0 & $0.0 \%$ & W \\
\hline
\end{tabular}

Table 3 indicates that implementing SPR had little impact on supply flows, but reduced average supply fan power about 30\% (largely because of fan pressure rise reductions). Total fan power was reduced slightly less: about 26\%. Cooling coil loads also decreased, but substantially less on a fractional basis compared to fan power. The absolute reduction in cooling coil loads is, however, substantial relative to the fan power reduction (slightly more than double). The actual impact on site electrical use is unknown though, because the coil load must be translated into chiller and cooling tower energy impacts. We do not have sufficient information about the building equipment and operation to make this translation. Although SPR reduced fan power and cooling coil loads, it increased preheat coil loads. The reason for this behavior is unknown. As with the cooling load changes, the heating loads would need to be translated to boiler energy impacts to assess the importance of this change.

Similar reductions occur during peak hours (2:00p to 6:00p) as well, as shown in Table 4. Two difference, however, is that preheat loads are negligible during the afternoon, and there is little change in preheat coil loads as a result. Also, cooling coil loads increased during this time. Again, this change needs to be translated to chiller and tower energy impacts to understand its significance in terms of whole building energy use, and especially on peak demand. Fortunately, in terms of average operation during the day, the net result is that cooling coil loads are reduced on average (as shown in Table 3).

In conclusion, although implementing SAV with $\mathrm{InCITe}^{\mathrm{TM}}$ substantially reduced fan power (as expected), the increases in cooling and heating coil loads require more information to assess the net savings resulting from this implementation of SPR. 
Table 4. Summary of Site Energy Reductions from Implementing SPR - Peak Periods

\begin{tabular}{|c|c|c|c|c|c|c|c|c|}
\hline & & \multicolumn{2}{|c|}{ Pre-SPR } & \multirow{2}{*}{$\begin{array}{l}\text { Post-SPR } \\
\text { M easured }\end{array}$} & \multirow{2}{*}{$\begin{array}{c}\text { Post/Pre } \\
\text { Ratio }\end{array}$} & \multicolumn{2}{|c|}{ Reduction } & \multirow[b]{2}{*}{ Units } \\
\hline & Floor & Measured & A djusted & & & Difference & Fraction & \\
\hline \multirow{2}{*}{\begin{tabular}{l|} 
Supply Fan \\
Flow (East)
\end{tabular}} & Control & 5,491 & & 6,131 & 1.1165 & \multirow[b]{2}{*}{-249} & \multirow[b]{2}{*}{$5.5 \%$} & \multirow[b]{2}{*}{$\mathrm{cfm}$} \\
\hline & Intervention & 4,047 & 4,518 & 4,767 & & & & \\
\hline \multirow{2}{*}{\begin{tabular}{r|} 
Supply Fan \\
Flow (W est)
\end{tabular}} & Control & 6,048 & & 6,344 & 1.0489 & \multirow[b]{2}{*}{11} & \multirow[b]{2}{*}{$0.2 \%$} & \multirow[b]{2}{*}{$\mathrm{cfm}$} \\
\hline & Intervention & 5,538 & 5,809 & 5,797 & & & & \\
\hline \multirow{2}{*}{$\begin{array}{r}\text { Supply Fan } \\
\text { Flow (East+W est) }\end{array}$} & Control & 11,539 & & 12,475 & 1.0811 & \multirow[b]{2}{*}{-203} & \multirow[b]{2}{*}{$-2.0 \%$} & \multirow[b]{2}{*}{$\mathrm{cfm}$} \\
\hline & Intervention & 9,584 & 10,361 & 10,564 & & & & \\
\hline \multirow{2}{*}{$\begin{array}{r}\text { Supply Fan } \\
\text { Power (East+W est) }\end{array}$} & Control & 4,616 & & 5,014 & 1.0861 & \multirow[b]{2}{*}{1,481} & \multirow[b]{2}{*}{$31.1 \%$} & \multirow[b]{2}{*}{ W } \\
\hline & Intervention & 4,380 & 4,758 & 3,277 & & & & \\
\hline \multirow{2}{*}{$\begin{array}{r}\text { Return Fan } \\
\text { Power (East+W est) }\end{array}$} & Control & 605 & & 301 & 0.4969 & \multirow[b]{2}{*}{-63} & \multirow[b]{2}{*}{$-24.8 \%$} & \multirow[b]{2}{*}{ W } \\
\hline & Intervention & 514 & 256 & 319 & & & & \\
\hline \multirow{2}{*}{$\begin{array}{l}\text { VAV Box Fan } \\
\text { Power (Total) }\end{array}$} & Control & 2,156 & & 1,844 & 0.8553 & \multirow[b]{2}{*}{295} & \multirow[b]{2}{*}{$29.4 \%$} & \multirow[b]{2}{*}{ w } \\
\hline & Intervention & 1,975 & 1,689 & 1,394 & & & & \\
\hline \multirow{2}{*}{$\begin{array}{r}\text { Total Fan } \\
\text { Power (Total) }\end{array}$} & Control & 7,378 & & 7,159 & 0.9703 & \multirow[b]{2}{*}{1,676} & \multirow[b]{2}{*}{$27.4 \%$} & \multirow[b]{2}{*}{ W } \\
\hline & Intervention & 6,870 & 6,666 & 4,990 & & & & \\
\hline \multirow{2}{*}{$\begin{array}{r}\text { Cooling Coil Sensible } \\
\text { Load (East+W est) }\end{array}$} & Control & 56,457 & & 86,219 & 1.5272 & & & \\
\hline & Intervention & 48,468 & 74,019 & 76,717 & & $-2,697$ & $3.6 \%$ & W \\
\hline Preheat Coil Sensible & Control & -561 & & 0 & 1.0000 & & & \\
\hline Load (East+W est) & Intervention & -733 & -733 & 0 & & 733 & $100.0 \%$ & W \\
\hline VAV Box Reheat Coil & Control & 0 & & 0 & 0.0000 & & & \\
\hline Power (Total) & Intervention & 0 & 0 & 0 & & 0 & $0.0 \%$ & W \\
\hline
\end{tabular}

\section{CONCLUSIONS}

This project has addressed two significant deficiencies in air-handling systems for large commercial building: duct leakage and duct static pressure reset. Both constitute significant energy reduction opportunities for these buildings.

A new duct leakage model has been successfully implemented in EnergyPlus, which will enable simulation users to assess the impacts of leakage on whole-building energy use and operation in a coupled manner. This feature also provides a foundation to support code change proposals and compliance analyses related to Title 24 where duct leakage is an issue. Our example simulations continue to show that leaky ducts substantially increase fan power: $10 \%$ upstream and $10 \%$ downstream leakage increases supply fan power $30 \%$ on average compared to a tight duct system (2.5\% upstream and 2.5\% downstream leakage). Much of this increase is related to the upstream leakage rather than to the downstream leakage. This does not mean, however, that downstream leakage is unimportant. Our simulations also demonstrate that ceiling heat transfer is a significant effect that needs to be included when assessing the impacts of duct leakage in large commercial buildings. This is not particularly surprising, given that "ceiling regain” issues have already been included in residential analyses as long as a decade ago (e.g., ASHRAE Standard 152); mainstream simulation programs that are used for large commercial building energy analyses have not had this capability until now.

Our analyses of data that we collected during our 2005 tests of the SAV with InCITe ${ }^{\mathrm{TM}}$ duct static pressure reset technology show that this technology can substantially reduce fan power (in this case, by about 25 to 30\%). Tempering this assessment, however, is that cooling and heating coil loads were observed to increase or decrease significantly depending on the time window used. Their impact on cooling and heating plant power needs to be addressed in future studies; without translating the coil loads to plant equipment energy use, it is not possible to judge the net 
impact of this SPR technology on whole-building energy use. If all of the loads had decreased, such a step would not be as necessary.

\section{ACKNOWLEDGEMENTS}

The authors wish to acknowledge the participation and technical support by Federspiel Controls during the experimental phase of this project. We also wish to acknowledge the assistance of Energy Performance of Buildings staff (especially Darryl Dickerhoff) at LBNL, who spent many late nights installing and troubleshooting monitoring equipment in the Sacramento office building that we tested, and subsequently analyzing the massive amounts of resulting data.

The building management staff at the site was extremely cooperative and supportive of our work. We would like to thank Bob Young, Andy Rhoades, Scott Kutylowski, Carlos Isquierdo, Julian Duran, and Lisa Rycroft from Thomas Properties Group.

Other former and current LBNL staff members in the Building Technologies Department were also helpful and supportive of this work, particularly regarding the intricacies of translating DOE-2.1E input from our past simulations for use in EnergyPlus (Joe Huang), and in implementing the duct leakage model in EnergyPlus (Fred Buhl).

Finally, the authors would like to acknowledge the financial support and contributions of the PIER Buildings Program, particularly the Contract Manager, Martha Brook. We also acknowledge the financial support of the U.S. Department of Energy, Office of Energy Efficiency and Renewable Energy, and the Team Lead -Commercial Buildings, Dru Crawley.

\section{GLOSSARY}

ACM

ASHRAE American Society of Heating, Refrigerating, and Air-Conditioning Engineers

CEC

$\mathrm{cfm}$

DOE

EIA

EMCS

GWh

HVAC

LBNL

MW

PIER

$\mathrm{RD} \& \mathrm{D}$

SMACNA

Alternative Calculation Method

California Energy Commission

Cubic feet per minute

U.S. Department of Energy

Energy Information Administration

Energy management control system

Giga Watt hours, $10^{9} \mathrm{Wh}, 10^{6} \mathrm{kWh}$

Heating, ventilating, and air conditioning

Lawrence Berkeley National Laboratory

Mega Watt, $10^{6} \mathrm{~W}$

Public Interest Energy Research

Research, Development, and Demonstration

Sheet Metal and Air Conditioning Contractors’ National Association 
UC University of California

VAV Variable Air Volume

\section{REFERENCES}

ASHRAE. 1996. "Psychrometrics: Theory and Practice". Atlanta: American Society of Heating, Refrigerating and Air-Conditioning Engineers, Inc.

ASHRAE. 2004. "ANSI/ASHRAE Standard 152 Method of Test for Determining the Design and Seasonal Efficiencies of Residential Thermal Distribution Systems”. Atlanta: American Society of Heating, Refrigerating and Air-Conditioning Engineers, Inc.

ASHRAE. 2007. “ANSI/ASHRAE Standard 90.1 Energy Standard for Buildings Except LowRise Residential Buildings”. Atlanta: American Society of Heating, Refrigerating and AirConditioning Engineers, Inc.

Brook, M. 2002. “California Electricity Outlook: Commercial Building Systems”. Presentation at PIER Buildings Program HVAC Diagnostics Meeting, Oakland, CA. April 16.

CEC. 2008a. "2008 Building Energy Efficiency Standards for Residential and Nonresidential Buildings - Standards/Regulations”. California Energy Commission, CEC-400-2008-001-CMF, December.

Delporte, N. 2004. "Diagnostic Tool for Screening Duct Leakage in Large Commercial Buildings”. Ecole Nationale Supérieure d'Arts et Métiers, Paris, France.

Diamond, R., C. Wray, D. Dickerhoff, N. Matson, and D. Wang. 2003. “Thermal Distribution Systems in Commercial Buildings”. Lawrence Berkeley National Laboratory Report, LBNL51860. http://epb.lbl.gov/publications/lbnl-51860.pdf

DOE. 2009. "EnergyPlus Engineering Reference: The Reference to EnergyPlus Calculations". U.S. Department of Energy

EPA. 2008. "ENERGY STAR ${ }^{\circledR}$ Building Upgrade Manual”. U.S. Environmental Protection Agency, Office of Air and Radiation.

Federspiel, C. 2004. "Detecting Optimal Fan Pressure”. Final Report of Federspiel Controls to the CEC Energy Innovations Small Grant Program. Grant \#: 02-03.

Federspiel, C. 2005. "Detecting Critical Supply Duct Pressure”. ASHRAE Transactions, Vol. 111, Part 1. Atlanta: American Society of Heating, Refrigerating and Air-Conditioning Engineers, Inc.

Franconi, E.M. 1999. "Thermodynamic Analysis for Improved HVAC Distribution System Performance”. Ph.D. Dissertation, Department of Civil, Environmental, and Architectural Engineering, University of Colorado, Boulder.

Hydeman, M., S. Taylor, J. Stein, E. Kolderup, and T. Hong. 2003. “Advanced Variable Air Volume System Design Guide”. CEC Report P500-03-082-A-11. October. 
PECI. 2004. "National Strategy for Building Commissioning”. Portland Energy Conservation, Inc. Report to US Department of Energy.

Wang, D. and M. Sherman. 2004. "TRAMS: A New Tracer Gas Airflow Measurement System”. EETD Summer Newsletter, Vol. 5, No. 3. Lawrence Berkeley National Laboratory. http://eetdnews.lbl.gov/nl18/nl_18.html

Wray, C.P. 2003. "Duct Thermal Performance Models for Large Commercial Buildings". Lawrence Berkeley National Laboratory Report to the California Energy Commission. LBNL53410. http://epb.lbl.gov/publications/lbnl-53410.pdf

Wray, C.P. and N.E. Matson. 2003. "Duct Leakage Impacts on VAV System Performance in California Large Commercial Buildings”. Lawrence Berkeley National Laboratory Report to the California Energy Commission. LBNL-53605. http://epb.lbl.gov/publications/lbnl-53605.pdf

Wray, C.P., R.C. Diamond, and M.H. Sherman. 2005. "Rationale for Measuring Duct Leakage Flows in Large Commercial Buildings". Proceedings - 26th AIVC Conference, Brussels, Belgium, September. LBNL-58252. http://epb.lbl.gov/publications/lbnl-58252.pdf 


\section{APPENDIX A: ENERGYPLUS ENGINEERING DOCUMENTATION RELATED TO THE NEW DUCT LEAKAGE MODEL}

The following is the documentation that was created in this project to describe the technical aspects of the duct leakage model that is now implemented in EnergyPlus:

\section{Simple Duct Leakage Model \\ Overview}

The input object ZoneHVAC:AirDistributionUnit also provides access to a model for duct leakage that can be a significant source of energy inefficiency in forced-air HVAC systems. Evaluating duct leakage energy losses can involve considerable user effort and computer resources if an airflow network is defined through a detailed description of the system components and airflow paths (including leakage paths). A nonlinear pressure-based solver is used to solve for pressures and flow rates in the network. By making certain assumptions and approximations for certain well defined configurations, however, it is possible to obtain accurate results with a simple mass and energy balance calculation and thus avoid the input and calculation costs of doing a full pressure-based airflow network simulation.

The Simple Duct Leakage Model (SDLM) assumes a central VAV air conditioning system with a constant static pressure setpoint. The model assumes that the leaks are in the supply ducts and that the system returns air through a ceiling plenum that contains the ducts. Thus, the ducts leak into the return plenum, and this part of the supply does not reach the conditioned zones. With the additional assumptions described below, it is possible to model this configuration with heat and mass balance equations and avoid the use of a nonlinear pressure-based solver. In the EnergyPlus context, this means that use of AirflowNetwork is avoided and the leakage calculations are obtained in the course of the normal thermal simulation.

\section{Principles and Description}

\section{$\underline{\text { Constant Flow Rate }}$}

The airflow rate through a duct leak is a function of the pressure difference between the duct and the surrounding space:

$$
\dot{V}_{\text {leak }}=C_{1} \cdot \Delta p_{\text {duct-space }}^{n}
$$

The exponent $\mathrm{n}$ is 0.5 for leaks that look like orifices (holes that are large relative to the thickness of the duct wall); for leaks that resemble cracks (e.g., lap joints), $\mathrm{n}$ is approximately 0.6 to 0.65 .

For a duct with constant flow rate and a linear pressure drop through the duct, the average static pressure in the duct will equal half of the duct static pressure drop. Assuming turbulent flow in the duct, the duct pressure drop is proportional to the square of the airflow through the duct. This can be expressed as: 


$$
\Delta p_{\text {duct-space }}=\frac{\Delta p_{\text {duct }}}{2}=C_{2}\left(\frac{\dot{V}_{\text {duct }}^{2}}{2}\right)
$$

Combining equations (1) and (2) and assuming the leaks are large holes ( $n$ equals 0.5). gives:

$$
\dot{V}_{\text {leak }}=C_{1} \cdot \Delta p_{\text {duct-space }}^{0.5}=C_{3} \cdot \dot{V}_{\text {duct }}
$$

where

$$
C_{3}=C_{1} \cdot\left(C_{2} / 2\right)^{0.5}
$$

Thus the leakage fraction $C_{3}$ remains constant regardless of the duct flow rate or static pressure. This result depends on the following assumptions:

- the duct airflow is turbulent;

- the duct pressure varies linearly along the duct;

- the average duct pressure approximates the pressure drop across the duct;

- $\quad$ the leaks are large and have pressure exponent 0.5 .

\section{$\underline{\text { Effects of Constant Pressure Upstream and Variable Flow and Pressure Downstream }}$}

Commonly VAV systems maintain a constant static pressure at some point in the duct system upstream of the VAV terminal units. That is, airflow rate will vary depending on the cooling requirement, but a constant pressure will be maintained at the static pressure sensor. Consequently, the leakage flow for a leak upstream of the VAV boxes will be approximately constant. Or to put it another way, the leakage fraction will vary in proportion to the flow rate.

For leaks downstream of the VAV terminal units, the airflow through the duct and the pressure in the downstream duct will vary as the box damper modulates in response to the differential between the room temperature and the thermostat setpoint. In this case, the situation is similar to the constant flow case: for an orifice-like leak, the pressure difference across the leak will vary linearly with the air speed (or flow rate); i.e., the leakage fraction will be approximately constant.

\section{SDLM}

For SDLM, our leakage model is then:

1. for leaks upstream of the terminal units, the leakage flow rate will be constant;

2. for leaks downstream of the terminal units, the leakage fraction will be constant.

This model assumes, in addition to the assumptions given above, that the VAV system is controlled to a constant static pressure setpoint. In EnergyPlus SDLM is not currently applicable to systems using static pressure reset. Using SDLM would require knowledge of static pressure as a function of system air flow rate. 


\section{Inputs and Data}

User data for the SDLM is entered through The ZoneHVAC:AirDistributionUnit (ADU) object. There are 2 data items per ADU:

1. the upstream nominal leakage fraction;

2. the downstream fixed leakage fraction.

Both inputs are leakage fractions. Input (1) is the leakage fraction at design flow rate, which together can be used to determine the constant leakage flow rate upstream of the VAV boxes; this leakage fraction varies with the flow rate. Input (2) is a fixed leakage fraction and is constant as the flow rate varies.

\section{Implementation}

The various zone mass flow rates are related in the following manner.

$$
\begin{aligned}
& \dot{m}_{s, u s}=\dot{m}_{t u}+\dot{m}_{l k, u s} \\
& \dot{m}_{t u}=\dot{m}_{l k, d s}+\dot{m}_{s, z} \\
& \dot{m}_{l k, u s}=F r a c_{u s} \cdot \dot{m}_{s, u s, \max } \\
& \dot{m}_{l k, d s}=F r a c_{d s} \cdot \dot{m}_{t u}
\end{aligned}
$$

Here

$\dot{m}_{s, u s}$ is the constant zone supply air mass flow rate upstream of the leaks [kg/s];

$\dot{m}_{t u}$ is the air mass flow rate through the terminal unit $[\mathrm{kg} / \mathrm{s}]$;

$\dot{m}_{l k, u s}$ is the upstream leakage air mass flow rate $[\mathrm{kg} / \mathrm{s}]$;

$\dot{m}_{l k, d s}$ is the downstream leakage air mass flow rate $[\mathrm{kg} / \mathrm{s}]$;

$\dot{m}_{s, u s, \max }$ is the maximum upstream supply air mass flow rate (program input) [kg/s];

$\dot{m}_{s, z}$ is the supply air mass flow rate delivered to the zone $[\mathrm{kg} / \mathrm{s}]$;

$\mathrm{Frac}_{u s}$ is the design upstream leakage fraction (program input);

Frac $_{d s}$ is the constant downstream leakage fraction (program input);

$\dot{m}_{t u}$ is calculated in the VAV terminal unit model in the usual manner: the mass flow rate is varied to meet the zone load. The limits on the mass flow rate variation are set by the $\dot{m}_{\text {MaxAvail }}$ and $\dot{m}_{\text {MinAvail }}$ values stored at the terminal unit's air inlet node. To account for upstream leakage the maximum air mass flow rate available is reset to:

$$
\dot{m}_{\text {MaxAvail }}^{\prime}=\dot{m}_{\text {MaxAvail }}-\dot{m}_{l k, u s}
$$


Downstream leakage must also be accounted for because not all of $\dot{m}_{t u}$ will reach the zone. This is done by having $\dot{m}_{t u}$ meet an adjusted zone load:

$$
\dot{Q}_{z, \text { adjusted }}=\frac{1}{1-\text { Frac }_{d s}} \dot{Q}_{z}
$$

Here $\dot{Q}_{z}$ [watts] is the actual zone load (met by $\dot{m}_{s, z}$ ) and $\dot{Q}_{z, \text { adjusted }}$ is the load used in the VAV terminal unit model to obtain $\dot{m}_{t u}$.

Once $\dot{m}_{t u}$ is known, all the other flow rates can be calculated. $\dot{m}_{s, u s}$ is assigned to the air distribution unit's air inlet node and $\dot{m}_{s, z}$ is assigned to the unit's air outlet node. Thus, air mass flow is not conserved through the unit: the two air leakage flow rates disappear. These two vanished flow rates are stored in the air distribution unit data structure. When the downstream return air plenum mass and energy balances are calculated, the leakage flow rate data is accessed and added back in as inlets to the return air plenum. Thus, the overall air system preserves a mass balance.

\section{References}

Wray, C.P. 2003. "Duct Thermal Performance Models for Large Commercial Buildings”, Lawrence Berkeley National Laboratory Report to the California Energy Commission. LBNL-53410.

Wray, C.P. and N.E. Matson. 2003. "Duct Leakage Impacts on VAV System Performance in California Large Commercial Buildings”, Lawrence Berkeley National Laboratory Report to the California Energy Commission. LBNL-53605.

Wray, C.P., R.C. Diamond, and M.H. Sherman. 2005. "Rationale for Measuring Duct Leakage Flows in Large Commercial Buildings". Proceedings - 26th AIVC Conference, Brussels, Belgium, September. LBNL-58252. 


\section{APPENDIX B: ENERGYPLUS INPUTIOUTPUT DOCUMENTATION RELATED TO THE NEW DUCT LEAKAGE MODEL}

The following is the documentation that was created in this project to describe the input and output aspects of the duct leakage model that is now implemented in EnergyPlus:

\section{ZoneHVAC:AirDistributionUnit}

The ZoneHVAC:AirDistributionUnit object gives further information on what air loop equipment (air terminal units) will be serving a particular zone. The ZoneHVAC:AirDistributionUnit is the part of the system that is supplied from a common main air handler simulated in the Air Loop Simulation and includes the equipment that controls or tempers the air going to each individual zone according to the desired thermostatic control. The current options for ZoneHVAC:AirDistributionUnit terminal unit types are:

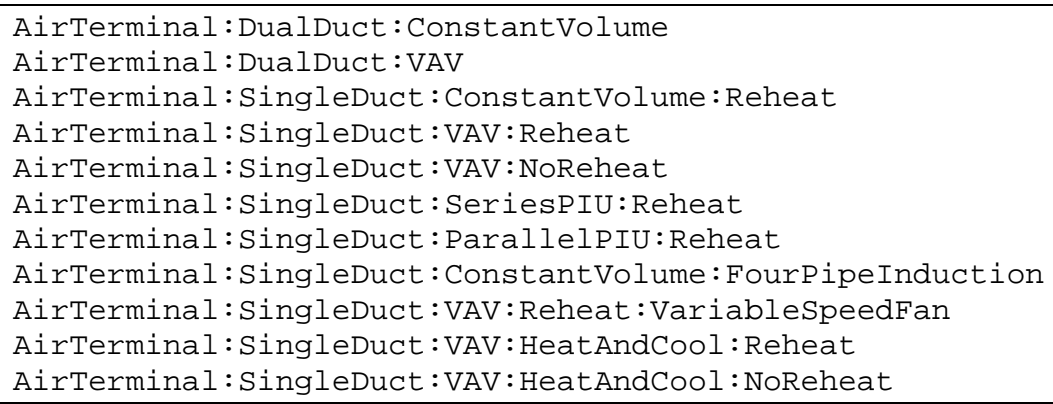

Connections between the air distribution unit, the supply air duct, and the zone are specified in the input syntax for the air distribution unit and the AirLoopHVAC:ZoneSplitter. The input syntax also explicitly defines an outlet identifier. This implies a connection to a zone through a NodeList for zone inlets (see the ZoneHVAC:EquipmentConnections statement). The air distribution unit is limited to one combined component-controller unit; because controls are normally based on the zone thermostat and can work in parallel or series in complex fashion. Since the control and the flow resolution can be complex, each air distribution unit is unique in addressing these combinations and therefore only one is allowed per zone.

The Air Distribution unit also allows the user to specify leaks in the supply air duct system. These inputs are used in the EnergyPlus Simplified Duct Leakage Model (SDLM). This model simulates a specific configuration: supply leaks to a return plenum in a commercial VAV or CV system. The system must have a constant static pressure setpoint. Within these limitations SDLM allows the user to easily evaluate the energy penalty due to duct leakage.

\section{Field: Name}

Unique identifying name of the air distribution unit.

\section{Field: Air Distribution Unit Outlet Node Name}

Outlet node name for the air distribution unit to the attached zone. 


\section{Field: Air Terminal Object Type}

Single combined component/controller unit for that attached zone. Selection of components as listed above.

\section{Field: Air Terminal Name}

The unique identifying component name.

\section{Field: Nominal Upstream Leakage Fraction}

This is the leakage upstream of the terminal unit as a fraction of the design flow rate through the unit. It is the leakage fraction at the design flow rate. It is used to calculate a leakage flow rate which is then held constant while the system air flow varies. This input is optional; the default is zero.

\section{Field: Constant Downstream Leakage Fraction}

This is the leakage downstream of the terminal unit as a fraction of the current flow rate through the terminal unit. This fraction is held constant, so the leakage flow rate will vary proportionally with the supply air flow rate. This input is optional; the default is zero.

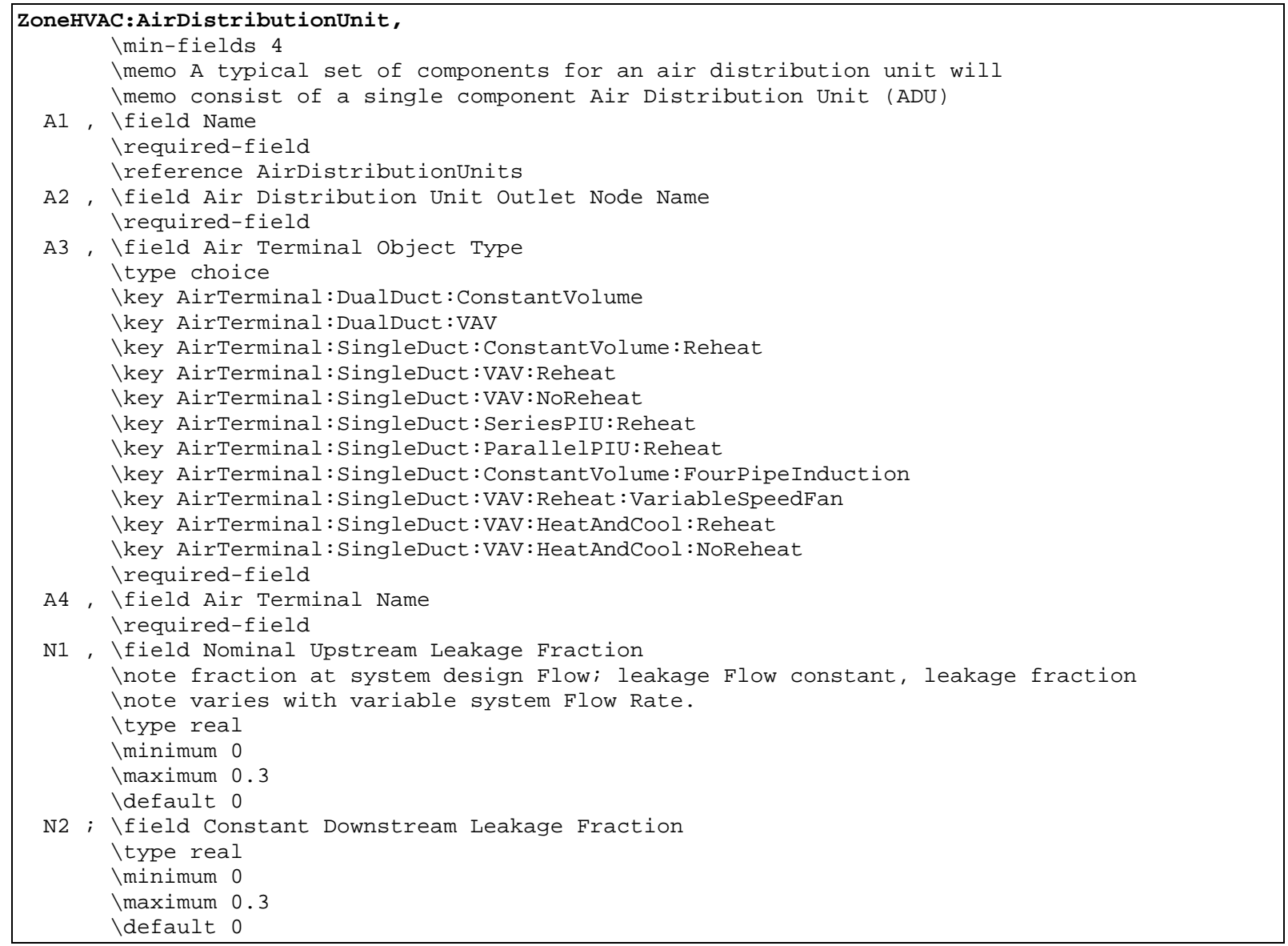


Two example IDF excerpts (one without duct leakage, one with):

\begin{tabular}{|ll}
\hline $\begin{array}{l}\text { ZoneHVAC:AirDistributionUnit, } \\
\text { SPACE1-1 ATU, }\end{array}$ & !- Air Distribution Unit Name \\
SPACE1-1 In Node, & !- Air Dist Unit Outlet Node Name \\
SINGLE DUCT:VAV:REHEAT, & !- KEY--System Component Type 1 \\
SPACE1-1 VAV Reheat; & !- Component Name 1 \\
& \\
ZoneHVAC:AirDistributionUnit, & \\
SPACE4-1 ATU, & !- Air Distribution Unit Name \\
SPACE4-1 In Node, & !- Air Dist Unit Outlet Node Name \\
SINGLE DUCT:VAV:REHEAT, & !- KEY--System Component Type 1 \\
SPACE4-1 VAV Reheat, & !- Component Name 1 \\
O.05, & !- upstream nominal leakage fraction \\
O.07; & !- downstream constant leakage fraction \\
\hline
\end{tabular}




\section{APPENDIX C: SAMPLE ENERGYPLUS INPUT DATA FILE RELATED TO THE NEW DUCT LEAKAGE MODEL}

The following is one of the input data files that we used in our EnergyPlus simulations to demonstrate the use of the duct leakage model. This file corresponds to a leaky system with $10 \%$ leakage upstream of VAV boxes and 10\% downstream.

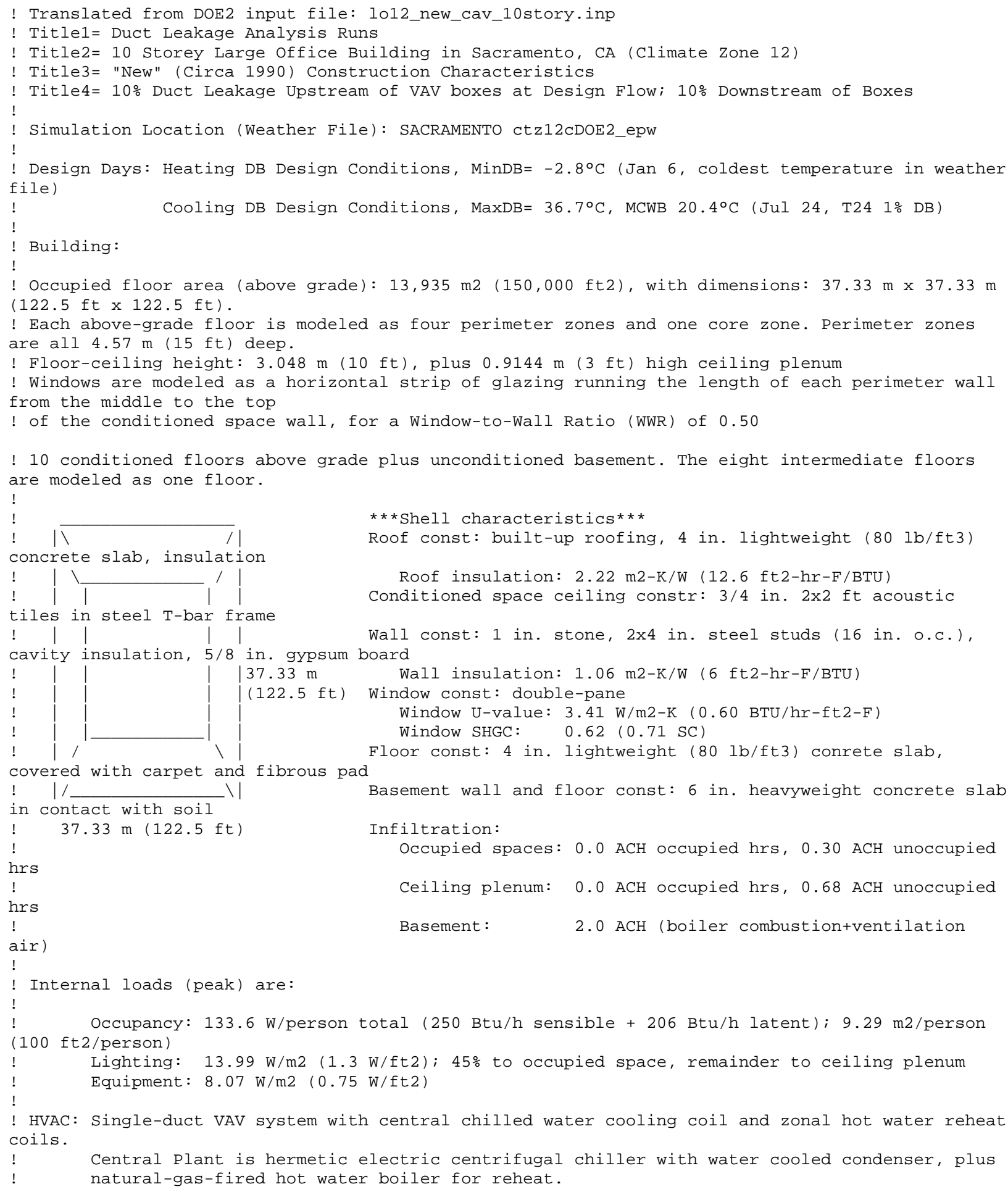




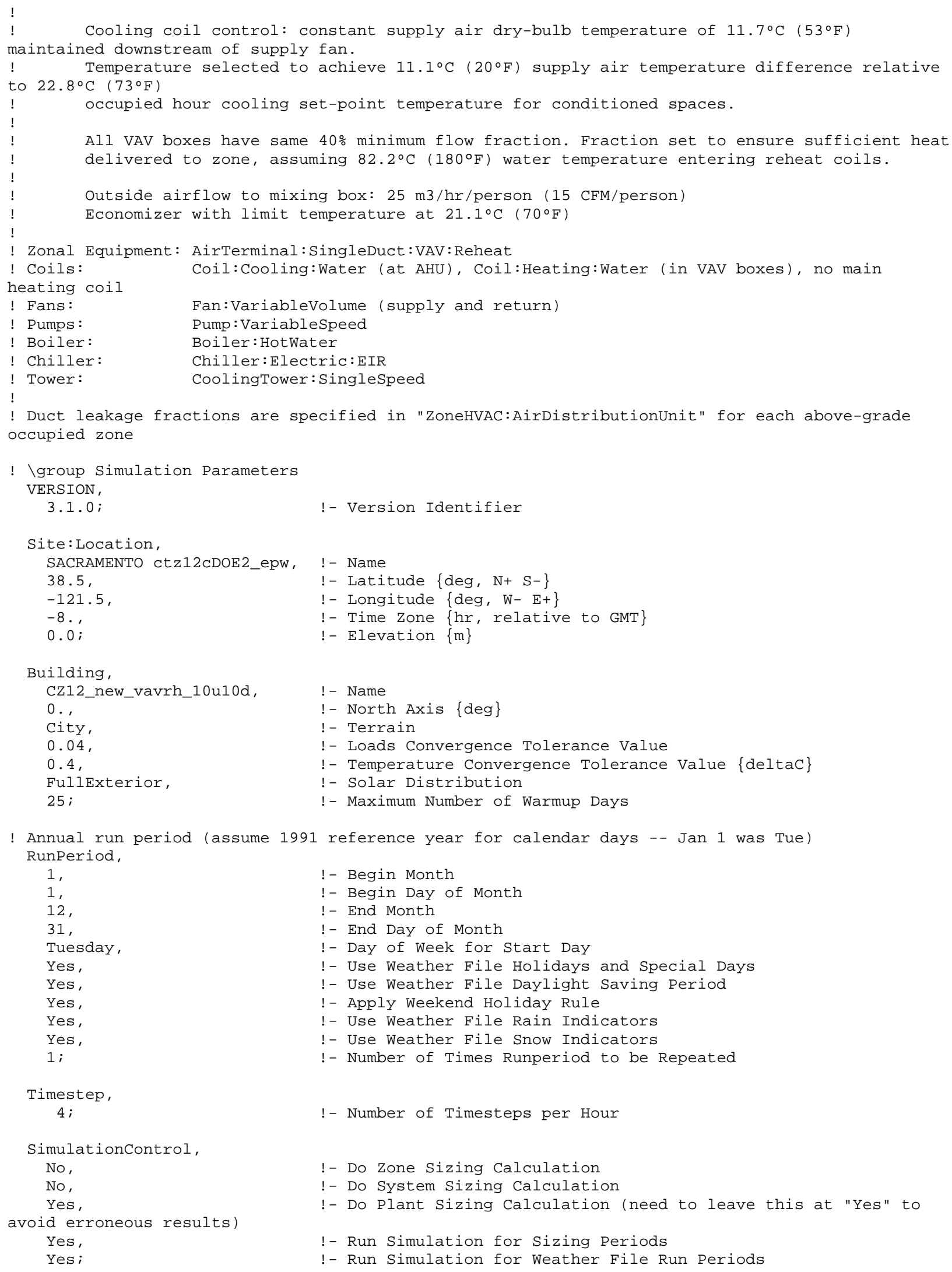

Output: DebuggingData, 


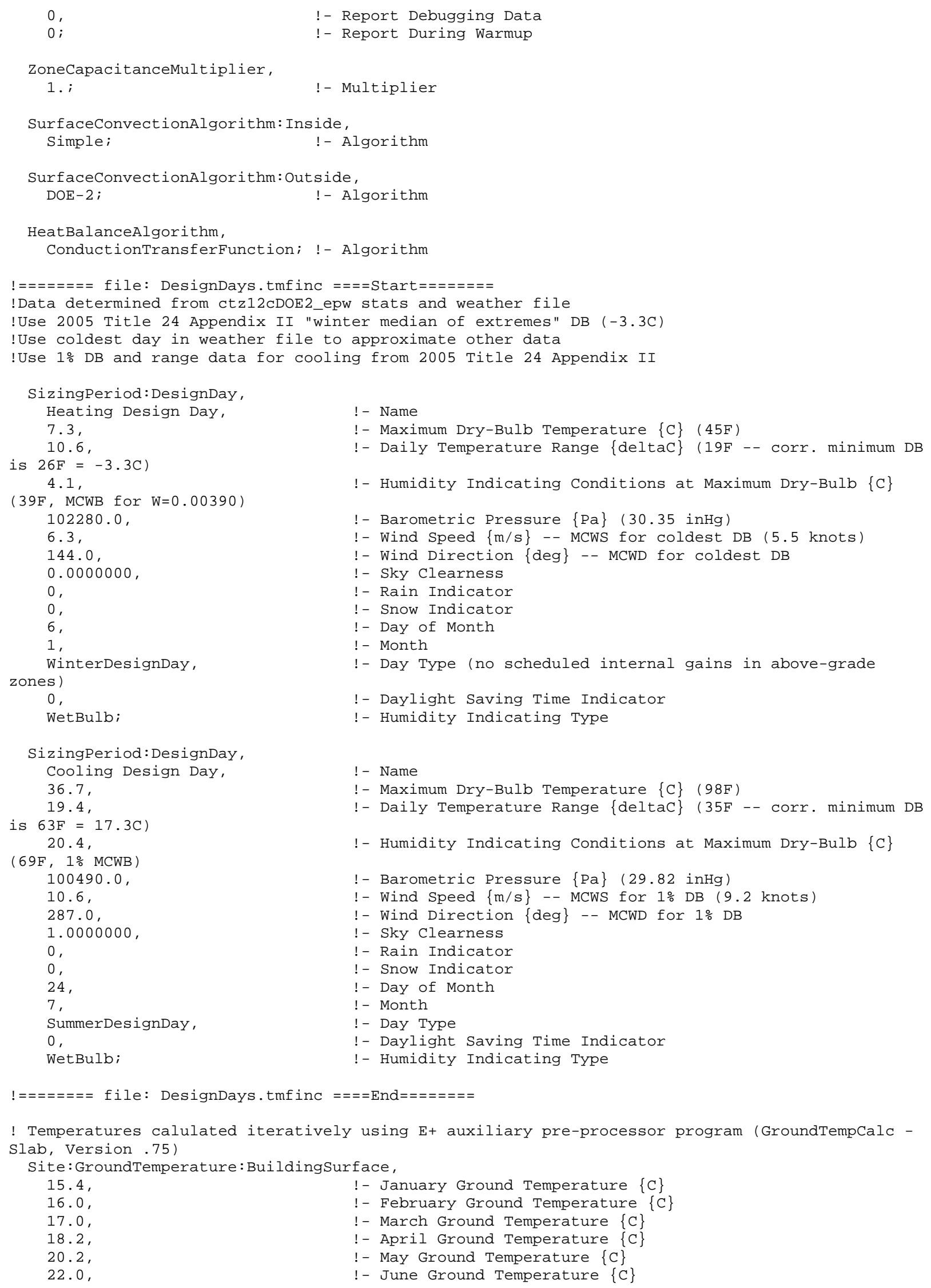




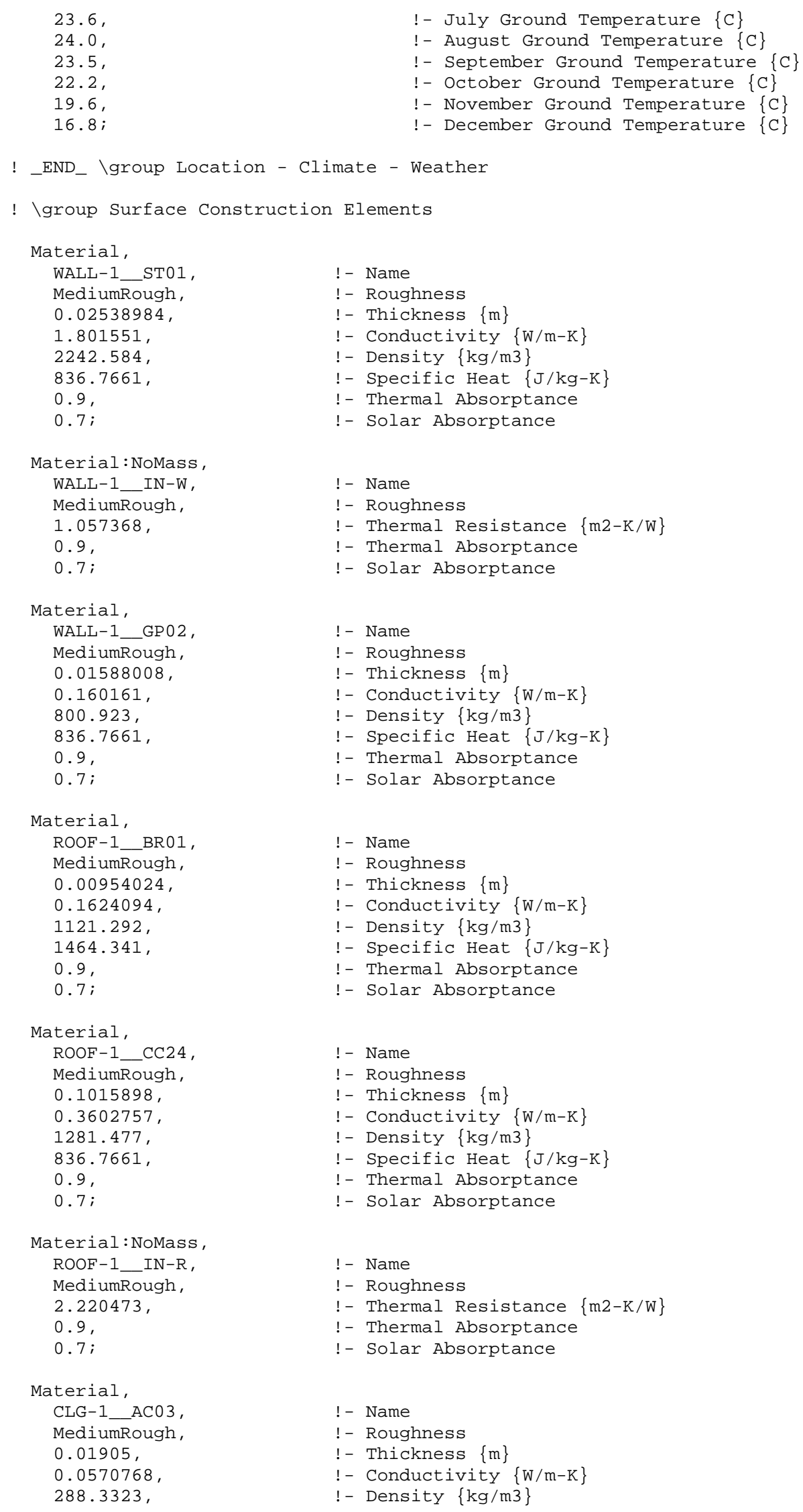




\author{
1338.826 \\ 0.9 , \\ 0.7 ; \\ Material, \\ FLOOR-1_CC24 \\ MediumRough, \\ ๑. 1015898, \\ 0.3602757 , \\ 1281.477, \\ 836.7661, \\ 0.9 , \\ 0.7 ;
}

Material: NoMass, FLOOR-1_CPO1, MediumRough,

0.3665542 ,

0.9 ,

0.7 ;

Material,

SLAB-1_SOIL

MediumRough,

0.6096 ,

1.7296,

1842.123

1087.796

0.9 ,

0.7 ;

Material,

SLAB-1_CC15,

MediumRough,

0.1524 ,

1.801724,

2242.584

836.7661,

0.9 ,

0.7 ;

!- Specific Heat $\{\mathrm{J} / \mathrm{kg}-\mathrm{K}\}$

! - Thermal Absorptance

!- Solar Absorptance

! - Name

! - Roughness

! - Thickness $\{\mathrm{m}\}$

! - Conductivity $\{\mathrm{W} / \mathrm{m}-\mathrm{K}\}$

! - Density $\{\mathrm{kg} / \mathrm{m} 3\}$

! - Specific Heat $\{\mathrm{J} / \mathrm{kg}-\mathrm{K}\}$

! - Thermal Absorptance

! - Solar Absorptance

! - Name

! - Roughness

!- Thermal Resistance $\{\mathrm{m} 2-\mathrm{K} / \mathrm{W}\}$

! - Thermal Absorptance

!- Solar Absorptance

! - Name

! - Roughness

! - Thickness $\{\mathrm{m}\}$

! - Conductivity $\{\mathrm{W} / \mathrm{m}-\mathrm{K}\}$

! - Density $\{\mathrm{kg} / \mathrm{m} 3\}$

! - Specific Heat $\{\mathrm{J} / \mathrm{kg}-\mathrm{K}\}$

! - Thermal Absorptance

! - Solar Absorptance

! Use "air" material for interior wall cavity

Material: AirGap,

WALL-1_AL21, ! - Name

$0.1570000 ; \quad$ ! - Thermal Resistance $\{\mathrm{m} 2-\mathrm{K} / \mathrm{W}\}$

Above-grade conditioned zone "FLOOR-WEIGHT" material for internal mass

! (floor plus this mass: $70 \mathrm{lb} / \mathrm{ft} 2$ from DOE-2 inputs)

! Material is Douglas fir plywood p.25.5 2005 ASHRAE Hdbk of Fundamentals

! (similar to LgoffVAV.idf example file)

Material,

IntMassMaterial, ! - Name

MediumSmooth, ! - Roughness

$0.4216, \quad !$ - Thickness $\{\mathrm{m}\}$

$0.115, \quad$ ! - Conductivity $\{\mathrm{W} / \mathrm{m}-\mathrm{K}\}$

545

1214,

0.9,

0.78,

! - Density $\{\mathrm{kg} / \mathrm{m} 3\}$

! - Specific Heat $\{\mathrm{J} / \mathrm{kg}-\mathrm{K}\}$

! - Thermal Absorptance

! - Solar Absorptance

$\odot .78$;

! - Visible Absorptance

! Basement "FLOOR-WEIGHT" material for internal mass

! (floor plus this mass: $130 \mathrm{lb} / \mathrm{ft} 2$ from DOE-2 inputs)

! Material is Douglas fir plywood p.25.5 2005 ASHRAE Hdbk of Fundamentals

! Thickness increased to match "FLOOR-WEIGHT" ratio (130/70)

! (similar to LgoffVAV.idf example file)

Material,

IntMassMaterial_Base, !- Name 


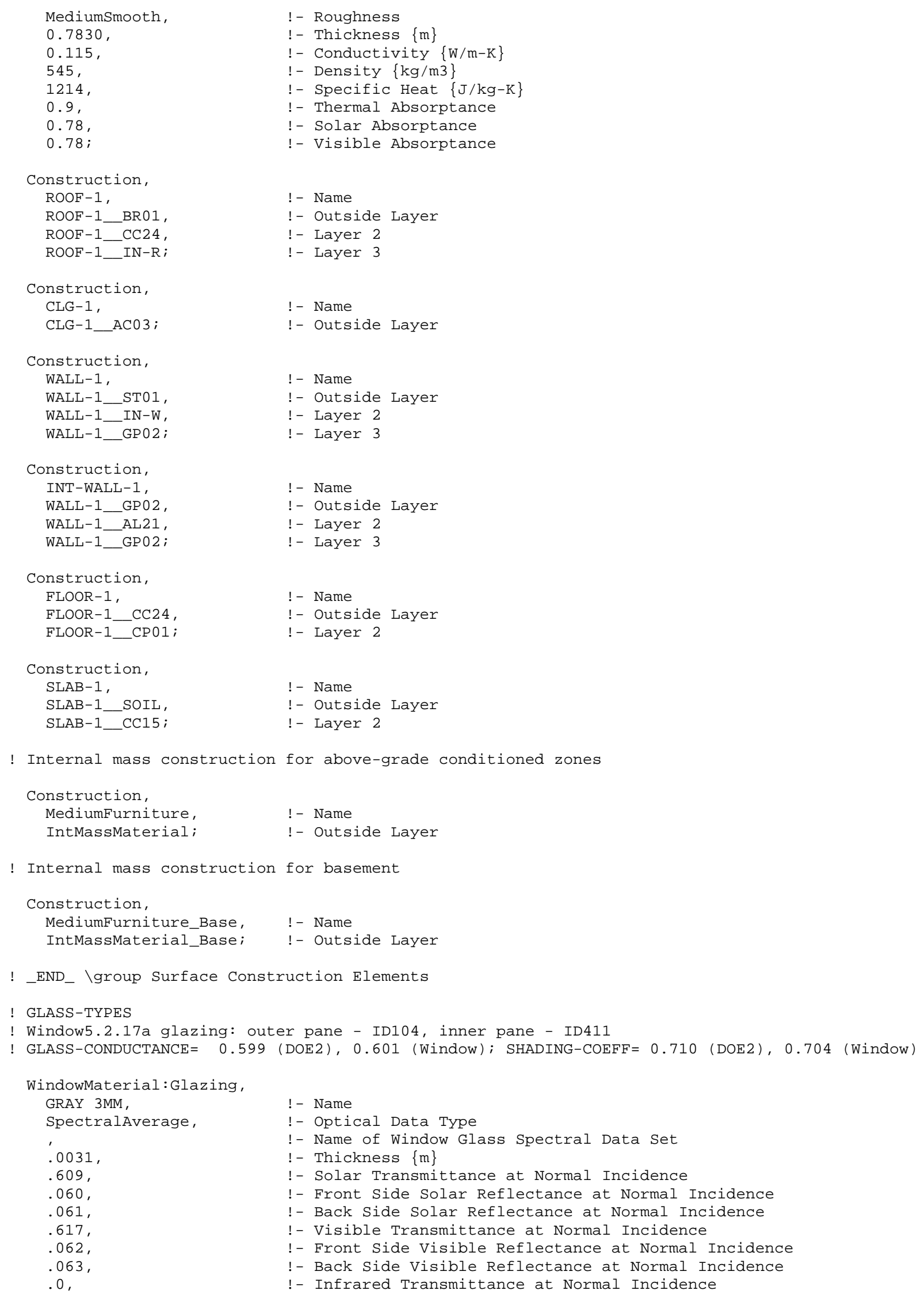




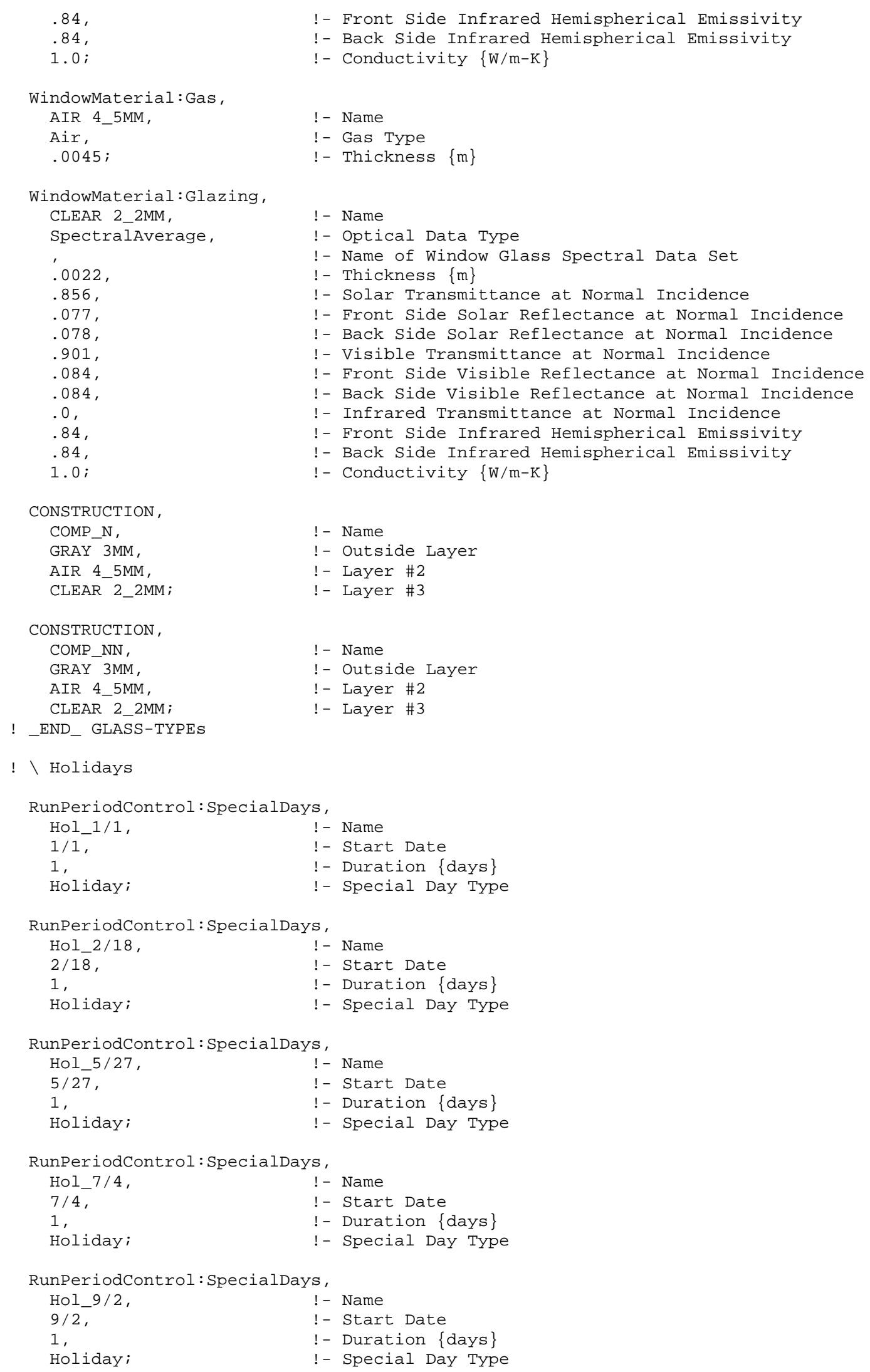

RunPeriodControl:SpecialDays, 


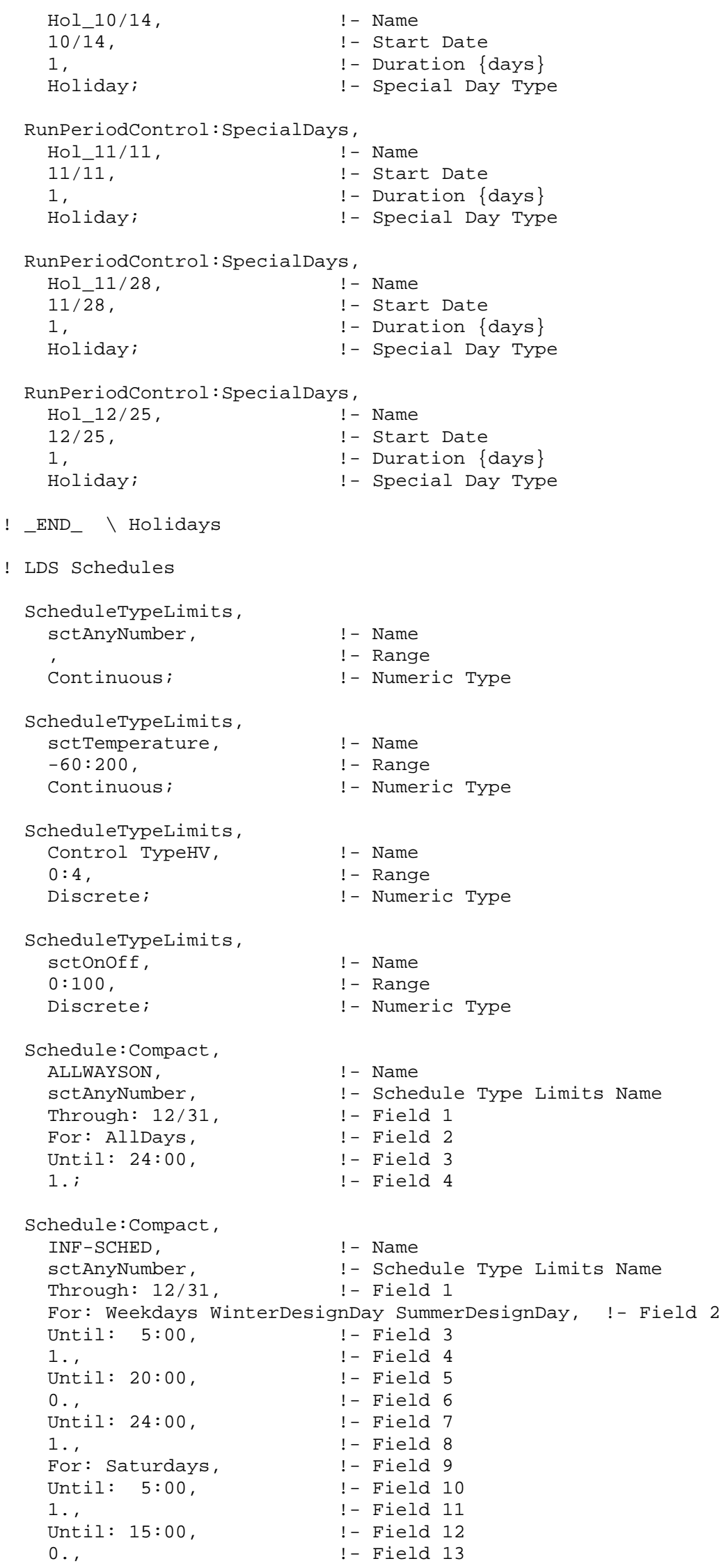




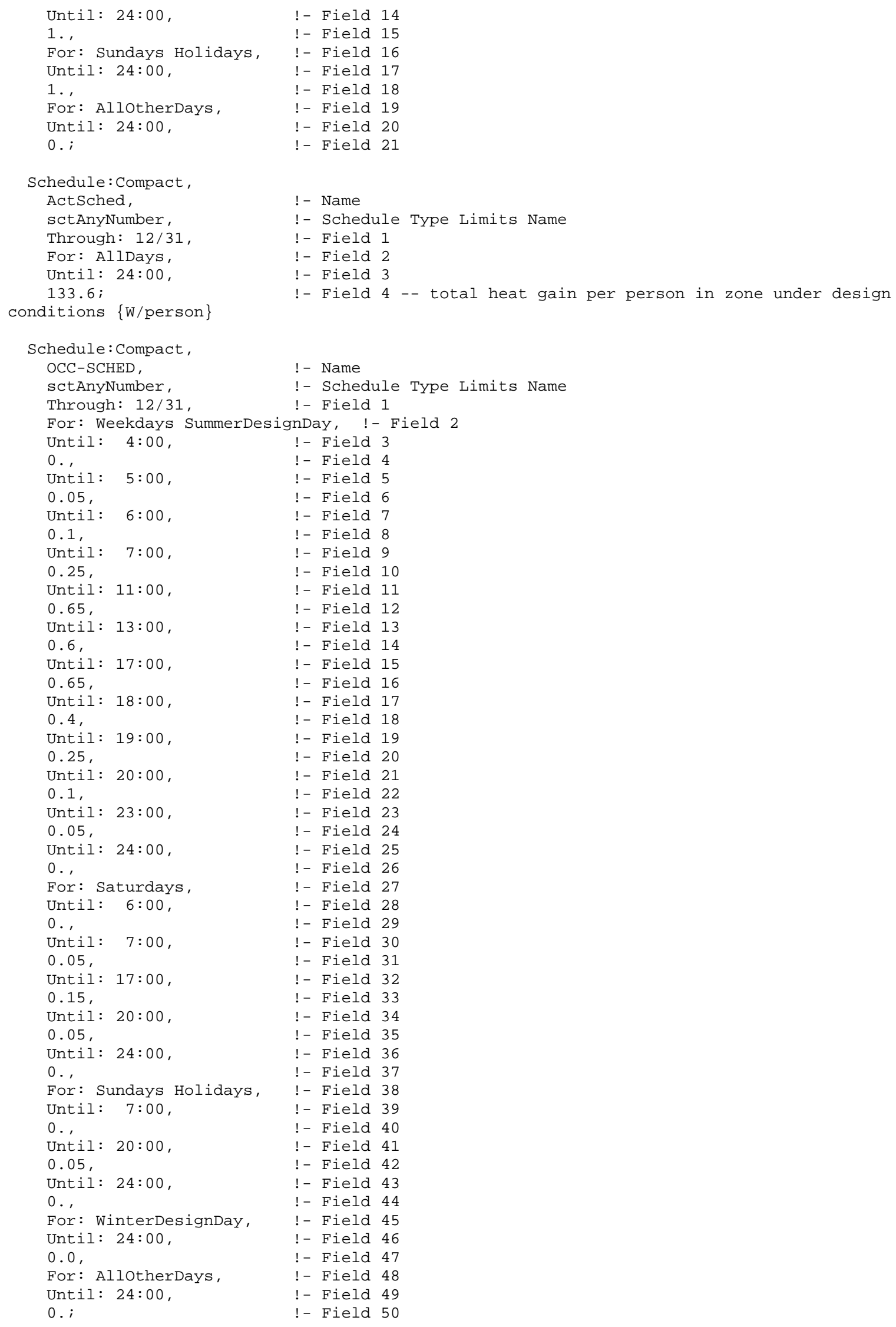




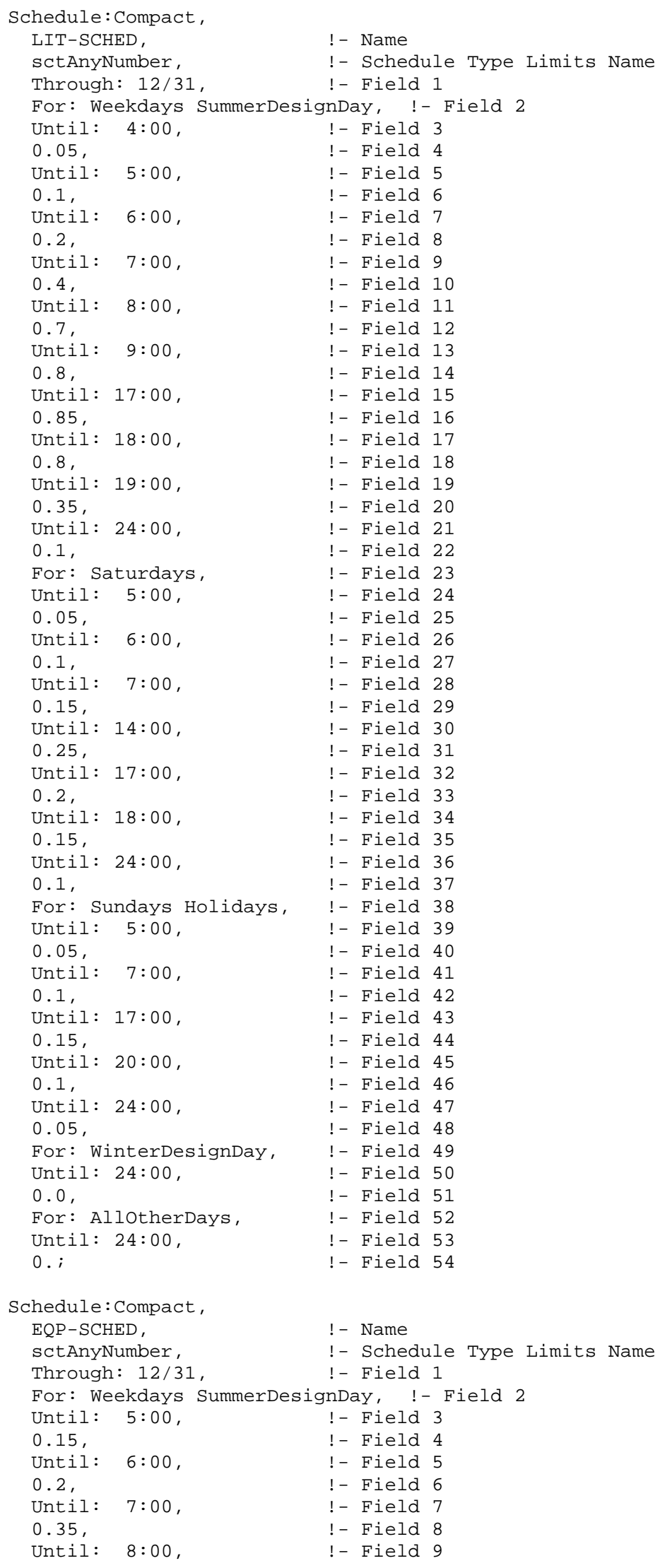




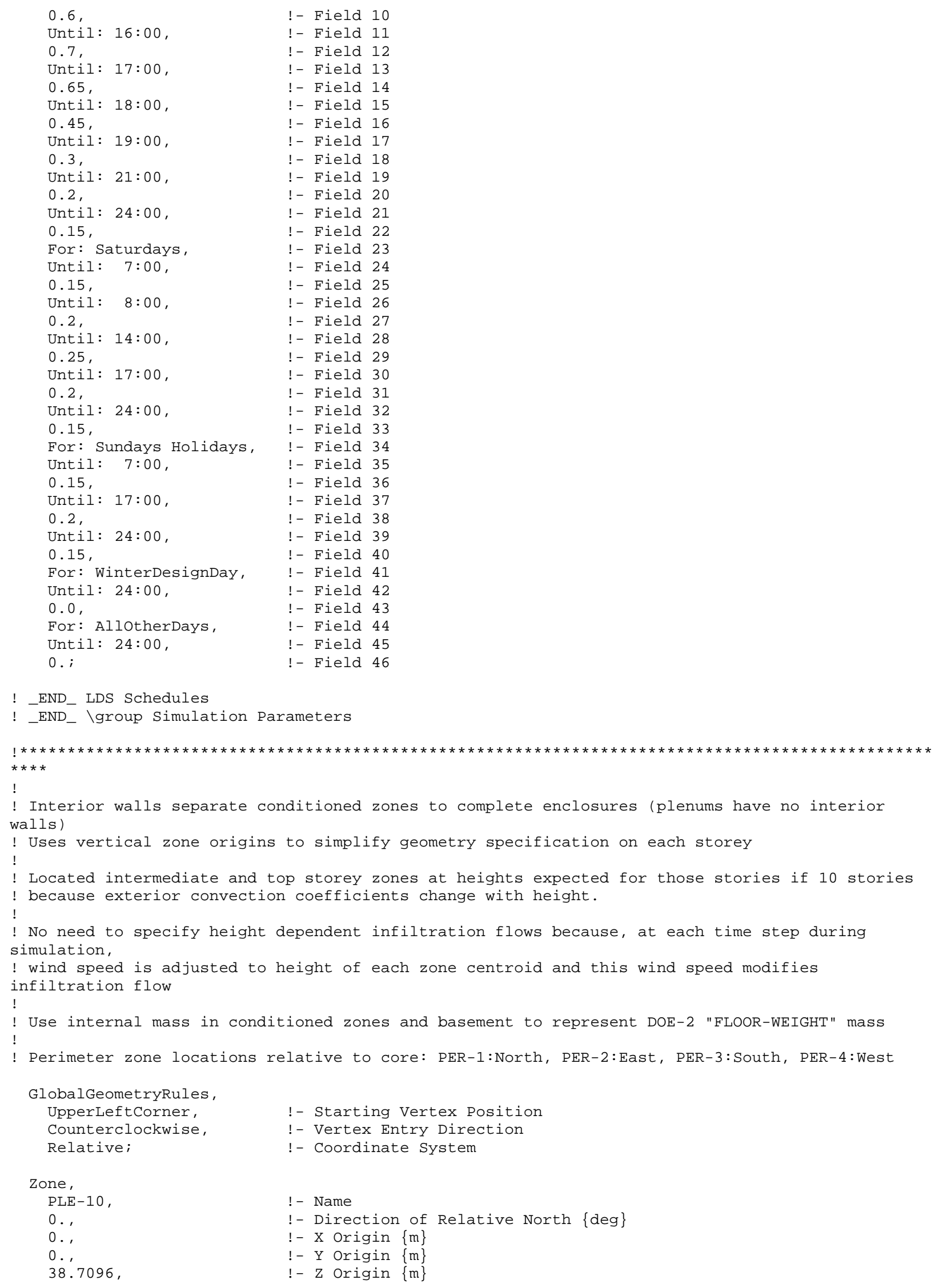



1,
1,
$\odot .9144$,
! - Type
๑.;
! - Multiplier
!- Ceiling Height $\{\mathrm{m}\}$
!- Volume $\{\mathrm{m} 3\}$-- Zero is autocalculate

BuildingSurface: Detailed, RF1-P1,

Roof,

ROOF-1,

PLE-10,

Outdoors,

SunExposed, WindExposed,

0 . ,

4,

$0 ., 37.3302,0.9144$

$\odot ., 0 ., 0.9144$,

$37.3302,0 ., 0.9144$

! - Name

- Surface Type

! - Construction Name

! - Zone Name

! - Outside Boundary Condition

! - Outside Boundary Condition object

! - Sun Exposure

! - Wind Exposure

! - View Factor to Ground

! - Number of Vertices

! - X,Y,Z ==> Vertex 1

! - X,Y,Z ==> Vertex 2

! - $X, Y, Z==>$ Vertex 3

$37.3302,37.3302,0.9144 ; !-X, Y, Z==>$ Vertex 4

BuildingSurface: Detailed, PLE-10E_1,

Wall,

WALL-1,

PLE-10,

Outdoors,

SunExposed, WindExposed,

0.5 ,

4,

$37.3302,37.3302,0.9144$,

$37.3302,37.3302,0 .$,

$0 ., 37.3302,0$.

$0 ., 37.3302,0.9144$;

! - Name

! - Surface Type

! - Construction Name

! - Zone Name

! - Outside Boundary Condition

! - Outside Boundary Condition object

! - Sun Exposure

! - Wind Exposure

! - View Factor to Ground

! - Number of Vertices

! - X,Y, Z ==> Vertex 1

! - X,Y,Z ==> Vertex 2

! - X,Y,Z ==> Vertex 3

! - X,Y,Z ==> Vertex 4

BuildingSurface: Detailed, PLE-10E_2,

Wall,

WALL-1,

PLE-10,

Outdoors,

'SunExposed, WindExposed,

0.5 ,

4,

$37.3302,0 ., 0.9144$

$37.3302,0 ., 0 .$,

$37.3302,37.3302,0 .$,

$37.3302,37.3302,0.9144$;

! - Name

! - Surface Type

! - Construction Name

! - Zone Name

! - Outside Boundary Condition

! - Outside Boundary Condition Object

! - Sun Exposure

! - Wind Exposure

! - View Factor to Ground

! - Number of Vertices

! - $X, Y, Z==>$ Vertex 1

! - X,Y,Z ==> Vertex 2

! - X,Y,Z ==> Vertex 3

! - $X, Y, Z==>$ Vertex 4

BuildingSurface: Detailed,

PLE-10E_3,

Wall,

WALL-1,

PLE-10,

Outdoors,

SunExposed,

WindExposed,

0.5 ,

4,

๑.,,., 0.9144

$0 ., 0 ., 0$.

$37.3302,0 ., 0 .$,

$37.3302,0 ., 0.9144$

! - Name

! - Surface Type

! - Construction Name

! - Zone Name

! - Outside Boundary Condition

! - Outside Boundary Condition Object

! - Sun Exposure

! - Wind Exposure

! - View Factor to Ground

! - Number of Vertices

! - $X, Y, Z==>$ Vertex 1

! - X,Y,Z ==> Vertex 2

! - X,Y,Z ==> Vertex 3

! - X,Y, Z ==> Vertex 4

BuildingSurface: Detailed, PLE-10E_4,

! - Name 


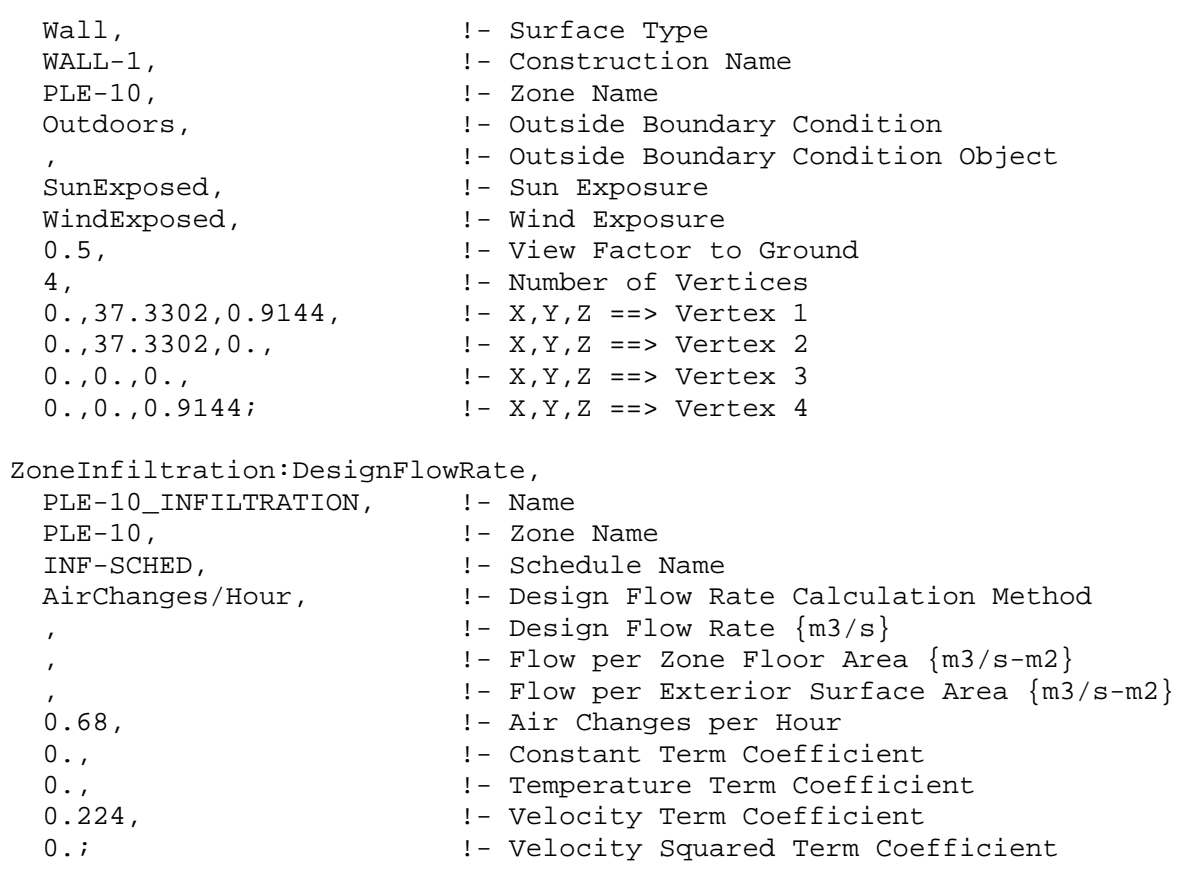




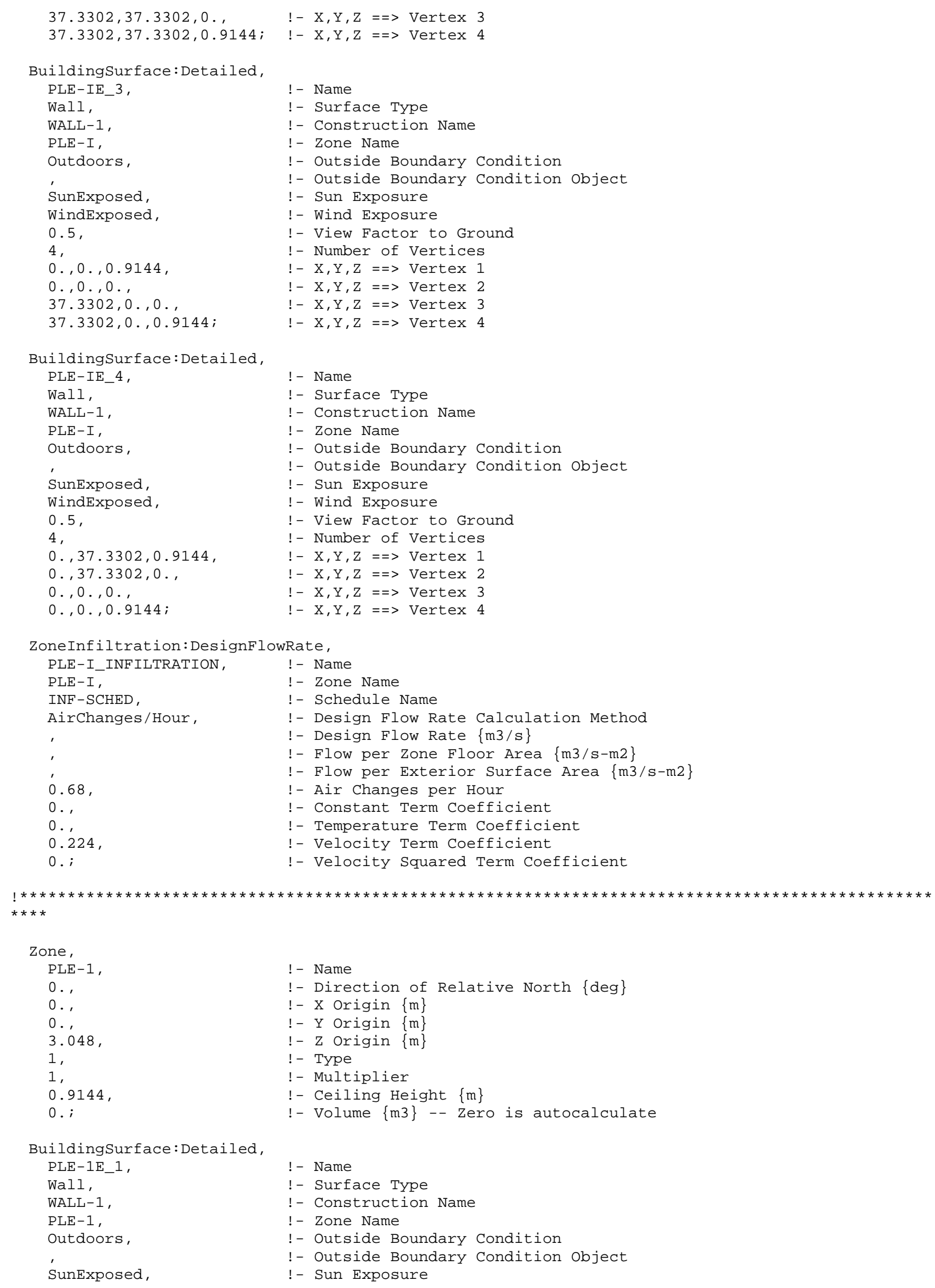

BuildingSurface: Detailed, 


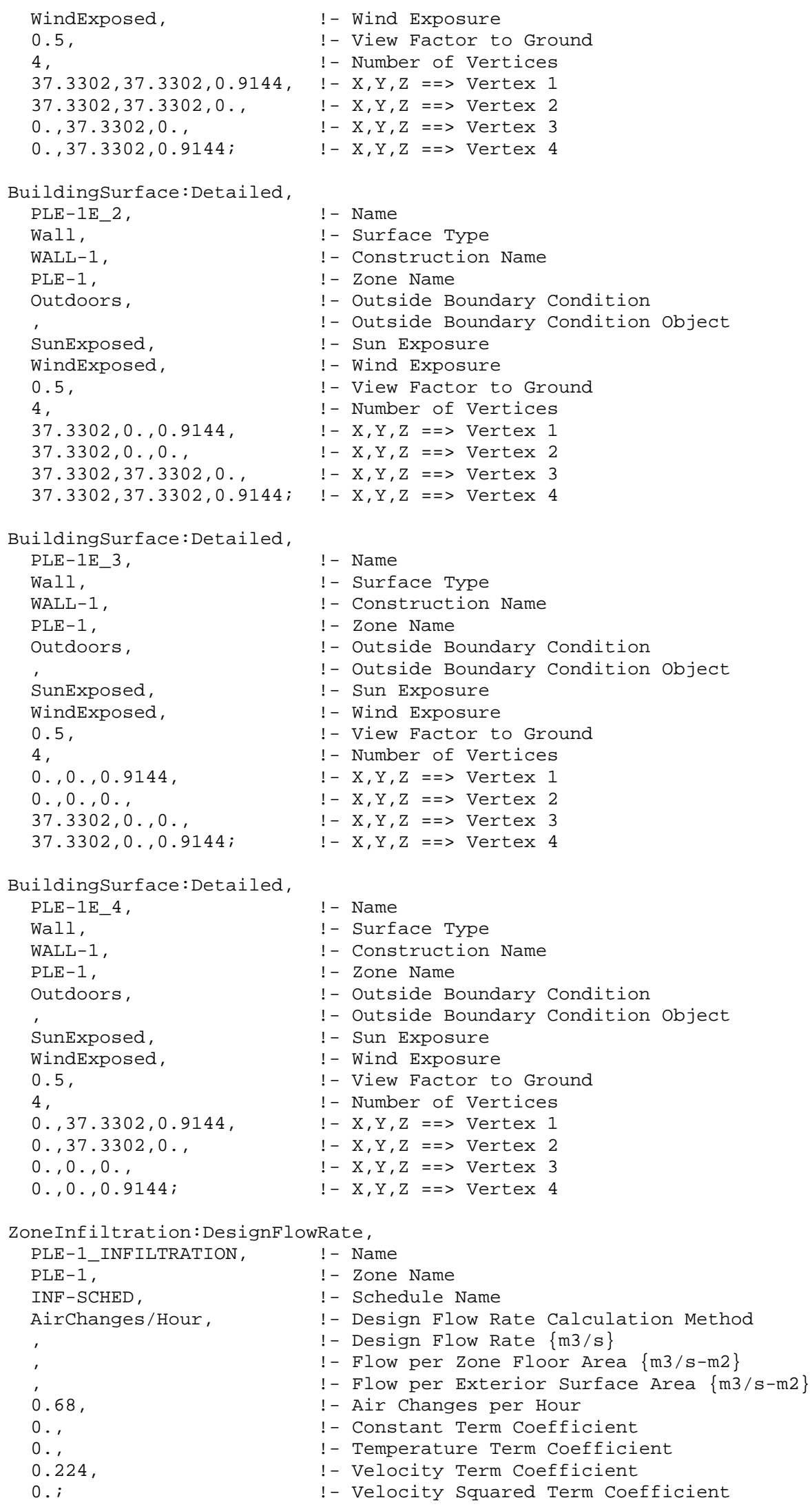




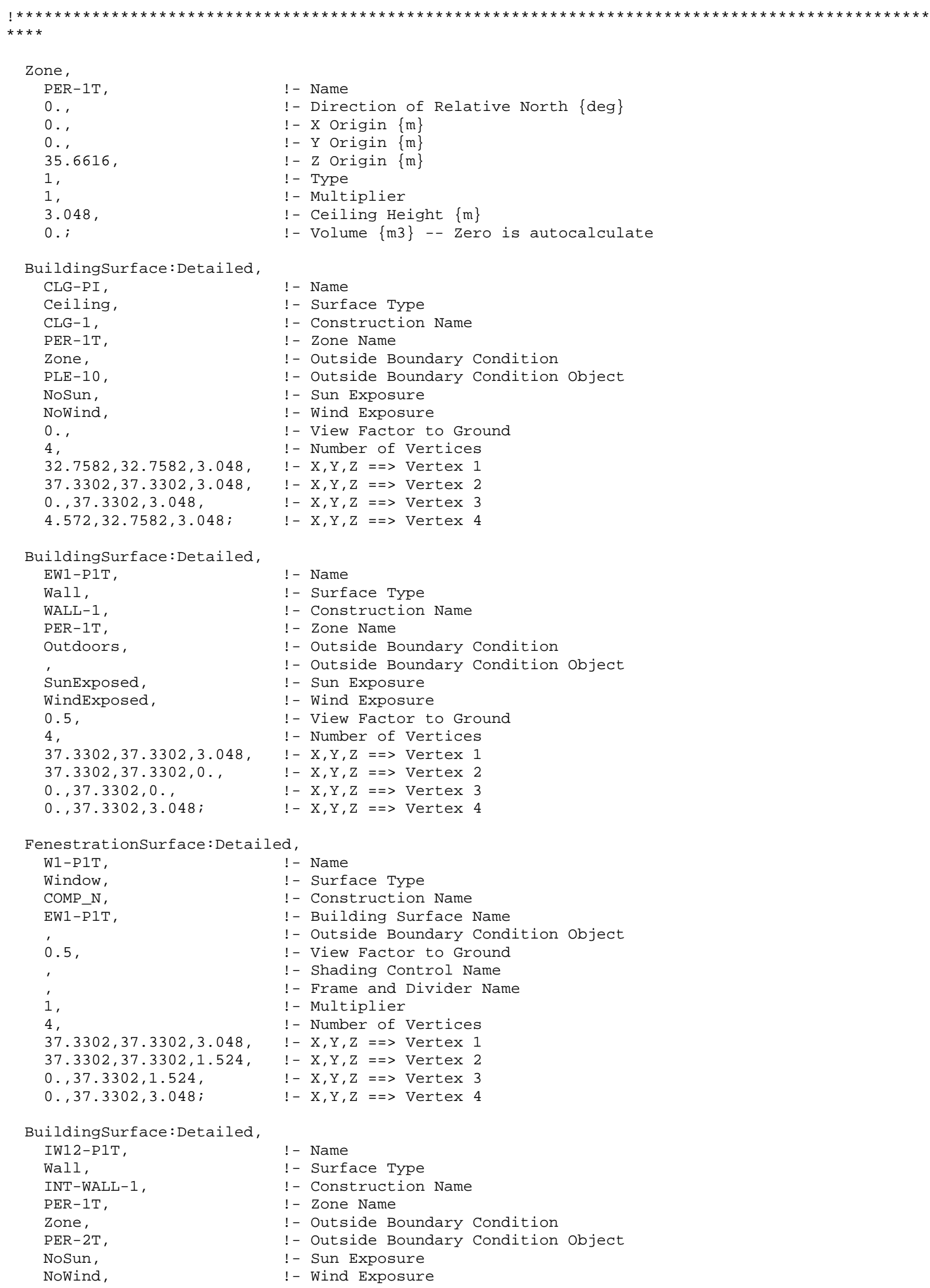

BuildingSurface: Detailed, EW1-P1T,

Fenestrationsurface: Detailed,

\begin{tabular}{|c|c|}
\hline & ! - Name \\
\hline Nindow, & ! - Surface Type \\
\hline COMP_N, & ! - Construction Name \\
\hline EW1-P1T, & $\begin{array}{l}\text { ! - Building Surface } \\
\text { ! - Outside Boundary }\end{array}$ \\
\hline 0.5 & ! - View Factor to Gr \\
\hline & ! - Shading Control \\
\hline & ! - Frame and Divider \\
\hline & !- Multiplier \\
\hline & ! - Number of Vertices \\
\hline $37.3302,37.3302,3.048$, & ! - X,Y,Z ==> VerteX \\
\hline $\begin{array}{l}37.3302,1.524, \\
302,1.524,\end{array}$ & $\begin{array}{l}!-X, Y, Z==>\text { VerteX } \\
!-X, Y, Z==>\text { Vertex }\end{array}$ \\
\hline $302,3.048 ;$ & ! - X,Y,Z ==> Vertex \\
\hline
\end{tabular}

BuildingSurface: Detailed, IW12-P1T, Wall,

INT - WALL - 1, PER-1T,

Zone,

PER-2T, NoSun,

Nowind, 


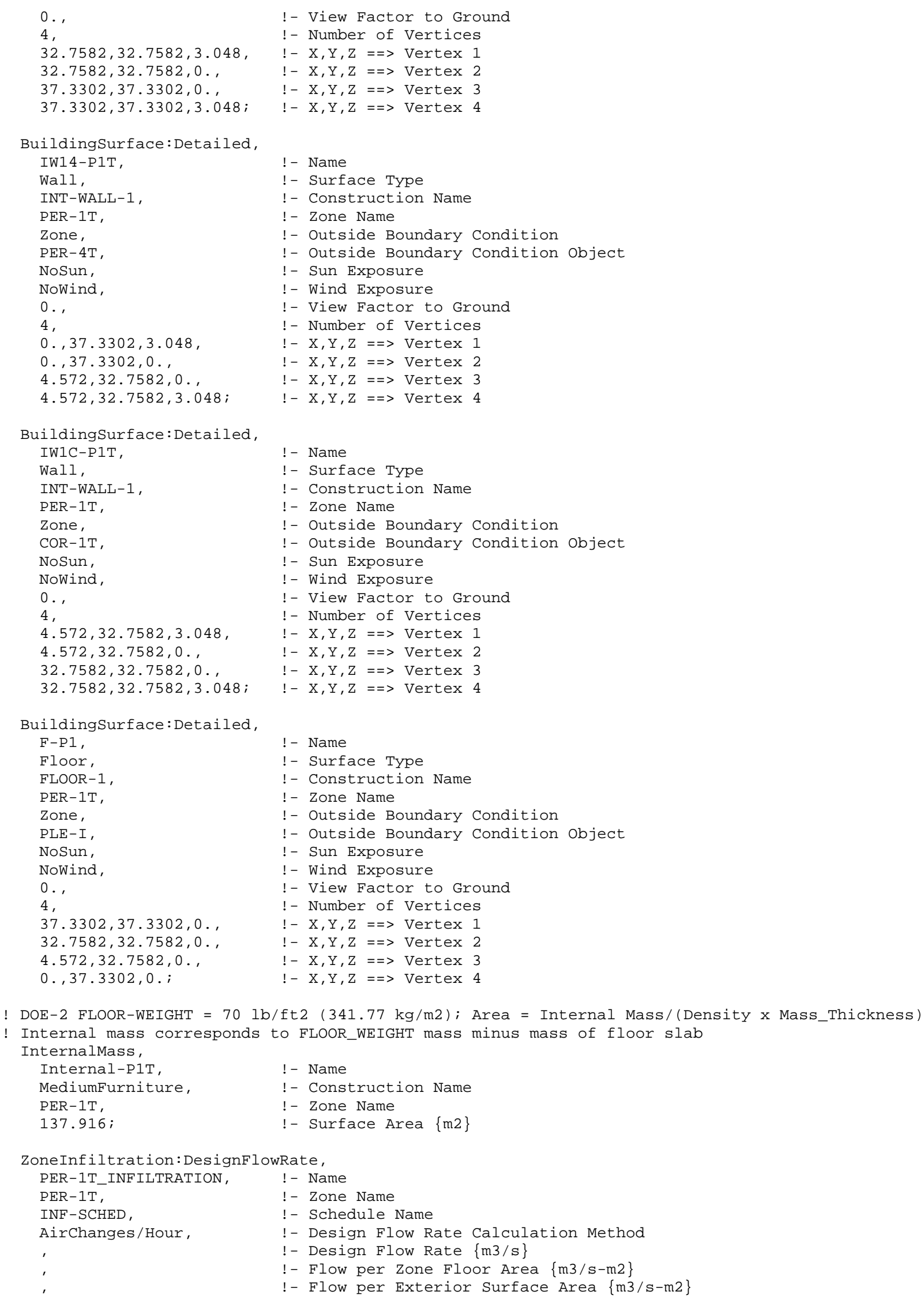

Buildingsurface: Detailed,

! DOE-2 FLOOR-WEIGHT $=70 \mathrm{lb} / \mathrm{ft} 2(341.77 \mathrm{~kg} / \mathrm{m} 2) ;$ Area = Internal Mass/(Density $\times$ Mass_Thickness)

! Internal mass corresponds to FLOOR_WEIGHT mass minus mass of floor slab InternalMass, 


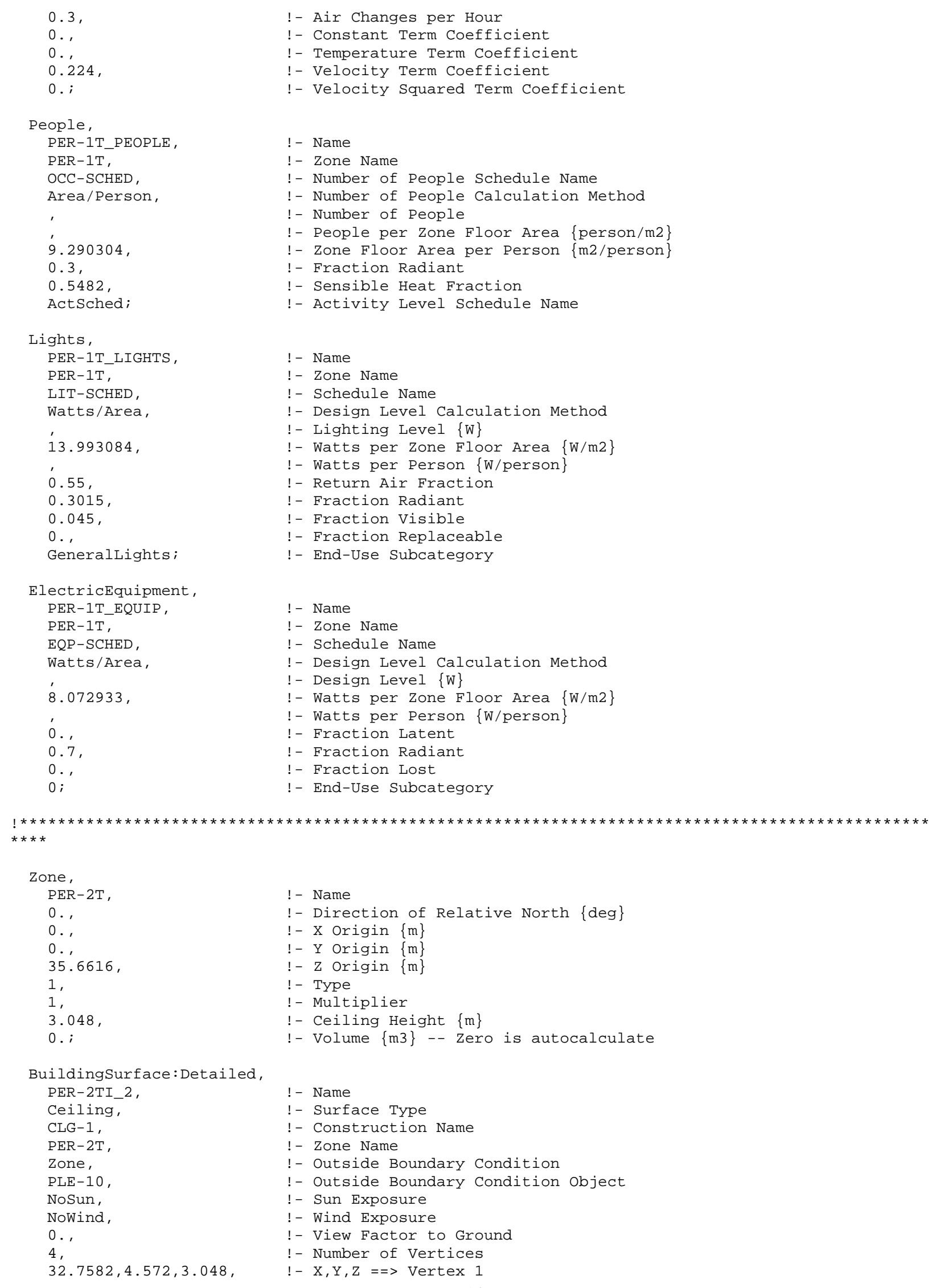




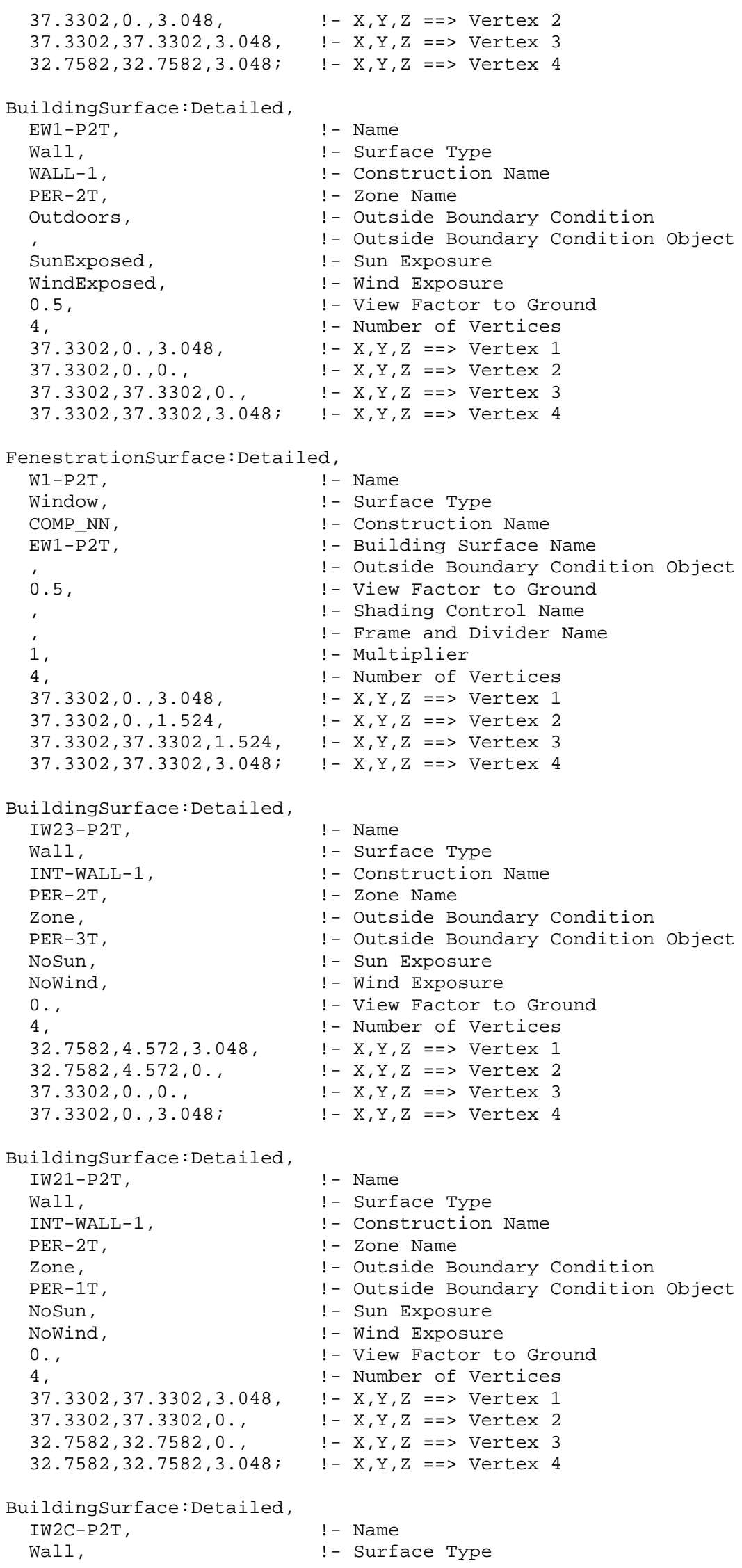

BuildingSurface: Detailed, IW21-P2T,

BuildingSurface: Detailed, IW2C-P2T, Wall, 


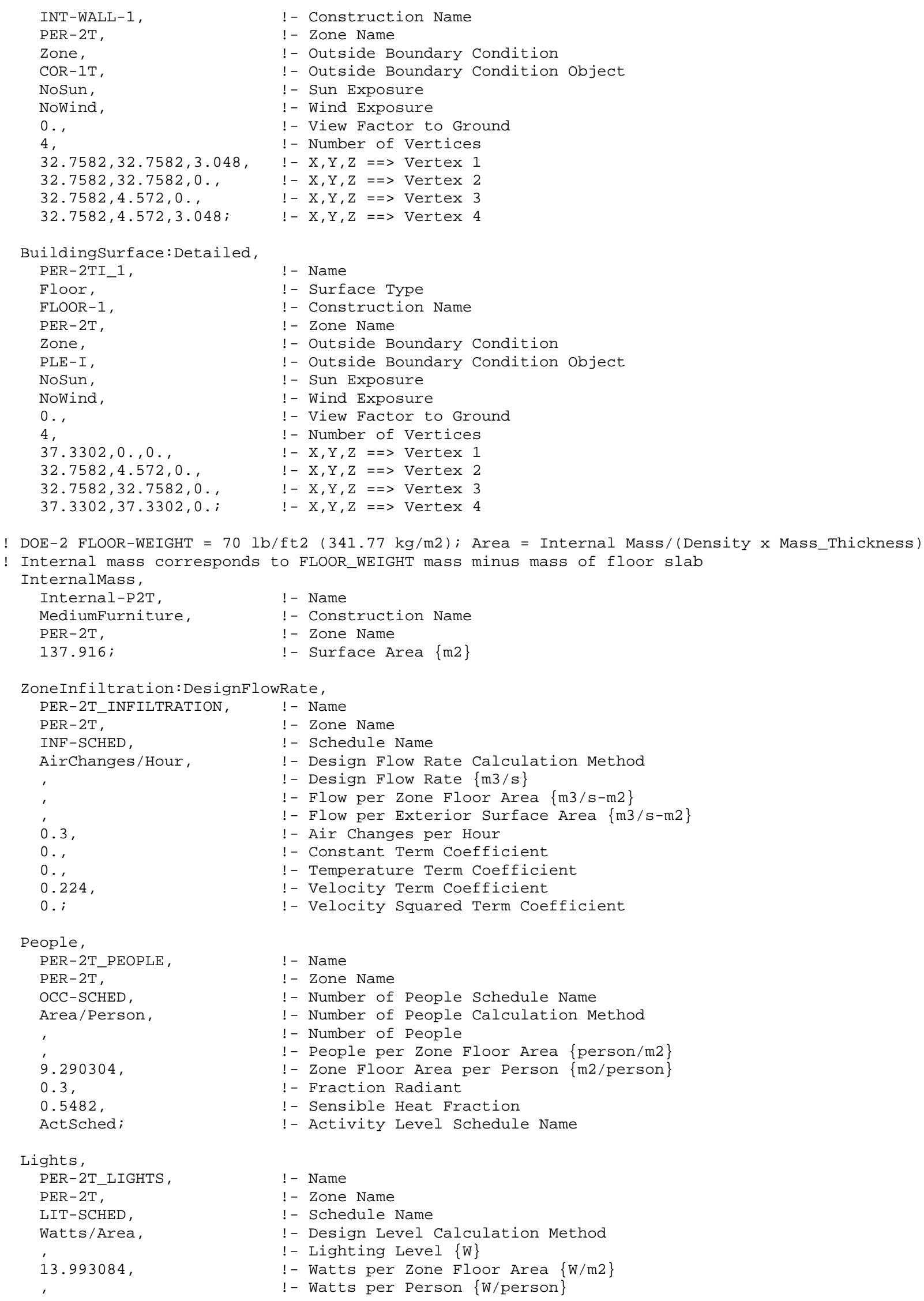




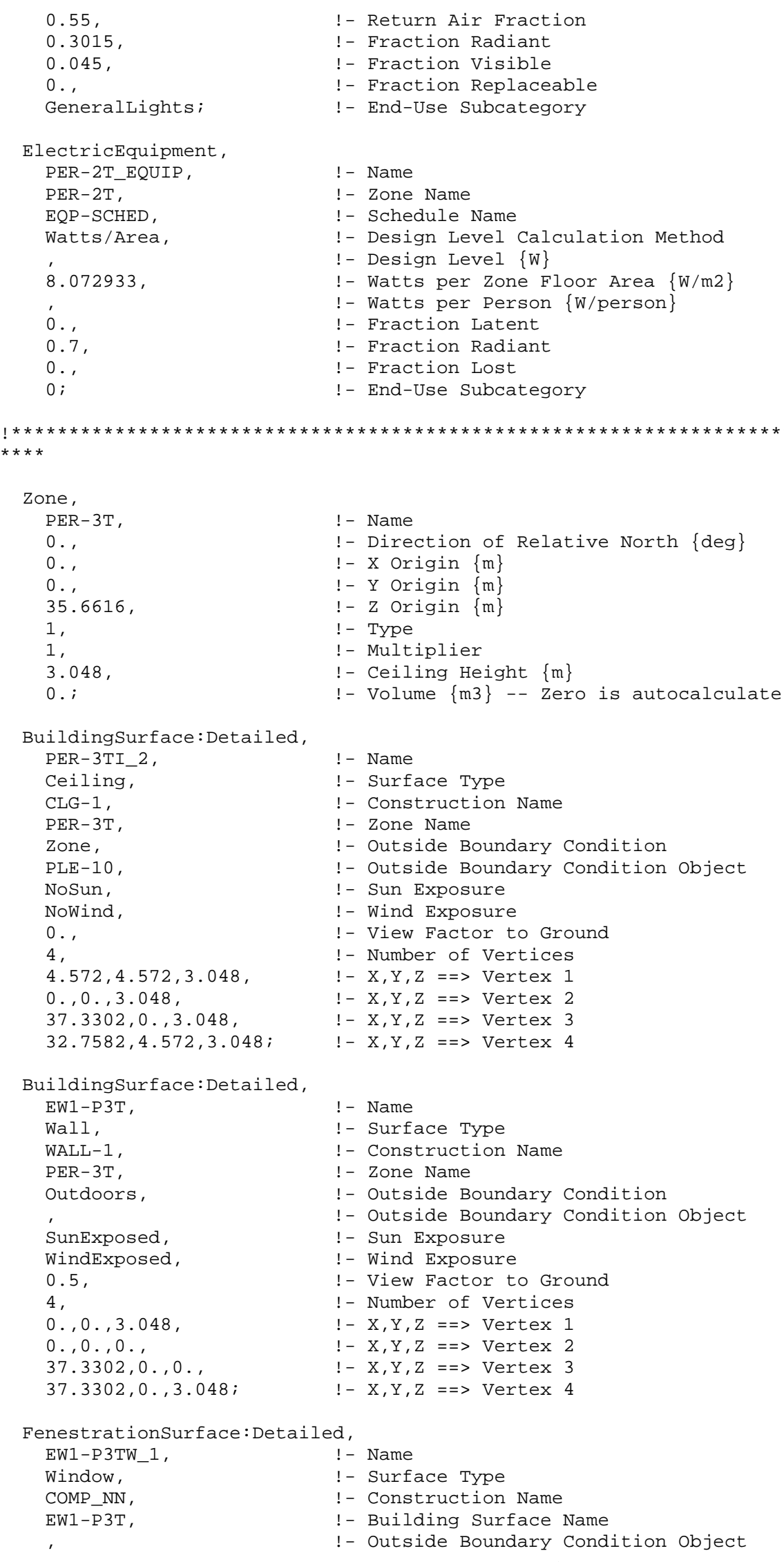




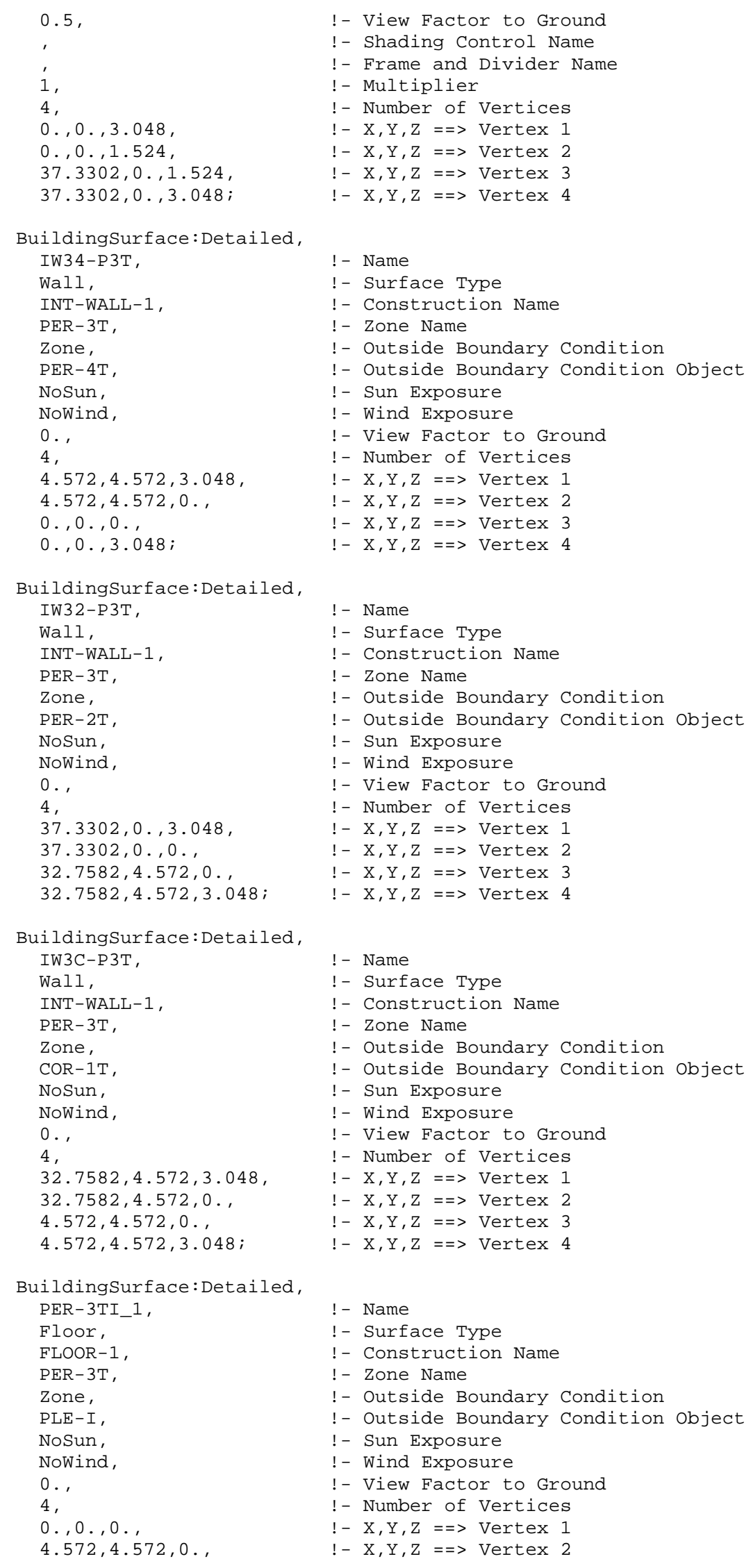




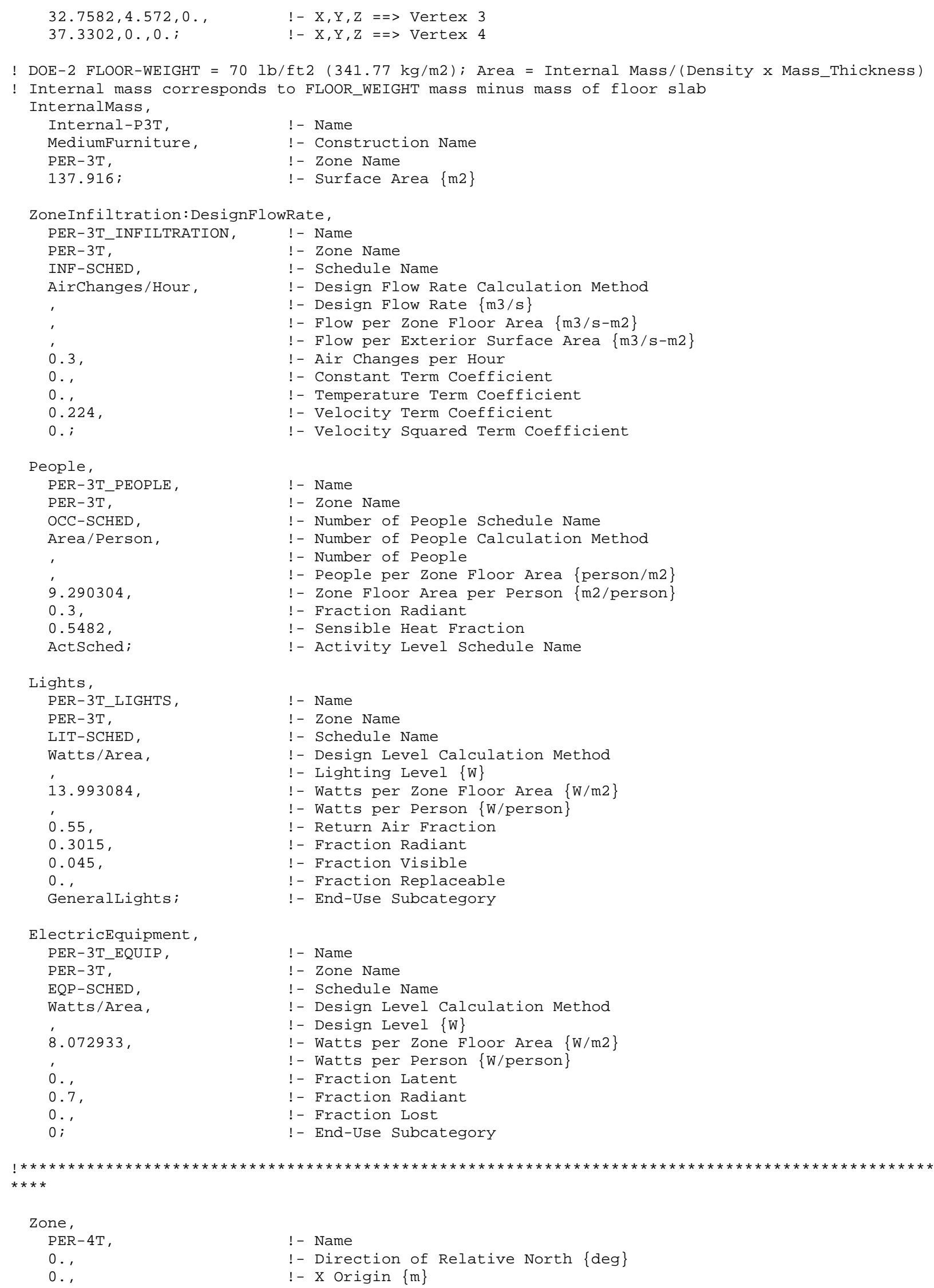




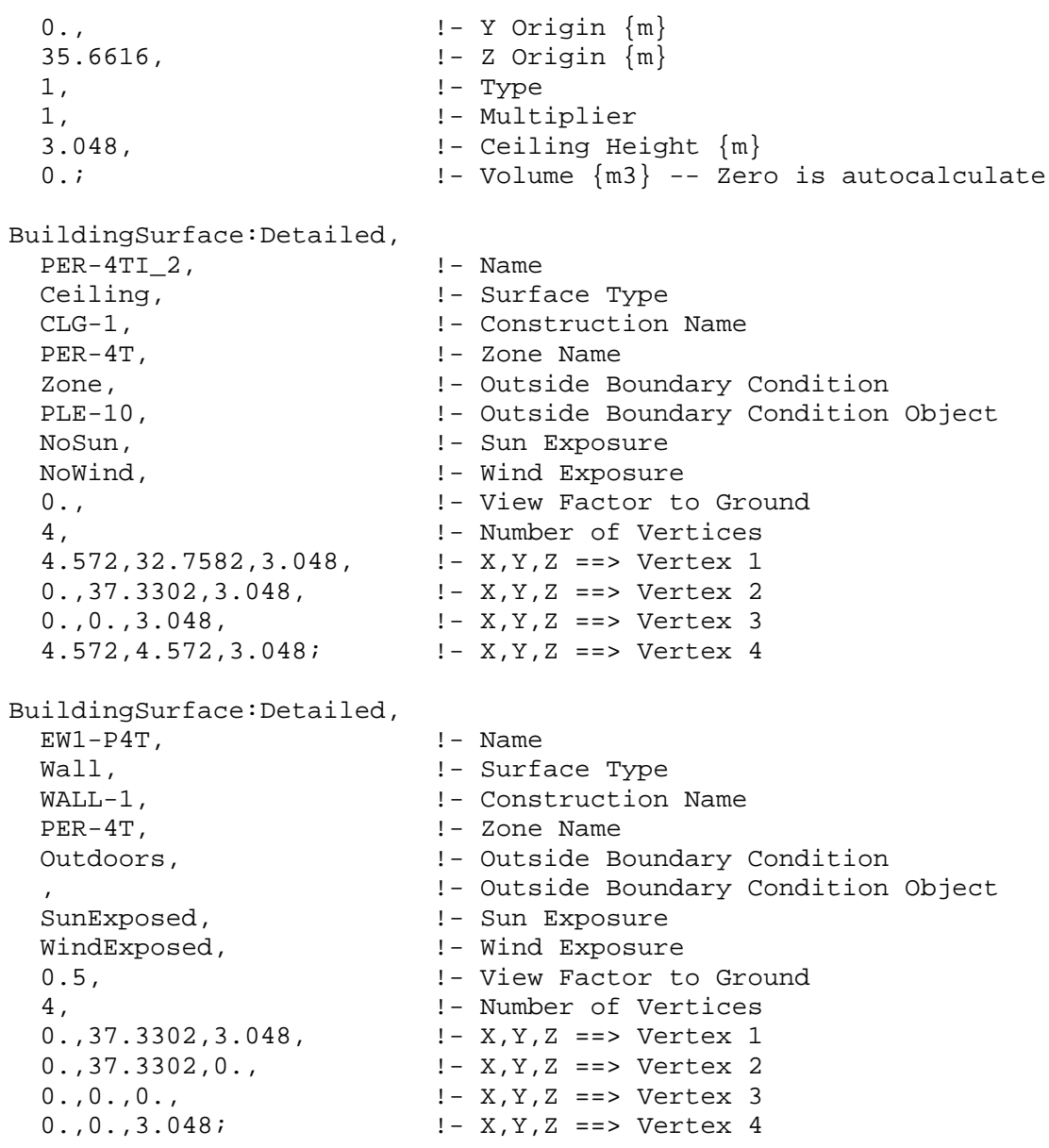

BuildingSurface: Detailed, EW1-P4T,

Fenestrationsurface: Detailed, 


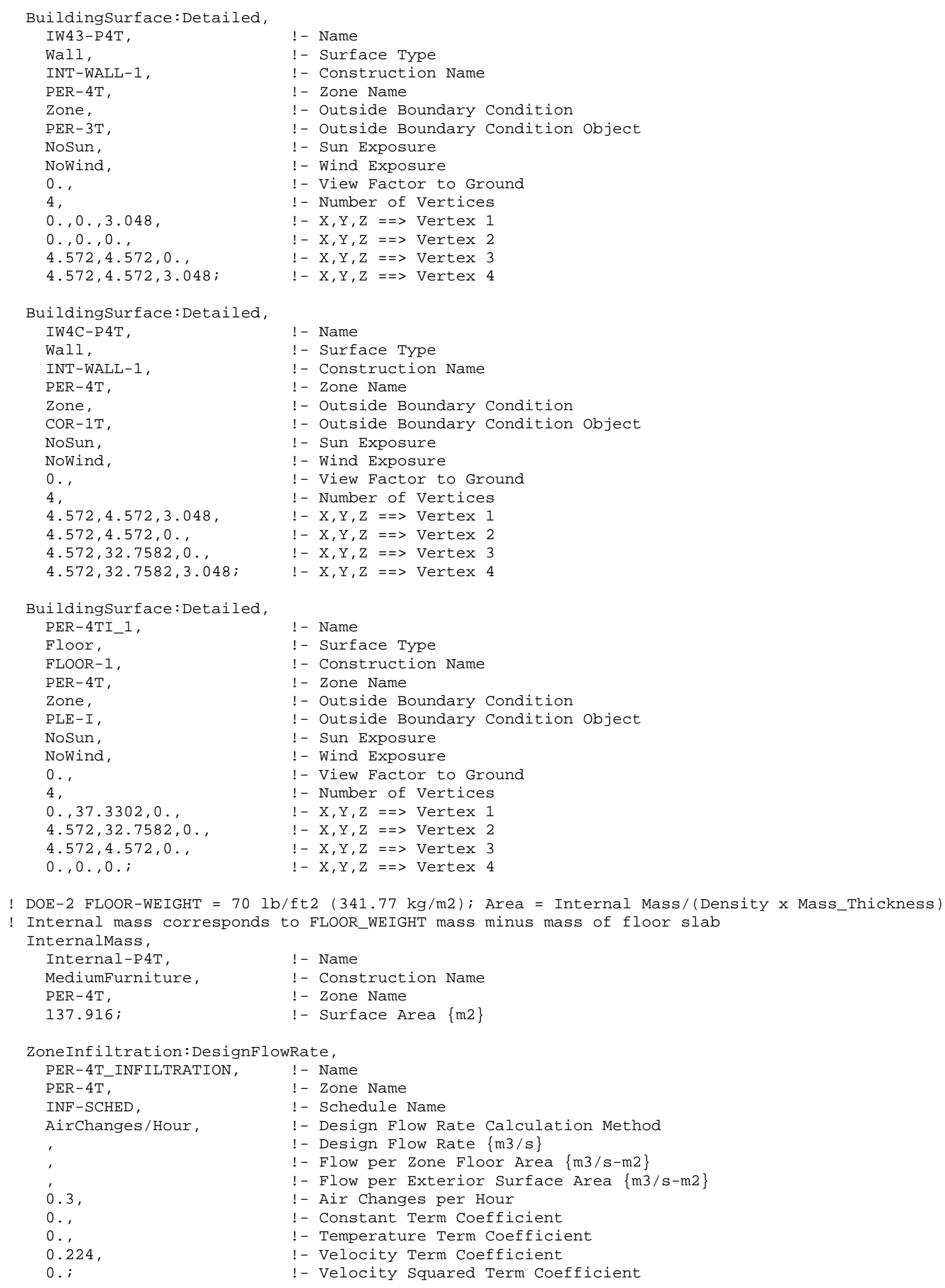

BuildingSurface: Detailed, PER-4TI_1,

! DOE-2 FLOOR-WEIGHT $=70 \mathrm{lb} / \mathrm{ft} 2(341.77 \mathrm{~kg} / \mathrm{m} 2) ;$ Area = Internal Mass/(Density $x$ Mass_Thickness)

! Internal mass corresponds to FLOOR_WEIGHT mass minus mass of floor slab

InternalMass,

Internal-P4T, !- Name

MediumFurniture, !- Construction Name

PER-4T, ! - Zone Name

137.916; !- Surface Area $\{\mathrm{m} 2\}$

ZoneInfiltration: DesignFlowRate

People, 


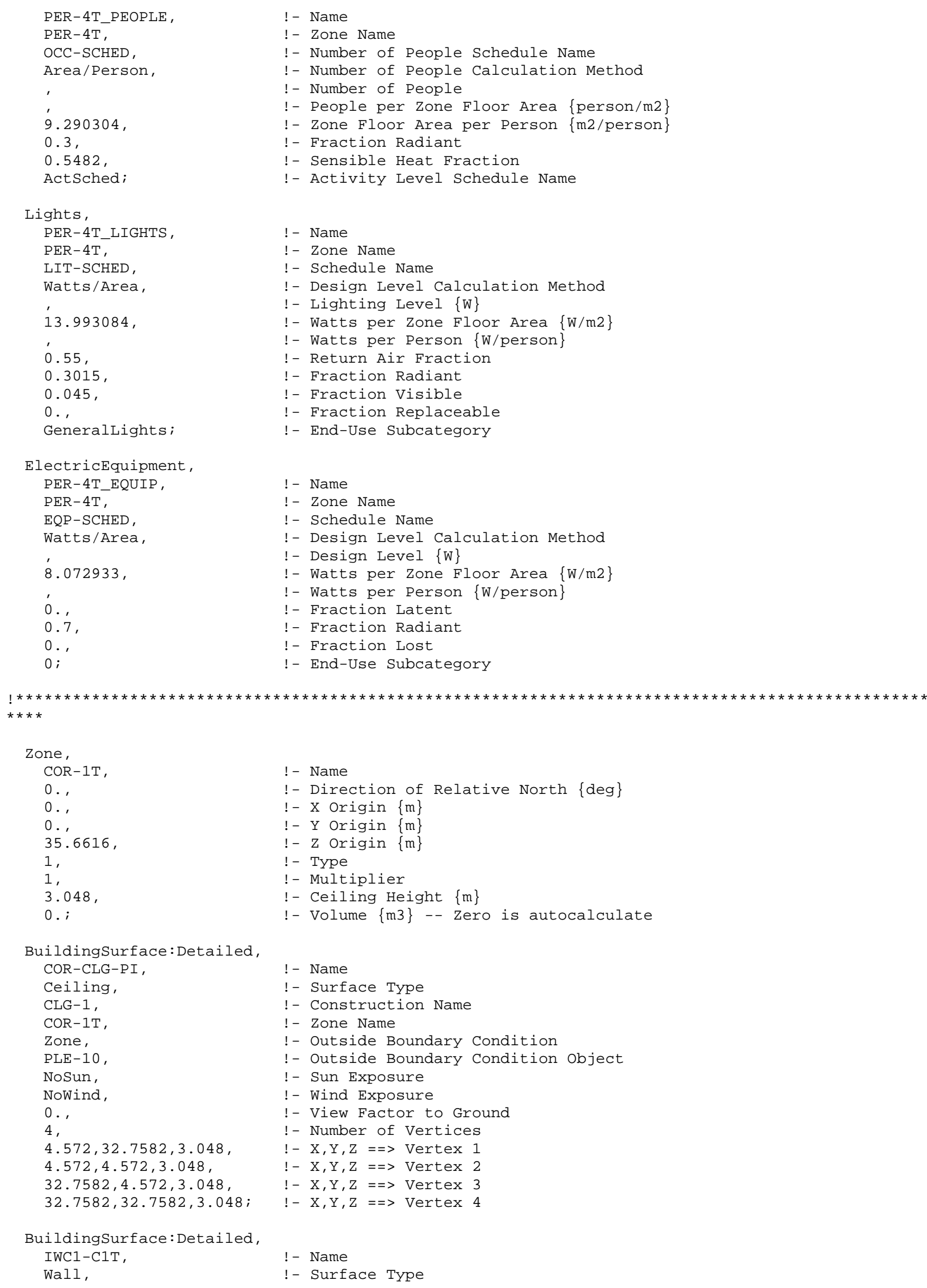

BuildingSurface: Detailed, IWC1-C1T, Wall, 


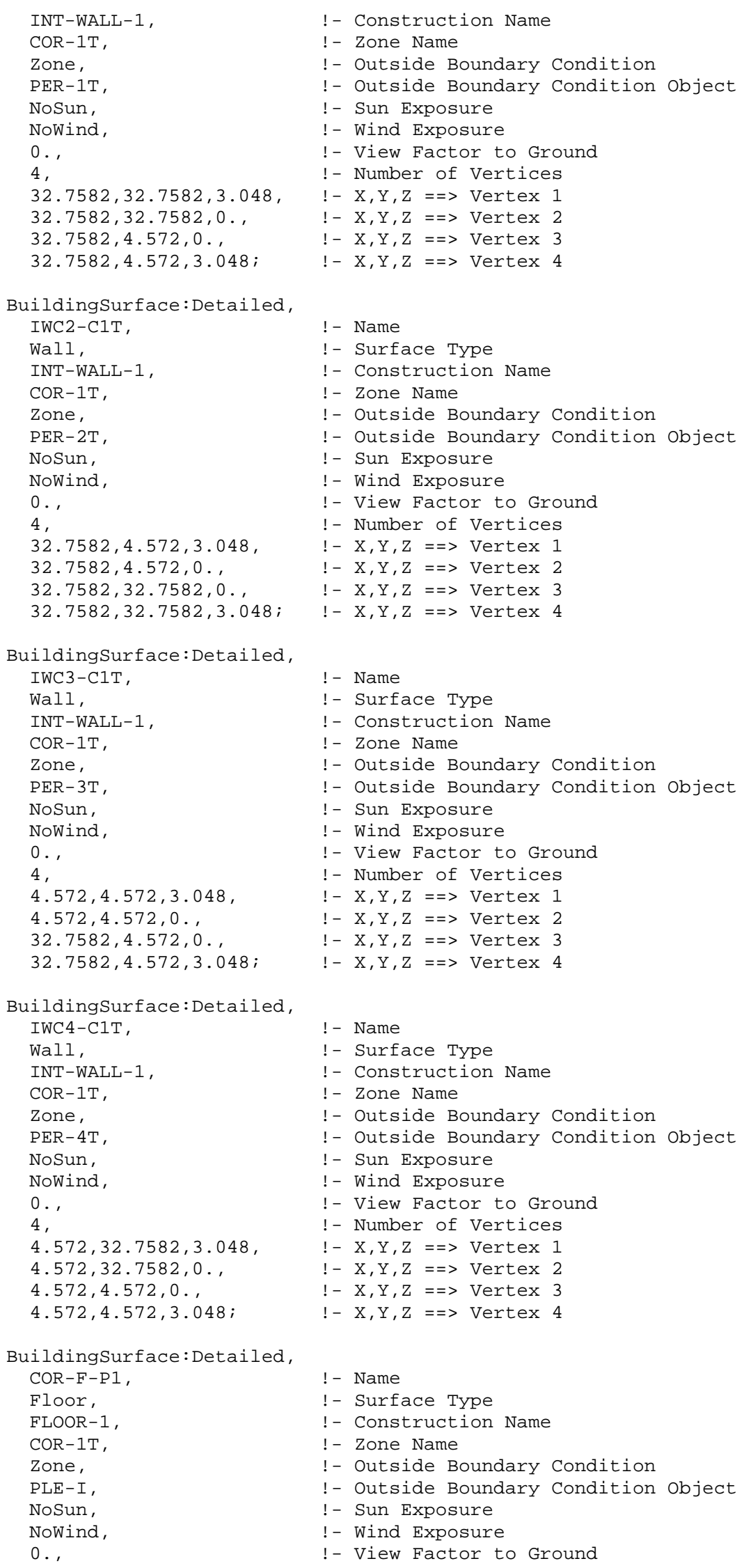

BuildingSurface: Detailed, IWC4-C1T,

BuildingSurface: Detailed, COR-F-P1,

Floor, FLOOR-1, COR-1T, Zone, PLE-I, NoSun, Nowind, 


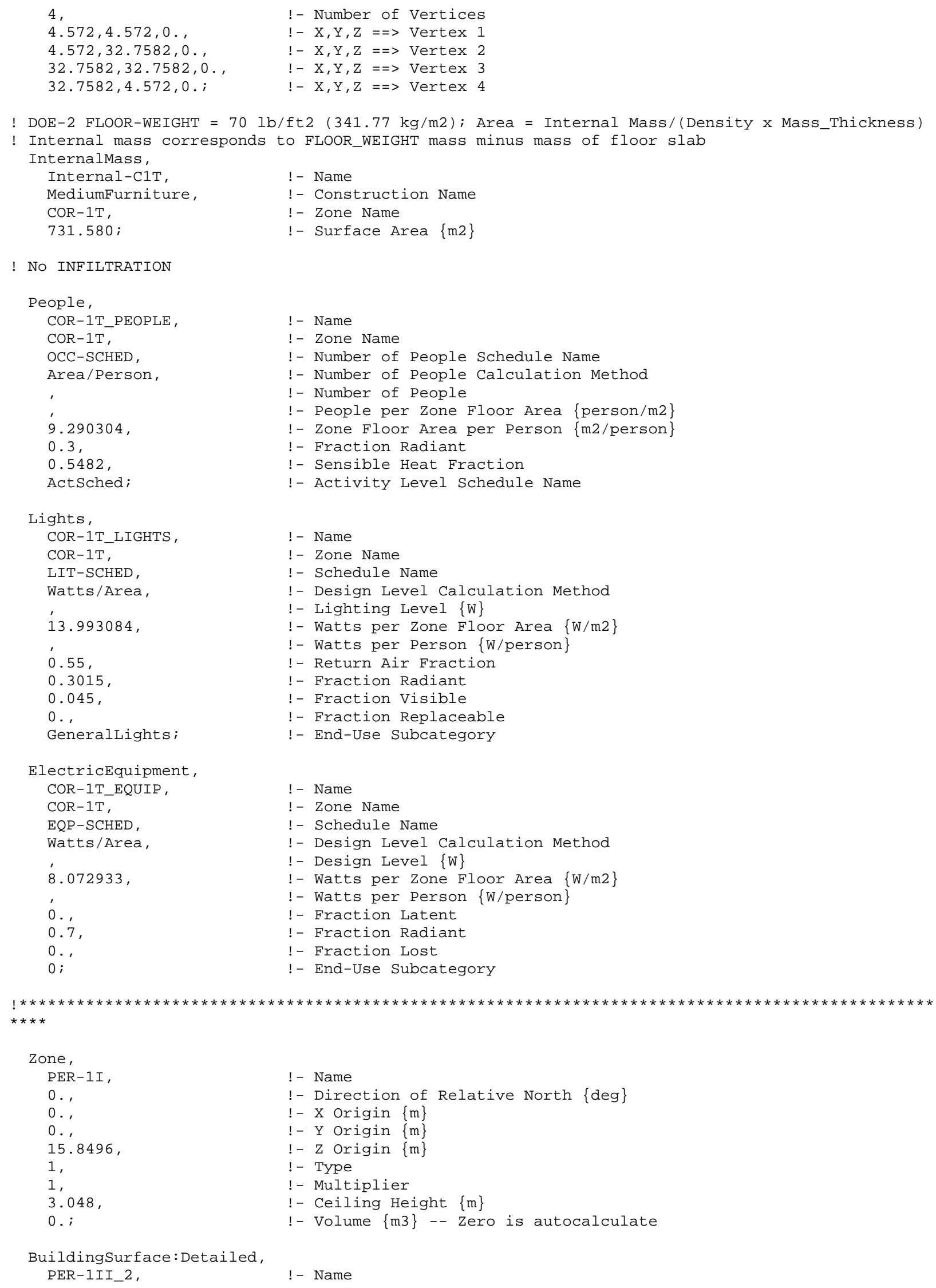




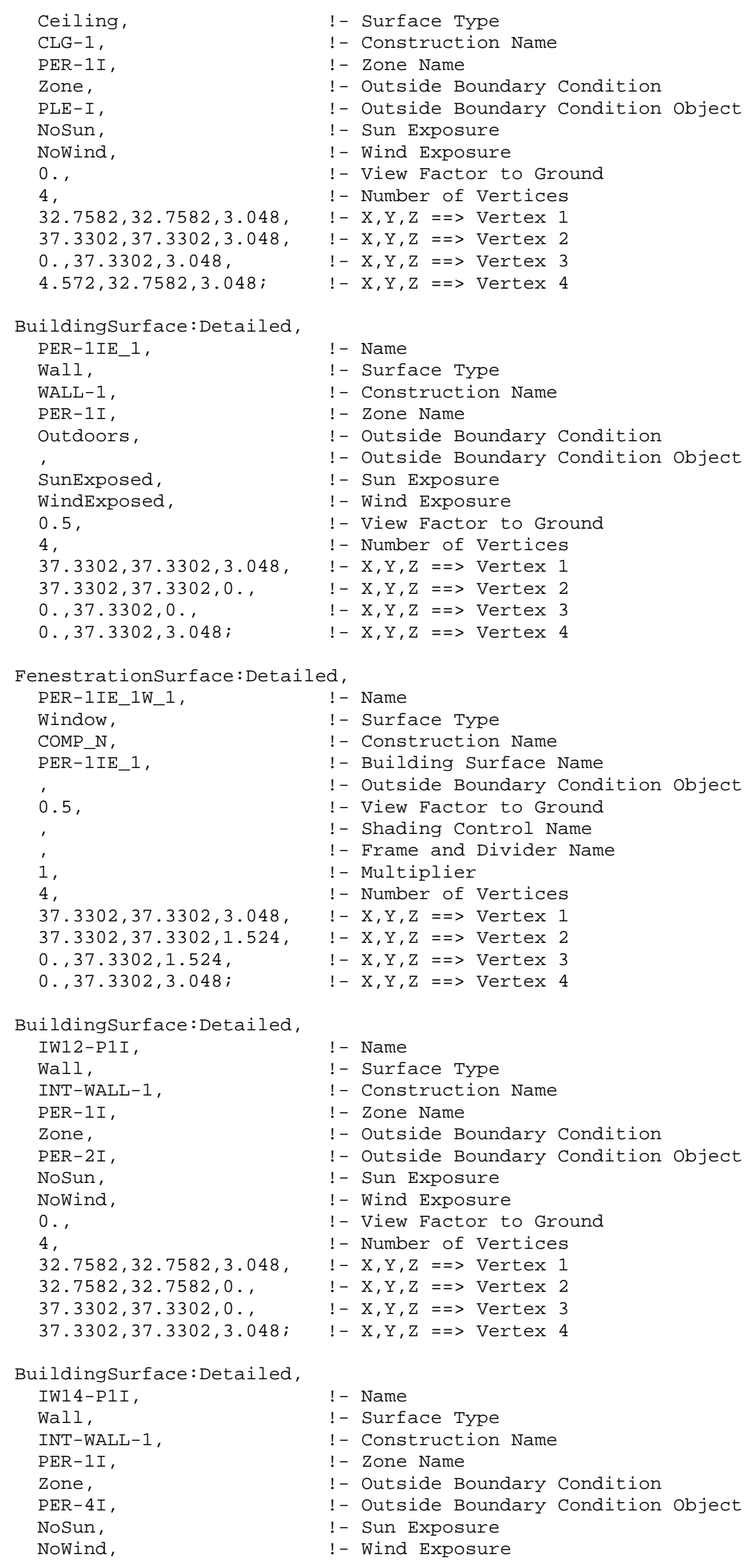




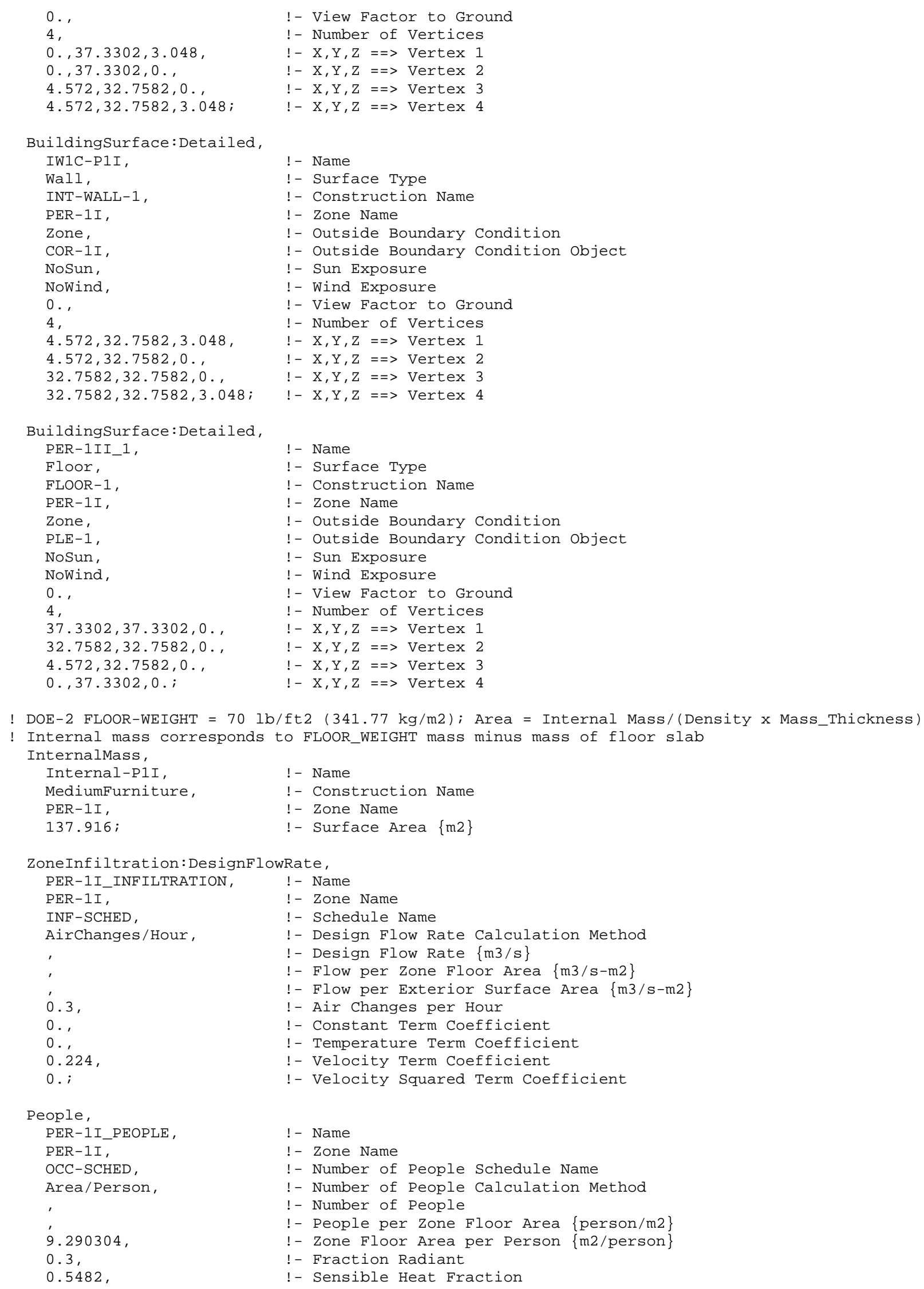

! DOE-2 FLOOR-WEIGHT $=70 \mathrm{lb} / \mathrm{ft} 2(341.77 \mathrm{~kg} / \mathrm{m} 2) ;$ Area = Internal Mass/(Density x Mass_Thickness)

! Internal mass corresponds to FLOOR_WEIGHT mass minus mass of floor slab

InternalMass,

Internal-P1I, !- Name

MediumFurniture, ! - Construction Name

PER-1I, ! - Zone Name

137.916; !- Surface Area $\{\mathrm{m} 2\}$

ZoneInfiltration: DesignFlowRate,

PER -1I TNFILTRATION,

PER-1I,

INF-SCHED,

! - Name

Airchanges/Hour, !- Design Flow Rate Calculation Method

,

,

ค. 3,

$0 .$,

๑.,

0.224,

0.;

- Zone

! - Design Flow Rate $\{\mathrm{m} 3 / \mathrm{s}\}$

! - Flow per Zone Floor Area $\{\mathrm{m} 3 / \mathrm{s}-\mathrm{m} 2\}$

! - Flow per Exterior Surface Area $\{\mathrm{m} 3 / \mathrm{s}-\mathrm{m} 2\}$

! - Air Changes per Hour

! - Constant Term Coefficient

! - Temperature Term Coefficient

! - Velocity Term Coefficient

! - Velocity Squared Term Coefficient

People,

PER-1I_PEOPLE, !- Name

PER-1I,

OCC-SCHED,

Area/Person,

' 290304 ,

0.3 ,

! - Zone Name

! - Number of People Schedule Name

! - Number of People Calculation Method

! - Number of People

! - People per Zone Floor Area \{person/m2\}

$\odot .5482$,

! - Zone Floor Area per Person \{m2/person\}

! - Fraction Radiant

! - Sensible Heat Fraction 


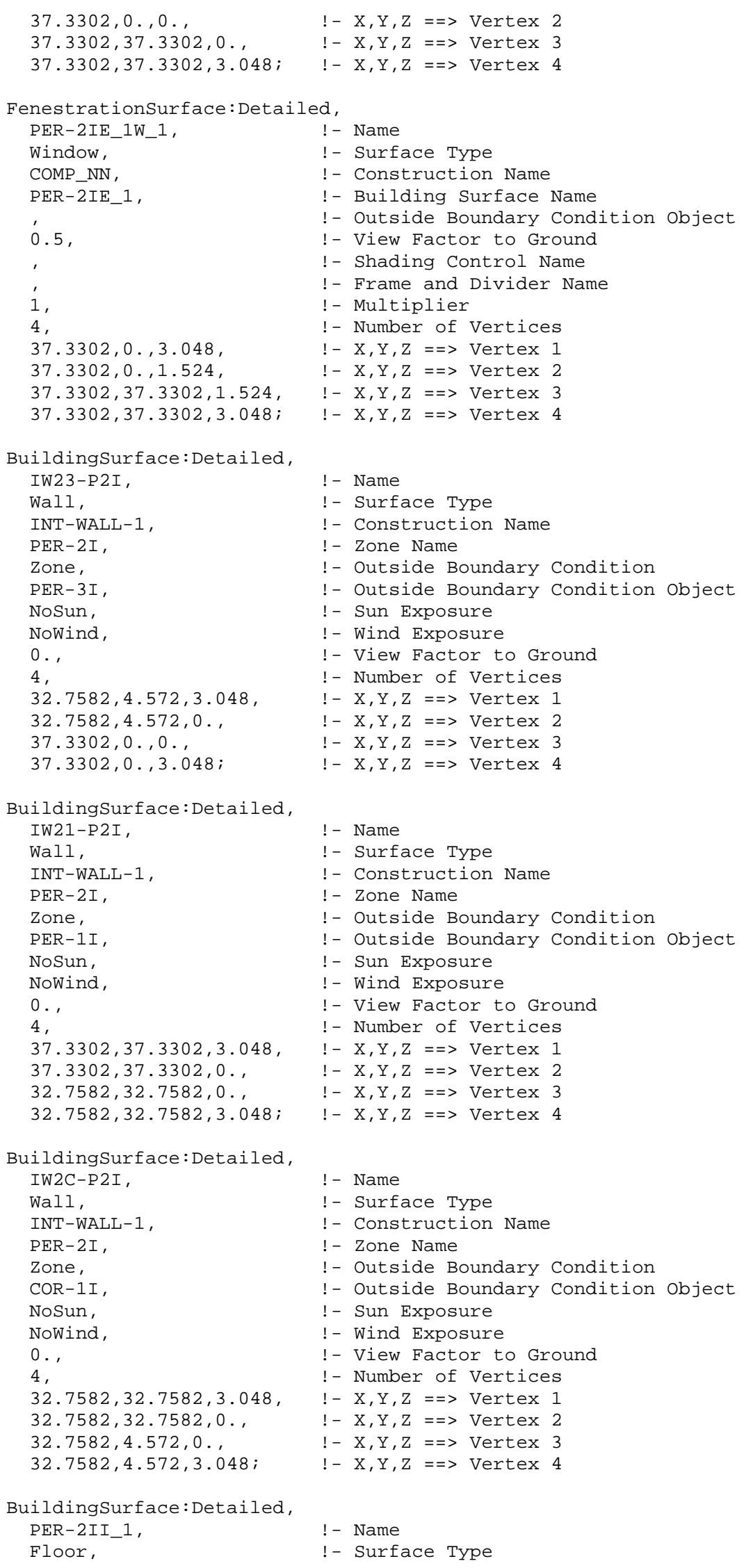

BuildingSurface: Detailed, IW2C-P2I,

BuildingSurface: Detailed, PER-2II 1 , Floor, 


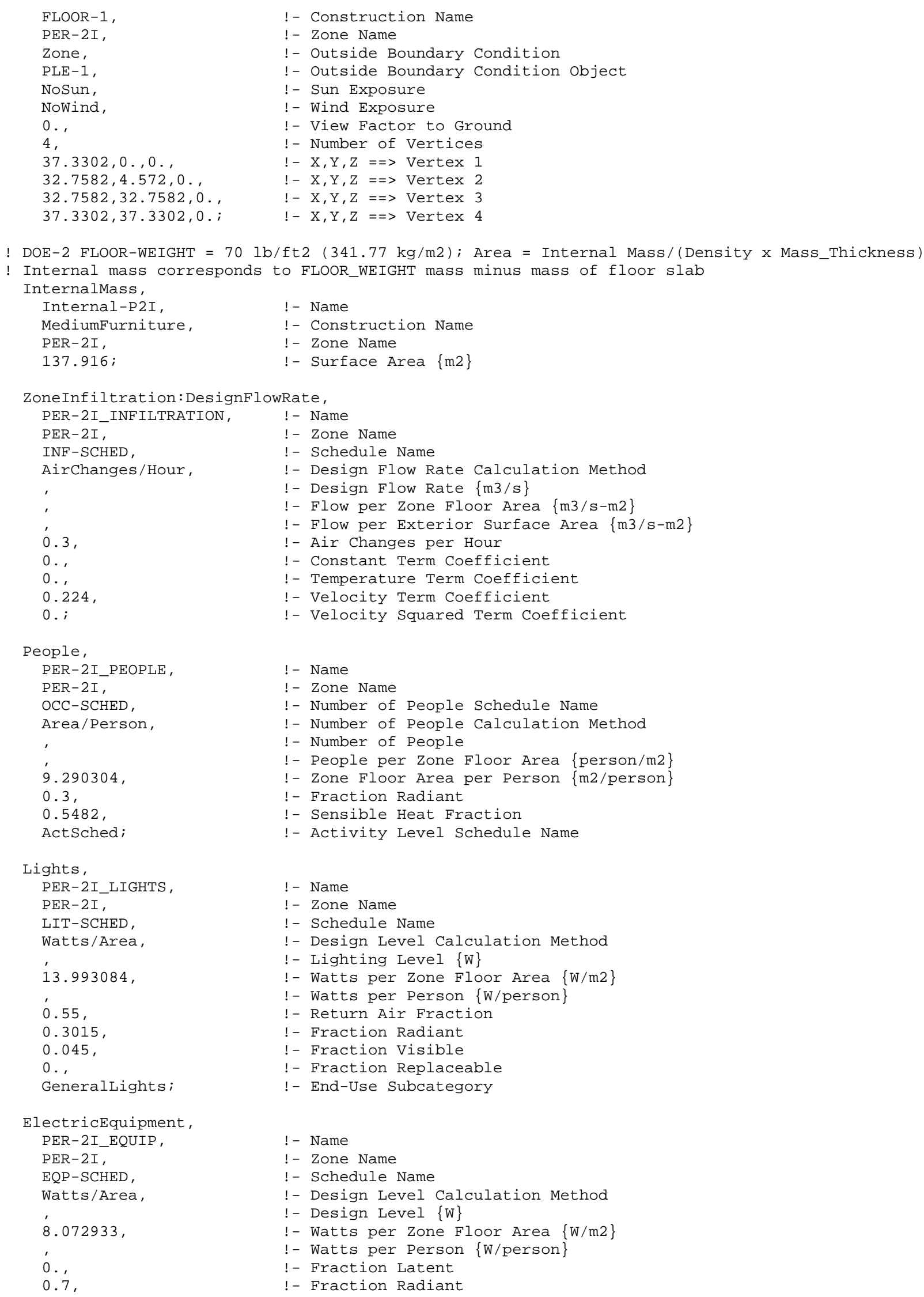




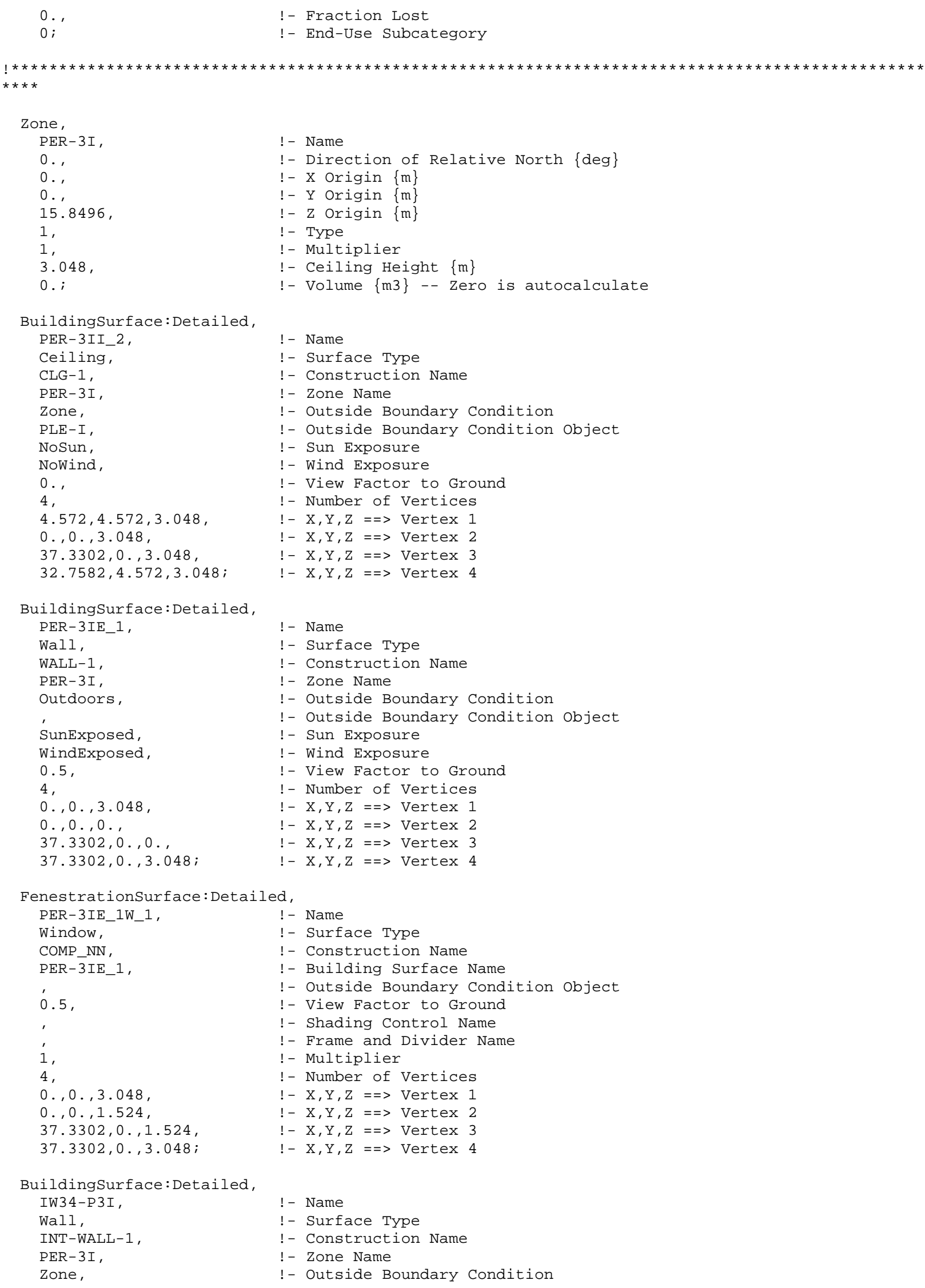




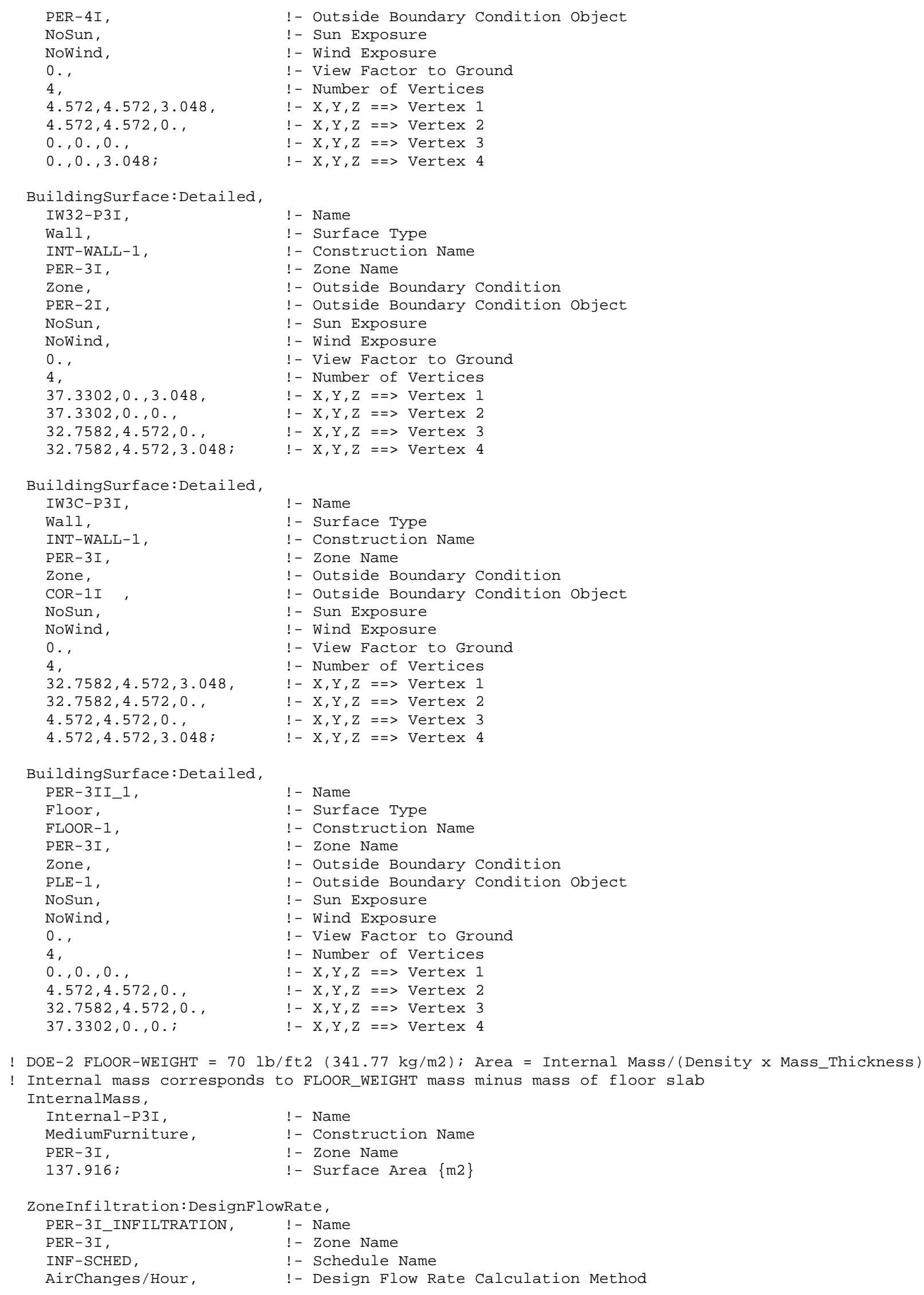

! DOE-2 FLOOR-WEIGHT $=70 \mathrm{lb} / \mathrm{ft} 2(341.77 \mathrm{~kg} / \mathrm{m} 2) ;$ Area $=$ Internal Mass/(Density $\times$ Mass_Thickness)

! Internal mass corresponds to FLOOR_WEIGHT mass minus mass of floor slab

InternalMass,

Internal-P3I, !- Name

MediumFurniture, !- Construction Name

PER-3I, ! - Zone Name

137.916; !- Surface Area \{m2\}

ZoneInfiltration: DesignFlowRate,

PER-3I_INFILTRATION, ! - Name

PER-3I,

INF-SCHED,

! - Zone Name

! - Schedule Name

AirChanges/Hour,

! - Design Flow Rate Calculation Method 


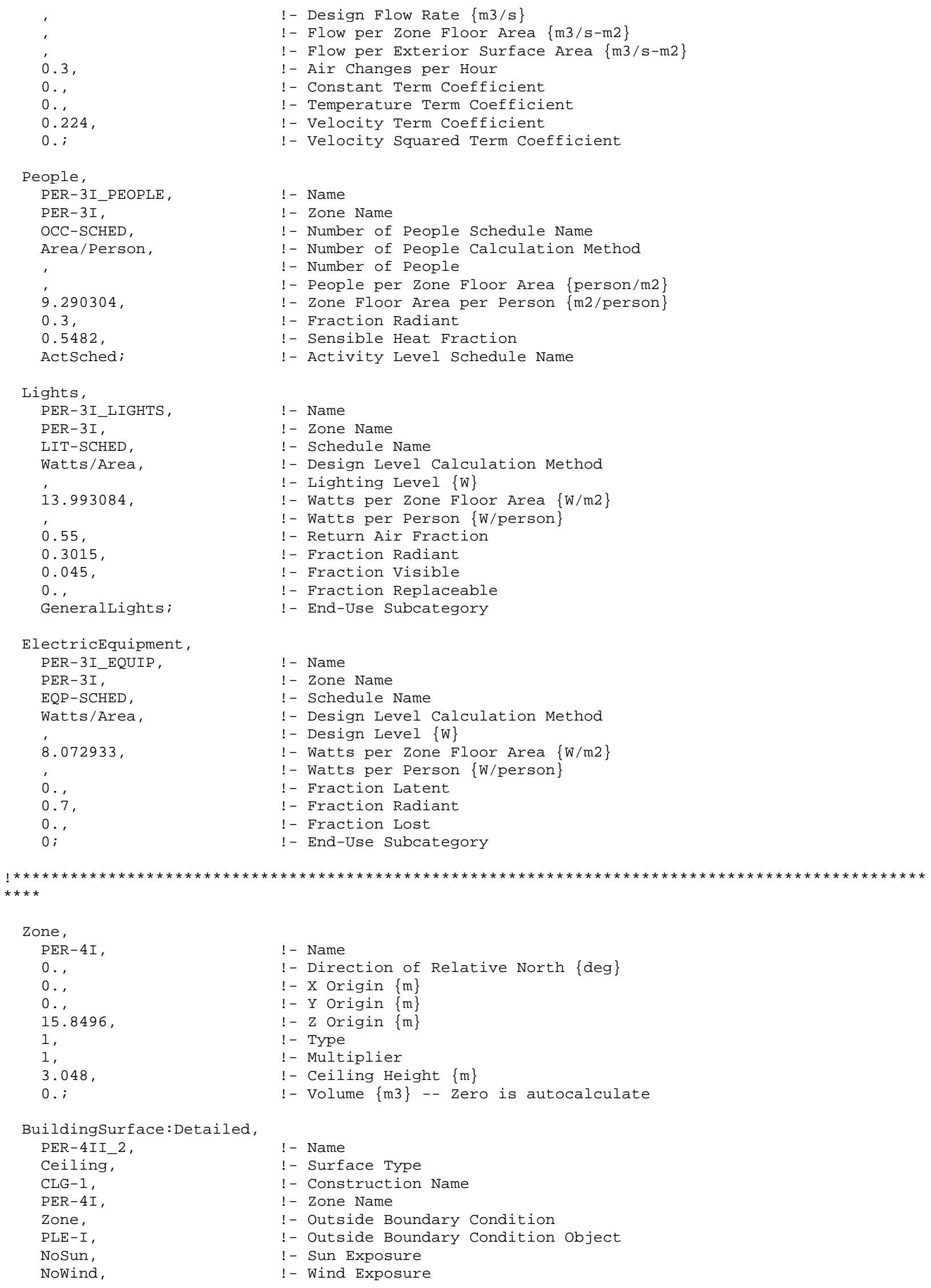




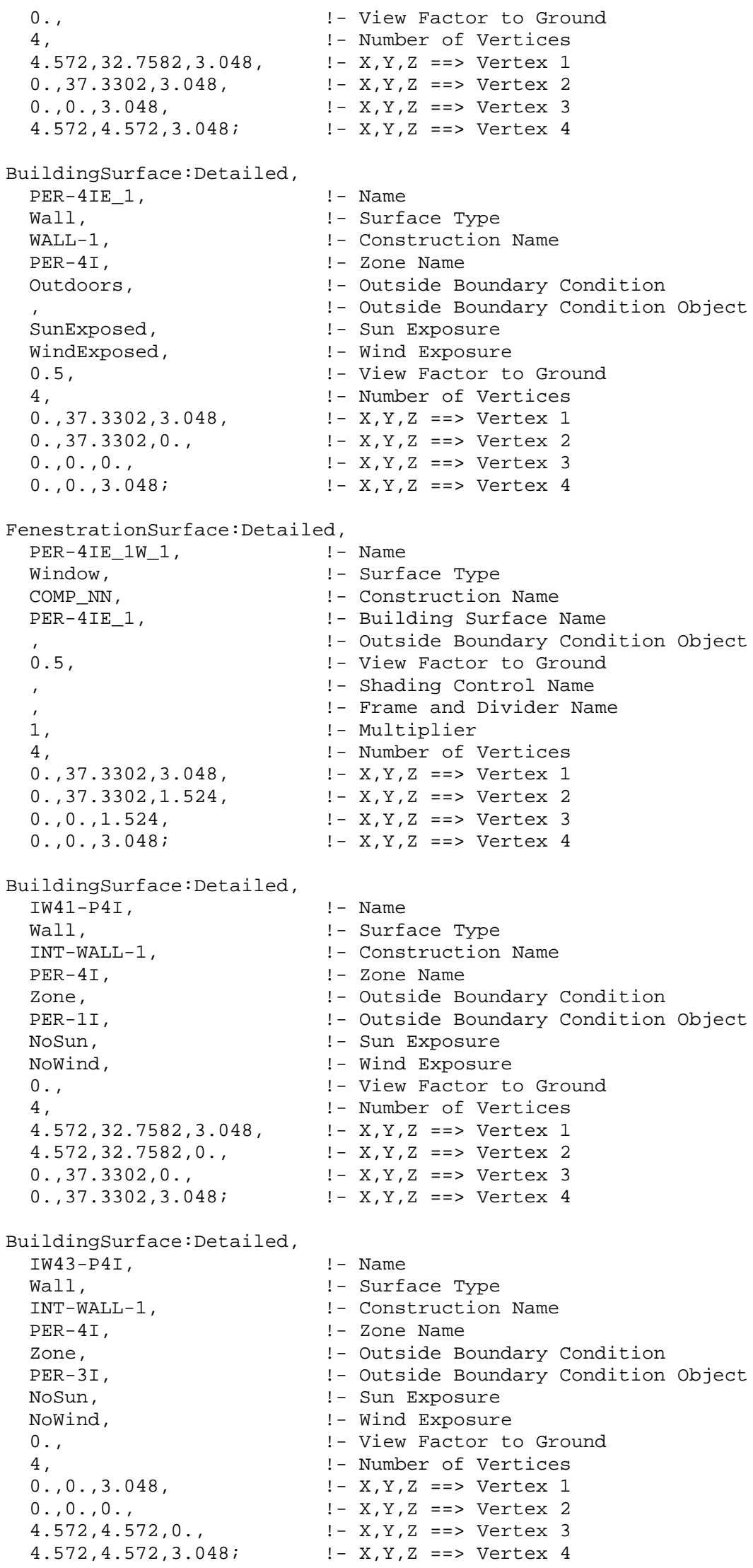




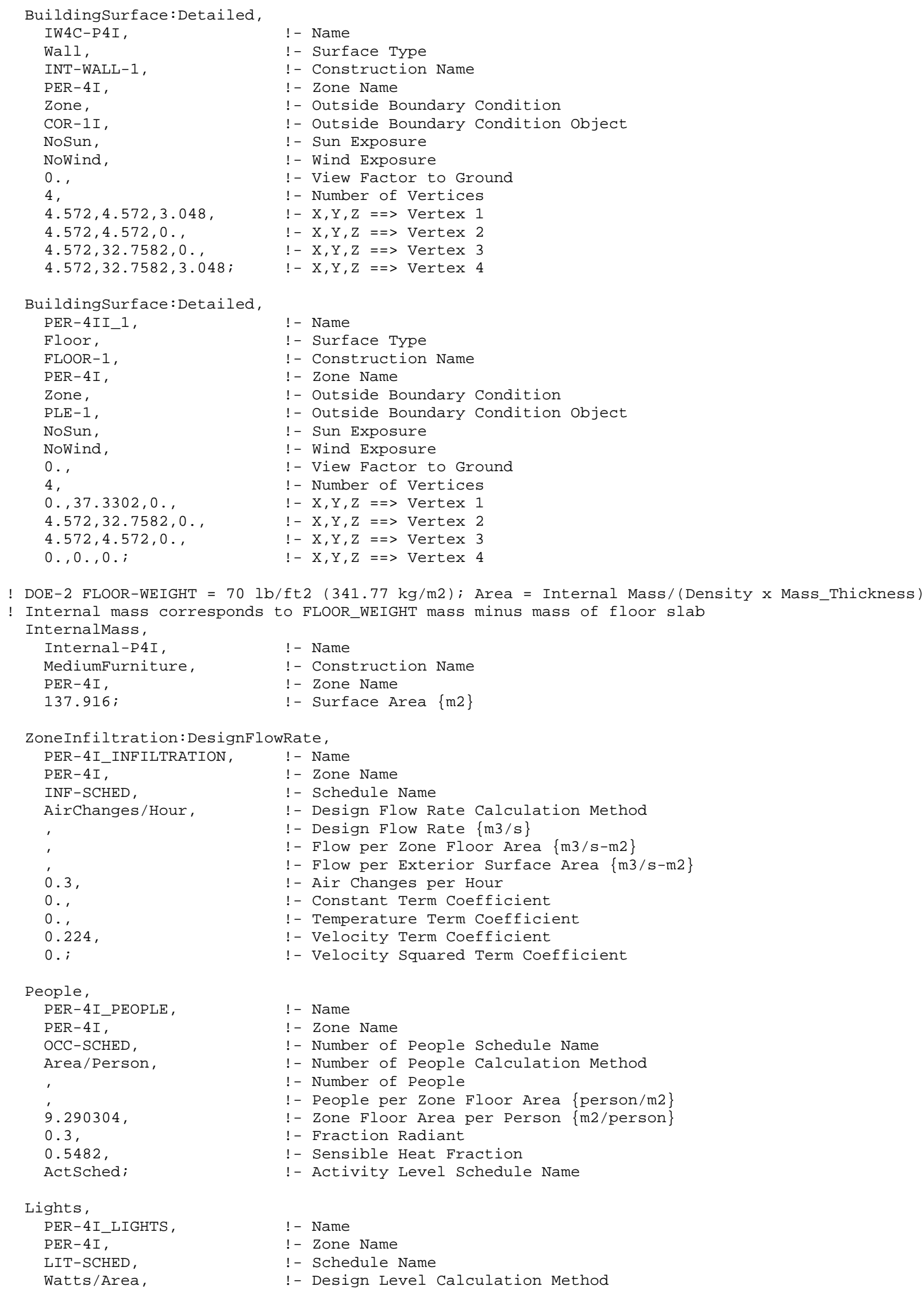




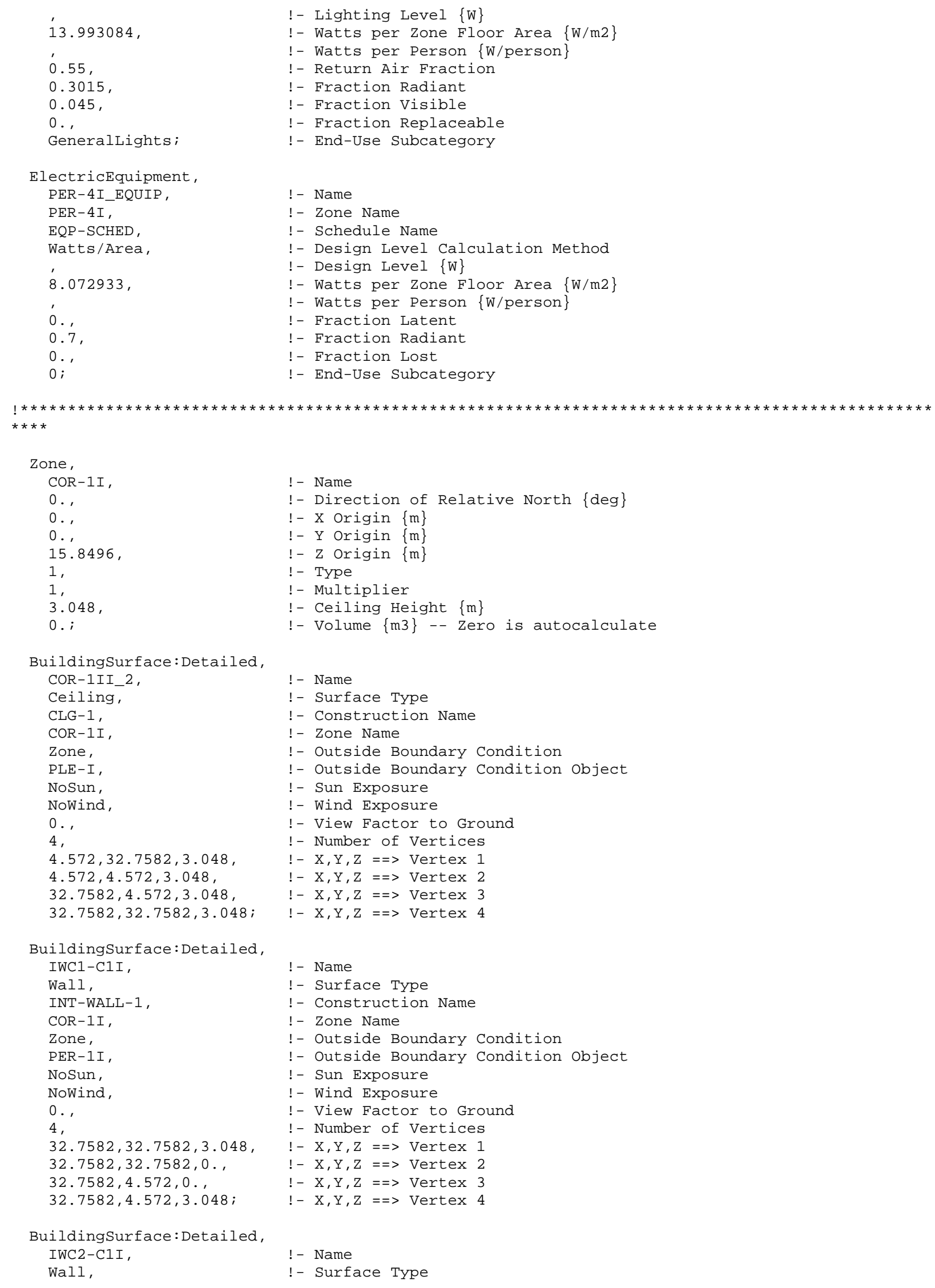




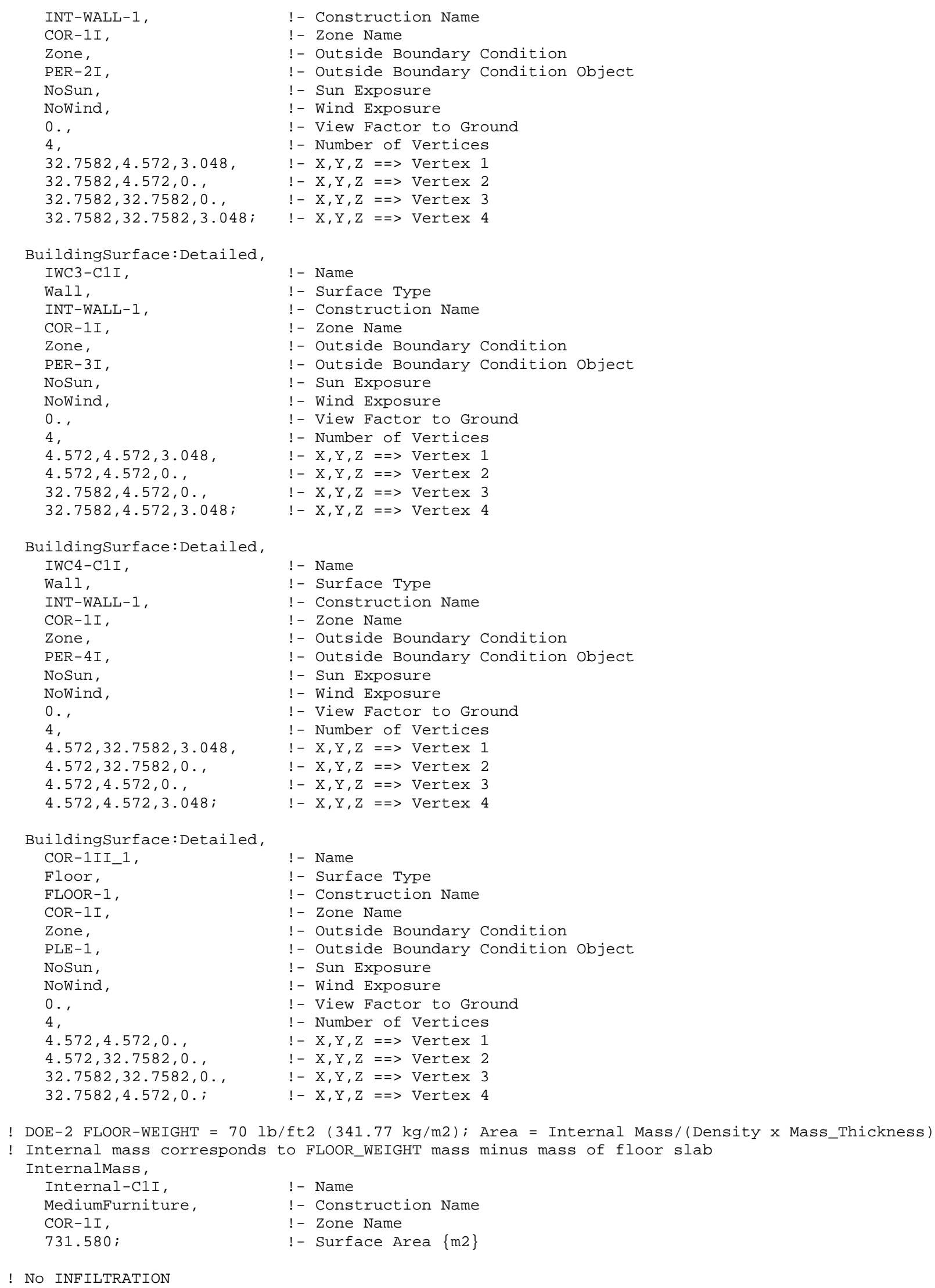

BuildingSurface: Detailed, COR-1II_1,

! DOE-2 FLOOR-WEIGHT $=70 \mathrm{lb} / \mathrm{ft} 2(341.77 \mathrm{~kg} / \mathrm{m} 2) ;$ Area $=$ Internal Mass $/($ Density $x$ Mass_Thickness $)$

! Internal mass corresponds to FLOOR_WEIGHT mass minus mass of floor slab InternalMass, Internal-C1I,

MediumFurniture, $\quad$ !- Construction Name COR-1I, 731.580

! - Name

! - Zone Name

!- Surface Area $\{\mathrm{m} 2\}$

! No INFILTRATION 


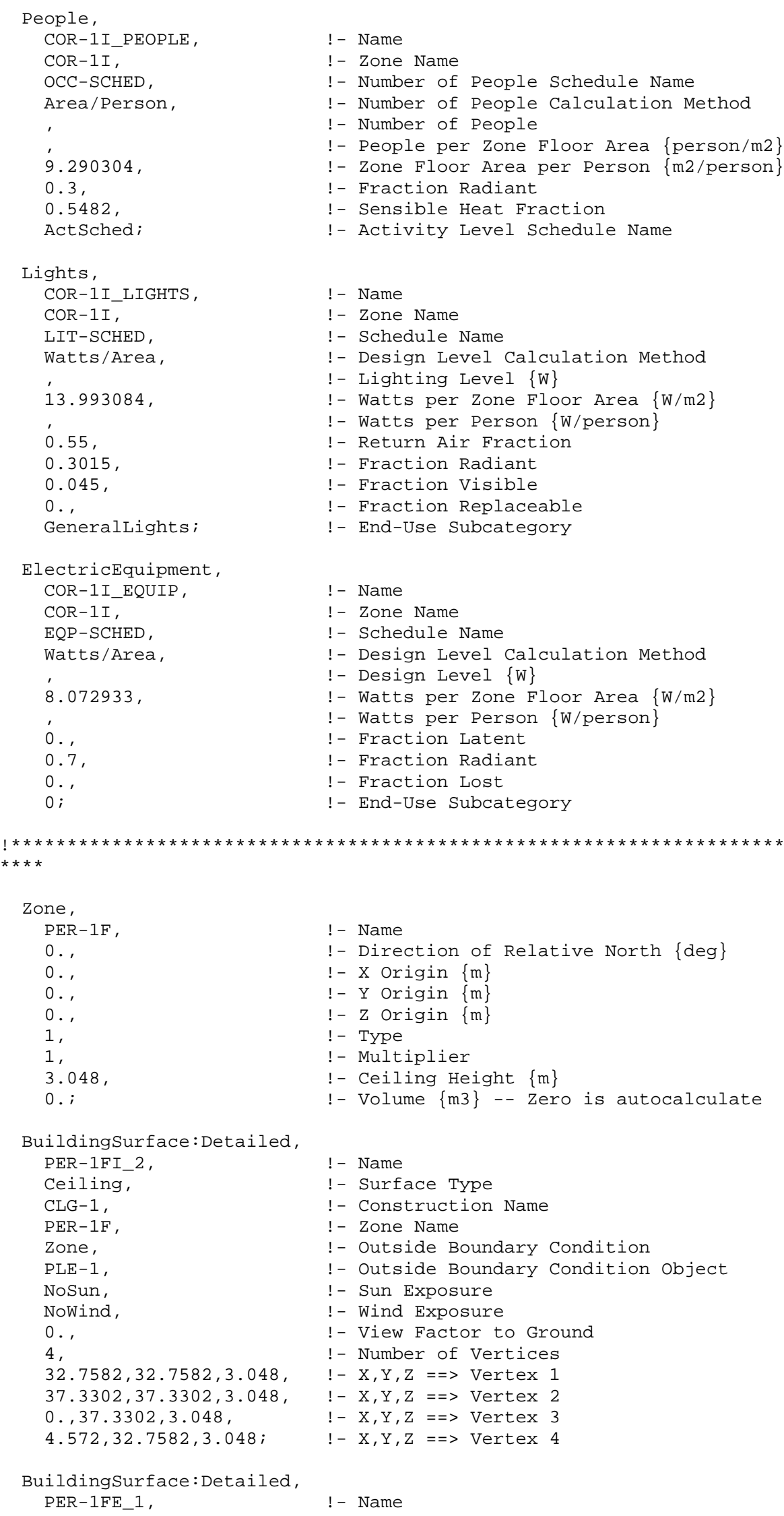




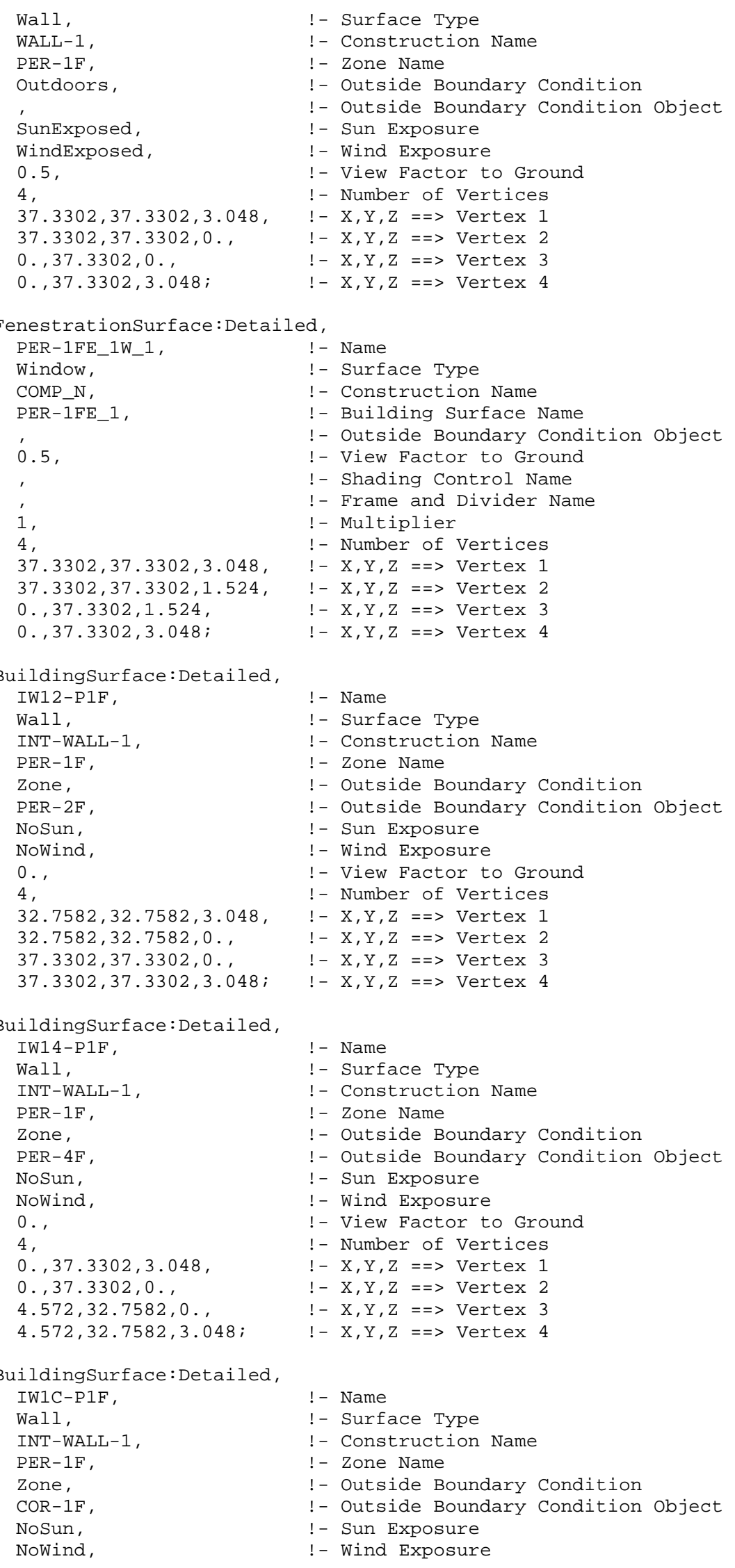




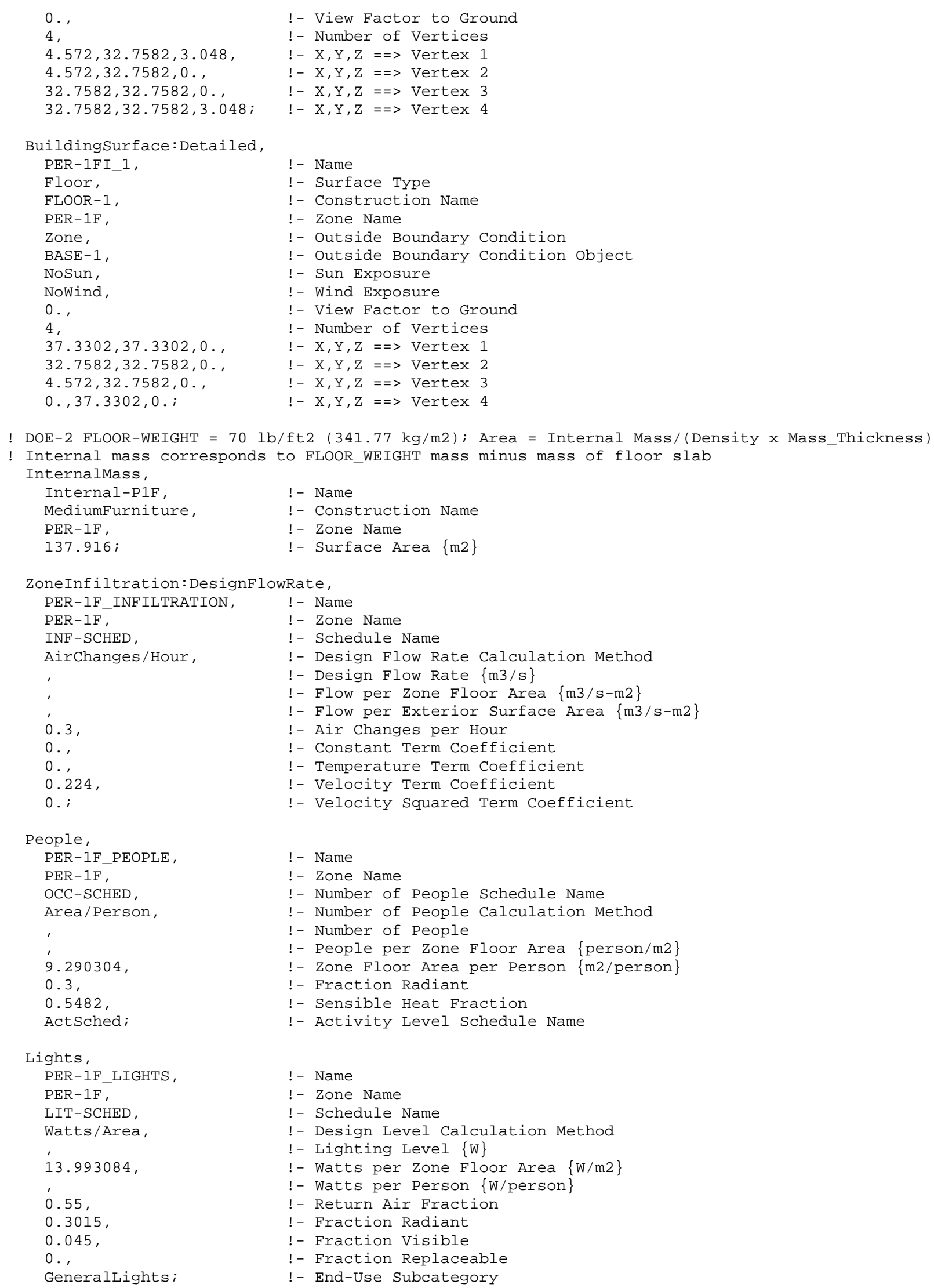




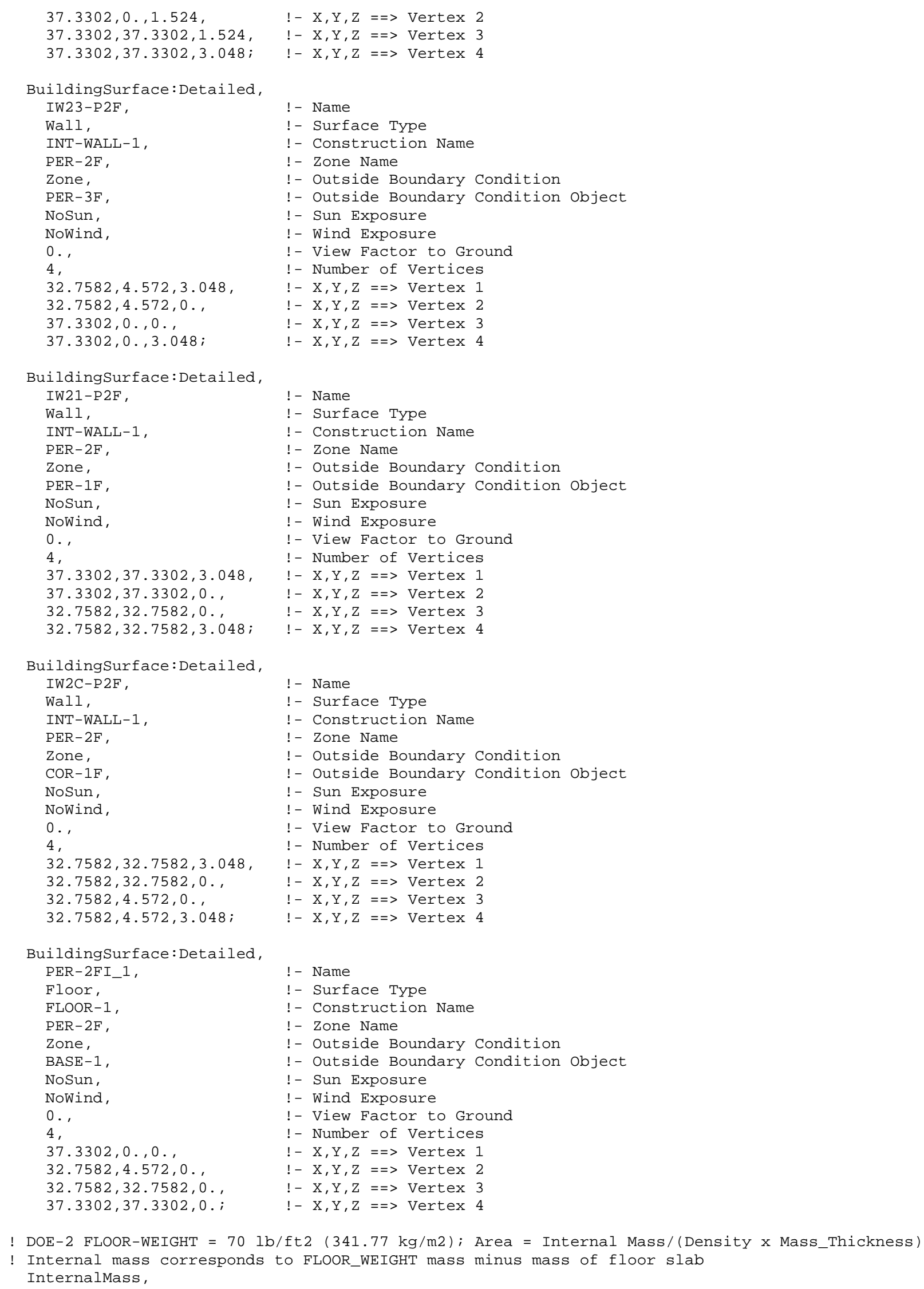

! DOE-2 FLOOR-WEIGHT $=70 \mathrm{lb} / \mathrm{ft} 2(341.77 \mathrm{~kg} / \mathrm{m} 2) ;$ Area = Internal Mass/(Density $\mathrm{x}$ Mass_Thickness)

! Internal mass corresponds to FLOOR_WEIGHT mass minus mass of floor slab InternalMass, 


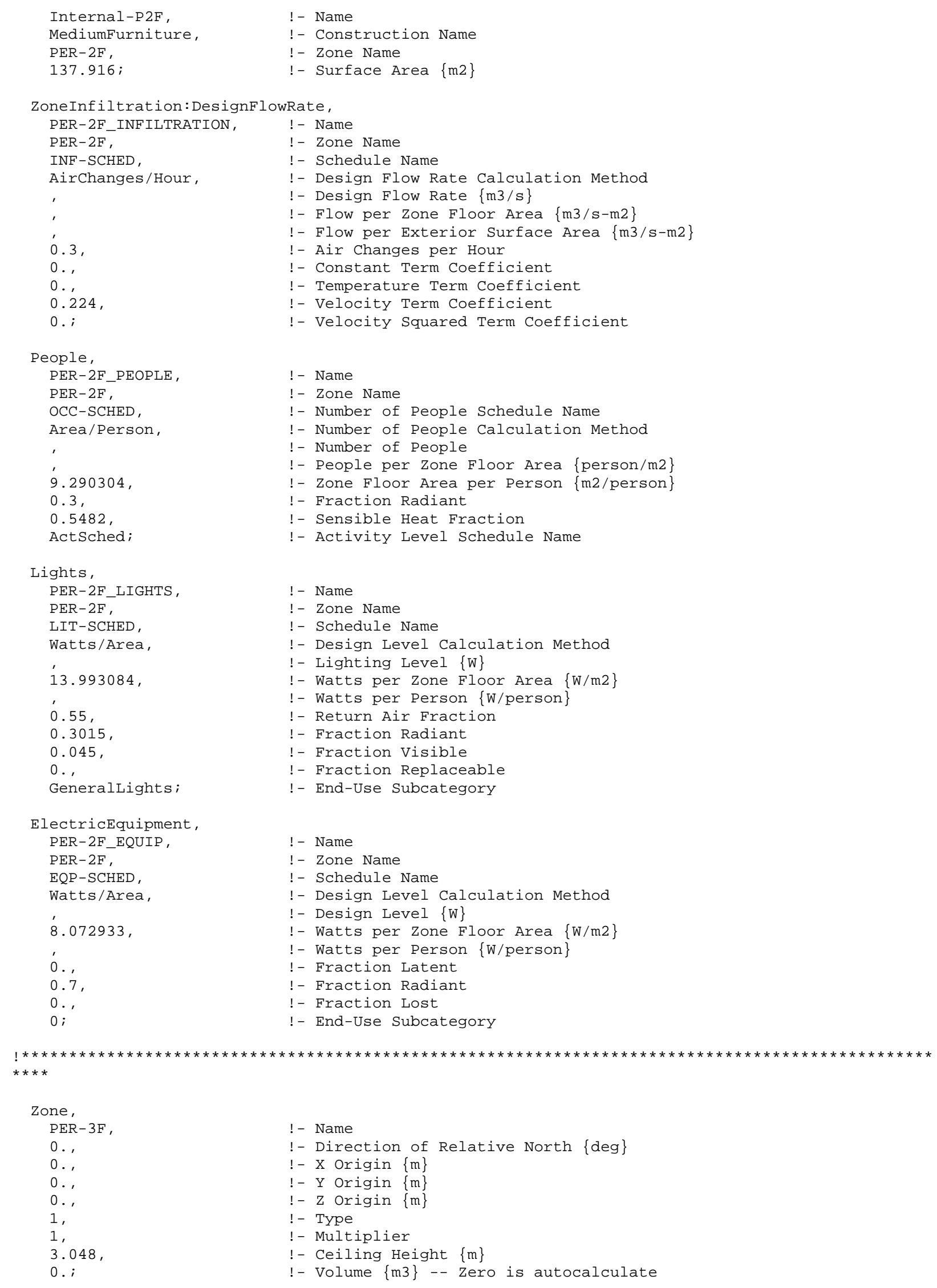




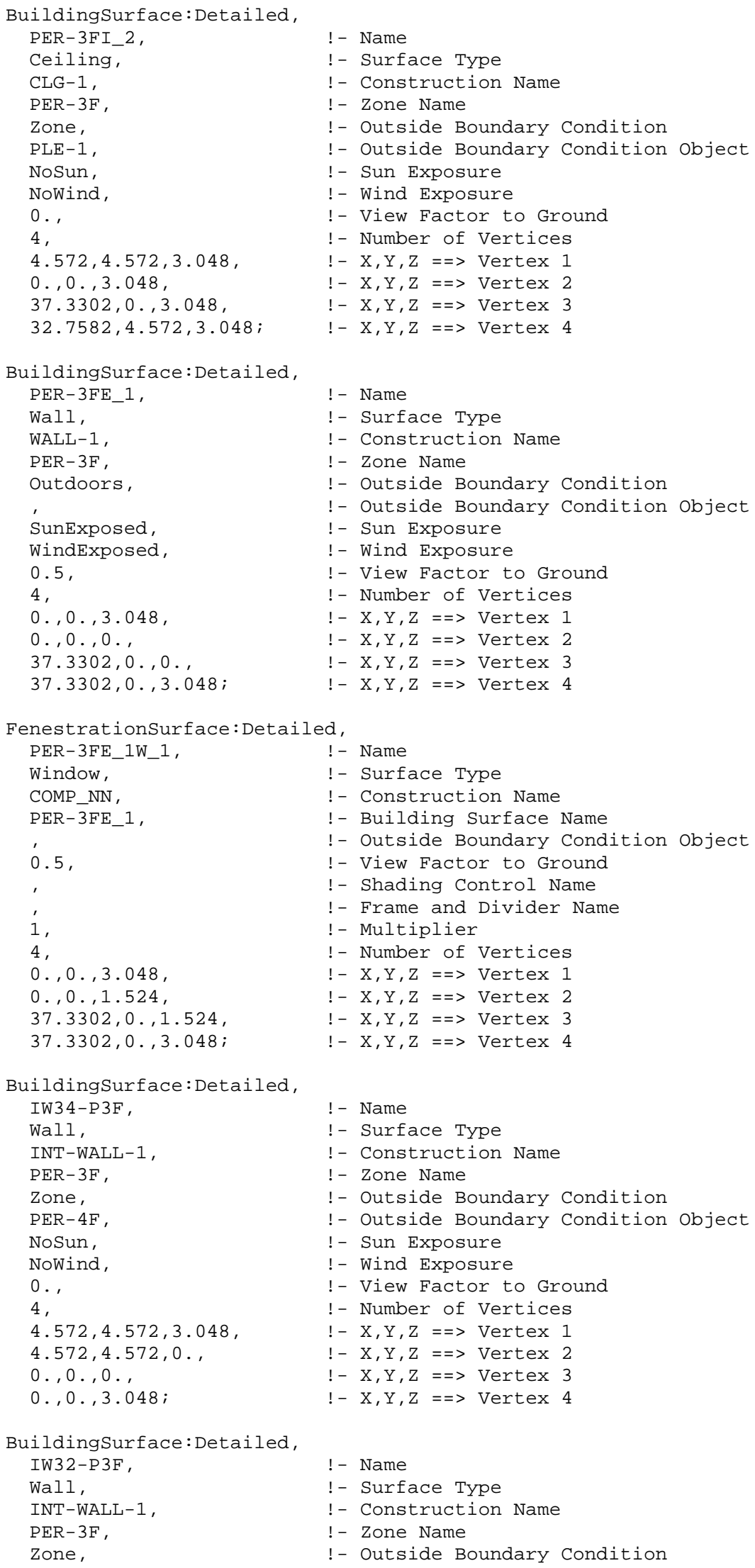




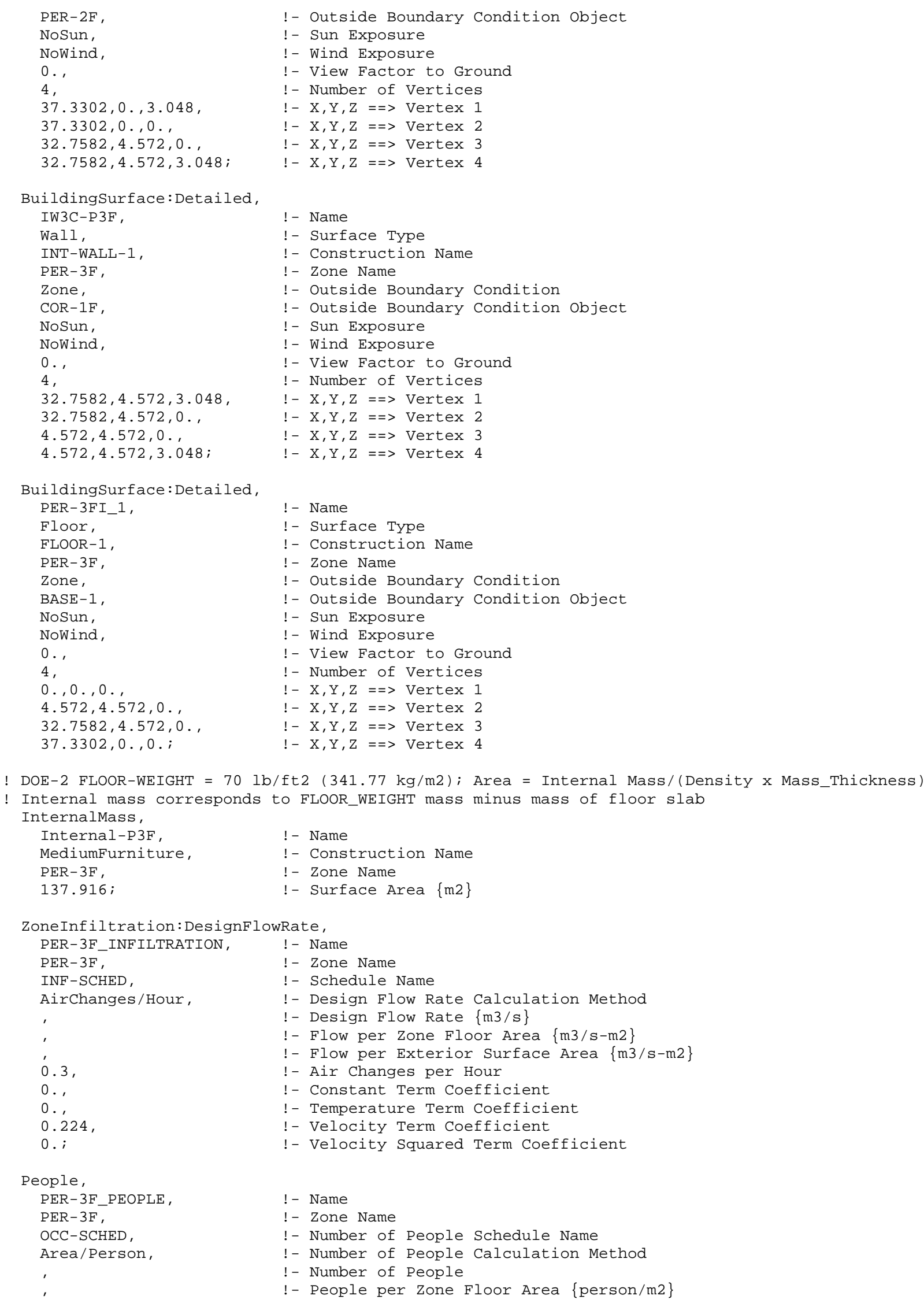




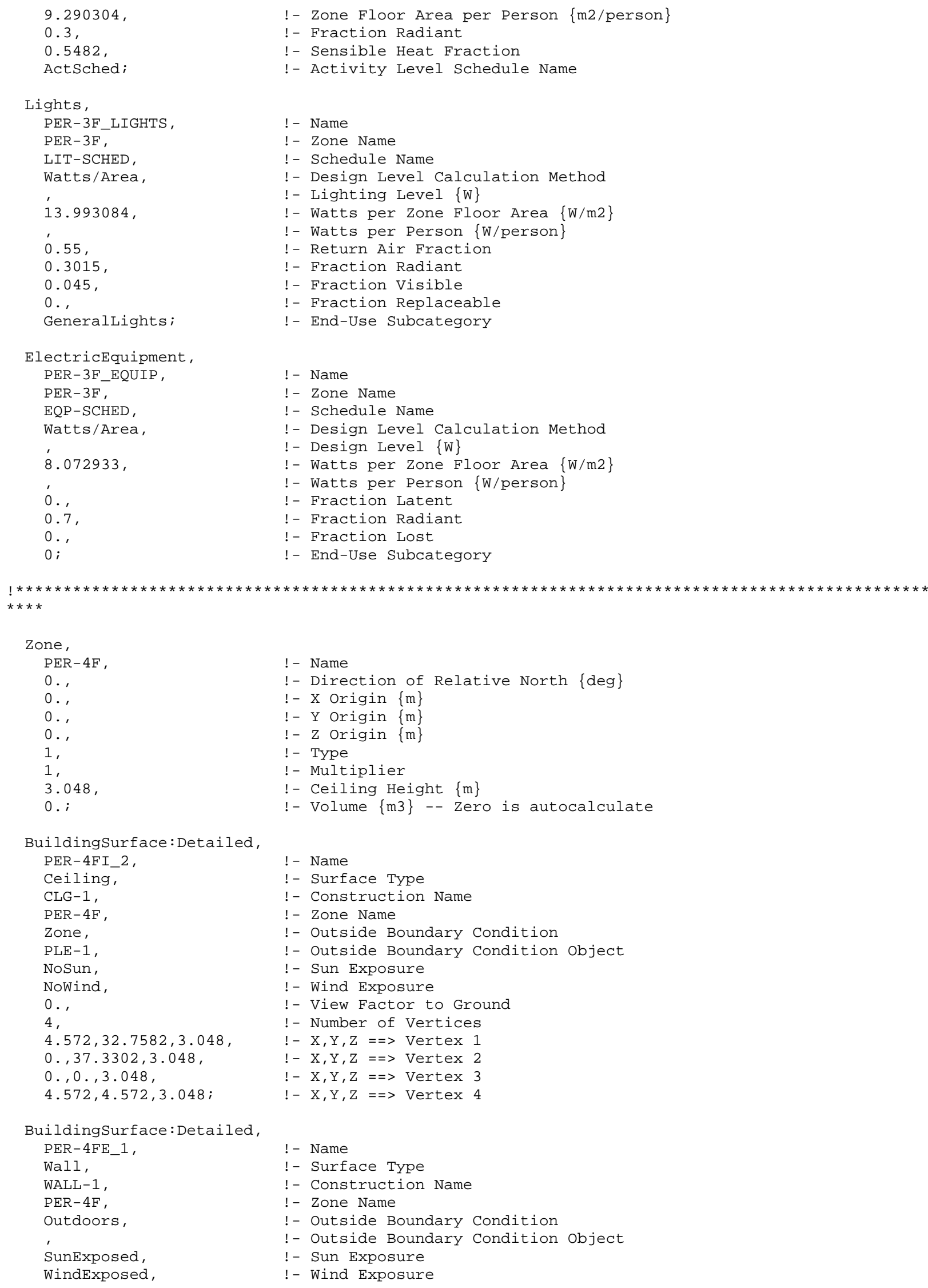

BuildingSurface: Detailed, PER-4FE_1, Wall,

WALL-1, PER-4F, Outdoors, 

0.5
! - View Factor to Ground
4,
! - Number of Vertices
$\odot ., 37.3302,3.048$,
! - X,Y, Z ==> Vertex 1
$0 ., 37.3302,0$.
! - X,Y,Z ==> Vertex 2
$\odot ., 0 ., 0$.
! - X,Y, Z ==> Vertex 3
$\odot ., 0 ., 3.048$;
! - X,Y, Z ==> Vertex 4

Fenestrationsurface: Detailed,

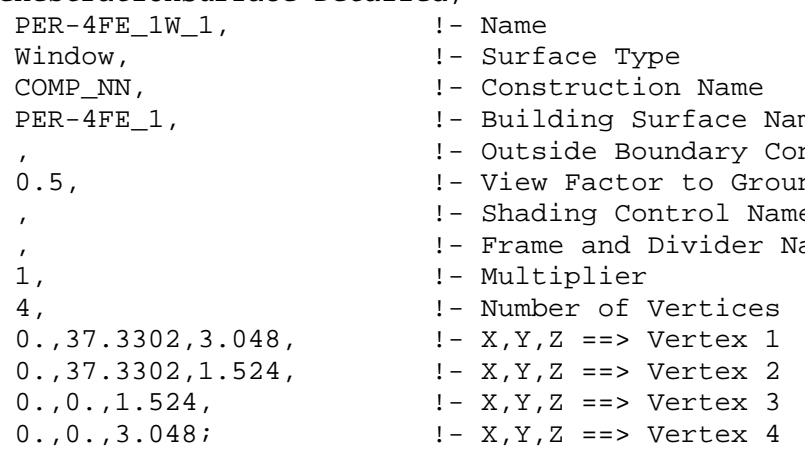

BuildingSurface: Detailed, IW41-P4F,

Wall,

INT -WALL-1,

PER-4F,

Zone,

PER-1F，

NoSun,

Nowind,

0. ,

4 ,

$4.572,32.7582,3.048$,

$4.572,32.7582,0$. ,

$0 ., 37.3302,0$.

$\odot ., 37.3302,3.048$;

! - Name

! - Surface Type

! - Construction Name

! - Zone Name

! - Outside Boundary Condition

! - Outside Boundary Condition object

! - Sun Exposure

! - Wind Exposure

! - View Factor to Ground

! - Number of Vertices

! - X,Y,Z ==> Vertex 1

! - X,Y,Z ==> Vertex 2

! - X,Y,Z ==> Vertex 3

! - X,Y,Z ==> Vertex 4

BuildingSurface: Detailed, IW43-P4F,

Wall,

INT-WALL-1,

PER-4F,

Zone,

PER-3F,

NoSun,

Nowind,

0. ,

4

$0 ., 0 ., 3.048$,

$0 ., 0,0 .$,

$4.572,4.572,0$.

$4.572,4.572,3.048$;

! - Name

! - Surface Type

! - Construction Name

! - Zone Name

! - Outside Boundary Condition

! - Outside Boundary Condition object

! - Sun Exposure

! - Wind Exposure

! - View Factor to Ground

! - Number of Vertices

! - X,Y,Z ==> Vertex 1

! - X,Y,Z ==> Vertex 2

! - X,Y, Z ==> Vertex 3

! - $X, Y, Z==>$ Vertex 4

Buildingsurface: Detailed, IW4C-P4F,

Wall,

INT - WALL - 1,

PER-4F，

Zone,

COR-1F，

NoSun,

Nowind,

$\odot .$,

4 ,

$4.572,4.572,3.048$

$4.572,4.572,0$.

$4.572,32.7582,0$.

! - Name

! - Surface Type

! - Construction Name

! - Zone Name

! - Outside Boundary Condition

! - Outside Boundary Condition Object

! - Sun Exposure

! - Wind Exposure

! - View Factor to Ground

! - Number of Vertices

! - X,Y, Z ==> Vertex 1

! - X,Y,Z ==> Vertex 2

! - X,Y,Z ==> Vertex 3

$4.572,32.7582,3.048$;

! - X,Y, Z ==> Vertex 4 


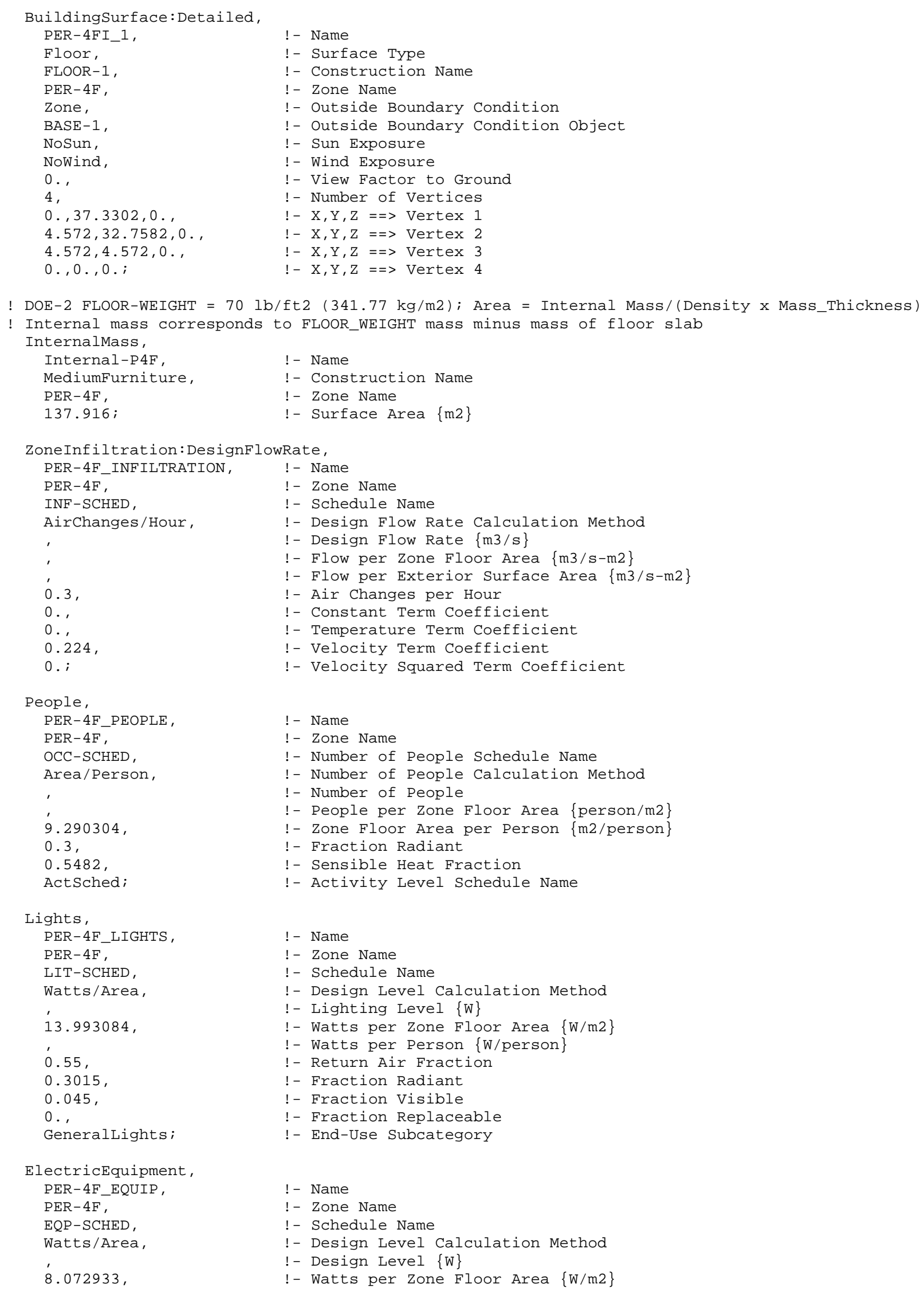




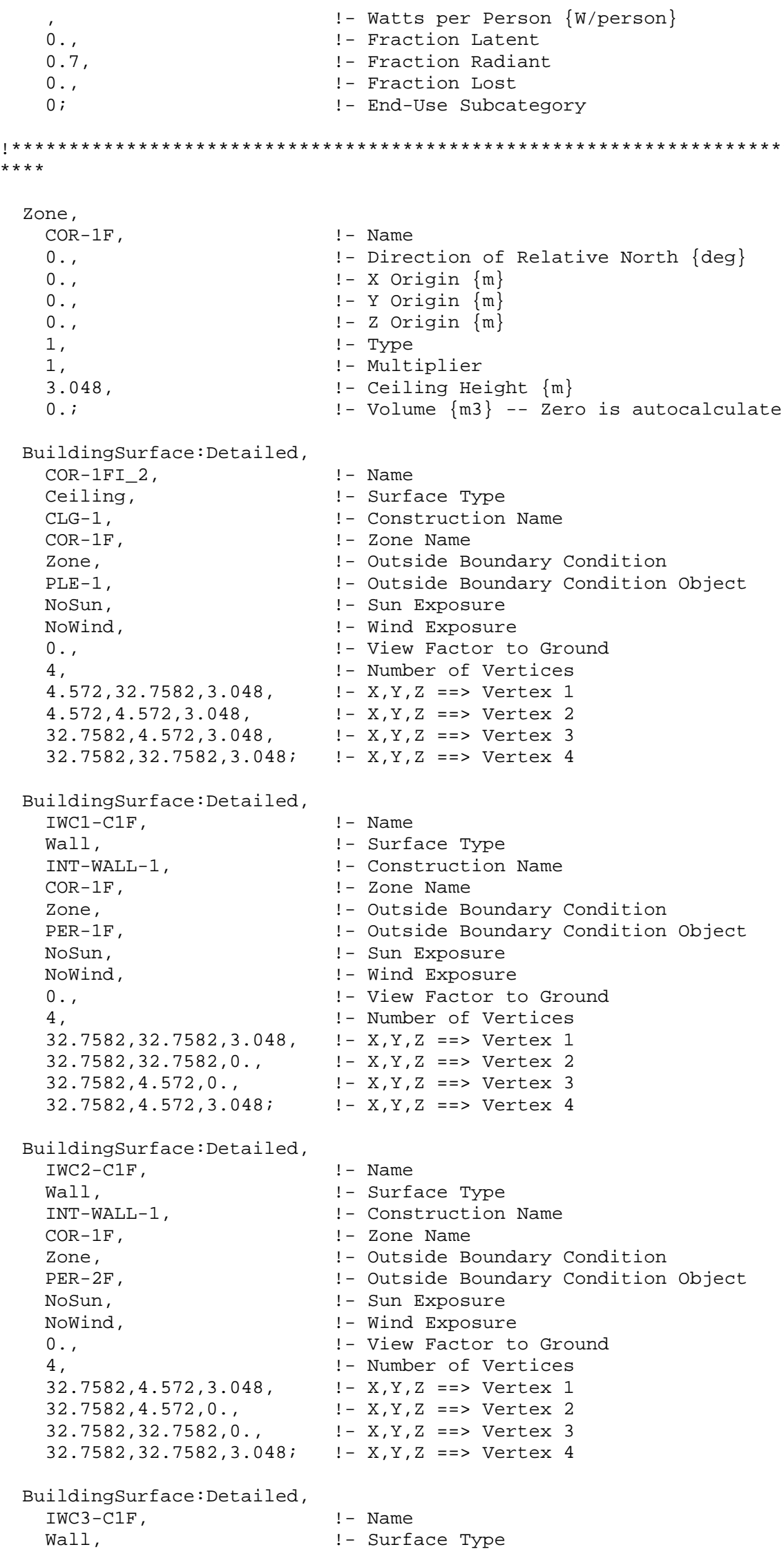

BuildingSurface: Detailed, COR-1FI_2,

Ceiling,

CLG-1,

COR-1F,

Zone,

PLE-1,

NoSun,

Nowind,

$0 .$,

4,

$4.572,32.7582,3.048$,

$4.572,4.572,3.048$

$32.7582,4.572,3.048$,

! - Surface Type

! - Construction Name

! - Zone Name

! - Outside Boundary Condition

! - Outside Boundary Condition Object

! - Sun Exposure

! - Wind Exposure

! - View Factor to Ground

! - Number of Vertices

! - X,Y, Z ==> Vertex 1

! - X,Y,Z ==> Vertex 2

! - X,Y,Z ==> Vertex 3

$32.7582,32.7582,3.048 ; \quad !-X, Y, Z==>$ Vertex 4

BuildingSurface: Detailed, IWC1-C1F

Wall,

INT -WALL-1,

COR-1F，

Zone,

PER-1F，

NoSun,

Nowind,

0. ,

4

$32.7582,32.7582,3.048$

$32.7582,32.7582,0 .$,

$32.7582,4.572,0 .$,

$32.7582,4.572,3.048$;

! - Name

! - Surface Type

! - Construction Name

! - Zone Name

! - Outside Boundary Condition

! - Outside Boundary Condition object

! - Sun Exposure

! - Wind Exposure

! - View Factor to Ground

! - Number of Vertices

! - X,Y, Z ==> Vertex 1

! - X,Y,Z ==> Vertex 2

! - X,Y, Z ==> Vertex 3

! - X,Y, Z ==> Vertex 4

BuildingSurface: Detailed, IWC2-C1F

Wall,

INT - WALL-1,

COR-1F,

Zone,

PER-2F,

NoSun,

Nowind,

$0 .$,

4 ,

$32.7582,4.572,3.048$,

$32.7582,4.572,0$.

$32.7582,32.7582,0$. ,

$32.7582,32.7582,3.048$;

! - Name

! - Surface Type

! - Construction Name

! - Zone Name

! - Outside Boundary Condition

! - Outside Boundary Condition Object

! - Sun Exposure

! - Wind Exposure

! - View Factor to Ground

! - Number of Vertices

! - X,Y,Z ==> Vertex 1

! - X,Y,Z ==> Vertex 2

! - X,Y,Z ==> Vertex 3

! - $X, Y, Z==>$ Vertex 4

BuildingSurface: Detailed, IWC3-C1F

! - Name

Wall,

! - Surface Type 


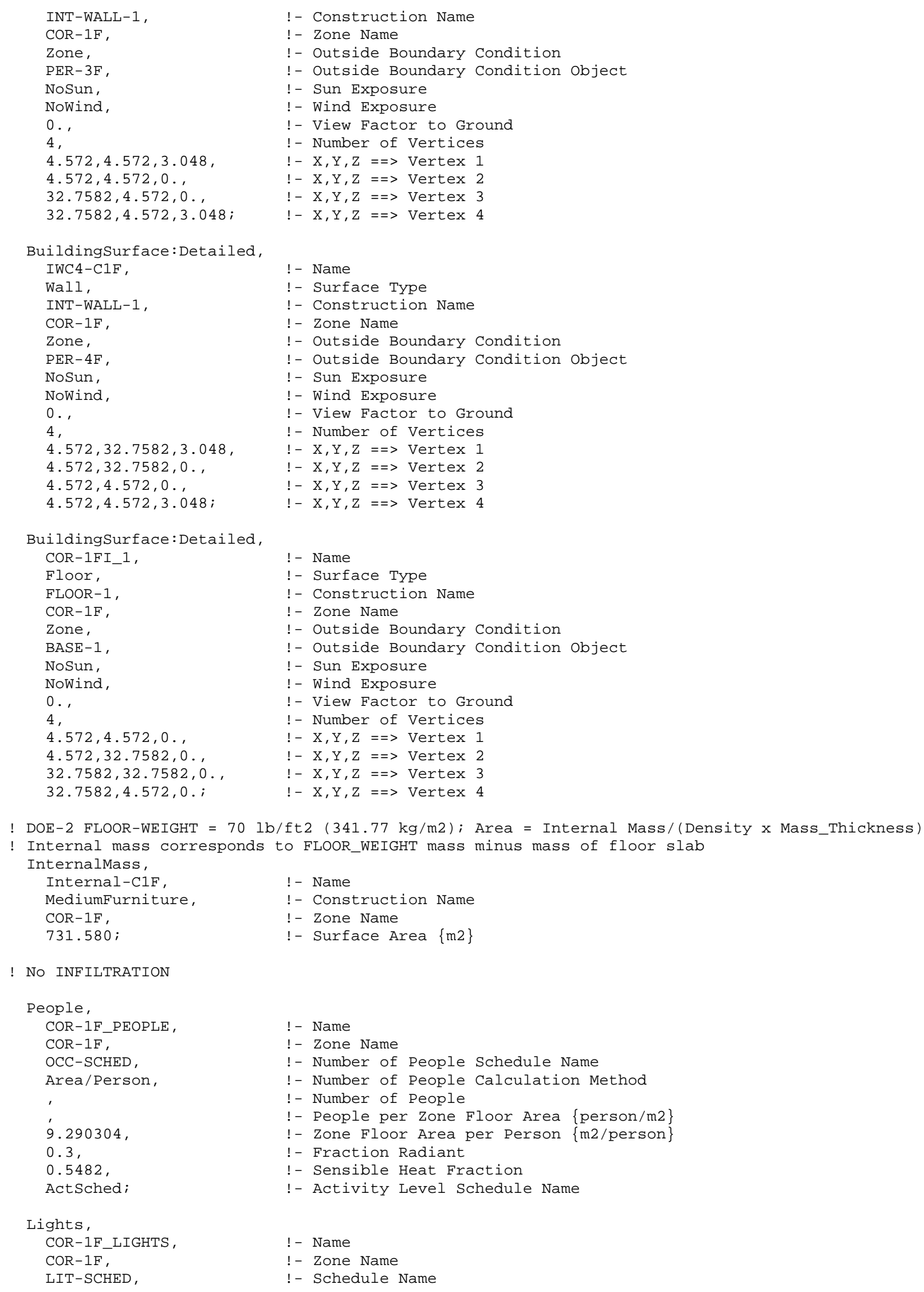




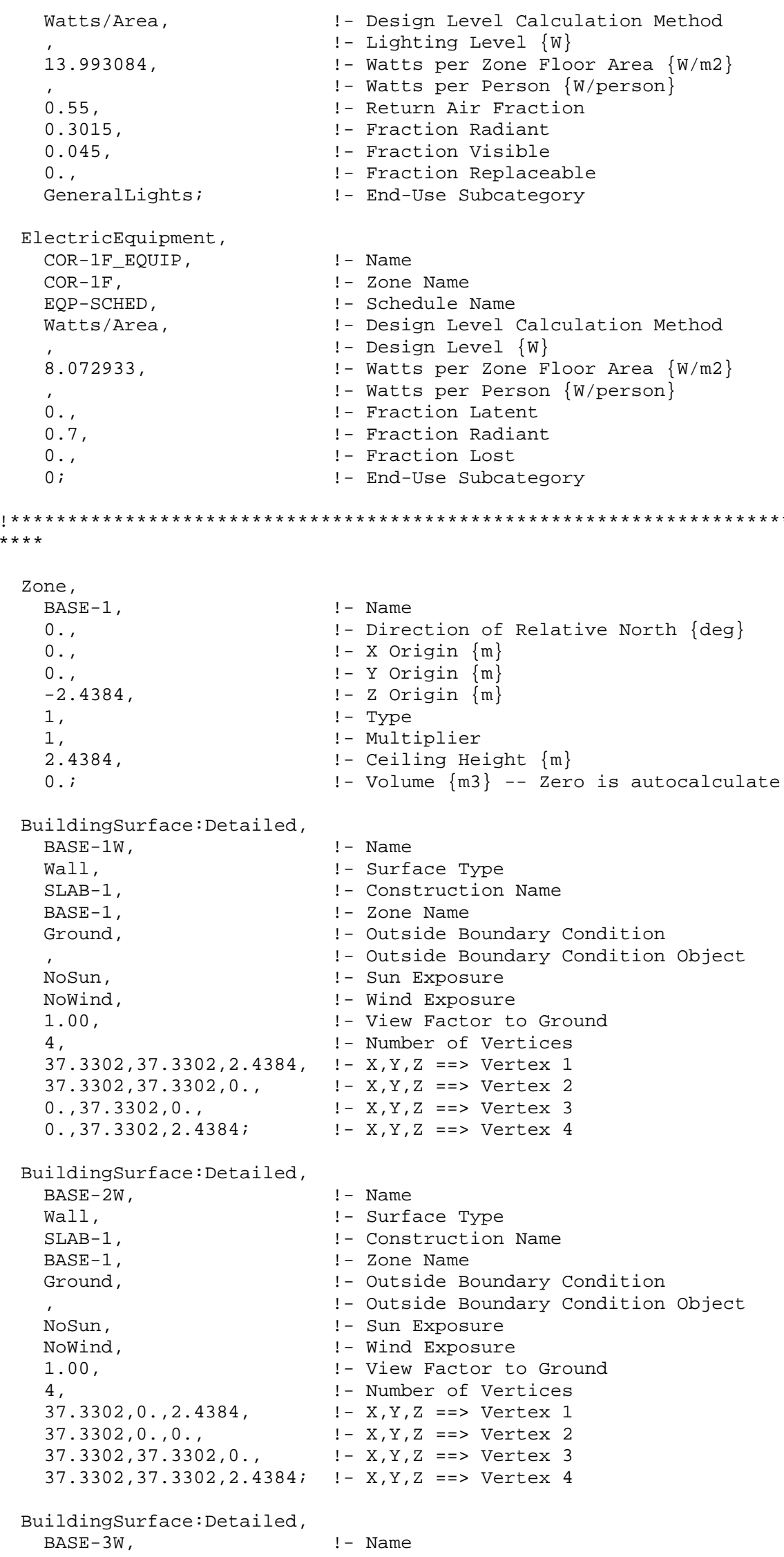

BuildingSurface: Detailed, BASE - $2 \mathrm{~W}$

Wall,

SLAB-1,

BASE-1,

Ground,

NoSun Nowind,

! - Name 


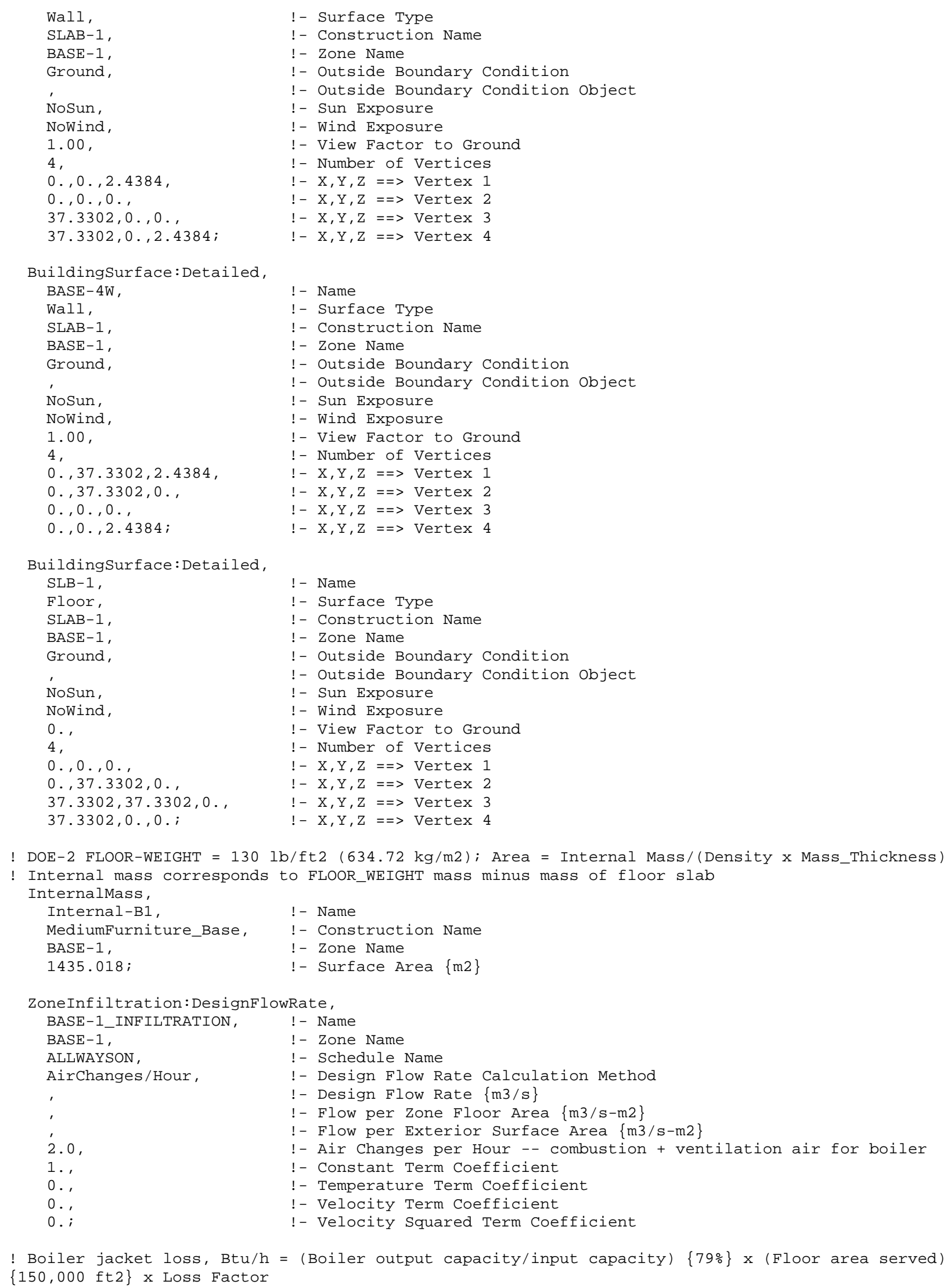

BuildingSurface: Detailed, SLB-1,

Floor,

SLAB-1,

BASE-1,

Ground,

'Nosun,

Nowind,

0. ,

4,

$\odot ., 0_{.}, \Theta_{.}$,

$\odot ., 37.3302,0$.

$37.3302,37.3302,0 .$,

$37.3302,0 ., 0$. ;

! - Name

! - Surface Type

! - Construction Name

! - Zone Name

! - Outside Boundary Condition

! - Outside Boundary Condition object

! - Sun Exposure

! - Wind Exposure

! - View Factor to Ground

! - Number of Vertices

! - X,Y, Z ==> Vertex 1

! - X,Y,Z ==> Vertex 2

! - X,Y,Z ==> Vertex 3

! - X,Y,Z ==> Vertex 4

! DOE-2 FLOOR-WEIGHT $=130 \mathrm{lb} / \mathrm{ft} 2(634.72 \mathrm{~kg} / \mathrm{m} 2) ;$ Area = Internal Mass/(Density $\mathrm{x}$ Mass_Thickness)

! Internal mass corresponds to FLOOR_WEIGHT mass minus mass of floor slab

InternalMass,

Internal-B1, ! - Name

MediumFurniture_Base, !- Construction Name

BASE-1, ! - Zone Name

1435.018; !- Surface Area $\{\mathrm{m} 2\}$

ZoneInfiltration: DesignFlowRate, BASE-1_INFILTRATION, ! - Name

BASE - 1,

! - Zone Name

ALLWAYSON,

! - Schedule Name

AirChanges/Hour, !- Design Flow Rate Calculation Method

,

! - Design Flow Rate $\{\mathrm{m} 3 / \mathrm{s}\}$

,

2. $\odot$,

1.,

- Flow per Zone Floor Area $\{\mathrm{m} 3 / \mathrm{s}-\mathrm{m} 2\}$

! - Flow per Exterior Surface Area \{m3/s-m2\}

! - Air Changes per Hour - - combustion + ventilation air for boiler

! - Constant Term Coefficient

! - Temperature Term Coefficient

! - Velocity Term Coefficient

○. ;

! - Velocity Squared Term Coefficient

! Boiler jacket loss, Btu/h $=$ (Boiler output capacity/input capacity) $\{79 \%\} \times$ (Floor area served) $\{150,000 \mathrm{ft} 2\} \times$ Loss Factor 
! Loss factor of 0.0057 corresponds to (boiler input capacity)/(ft2 floor area) \{nominally 35 $\mathrm{Btu} /(\mathrm{h} \mathrm{ft} 2)\} \times$

! (Jacket loss)/(Boiler output capacity) $\{1.3 \%\}$

otherEquipment

BASE-1_SOURCE,

BASE-1,

! - Name (boiler jacket heat loss into basement)

ALLWAYSON,

! - Zone Name

EquipmentLevel, 19795,

! - Schedule Name

! - Design Level Calculation Method

'.

$0 .$,

! - Design Level $\{\mathrm{W}\}$-- $[67,545 \mathrm{BTU} / \mathrm{h}]$

! - Watts per Zone Floor Area $\{\mathrm{W} / \mathrm{m} 2\}$

0.7

! - Watts per Person \{W/Person\}

! - Fraction Latent

$\odot . ;$

! - Fraction Radiant

! - Fraction Lost

! Use sizing parameters to account for pull-up loads and duct leakage

! (increase oversizing factor if needed to reduce "too many iterations" warnings)

! Global sizing ratio is applied to all zone design loads and supply/return airflow rates

! Zone airflows correspond to cooling design condition

! System airflows correspond to coincident cooling design condition

! Humidity ratio 0.008 corresponds to supply air at 53F, $90 \% \mathrm{RH}$

Sizing:Parameters,

1.0 ,

$1 ;$

Sizing:Zone

PER-1T,

11.667,

32.222,

0.008 ,

0.008 ,

Flow/Person,

$\odot .007079$

0.0 ,

0.0,

0.0 ,

Flow/Zone,

value 0 )

0.61779 ,

,

,

Flow/Zone,

value $\Theta$ )

1.00402,

'

;

Sizing:Zone,

PER-2T,

11.667,

32.222,

0.008 ,

0.008 ,

Flow/Person,

0.007079,

0.0 ,

0.0,

0.0 ,

Flow/Zone,

value $\Theta$ )

1.295,

,

,

'Flow/Zone,

value $\odot$ )

1.00912,
! - Sizing Factor

!- Timesteps in Averaging Window

! - Zone Name

! - Zone Cooling Design Supply Air Temperature 53F $\{\mathrm{C}\}$

!- Zone Heating Design Supply Air Temperature 90F $\{\mathrm{C}\}$

! - Zone Cooling Design Supply Air Humidity Ratio $\{\mathrm{kg}-\mathrm{H} 20 / \mathrm{kg}-\mathrm{air}\}$

!- Zone Heating Design Supply Air Humidity Ratio $\{\mathrm{kg}-\mathrm{H} 20 / \mathrm{kg}-\mathrm{air}\}$

! - Outdoor Air Method

!- Outdoor Air Flow per Person $15 \mathrm{cfm}\{\mathrm{m} 3 / \mathrm{s}\}$

! - Outdoor Air Flow per Zone Floor Area $\{\mathrm{m} 3 / \mathrm{s}-\mathrm{m} 2\}$

!- Outdoor Air Flow per Zone $\{\mathrm{m} 3 / \mathrm{s}\}$

! - Zone Sizing Factor

! - Cooling Design Air Flow Method (DesignDay if autosize with next

! - Cooling Design Air Flow Rate $\{\mathrm{m} 3 / \mathrm{s}\}$

!- Cooling Minimum Air Flow per Zone Floor Area \{m3/s-m2\}

! - Cooling Minimum Air Flow $\{\mathrm{m} 3 / \mathrm{s}\}$

! - Cooling Minimum Air Flow Fraction

! - Heating Design Air Flow Method (DesignDay if autosize with next

! - Heating Design Air Flow Rate $\{\mathrm{m} 3 / \mathrm{s}\}$

! - Heating Maximum Air Flow per Zone Floor Area \{m3/s-m2\}

! - Heating Maximum Air Flow $\{\mathrm{m} 3 / \mathrm{s}\}$

! - Heating Maximum Air Flow Fraction

! - Zone Name

! - Zone Cooling Design Supply Air Temperature 53F $\{\mathrm{C}\}$

! - Zone Heating Design Supply Air Temperature 90F $\{\mathrm{C}\}$

! - Zone Cooling Design Supply Air Humidity Ratio $\{\mathrm{kg}-\mathrm{H} 20 / \mathrm{kg}-\mathrm{air}\}$

!- Zone Heating Design Supply Air Humidity Ratio $\{\mathrm{kg}-\mathrm{H} 20 / \mathrm{kg}-\mathrm{air}\}$

! - Outdoor Air Method

!- Outdoor Air Flow per Person $15 \mathrm{cfm}\{\mathrm{m} 3 / \mathrm{s}\}$

!- Outdoor Air Flow per Zone Floor Area $\{\mathrm{m} 3 / \mathrm{s}-\mathrm{m} 2\}$

! - Outdoor Air Flow per Zone $\{\mathrm{m} 3 / \mathrm{s}\}$

! - Zone Sizing Factor

! - Cooling Design Air Flow Method (DesignDay if autosize with next

! - Cooling Design Air Flow Rate $\{\mathrm{m} 3 / \mathrm{s}\}$

! - Cooling Minimum Air Flow per Zone Floor Area $\{\mathrm{m} 3 / \mathrm{s}-\mathrm{m} 2\}$

! - Cooling Minimum Air Flow $\{\mathrm{m} 3 / \mathrm{s}\}$

! - Cooling Minimum Air Flow Fraction

! - Heating Design Air Flow Method (DesignDay if autosize with next

! - Heating Design Air Flow Rate $\{\mathrm{m} 3 / \mathrm{s}\}$ 


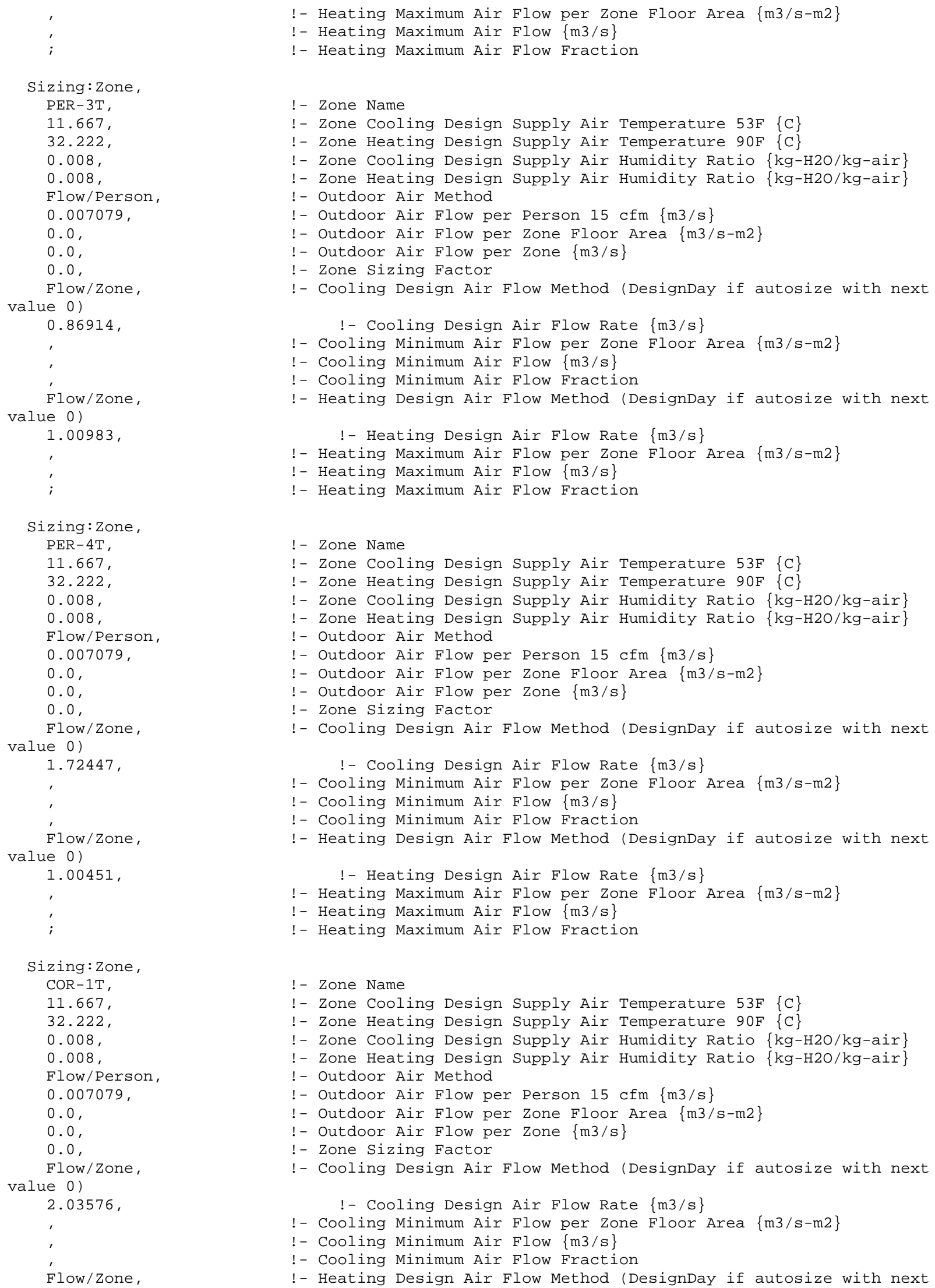
(1)

- Heating Maximum Air Flow per Zone Floor Area $\{\mathrm{m} 3 / \mathrm{s}-\mathrm{m} 2\}$

! - Heating Maximum Air Flow $\{\mathrm{m} 3 / \mathrm{s}\}$

! - Heating Maximum Air Flow Fraction

! - Zone Name

! - Zone Cooling Design Supply Air Temperature 53F $\{\mathrm{C}\}$

! - Zone Heating Design Supply Air Temperature 90F $\{\mathrm{C}\}$

! - Zone Cooling Design Supply Air Humidity Ratio $\{\mathrm{kg}-\mathrm{H} 20 / \mathrm{kg}-\mathrm{air}\}$

! - Zone Heating Design Supply Air Humidity Ratio $\{\mathrm{kg}-\mathrm{H} 20 / \mathrm{kg}-\mathrm{air}\}$

! - Outdoor Air Method

! - Outdoor Air Flow per Person $15 \mathrm{cfm}\{\mathrm{m} 3 / \mathrm{s}\}$

!- Outdoor Air Flow per Zone Floor Area $\{\mathrm{m} 3 / \mathrm{s}-\mathrm{m} 2\}$

!- Outdoor Air Flow per Zone $\{\mathrm{m} 3 / \mathrm{s}\}$

! - Zone Sizing Factor

! - Cooling Design Air Flow Method (DesignDay if autosize with next

! - Cooling Design Air Flow Rate $\{\mathrm{m} 3 / \mathrm{s}\}$

!- Cooling Minimum Air Flow per Zone Floor Area \{m3/s-m2\}

! - Cooling Minimum Air Flow $\{\mathrm{m} 3 / \mathrm{s}\}$

! - Cooling Minimum Air Flow Fraction

!- Heating Design Air Flow Method (DesignDay if autosize with next

! - Heating Design Air Flow Rate $\{\mathrm{m} 3 / \mathrm{s}\}$

! - Heating Maximum Air Flow per Zone Floor Area \{m3/s-m2\}

! - Heating Maximum Air Flow $\{\mathrm{m} 3 / \mathrm{s}\}$

!- Heating Maximum Air Flow Fraction

! - Zone Name

!- Zone Cooling Design Supply Air Temperature 53F $\{\mathrm{C}\}$

! - Zone Heating Design Supply Air Temperature $90 \mathrm{~F}\{\mathrm{C}\}$

! - Zone Cooling Design Supply Air Humidity Ratio $\{\mathrm{kg}-\mathrm{H} 20 / \mathrm{kg}-\mathrm{air}\}$

! - Zone Heating Design Supply Air Humidity Ratio $\{\mathrm{kg}-\mathrm{H} 20 / \mathrm{kg}-\mathrm{air}\}$

! - Outdoor Air Method

! - Outdoor Air Flow per Person $15 \mathrm{cfm}\{\mathrm{m} 3 / \mathrm{s}\}$

!- Outdoor Air Flow per Zone Floor Area $\{\mathrm{m} 3 / \mathrm{s}-\mathrm{m} 2\}$

! - Outdoor Air Flow per Zone $\{\mathrm{m} 3 / \mathrm{s}\}$

! - Zone Sizing Factor

! - Cooling Design Air Flow Method (DesignDay if autosize with next

! - Cooling Design Air Flow Rate $\{\mathrm{m} 3 / \mathrm{s}\}$

! - Cooling Minimum Air Flow per Zone Floor Area $\{\mathrm{m} 3 / \mathrm{s}-\mathrm{m} 2\}$

! - Cooling Minimum Air Flow $\{\mathrm{m} 3 / \mathrm{s}\}$

! - Cooling Minimum Air Flow Fraction

!- Heating Design Air Flow Method (DesignDay if autosize with next

! - Heating Design Air Flow Rate $\{\mathrm{m} 3 / \mathrm{s}\}$

! - Heating Maximum Air Flow per Zone Floor Area \{m3/s-m2\}

! - Heating Maximum Air Flow $\{\mathrm{m} 3 / \mathrm{s}\}$

! - Heating Maximum Air Flow Fraction

! - Zone Name

!- Zone Cooling Design Supply Air Temperature 53F $\{\mathrm{C}\}$

! - Zone Heating Design Supply Air Temperature $9 \odot \mathrm{F}\{\mathrm{C}\}$

! - Zone Cooling Design Supply Air Humidity Ratio $\{\mathrm{kg}-\mathrm{H} 20 / \mathrm{kg}-\mathrm{air}\}$

! - Zone Heating Design Supply Air Humidity Ratio $\{\mathrm{kg}-\mathrm{H} 20 / \mathrm{kg}-\mathrm{air}\}$

! - Outdoor Air Method

!- Outdoor Air Flow per Person $15 \mathrm{cfm}\{\mathrm{m} 3 / \mathrm{s}\}$

! - Outdoor Air Flow per Zone Floor Area $\{\mathrm{m} 3 / \mathrm{s}-\mathrm{m} 2\}$

!- Outdoor Air Flow per Zone $\{\mathrm{m} 3 / \mathrm{s}\}$

! - Zone Sizing Factor

!- Cooling Design Air Flow Method (DesignDay if autosize with next

! - Cooling Design Air Flow Rate $\{\mathrm{m} 3 / \mathrm{s}\}$

!- Cooling Minimum Air Flow per Zone Floor Area \{m3/s-m2\}

! - Cooling Minimum Air Flow $\{\mathrm{m} 3 / \mathrm{s}\}$

! - Cooling Minimum Air Flow Fraction

! - Heating Design Air Flow Method (DesignDay if autosize with next 


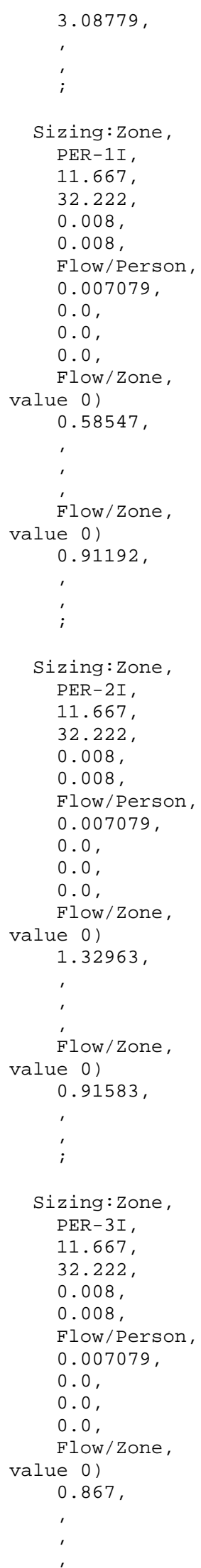

!- Heating Design Air Flow Rate $\{\mathrm{m} 3 / \mathrm{s}\}$

! - Heating Maximum Air Flow per Zone Floor Area \{m3/s-m2\}

! - Heating Maximum Air Flow $\{\mathrm{m} 3 / \mathrm{s}\}$

!- Heating Maximum Air Flow Fraction

! - Zone Name

! - Zone Cooling Design Supply Air Temperature 53F $\{\mathrm{C}\}$

! - Zone Heating Design Supply Air Temperature 90F $\{\mathrm{C}\}$

! - Zone Cooling Design Supply Air Humidity Ratio $\{\mathrm{kg}-\mathrm{H} 20 / \mathrm{kg}-\mathrm{air}\}$

! - Zone Heating Design Supply Air Humidity Ratio $\{\mathrm{kg}-\mathrm{H} 20 / \mathrm{kg}-\mathrm{air}\}$

! - Outdoor Air Method

!- Outdoor Air Flow per Person $15 \mathrm{cfm}\{\mathrm{m} 3 / \mathrm{s}\}$

! - Outdoor Air Flow per Zone Floor Area $\{\mathrm{m} 3 / \mathrm{s}-\mathrm{m} 2\}$

! - Outdoor Air Flow per Zone $\{\mathrm{m} 3 / \mathrm{s}\}$

! - Zone Sizing Factor

!- Cooling Design Air Flow Method (DesignDay if autosize with next !- Cooling Design Air Flow Rate $\{\mathrm{m} 3 / \mathrm{s}\}$

! - Cooling Minimum Air Flow per Zone Floor Area \{m3/s-m2\}

! - Cooling Minimum Air Flow $\{\mathrm{m} 3 / \mathrm{s}\}$

! - Cooling Minimum Air Flow Fraction

!- Heating Design Air Flow Method (DesignDay if autosize with next ! - Heating Design Air Flow Rate $\{\mathrm{m} 3 / \mathrm{s}\}$

!- Heating Maximum Air Flow per Zone Floor Area \{m3/s-m2\}

! - Heating Maximum Air Flow $\{\mathrm{m} 3 / \mathrm{s}\}$

! - Heating Maximum Air Flow Fraction

! - Zone Name

! - Zone Cooling Design Supply Air Temperature 53F $\{\mathrm{C}\}$

! - Zone Heating Design Supply Air Temperature 90F $\{\mathrm{C}\}$

! - Zone Cooling Design Supply Air Humidity Ratio $\{\mathrm{kg}-\mathrm{H} 20 / \mathrm{kg}-\mathrm{air}\}$

!- Zone Heating Design Supply Air Humidity Ratio $\{\mathrm{kg}-\mathrm{H} 20 / \mathrm{kg}-\mathrm{air}\}$

! - Outdoor Air Method

!- Outdoor Air Flow per Person $15 \mathrm{cfm}\{\mathrm{m} 3 / \mathrm{s}\}$

!- Outdoor Air Flow per Zone Floor Area $\{\mathrm{m} 3 / \mathrm{s}-\mathrm{m} 2\}$

! - Outdoor Air Flow per Zone $\{\mathrm{m} 3 / \mathrm{s}\}$

! - Zone Sizing Factor

! - Cooling Design Air Flow Method (DesignDay if autosize with next ! - Cooling Design Air Flow Rate $\{\mathrm{m} 3 / \mathrm{s}\}$

!- Cooling Minimum Air Flow per Zone Floor Area \{m3/s-m2\}

! - Cooling Minimum Air Flow $\{\mathrm{m} 3 / \mathrm{s}\}$

! - Cooling Minimum Air Flow Fraction

! - Heating Design Air Flow Method (DesignDay if autosize with next

! - Heating Design Air Flow Rate $\{\mathrm{m} 3 / \mathrm{s}\}$

!- Heating Maximum Air Flow per Zone Floor Area $\{\mathrm{m} 3 / \mathrm{s}-\mathrm{m} 2\}$

! - Heating Maximum Air Flow $\{\mathrm{m} 3 / \mathrm{s}\}$

! - Heating Maximum Air Flow Fraction

! - Zone Name

! - Zone Cooling Design Supply Air Temperature 53F $\{\mathrm{C}\}$

! - Zone Heating Design Supply Air Temperature 90F $\{\mathrm{C}\}$

! - Zone Cooling Design Supply Air Humidity Ratio $\{\mathrm{kg}-\mathrm{H} 20 / \mathrm{kg}-\mathrm{air}\}$

!- Zone Heating Design Supply Air Humidity Ratio $\{\mathrm{kg}-\mathrm{H} 20 / \mathrm{kg}-\mathrm{air}\}$

! - Outdoor Air Method

! - Outdoor Air Flow per Person $15 \mathrm{cfm}\{\mathrm{m} 3 / \mathrm{s}\}$

! - Outdoor Air Flow per Zone Floor Area $\{\mathrm{m} 3 / \mathrm{s}-\mathrm{m} 2\}$

! - Outdoor Air Flow per Zone $\{\mathrm{m} 3 / \mathrm{s}\}$

! - Zone Sizing Factor

! - Cooling Design Air Flow Method (DesignDay if autosize with next ! - Cooling Design Air Flow Rate $\{\mathrm{m} 3 / \mathrm{s}\}$

! - Cooling Minimum Air Flow per Zone Floor Area \{m3/s-m2\}

! - Cooling Minimum Air Flow $\{\mathrm{m} 3 / \mathrm{s}\}$

! - Cooling Minimum Air Flow Fraction 
value 0 )

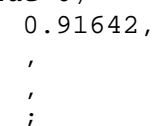

!- Heating Design Air Flow Method (DesignDay if autosize with next

$$
\text { ! - Heating Design Air Flow Rate }\{\mathrm{m} 3 / \mathrm{s}\}
$$

! - Heating Maximum Air Flow per Zone Floor Area \{m3/s-m2\}

! - Heating Maximum Air Flow $\{\mathrm{m} 3 / \mathrm{s}\}$

!- Heating Maximum Air Flow Fraction

! - Zone Name

! - Zone Cooling Design Supply Air Temperature 53F $\{\mathrm{C}\}$

! - Zone Heating Design Supply Air Temperature 90F $\{\mathrm{C}\}$

! - Zone Cooling Design Supply Air Humidity Ratio $\{\mathrm{kg}-\mathrm{H} 20 / \mathrm{kg}-\mathrm{air}\}$

! - Zone Heating Design Supply Air Humidity Ratio $\{\mathrm{kg}-\mathrm{H} 20 / \mathrm{kg}-\mathrm{air}\}$

! - Outdoor Air Method

!- Outdoor Air Flow per Person $15 \mathrm{cfm}\{\mathrm{m} 3 / \mathrm{s}\}$

!- Outdoor Air Flow per Zone Floor Area $\{\mathrm{m} 3 / \mathrm{s}-\mathrm{m} 2\}$

! - Outdoor Air Flow per Zone $\{\mathrm{m} 3 / \mathrm{s}\}$

! - Zone Sizing Factor

! - Cooling Design Air Flow Method (DesignDay if autosize with next ! - Cooling Design Air Flow Rate $\{\mathrm{m} 3 / \mathrm{s}\}$

!- Cooling Minimum Air Flow per Zone Floor Area \{m3/s-m2\}

! - Cooling Minimum Air Flow $\{\mathrm{m} 3 / \mathrm{s}\}$

! - Cooling Minimum Air Flow Fraction

! - Heating Design Air Flow Method (DesignDay if autosize with next ! - Heating Design Air Flow Rate $\{\mathrm{m} 3 / \mathrm{s}\}$

! - Heating Maximum Air Flow per Zone Floor Area \{m3/s-m2\}

! - Heating Maximum Air Flow $\{\mathrm{m} 3 / \mathrm{s}\}$

! - Heating Maximum Air Flow Fraction

! - Zone Name

! - Zone Cooling Design Supply Air Temperature 53F $\{\mathrm{C}\}$

! - Zone Heating Design Supply Air Temperature 90F $\{\mathrm{C}\}$

! - Zone Cooling Design Supply Air Humidity Ratio $\{\mathrm{kg}-\mathrm{H} 20 / \mathrm{kg}-\mathrm{air}\}$

!- Zone Heating Design Supply Air Humidity Ratio $\{\mathrm{kg}-\mathrm{H} 20 / \mathrm{kg}-\mathrm{air}\}$

! - Outdoor Air Method

! - Outdoor Air Flow per Person $15 \mathrm{cfm}\{\mathrm{m} 3 / \mathrm{s}\}$

!- Outdoor Air Flow per Zone Floor Area $\{\mathrm{m} 3 / \mathrm{s}-\mathrm{m} 2\}$

! - Outdoor Air Flow per Zone $\{\mathrm{m} 3 / \mathrm{s}\}$

! - Zone Sizing Factor

! - Cooling Design Air Flow Method (DesignDay if autosize with next ! - Cooling Design Air Flow Rate $\{\mathrm{m} 3 / \mathrm{s}\}$

! - Cooling Minimum Air Flow per Zone Floor Area \{m3/s-m2\}

! - Cooling Minimum Air Flow $\{\mathrm{m} 3 / \mathrm{s}\}$

! - Cooling Minimum Air Flow Fraction

! - Heating Design Air Flow Method (DesignDay if autosize with next

! - Heating Design Air Flow Rate $\{\mathrm{m} 3 / \mathrm{s}\}$

! - Heating Maximum Air Flow per Zone Floor Area $\{\mathrm{m} 3 / \mathrm{s}-\mathrm{m} 2\}$

! - Heating Maximum Air Flow $\{\mathrm{m} 3 / \mathrm{s}\}$

! - Heating Maximum Air Flow Fraction

! - Zone Name

! - Zone Cooling Design Supply Air Temperature 53F $\{\mathrm{C}\}$

! - Zone Heating Design Supply Air Temperature 90F $\{\mathrm{C}\}$

! - Zone Cooling Design Supply Air Humidity Ratio $\{\mathrm{kg}-\mathrm{H} 20 / \mathrm{kg}-\mathrm{air}\}$

! - Zone Heating Design Supply Air Humidity Ratio $\{\mathrm{kg}-\mathrm{H} 20 / \mathrm{kg}-\mathrm{air}\}$

! - Outdoor Air Method

! - Outdoor Air Flow per Person $15 \mathrm{cfm}\{\mathrm{m} 3 / \mathrm{s}\}$

!- Outdoor Air Flow per Zone Floor Area $\{\mathrm{m} 3 / \mathrm{s}-\mathrm{m} 2\}$

! - Outdoor Air Flow per Zone $\{\mathrm{m} 3 / \mathrm{s}\}$

! - Zone Sizing Factor

! - Cooling Design Air Flow Method (DesignDay if autosize with next ! - Cooling Design Air Flow Rate $\{\mathrm{m} 3 / \mathrm{s}\}$

! - Cooling Minimum Air Flow per Zone Floor Area $\{\mathrm{m} 3 / \mathrm{s}-\mathrm{m} 2\}$

! - Cooling Minimum Air Flow $\{\mathrm{m} 3 / \mathrm{s}\}$ 


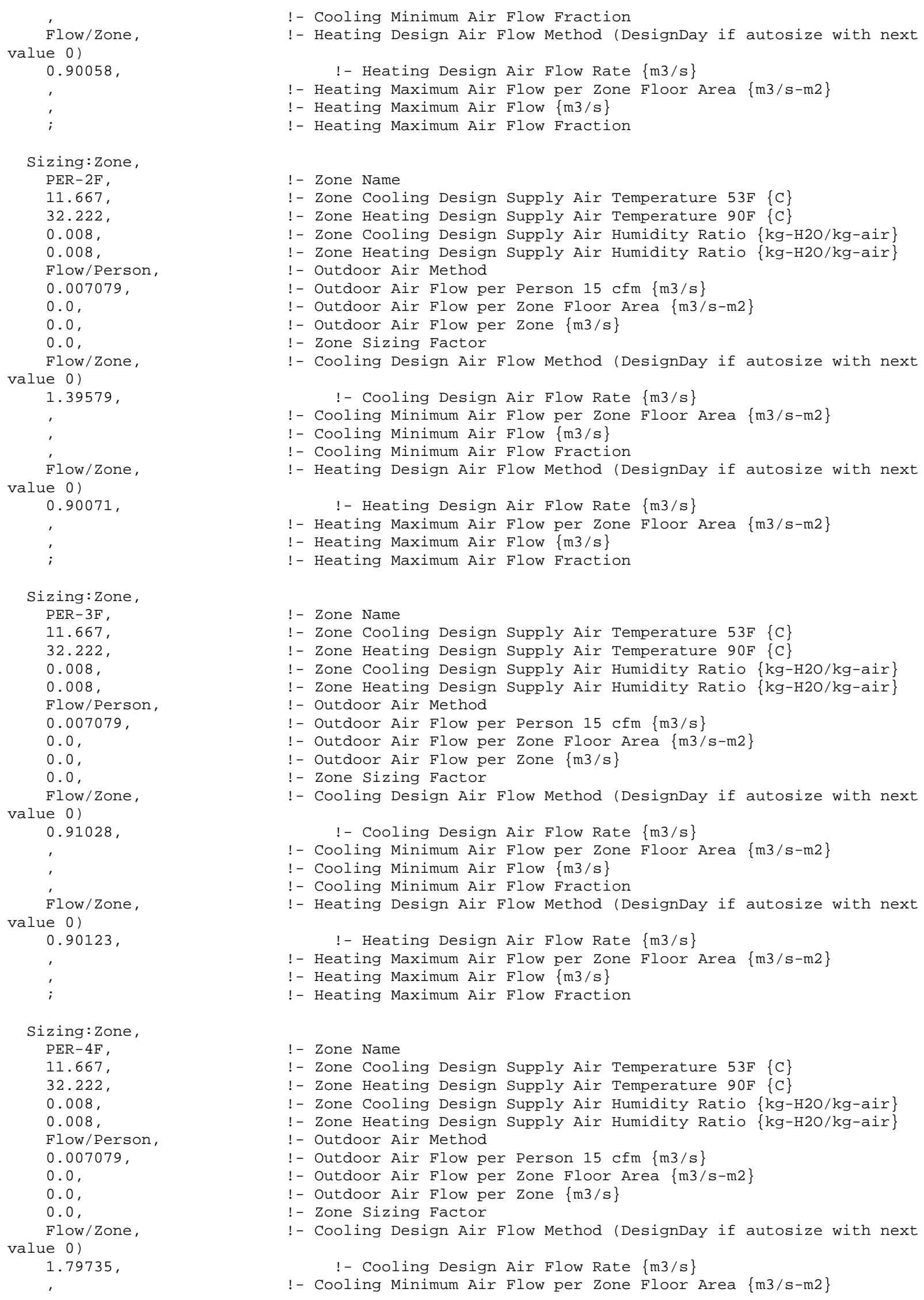

! - Cooling Minimum Air Flow Fraction

!- Heating Design Air Flow Method (DesignDay if autosize with next

! - Heating Design Air Flow Rate $\{\mathrm{m} 3 / \mathrm{s}\}$

! - Heating Maximum Air Flow per Zone Floor Area \{m3/s-m2\}

! - Heating Maximum Air Flow $\{\mathrm{m} 3 / \mathrm{s}\}$

!- Heating Maximum Air Flow Fraction

! - Zone Name

!- Zone Cooling Design Supply Air Temperature 53F $\{\mathrm{C}\}$

! - Zone Heating Design Supply Air Temperature 90F $\{C\}$

! - Zone Cooling Design Supply Air Humidity Ratio $\{\mathrm{kg}-\mathrm{H} 20 / \mathrm{kg}-\mathrm{air}\}$

! - Zone Heating Design Supply Air Humidity Ratio $\{\mathrm{kg}-\mathrm{H} 20 / \mathrm{kg}-\mathrm{air}\}$

! - Outdoor Air Method

! - Outdoor Air Flow per Person $15 \mathrm{cfm}\{\mathrm{m} 3 / \mathrm{s}\}$

! - Outdoor Air Flow per Zone Floor Area $\{\mathrm{m} 3 / \mathrm{s}-\mathrm{m} 2\}$

! - Outdoor Air Flow per Zone $\{\mathrm{m} 3 / \mathrm{s}\}$

! - Zone Sizing Factor

!- Cooling Design Air Flow Method (DesignDay if autosize with next

! - Cooling Design Air Flow Rate $\{\mathrm{m} 3 / \mathrm{s}\}$

! - Cooling Minimum Air Flow per Zone Floor Area $\{\mathrm{m} 3 / \mathrm{s}-\mathrm{m} 2\}$

! - Cooling Minimum Air Flow $\{\mathrm{m} 3 / \mathrm{s}\}$

! - Cooling Minimum Air Flow Fraction

!- Heating Design Air Flow Method (DesignDay if autosize with next

! - Heating Design Air Flow Rate $\{\mathrm{m} 3 / \mathrm{s}\}$

! - Heating Maximum Air Flow per Zone Floor Area \{m3/s-m2\}

! - Heating Maximum Air Flow $\{\mathrm{m} 3 / \mathrm{s}\}$

!- Heating Maximum Air Flow Fraction

! - Zone Name

! - Zone Cooling Design Supply Air Temperature 53F $\{\mathrm{C}\}$

! - Zone Heating Design Supply Air Temperature 90F $\{\mathrm{C}\}$

! - Zone Cooling Design Supply Air Humidity Ratio $\{\mathrm{kg}-\mathrm{H} 20 / \mathrm{kg}-\mathrm{air}\}$

! - Zone Heating Design Supply Air Humidity Ratio $\{\mathrm{kg}-\mathrm{H} 20 / \mathrm{kg}-\mathrm{air}\}$

! - Outdoor Air Method

! - Outdoor Air Flow per Person $15 \mathrm{cfm}\{\mathrm{m} 3 / \mathrm{s}\}$

! - Outdoor Air Flow per Zone Floor Area $\{\mathrm{m} 3 / \mathrm{s}-\mathrm{m} 2\}$

! - Outdoor Air Flow per Zone $\{\mathrm{m} 3 / \mathrm{s}\}$

! - Zone Sizing Factor

!- Cooling Design Air Flow Method (DesignDay if autosize with next

! - Cooling Design Air Flow Rate $\{\mathrm{m} 3 / \mathrm{s}\}$

! - Cooling Minimum Air Flow per Zone Floor Area $\{\mathrm{m} 3 / \mathrm{s}-\mathrm{m} 2\}$

! - Cooling Minimum Air Flow $\{\mathrm{m} 3 / \mathrm{s}\}$

! - Cooling Minimum Air Flow Fraction

! - Heating Design Air Flow Method (DesignDay if autosize with next

! - Heating Design Air Flow Rate $\{\mathrm{m} 3 / \mathrm{s}\}$

! - Heating Maximum Air Flow per Zone Floor Area \{m3/s-m2\}

! - Heating Maximum Air Flow $\{\mathrm{m} 3 / \mathrm{s}\}$

! - Heating Maximum Air Flow Fraction

! - Zone Name

!- Zone Cooling Design Supply Air Temperature 53F $\{\mathrm{C}\}$

! - Zone Heating Design Supply Air Temperature 90F $\{\mathrm{C}\}$

! - Zone Cooling Design Supply Air Humidity Ratio $\{\mathrm{kg}-\mathrm{H} 20 / \mathrm{kg}-\mathrm{air}\}$

! - Zone Heating Design Supply Air Humidity Ratio $\{\mathrm{kg}-\mathrm{H} 20 / \mathrm{kg}-\mathrm{air}\}$

! - Outdoor Air Method

!- Outdoor Air Flow per Person $15 \mathrm{cfm}\{\mathrm{m} 3 / \mathrm{s}\}$

! - Outdoor Air Flow per Zone Floor Area $\{\mathrm{m} 3 / \mathrm{s}-\mathrm{m} 2\}$

! - Outdoor Air Flow per Zone $\{\mathrm{m} 3 / \mathrm{s}\}$

! - Zone Sizing Factor

!- Cooling Design Air Flow Method (DesignDay if autosize with next

!- Cooling Design Air Flow Rate $\{\mathrm{m} 3 / \mathrm{s}\}$

! - Cooling Minimum Air Flow per Zone Floor Area \{m3/s-m2\} 


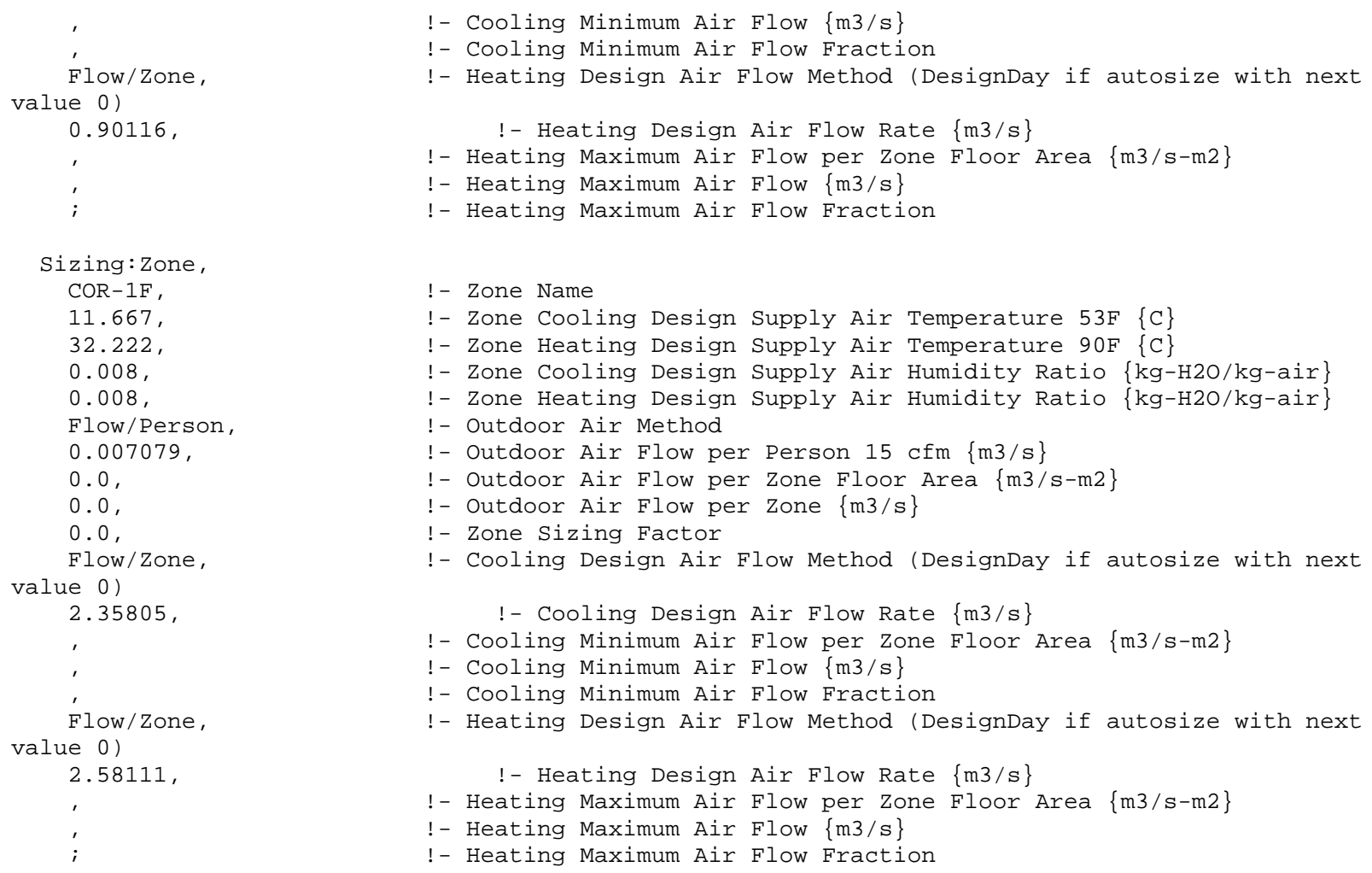

! Each VAV box damper is held at $40 \%$ of box design flow when there is a zone heating demand, ! so minimum SYSTEM air flow ratio is set to this minimum flow ratio.

! If the zone VAV dampers were reverse action and could open to full flow to meet heating demand, ! this ratio should be set to 1 .

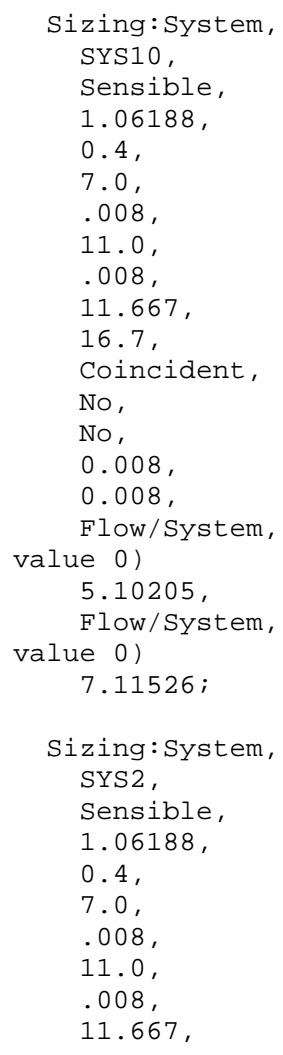




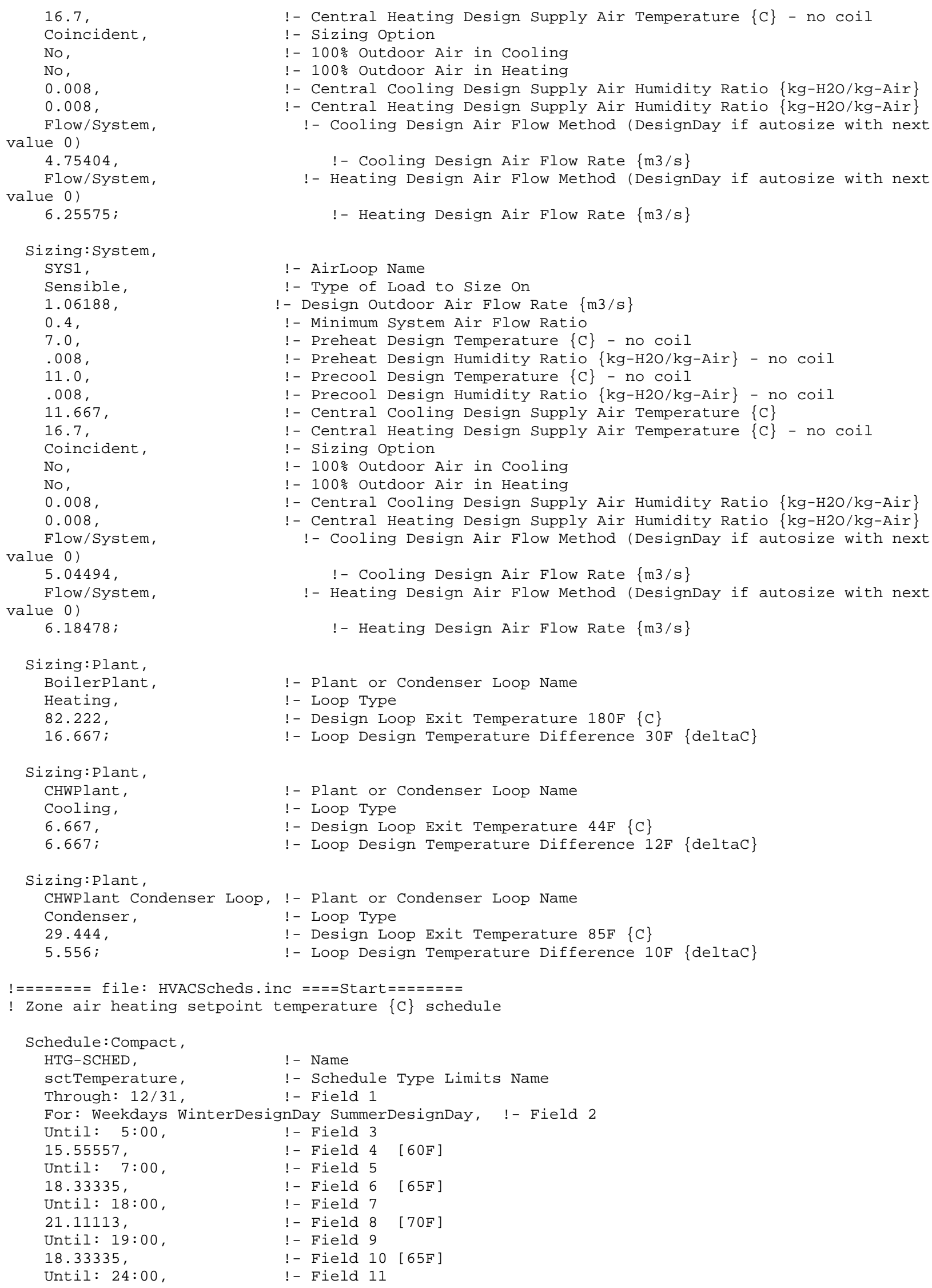




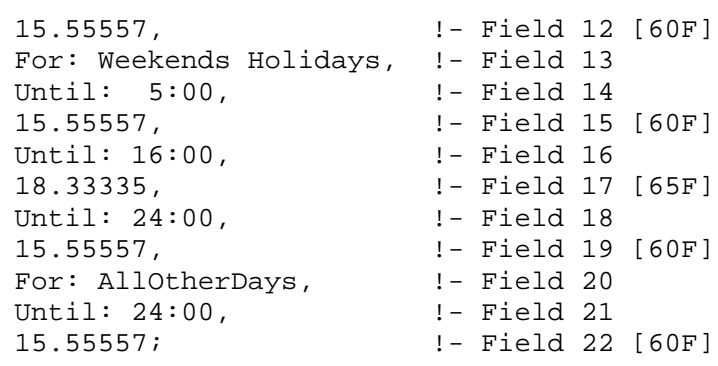

! Zone air cooling setpoint temperature $\{\mathrm{C}\}$ schedule

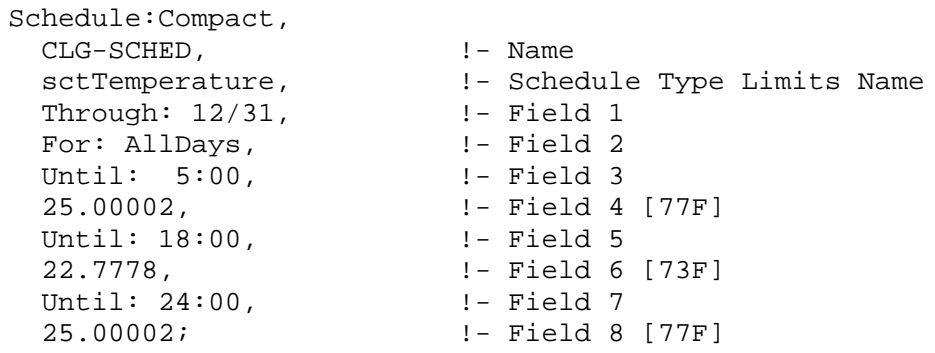

!Valid Control Types are:

! $\odot$ - Uncontrolled (No specification or default)

! 1 - Single Heating Setpoint

! 2 - Single Cooling SetPoint

! 3 - Single Heating/Cooling Setpoint

! 4 - Dual Setpoint (Heating and Cooling) with deadband

Schedule: Compact, Zone-Control-Type-Sched, !- Name

Control TypeHV, !- Schedule Type Limits Name

Through: 12/31, !- Field 1

For: AllDays, !- Field 2

Until: 24:00, !- Field 3

4; !- Field 4

! MinOA schedule same as FAN-SCHED

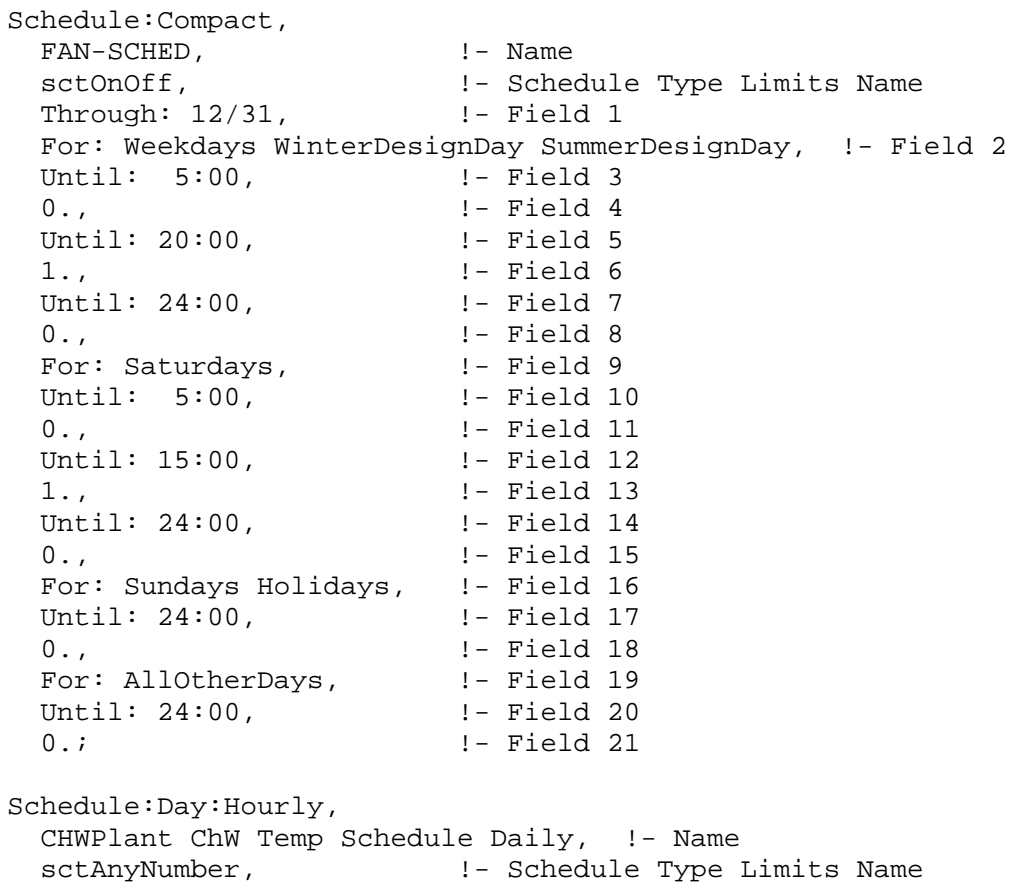




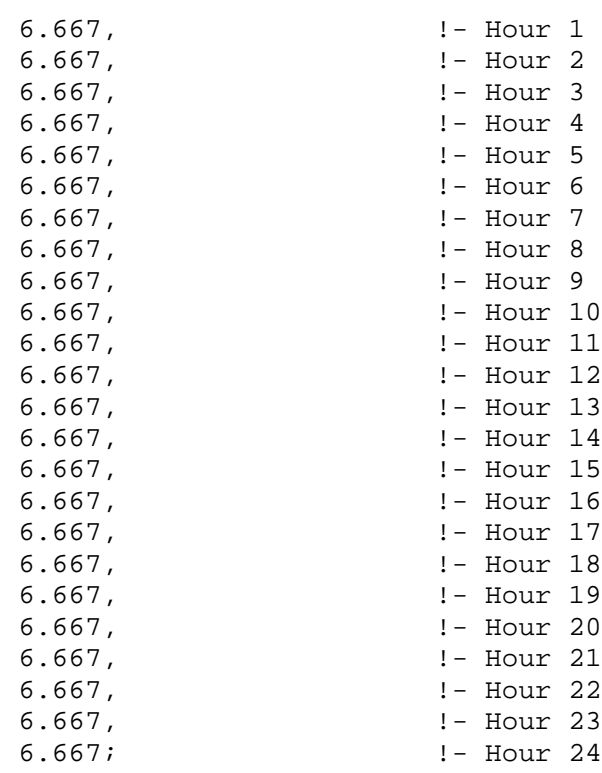

Schedule:Week: Daily,

CHWPlant ChW Temp Schedule Weekly, !- Name

CHWPlant ChW Temp Schedule Daily, ! - Sunday Schedule:Day Name

CHWPlant ChW Temp Schedule Daily, !- Monday Schedule:Day Name

CHWPlant ChW Temp Schedule Daily, !- Tuesday Schedule:Day Name

CHWPlant ChW Temp Schedule Daily, !- Wednesday Schedule:Day Name

CHWPlant ChW Temp Schedule Daily, !- Thursday Schedule:Day Name

CHWPlant ChW Temp Schedule Daily, ! - Friday Schedule:Day Name

CHWPlant ChW Temp Schedule Daily, !- Saturday Schedule:Day Name

CHWPlant ChW Temp Schedule Daily, !- Holiday Schedule:Day Name

CHWPlant ChW Temp Schedule Daily, !- SummerDesignDay Schedule:Day Name

CHWPlant ChW Temp Schedule Daily, !- WinterDesignDay Schedule:Day Name

CHWPlant ChW Temp Schedule Daily, !- CustomDay1 Schedule:Day Name

CHWPlant ChW Temp Schedule Daily; !- CustomDay2 Schedule:Day Name

Schedule:Year

CHWPlant ChW Temp Schedule, !- Name

sctAnyNumber, !- Schedule Type Limits Name

CHWPlant ChW Temp Schedule Weekly, !- Schedule:Week Name 1 1 ,

1,

! - Start Month 1

31 ;

! - End Month 1

! - End Day 1

Schedule: Compact,

ConstSetSched82.2, !- Name

sctAnyNumber,

Through: 12/31,

For: AllDays,

Until: 24:00,

! - Schedule Type Limits Name

82. 222;

! - Field 1

! - Field 2

! - Field 3

Schedule: Compact,

ConstSetSched11.7, !- Name

sctTemperature,

Through: 12/31,

! - Schedule Type Limits Name

For: AllDays,

Until: 24:0९,

! - Field 1

! - Field 2

11.667;

! - Field 3

! - Field 4

Schedule: Compact RPT-SCHED, ! - Name

sctonoff, !- Schedule Type Limits Name

Through: 12/31, !- Field 1

For: Weekdays WinterDesignDay SummerDesignDay, !- Field 2

Until: 5:00, !- Field 3 


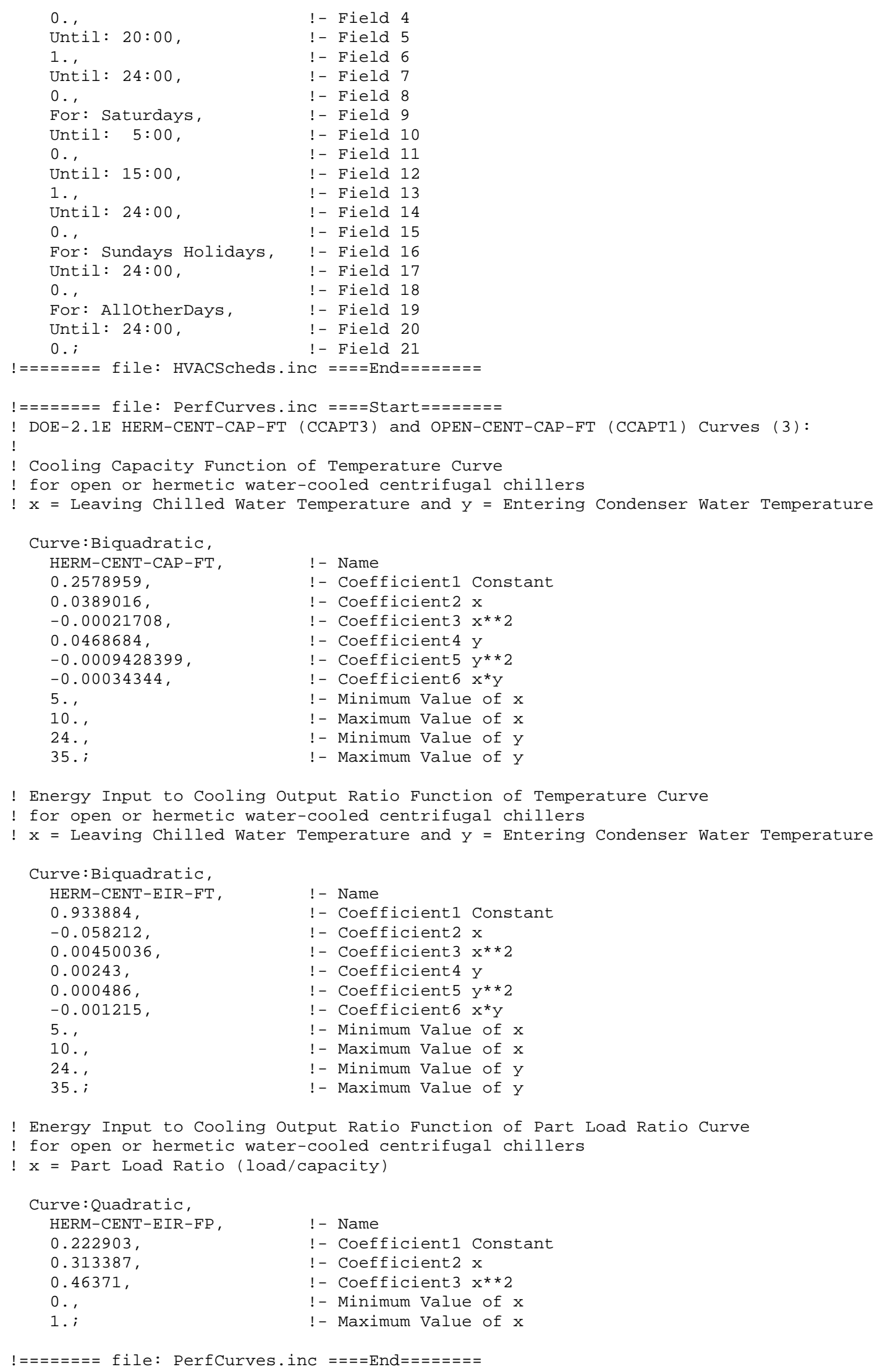

! Energy Input to Cooling Output Ratio Function of Temperature Curve

! for open or hermetic water-cooled centrifugal chillers

! $\mathrm{x}=$ Leaving Chilled water Temperature and $\mathrm{y}=$ Entering Condenser water Temperature

Curve:Biquadratic, HERM-CENT-EIR-FT, ! - Name

! Energy Input to Cooling Output Ratio Function of Part Load Ratio Curve

! for open or hermetic water-cooled centrifugal chillers

! $x$ = Part Load Ratio (load/capacity)

Curve: Quadratic, 


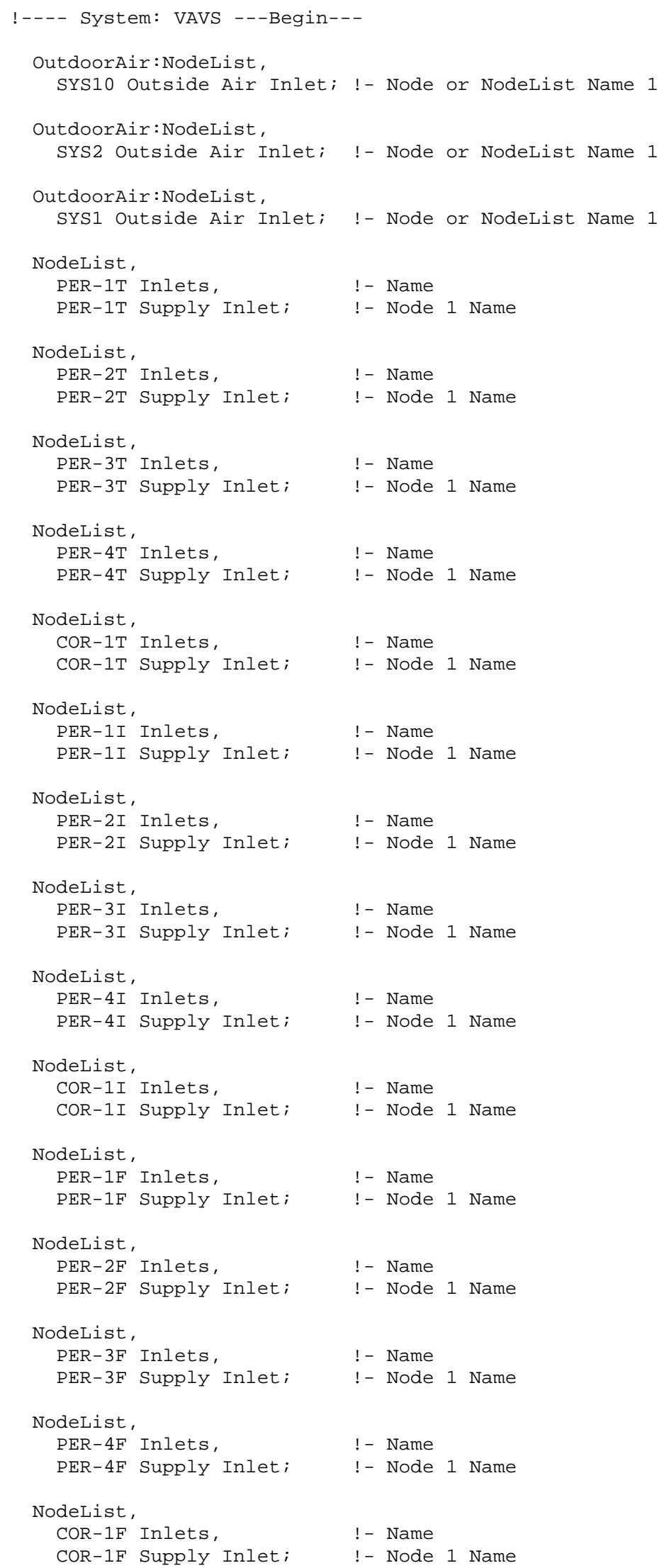




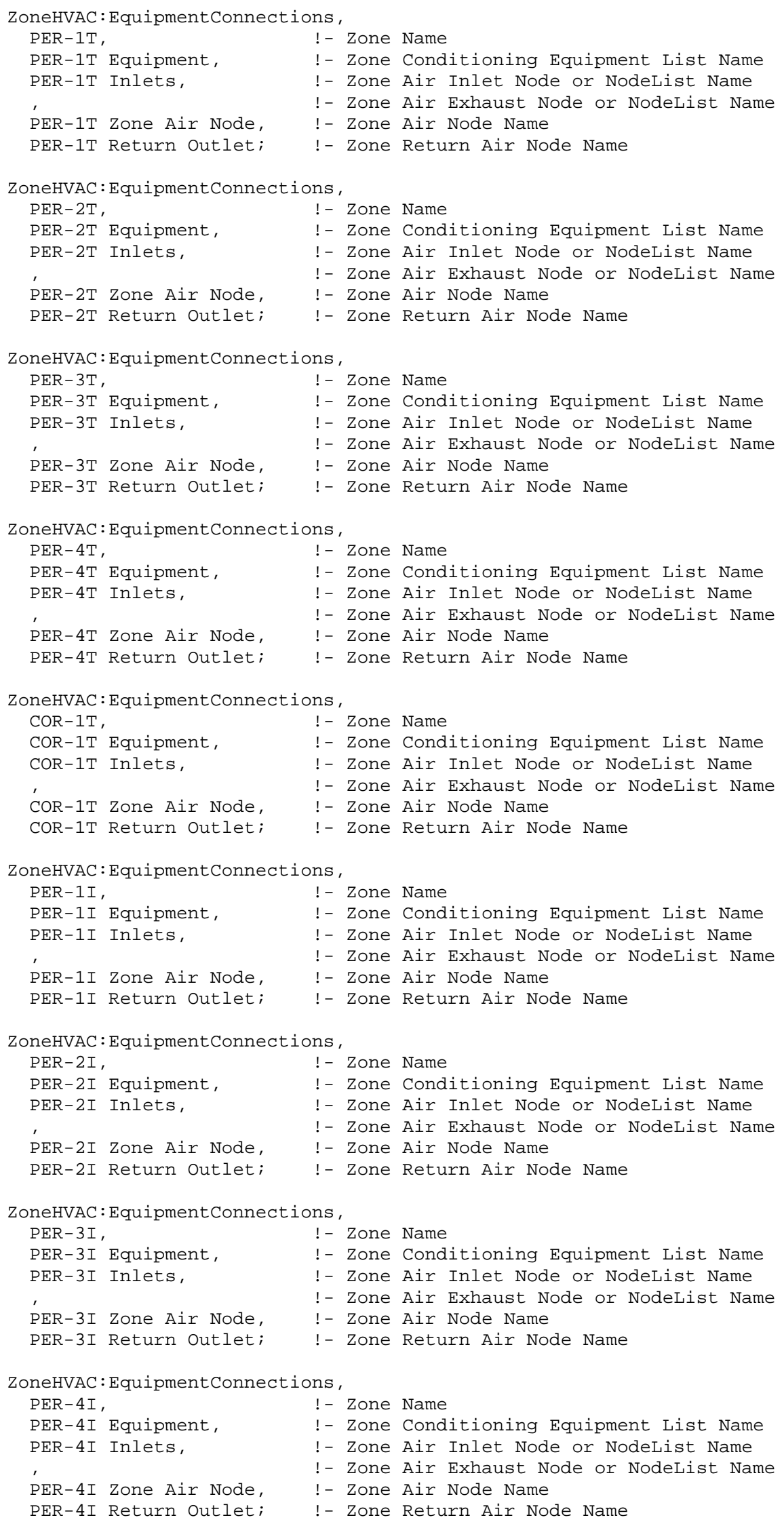




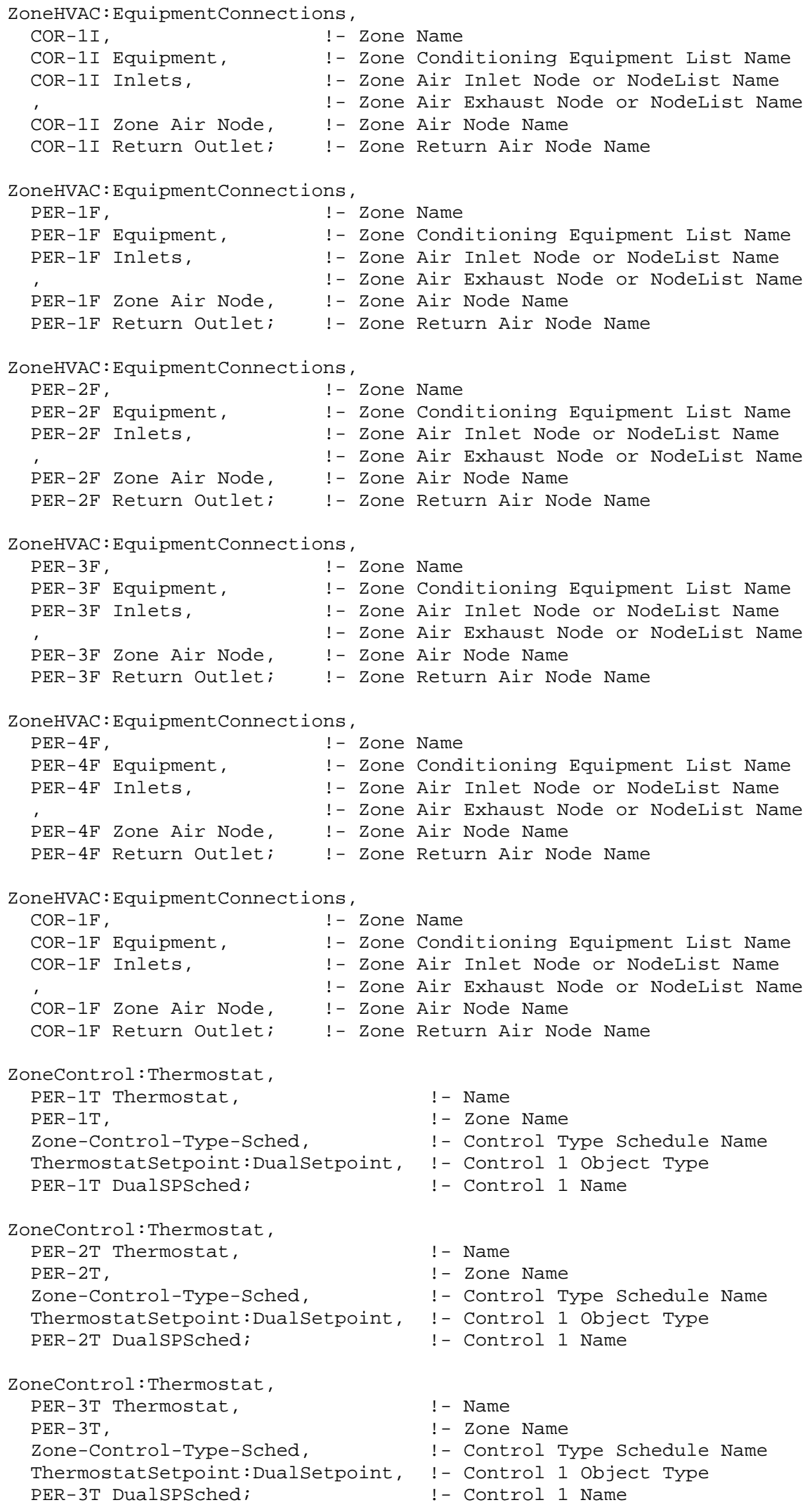

ZoneControl: Thermostat, 


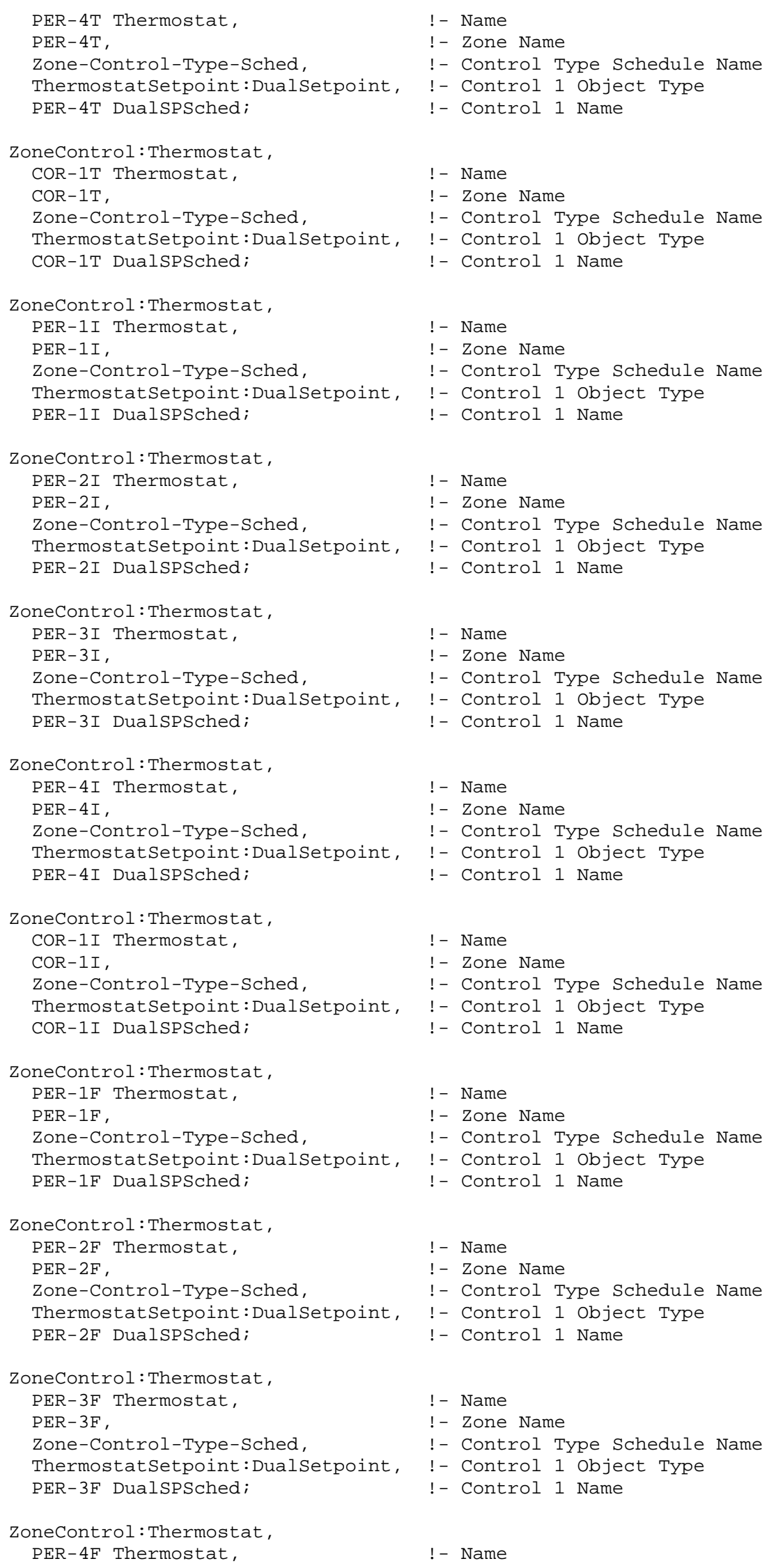




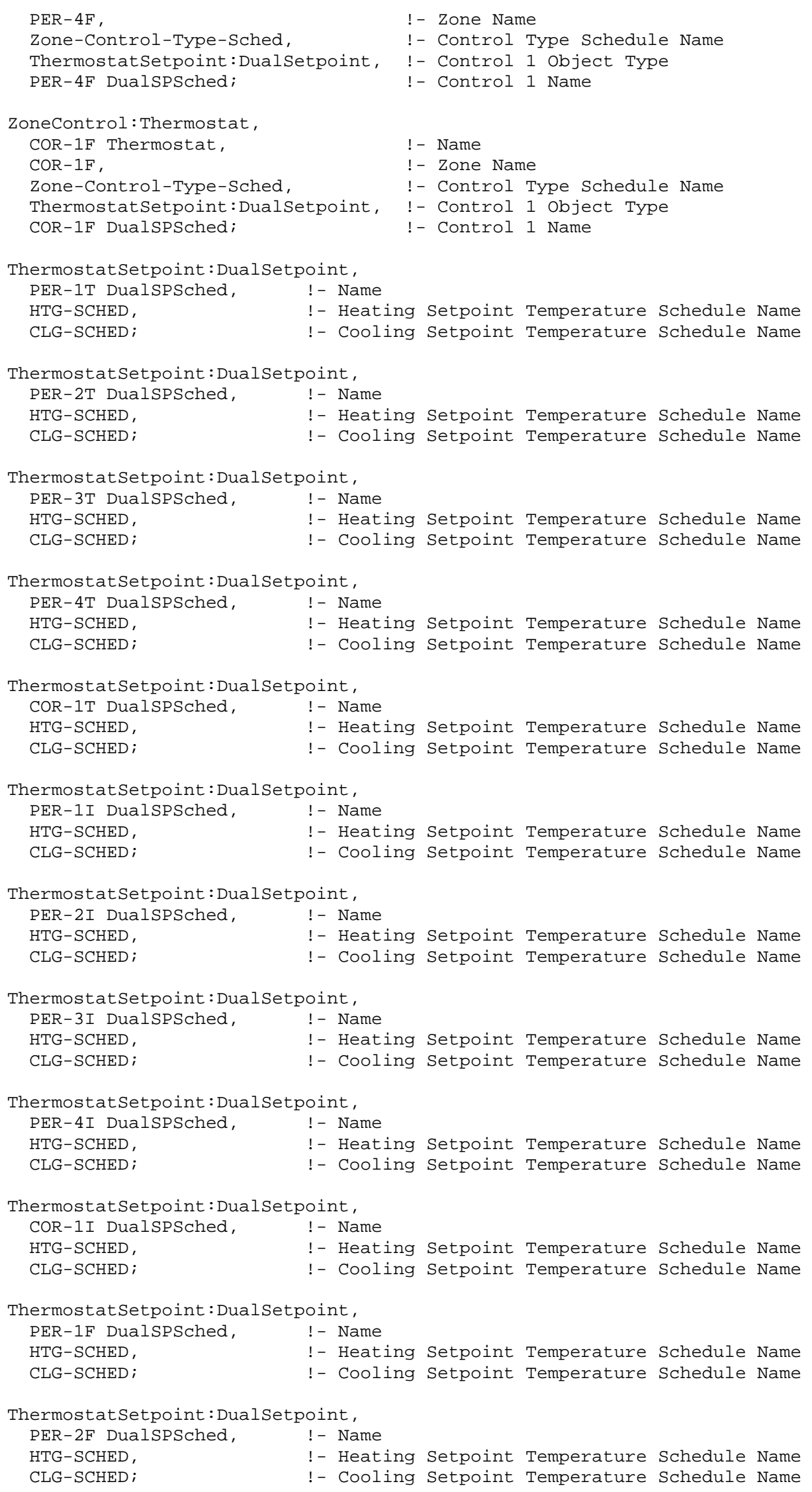




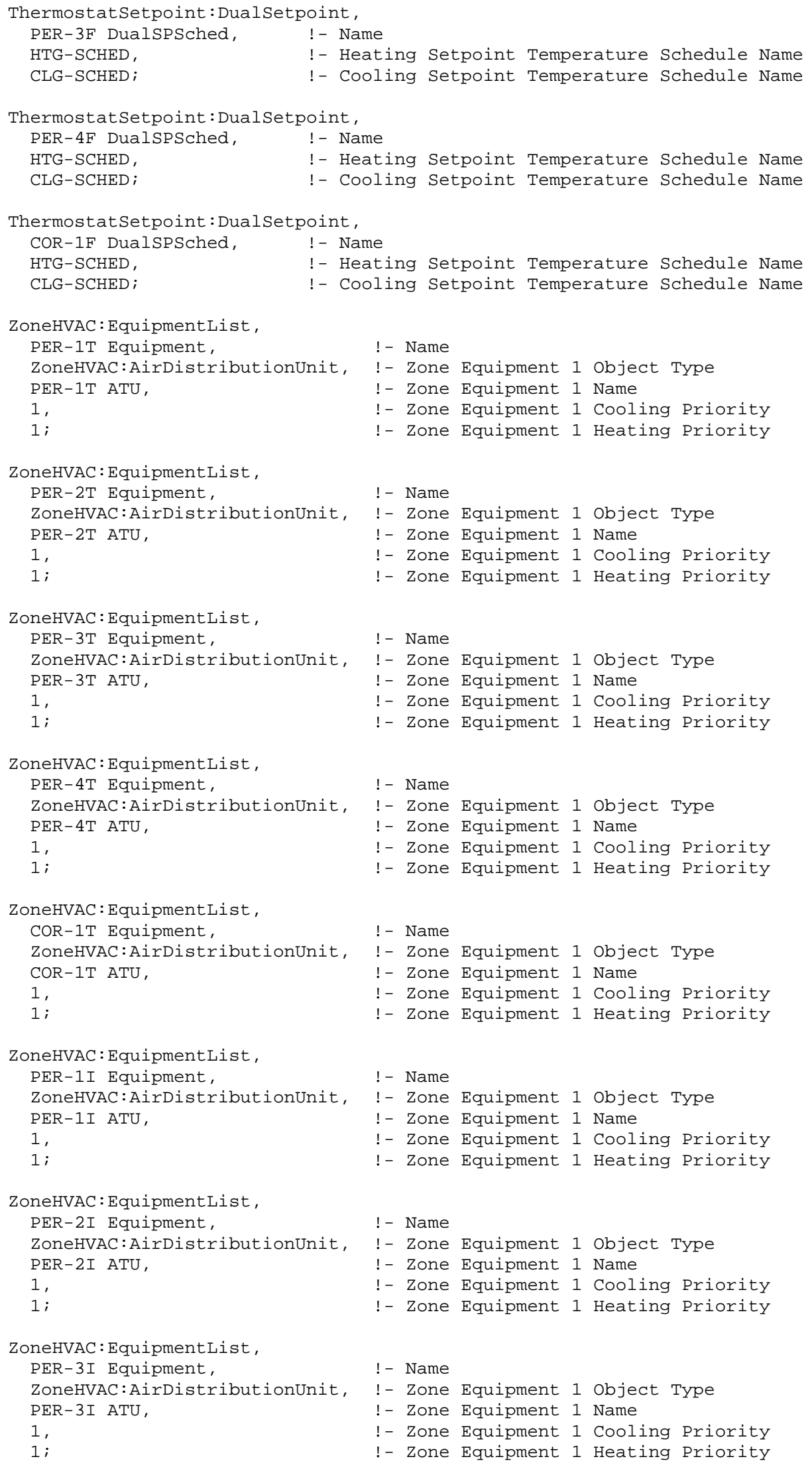




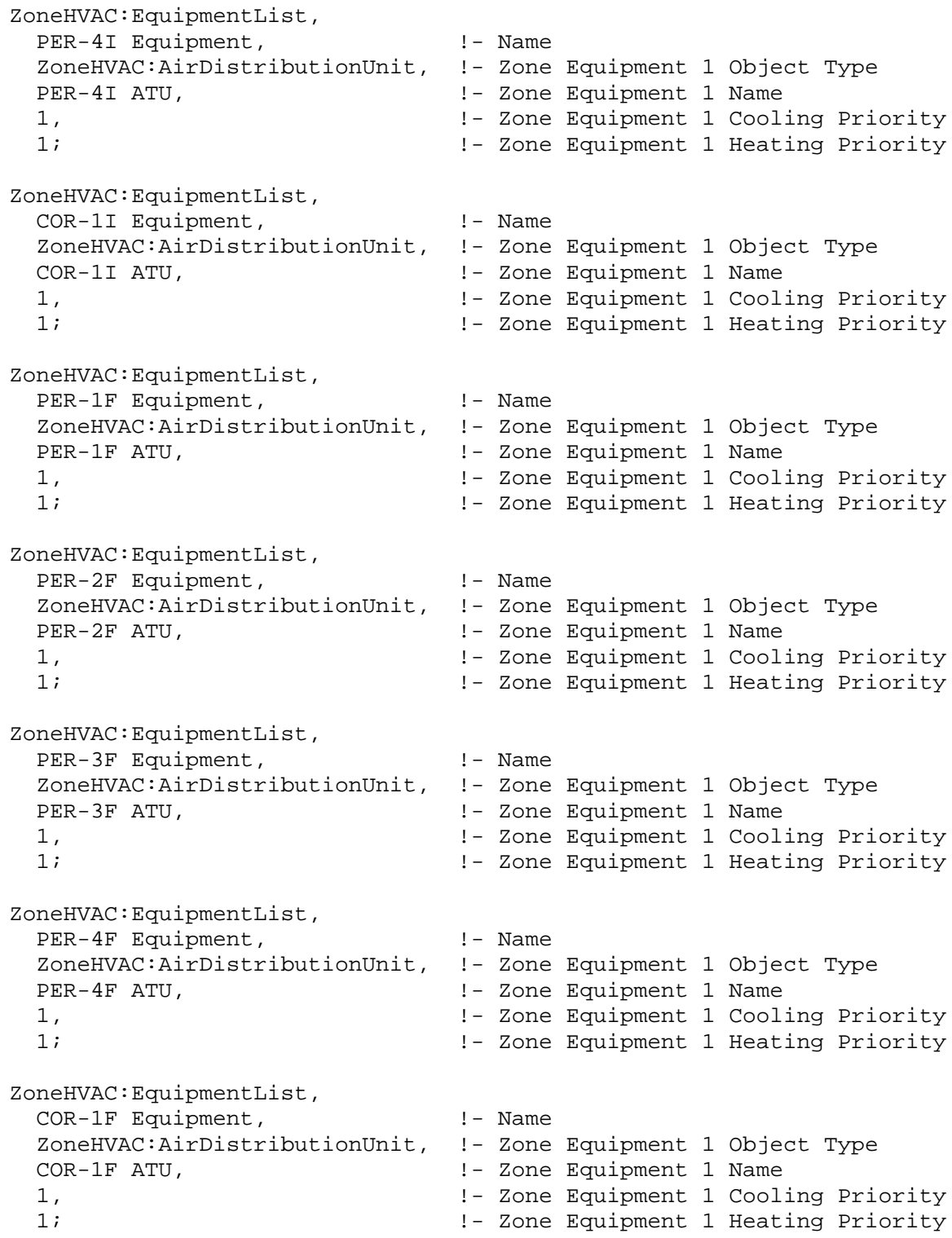

ZoneHVAC: AirDistributionUnit, 


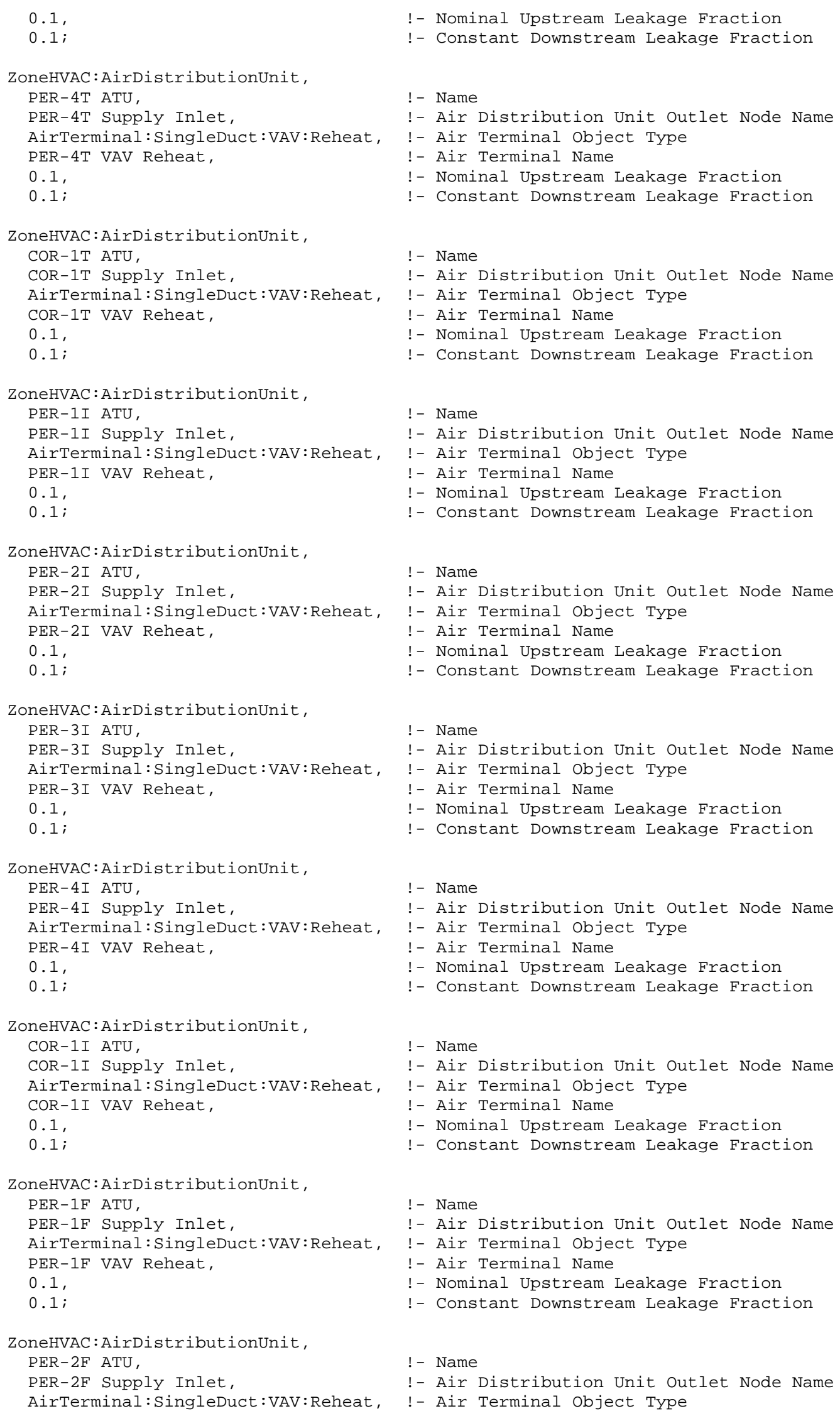




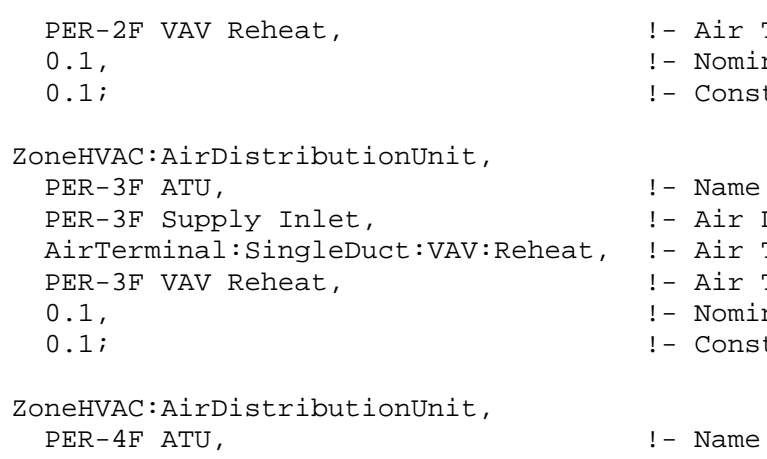




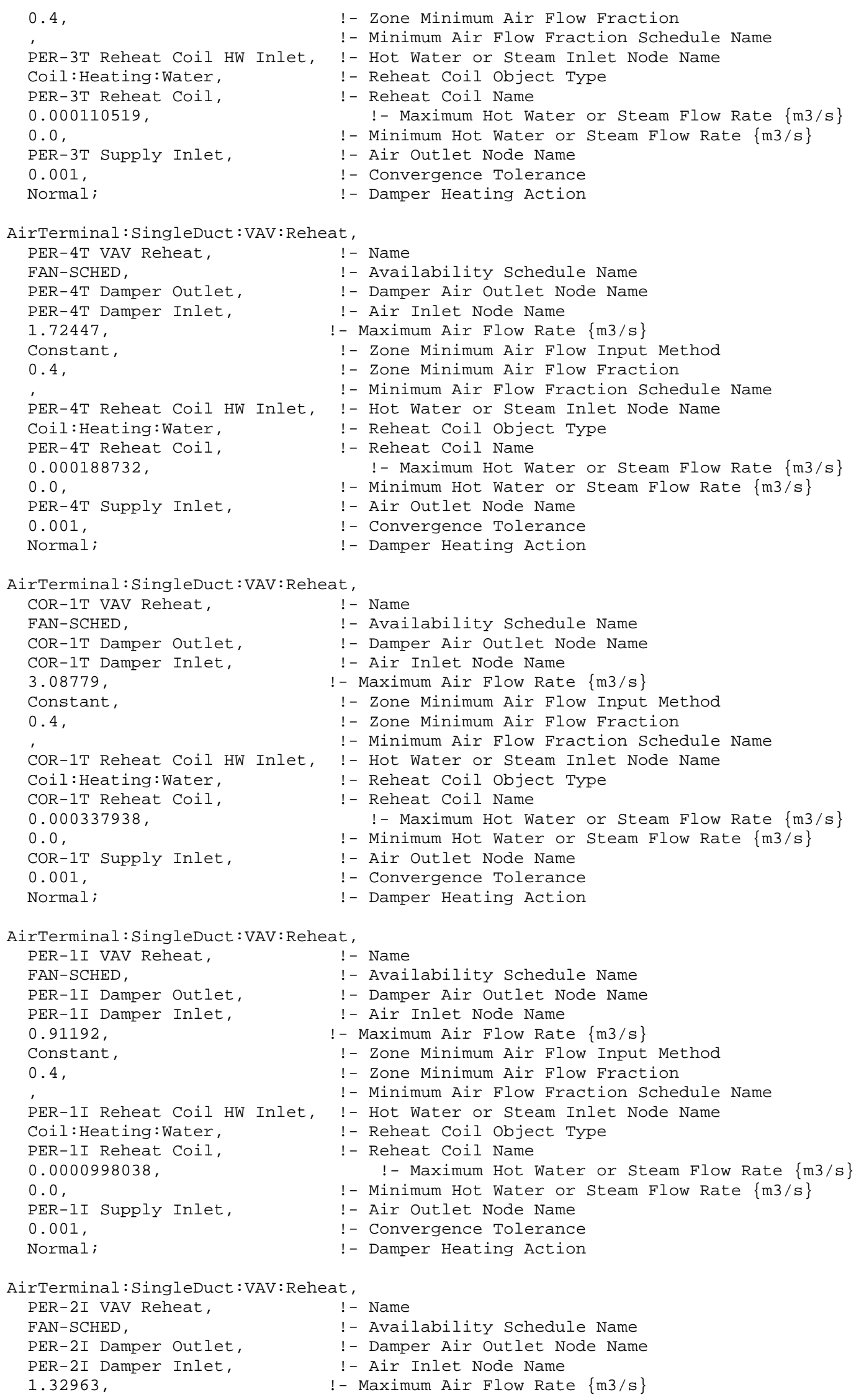

AirTerminal: SingleDuct: VAV: Reheat,

AirTerminal: SingleDuct: VAV: Reheat, PER-2I VAV Reheat, FAN-SCHED, PER-2I Damper outlet, PER-2I Damper Inlet, 1.32963,

! - Name

! - Availability Schedule Name

! - Damper Air Outlet Node Name

! - Air Inlet Node Name

! - Maximum Air Flow Rate $\{\mathrm{m} 3 / \mathrm{s}\}$ 


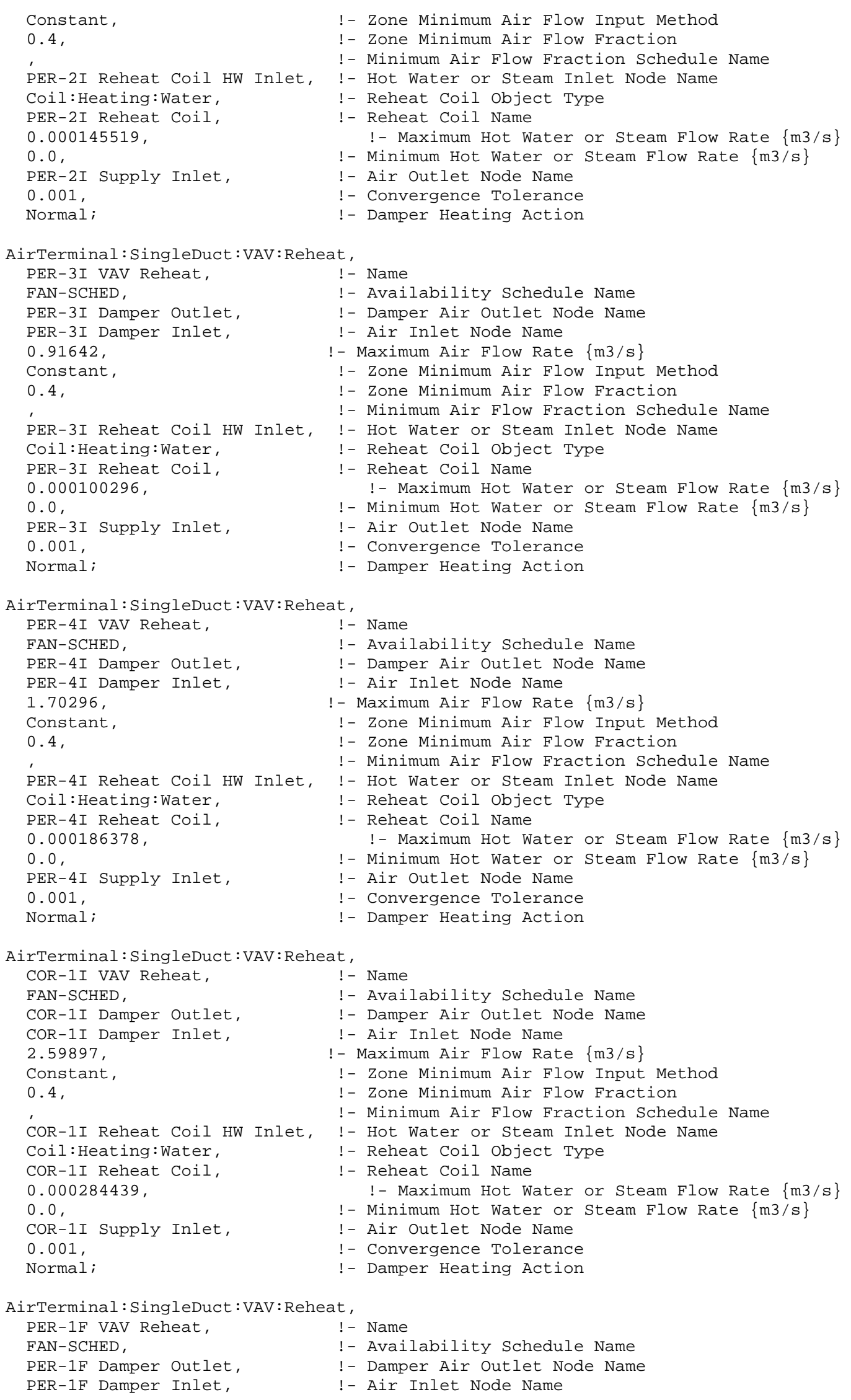

AirTerminal: SingleDuct:VAV:Reheat, 


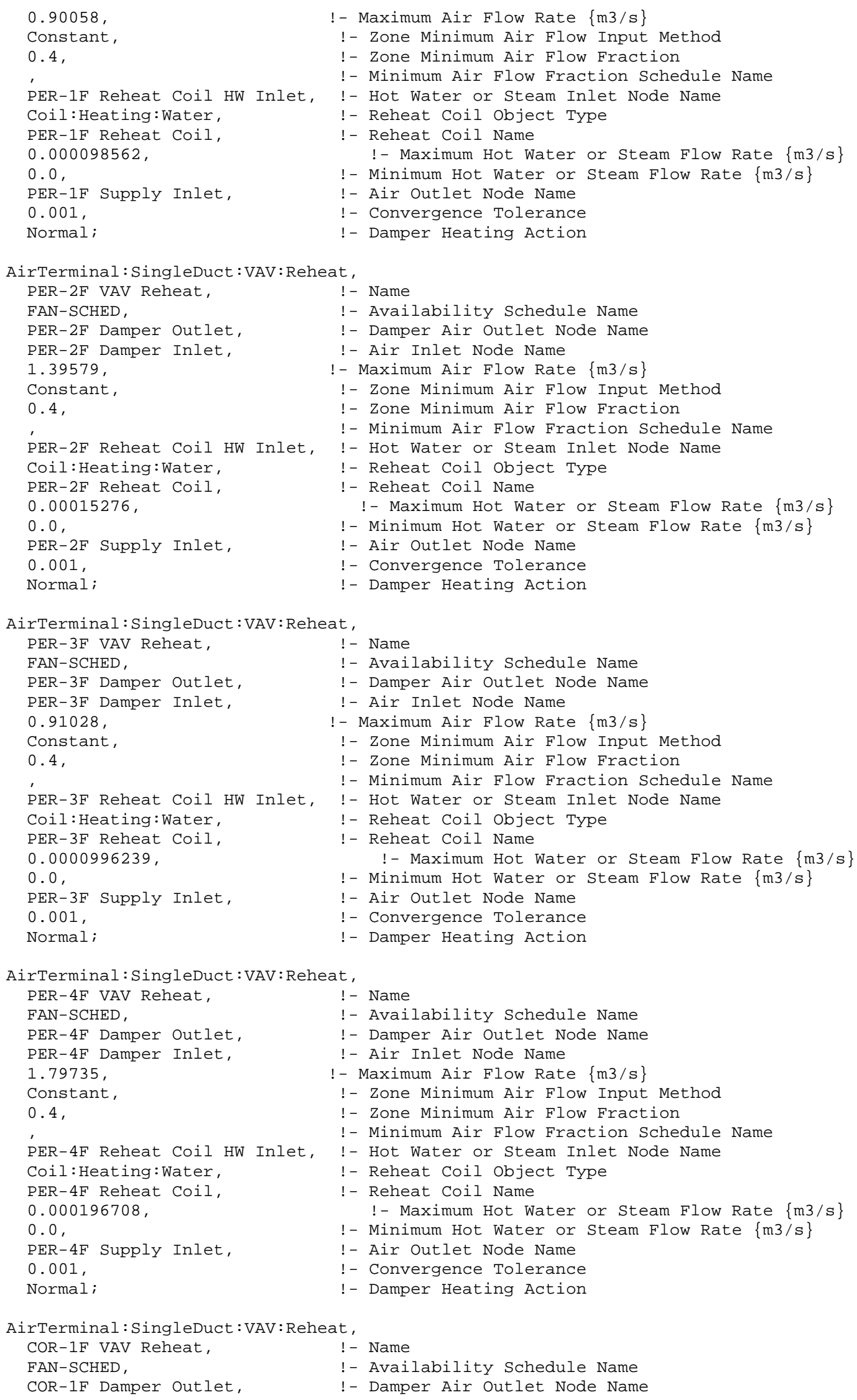

AirTerminal: SingleDuct: VAV: Reheat,

AirTerminal: SingleDuct: VAV: Reheat COR-1F VAV Reheat, 


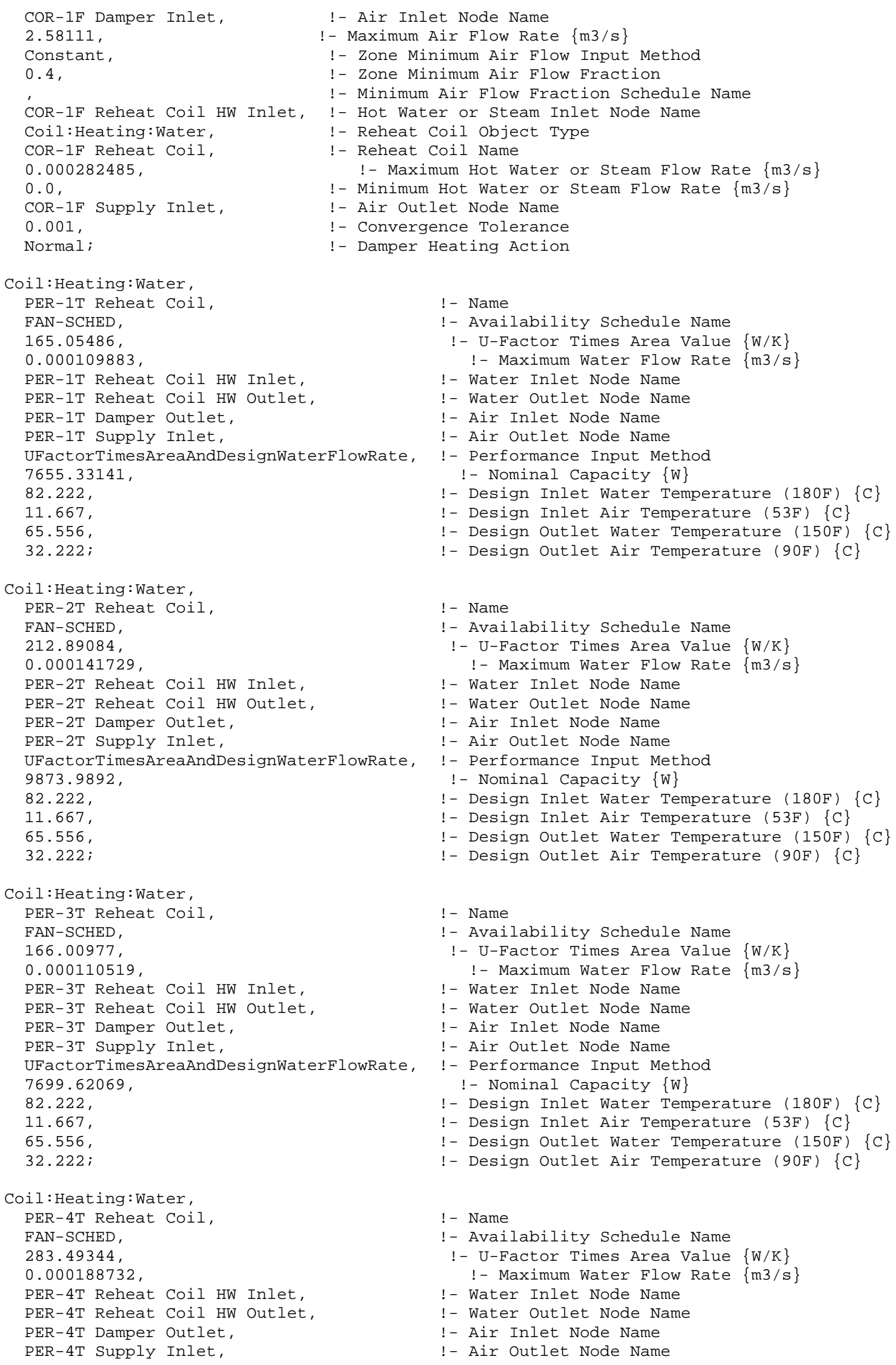




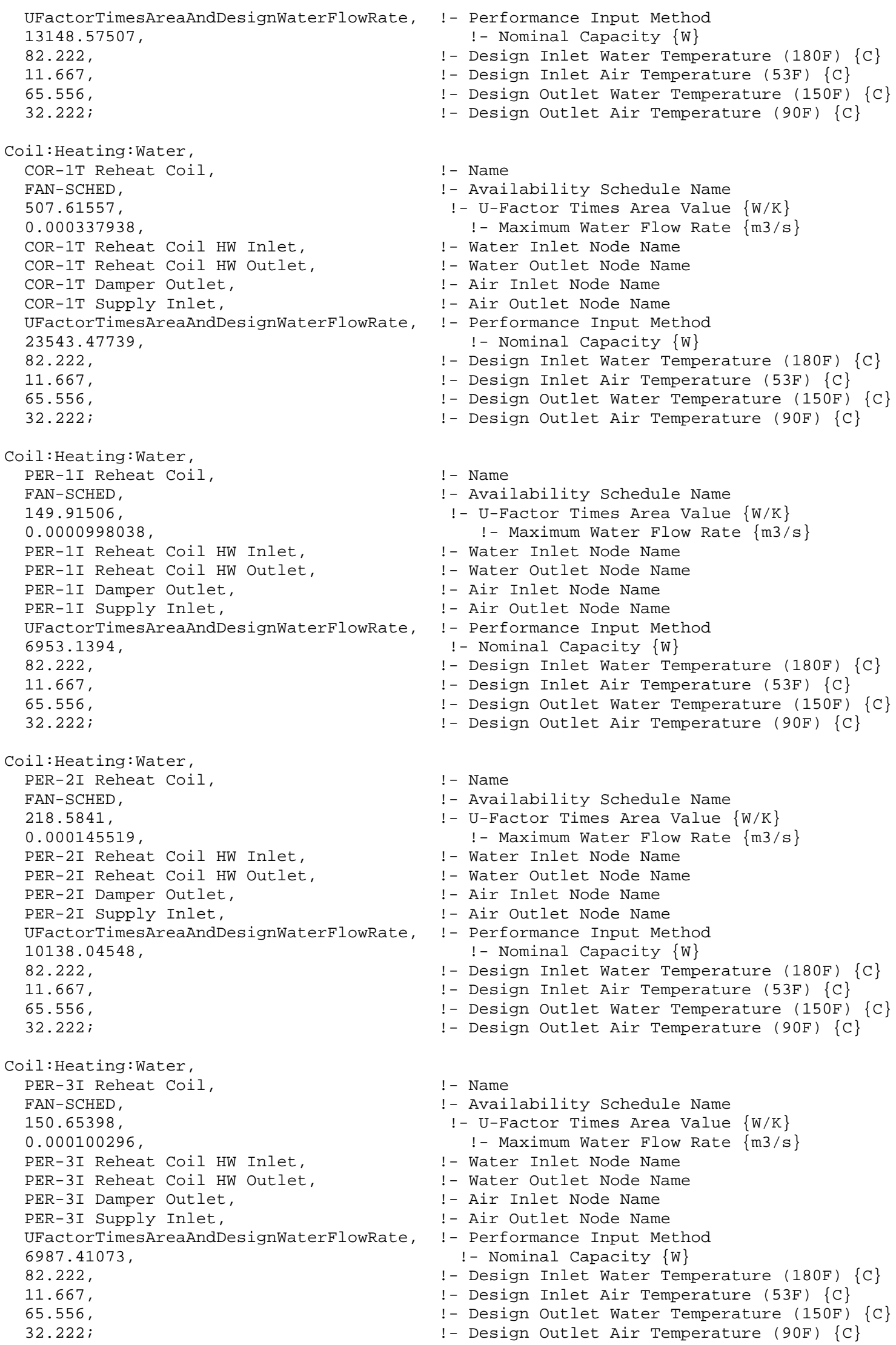




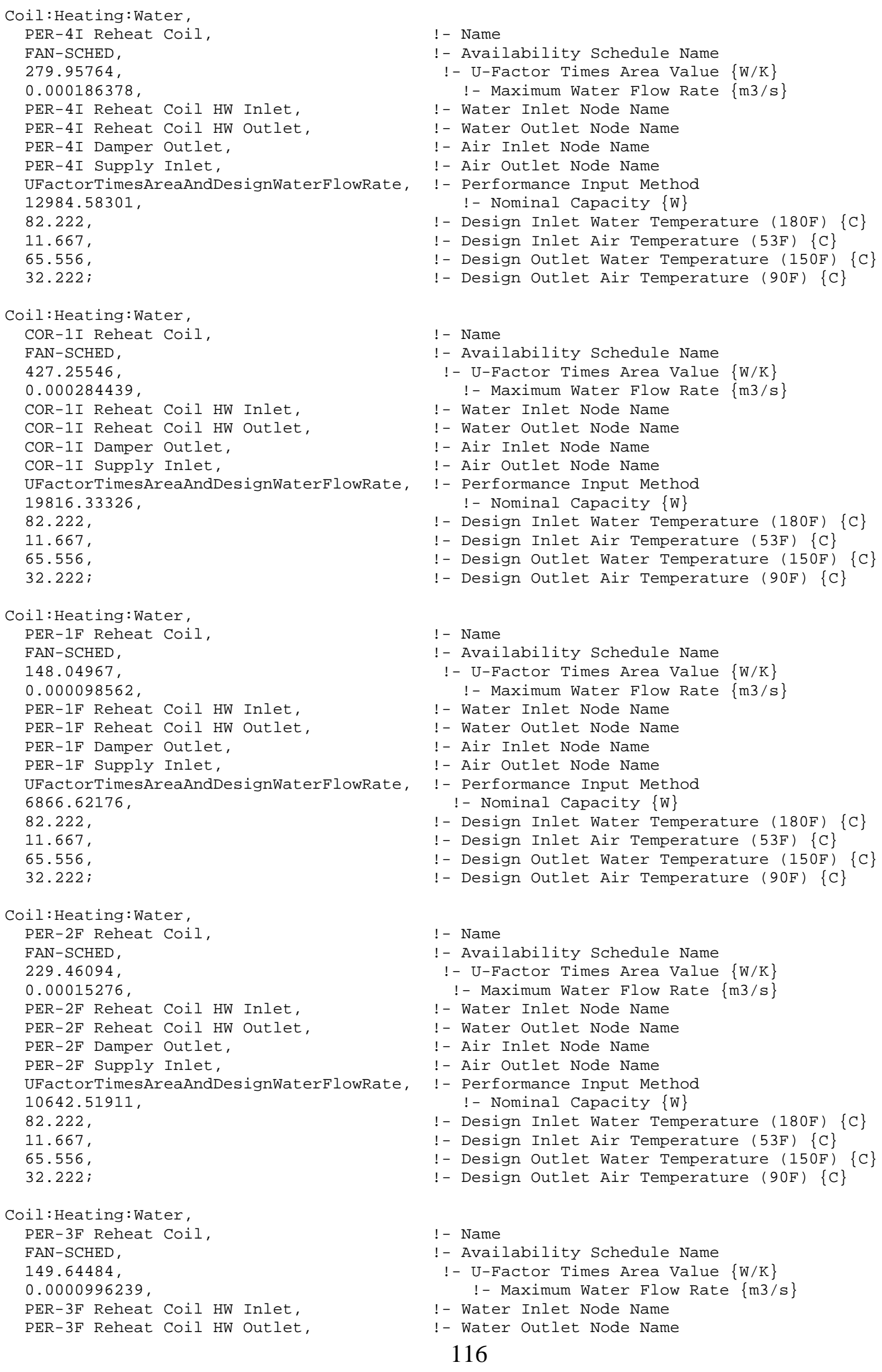

PER-4I Reheat Coil, !- Name

! - Availability Schedule Name

! - U-Factor Times Area Value $\{\mathrm{W} / \mathrm{K}\}$

! - Maximum Water Flow Rate $\{\mathrm{m} 3 / \mathrm{s}\}$

! - Water Inlet Node Name

! - Water Outlet Node Name

! - Air Inlet Node Name

! - Air Outlet Node Name

! - Performance Input Method ! - Nominal Capacity $\{W\}$

! - Design Inlet Water Temperature (180F) $\{\mathrm{C}\}$

! - Design Inlet Air Temperature (53F) $\{\mathrm{C}\}$

! - Design Outlet Water Temperature (150F) $\{\mathrm{C}\}$

!- Design Outlet Air Temperature (9OF) $\{\mathrm{C}\}$

! - Name

!- Availability Schedule Name

! - U-Factor Times Area Value $\{\mathrm{W} / \mathrm{K}\}$ ! - Maximum Water Flow Rate $\{\mathrm{m} 3 / \mathrm{s}\}$

! - Water Inlet Node Name

! - Water Outlet Node Name

! - Air Inlet Node Name

! - Air Outlet Node Name

! - Performance Input Method ! - Nominal Capacity $\{W\}$

! - Design Inlet Water Temperature (180F) $\{C\}$

! - Design Inlet Air Temperature (53F) $\{\mathrm{C}\}$

! - Design Outlet Water Temperature (150F) $\{C\}$

!- Design Outlet Air Temperature (9๑F) $\{\mathrm{C}\}$

! - Name

! - Availability Schedule Name

! - U-Factor Times Area Value $\{\mathrm{W} / \mathrm{K}\}$

!- Maximum Water Flow Rate $\{\mathrm{m} 3 / \mathrm{s}\}$

! - Water Inlet Node Name

! - Water Outlet Node Name

! - Air Inlet Node Name

! - Air Outlet Node Name

! - Performance Input Method

! - Nominal Capacity $\{W\}$

! - Design Inlet Water Temperature (180F) $\{\mathrm{C}\}$

! - Design Inlet Air Temperature (53F) $\{\mathrm{C}\}$

! - Design Outlet Water Temperature (150F) $\{\mathrm{C}\}$

!- Design outlet Air Temperature (90F) $\{\mathrm{C}\}$

! - Name

! - Availability Schedule Name

! - U-Factor Times Area Value $\{\mathrm{W} / \mathrm{K}\}$

! - Maximum Water Flow Rate $\{\mathrm{m} 3 / \mathrm{s}\}$

! - Water Inlet Node Name

! - Water Outlet Node Name

! - Air Inlet Node Name

! - Air Outlet Node Name

! - Performance Input Method ! - Nominal Capacity $\{W\}$

! - Design Inlet Water Temperature (180F) $\{\mathrm{C}\}$

! - Design Inlet Air Temperature (53F) \{C\}

! - Design Outlet water Temperature (150F) $\{\mathrm{C}\}$

! - Design outlet Air Temperature (9๑F) $\{\mathrm{C}\}$

! - Name

! - Availability Schedule Name

! - U-Factor Times Area Value $\{\mathrm{W} / \mathrm{K}\}$

! - Maximum Water Flow Rate $\{\mathrm{m} 3 / \mathrm{s}\}$

! - Water Inlet Node Name

! - Water Outlet Node Name

\section{6}




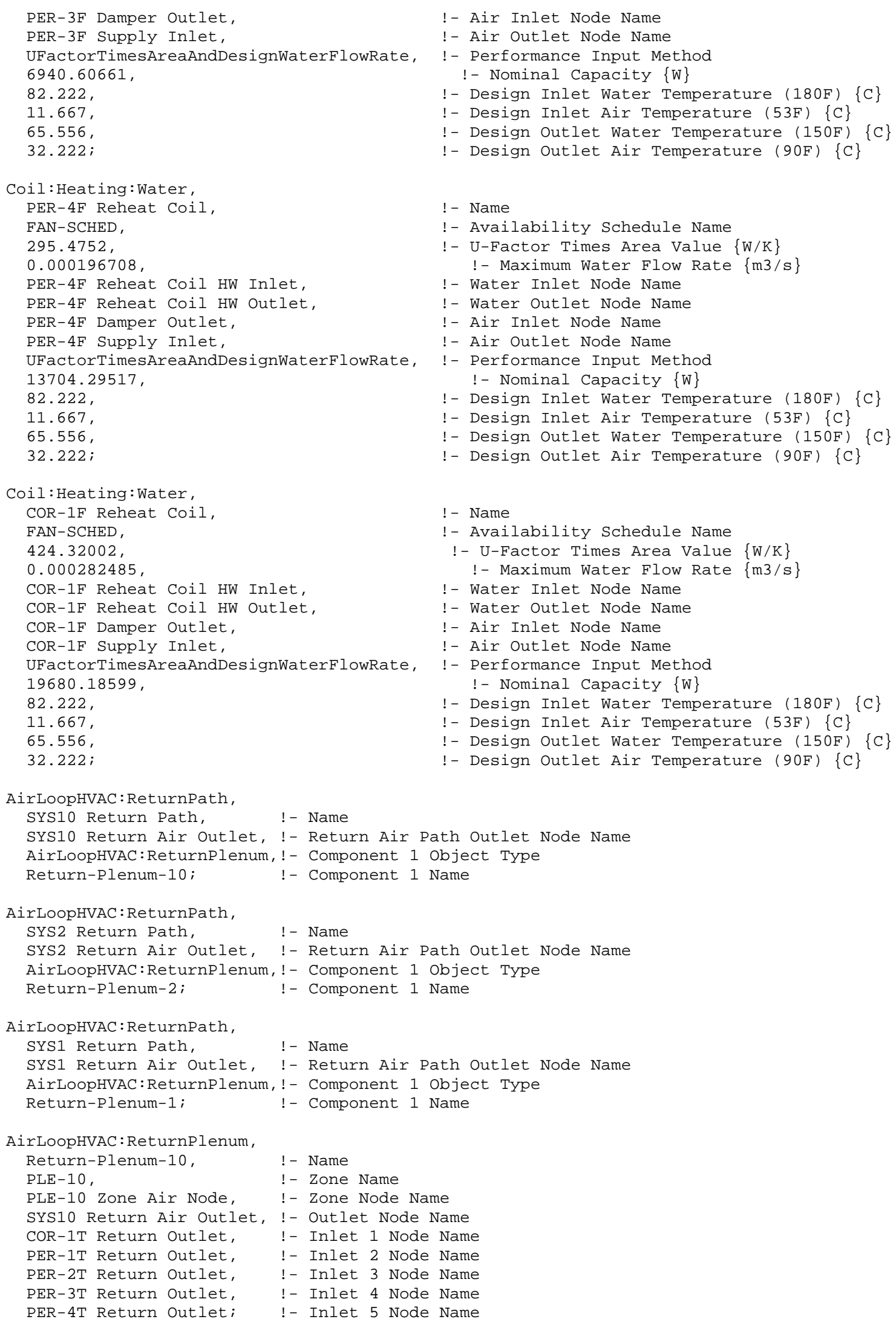

AirLoopHVAC: ReturnPath, SYS10 Return Path, !- Name SYS10 Return Air Outlet, !- Return Air Path Outlet Node Name AirLoopHVAC:ReturnPlenum, !- Component 1 Object Type Return-Plenum-10; !- Component 1 Name

AirLoopHVAC: ReturnPath, SYS2 Return Path, ! - Name SYS2 Return Air Outlet, !- Return Air Path Outlet Node Name AirLoopHVAC:ReturnPlenum, ! - Component 1 object Type Return-Plenum-2; !- Component 1 Name

AirLoopHVAC: ReturnPath, SYS1 Return Path, ! - Name SYS1 Return Air Outlet, !- Return Air Path Outlet Node Name AirLoopHVAC: ReturnPlenum, !- Component 1 Object Type Return-Plenum-1; !- Component 1 Name

AirLoopHVAC: ReturnPlenum, Return-Plenum-10, ! - Name PLE-10, ! - Zone Name PLE-10 Zone Air Node, ! - Zone Node Name SYS10 Return Air Outlet, !- Outlet Node Name COR-1T Return Outlet, ! - Inlet 1 Node Name PER-1T Return Outlet, ! - Inlet 2 Node Name PER-2T Return outlet, ! - Inlet 3 Node Name PER-3T Return Outlet, ! - Inlet 4 Node Name PER-4T Return outlet; !- Inlet 5 Node Name

AirLoopHVAC: ReturnPlenum, 


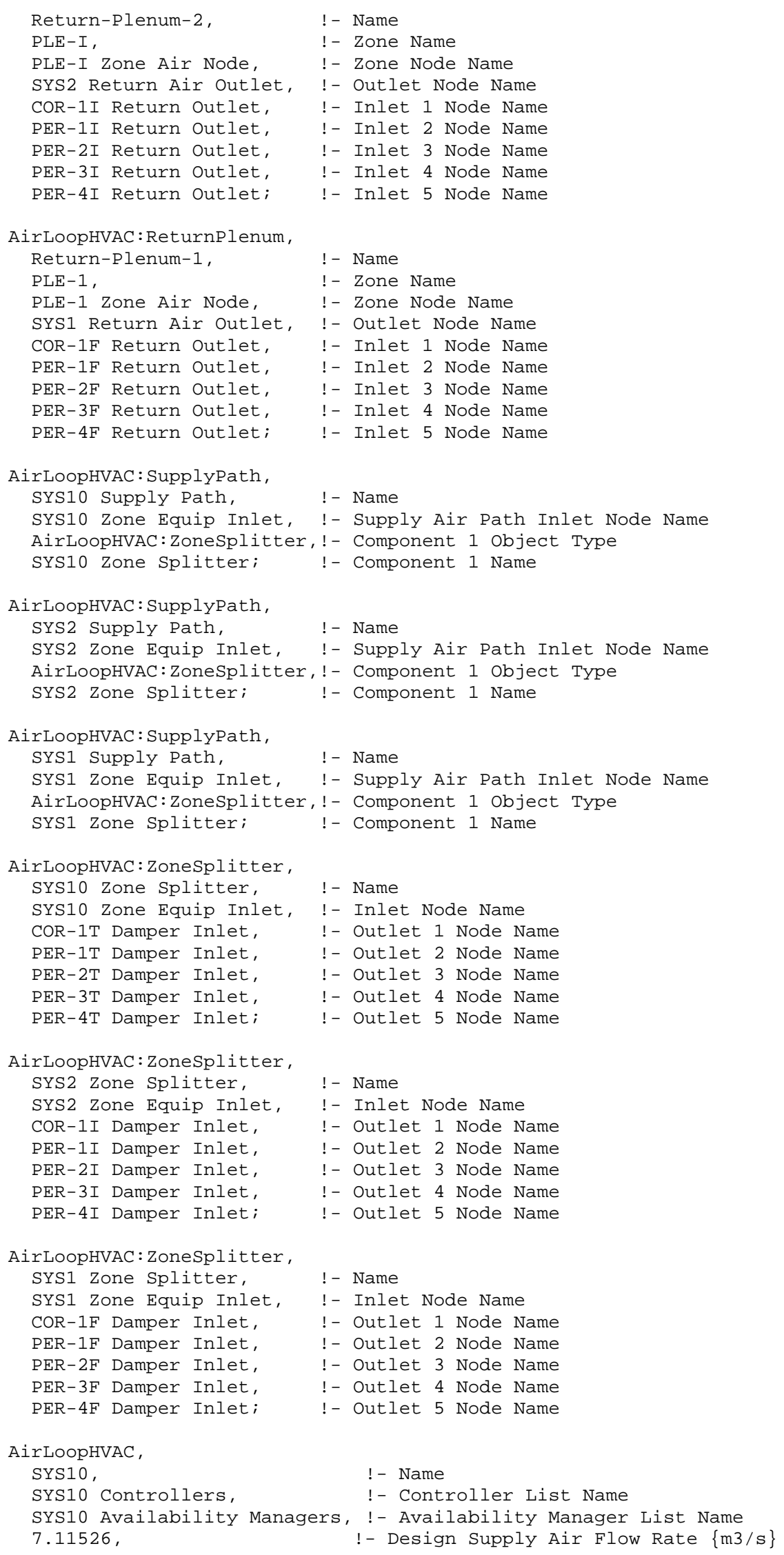




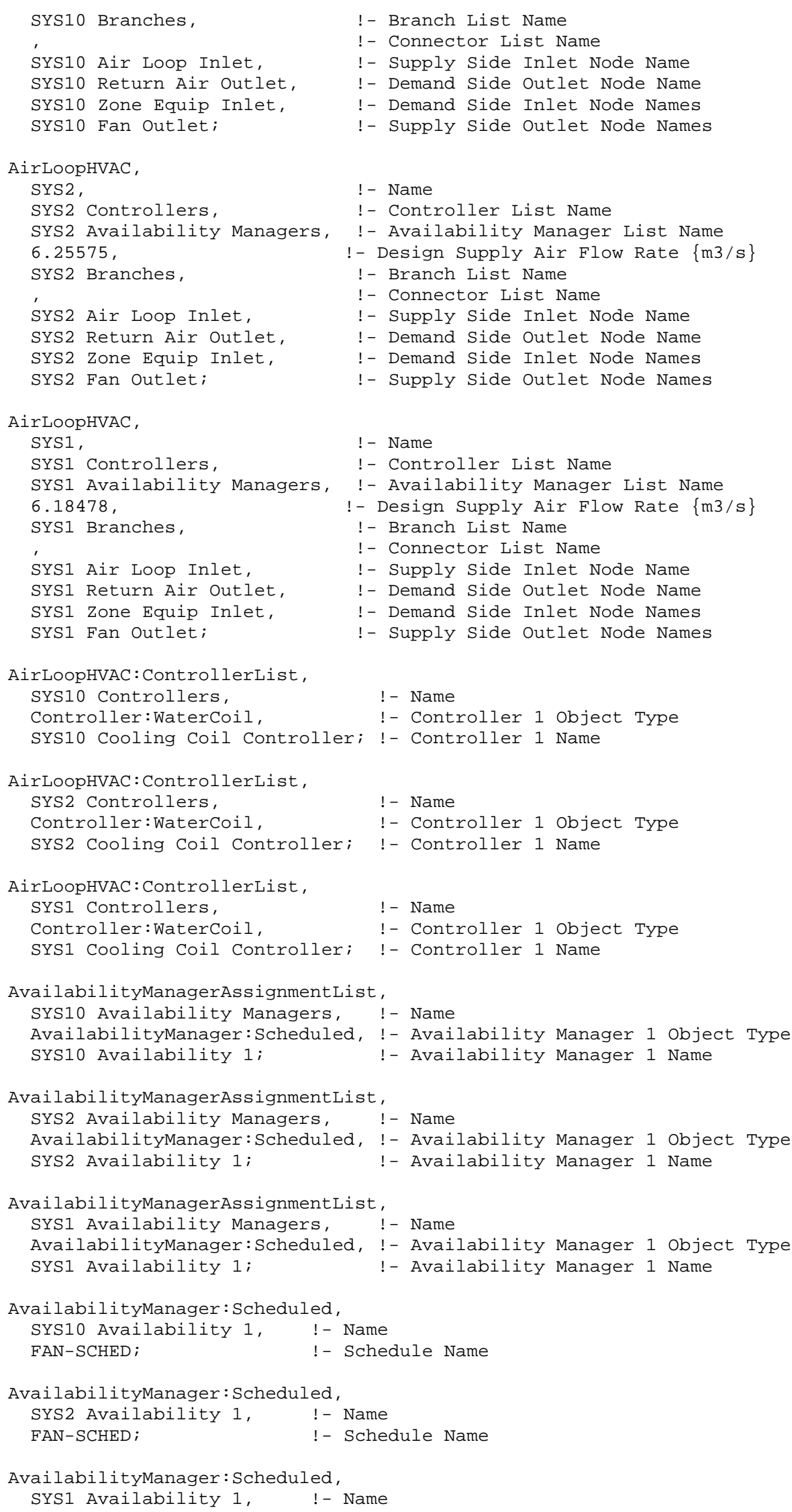


FAN-SCHED;

SYS10 Branches, ! - Name

SYS10 Main Branch; !- Branch 1 Name

BranchList,

SYS2 Branches, ! - Name

SYS2 Main Branch; !- Branch 1 Name

BranchList

SYS1 Branches, !- Name

SYS1 Main Branch; !- Branch 1 Name

I Use return fan (Comp1) for each main branch

! No main heating coil

Branch,

SYS10 Main Branch,

7.11526,

Fan:VariableVolume,

SYS10 Return Fan,

SYS10 Air Loop Inlet,

SYS10 Return Fan outlet,

Passive,

AirLoopHVAC: OutdoorAirSystem,

SYS10 OA System,

SYS10 Return Fan outlet,

SYS10 Mixed Air outlet,

Passive,

Coil: Cooling:Water,

SYS10 Cooling Coil,

SYS10 Mixed Air outlet,

SYS10 Cooling Coil outlet,

Passive,

Fan:VariableVolume,

SYS10 Supply Fan,

SYS10 Cooling Coil outlet,

SYS10 Fan outlet,

Active;

Branch

SYS2 Main Branch,

6.25575 ,

Fan:Variablevolume,

SYS2 Return Fan,

SYS2 Air Loop Inlet,

SYS2 Return Fan outlet,

Passive,

AirLoopHVAC: OutdoorAirSystem,

SYS2 OA System,

SYS2 Return Fan outlet,

SYS2 Mixed Air outlet,

Passive,

Coil: Cooling:Water,

SYS2 Cooling Coil,

SYS2 Mixed Air outlet

SYS2 Cooling Coil Outlet,

Passive,

Fan:VariableVolume,

SYS2 Supply Fan,

SYS2 Cooling Coil outlet,

SYS2 Fan outlet,

Active;

Branch,

SYS1 Main Branch,

6.18478 ,

Fan:VariableVolume,

SYS1 Return Fan,

SYS1 Air Loop Inlet,

\footnotetext{
! - Name

! - Maximum Flow Rate $\{\mathrm{m} 3 / \mathrm{s}\}$

! - Component 1 Object Type

! - Component 1 Name

! - Component 1 Inlet Node Name

! - Component 1 Outlet Node Name

!- Component 1 Branch Control Type

! - Component 2 Object Type

!- Component 2 Name

! - Component 2 Inlet Node Name

! - Component 2 Outlet Node Name

! - Component 2 Branch Control Type

! - Component 3 object Type

! - Component 3 Name

! - Component 3 Inlet Node Name

! - Component 3 outlet Node Name

! - Component 3 Branch Control Type

! - Component 4 Object Type

! - Component 4 Name

!- Component 4 Inlet Node Name

! - Component 4 Outlet Node Name

!- Component 4 Branch Control Type
}

! - Name

! - Maximum Flow Rate $\{\mathrm{m} 3 / \mathrm{s}\}$

! - Component 1 object Type

! - Component 1 Name

!- Component 1 Inlet Node Name

! - Component 1 Outlet Node Name

! - Component 1 Branch Control Type

! - Component 2 object Type

!- Component 2 Name

! - Component 2 Inlet Node Name

! - Component 2 Outlet Node Name

!- Component 2 Branch Control Type

! - Component 3 object Type

! - Component 3 Name

! - Component 3 Inlet Node Name

! - Component 3 Outlet Node Name

! - Component 3 Branch Control Type

!- Component 4 object Type

! - Component 4 Name

!- Component 4 Inlet Node Name

! - Component 4 Outlet Node Name

!- Component 4 Branch Control Type

! - Name

! - Maximum Flow Rate $\{\mathrm{m} 3 / \mathrm{s}\}$

! - Component 1 object Type

! - Component 1 Name

!- Component 1 Inlet Node Name 
SYS1 Return Fan outlet, Passive,

AirLoopHVAC: OutdoorAirSystem,

SYS1 OA System,

SYS1 Return Fan outlet,

SYS1 Mixed Air Outlet,

Passive,

Coil: Cooling: Water,

SYS1 Cooling Coil,

SYS1 Mixed Air Outlet, SYS1 Cooling Coil outlet, Passive,

Fan:VariableVolume,

SYS1 Supply Fan,

SYS1 Cooling Coil outlet,

SYS1 Fan outlet,

Active;

! - Component 1 outlet Node Name

! - Component 1 Branch Control Type

! - Component 2 object Type

! - Component 2 Name

!- Component 2 Inlet Node Name

! - Component 2 Outlet Node Name

!- Component 2 Branch Control Type

! - Component 3 object Type

! - Component 3 Name

! - Component 3 Inlet Node Name

! - Component 3 outlet Node Name

! - Component 3 Branch Control Type

! - Component 4 Object Type

! - Component 4 Name

! - Component 4 Inlet Node Name

! - Component 4 Outlet Node Name

!- Component 4 Branch Control Type

AirLoopHVAC : OutdoorAirSystem, SYS10 OA System, ! - Name

SYS10 OA System Controllers, !- Controller List Name

SYS10 OA System Equipment, !- Outdoor Air Equipment List Name

SYS10 Availability Managers; !- Availability Manager List Name

AirLoopHVAC: OutdoorAirSystem, SYS2 OA System,

SYS2 OA System Controllers,

SYS2 OA System Equipment,

! - Name

! - Controller List Name

! - Outdoor Air Equipment List Name

SYS2 Availability Managers;

! - Availability Manager List Name

AirLoopHVAC: OutdoorAirSystem, SYS1 OA System, ! - Name

SYS1 OA System Controllers, !- Controller List Name

SYS1 OA System Equipment, !- Outdoor Air Equipment List Name

SYS1 Availability Managers; !- Availability Manager List Name

AirLoopHVAC: ControllerList, SYS10 OA System Controllers, !- Name

Controller:OutdoorAir, !- Controller 1 object Type

SYS10 OA Controller; !- Controller 1 Name

AirLoopHVAC: ControllerList, SYS2 OA System Controllers, !- Name

Controller:OutdoorAir, !- Controller 1 object Type

SYS2 OA Controller; !- Controller 1 Name

AirLoopHVAC: ControllerList, SYS1 OA System Controllers, !- Name

Controller:OutdoorAir, !- Controller 1 object Type

SYS1 OA Controller;

! - Controller 1 Name

AirLoopHVAC: OutdoorAirSystem : EquipmentList,

SYS10 OA System Equipment, !- Name SYS10 OA Mixing Box;

!- Component 1 object Type

! - Component 1 Name

AirLoopHVAC: OutdoorAirSystem: EquipmentList, SYS2 OA System Equipment, ! - Name

OutdoorAir:Mixer, !- Component 1 object Type

SYS2 OA Mixing Box; !- Component 1 Name

AirLoopHVAC: OutdoorAirSystem: EquipmentList,

SYS1 OA System Equipment, ! - Name

OutdoorAir:Mixer, !- Component 1 object Type

SYS1 OA Mixing Box; !- Component 1 Name

OutdoorAir:Mixer,

SYS10 OA Mixing Box, ! - Name

SYS10 Mixed Air Outlet, !- Mixed Air Node Name

SYS10 Outside Air Inlet, !- Outdoor Air Stream Node Name

SYS10 Relief Air Outlet, !- Relief Air stream Node Name 


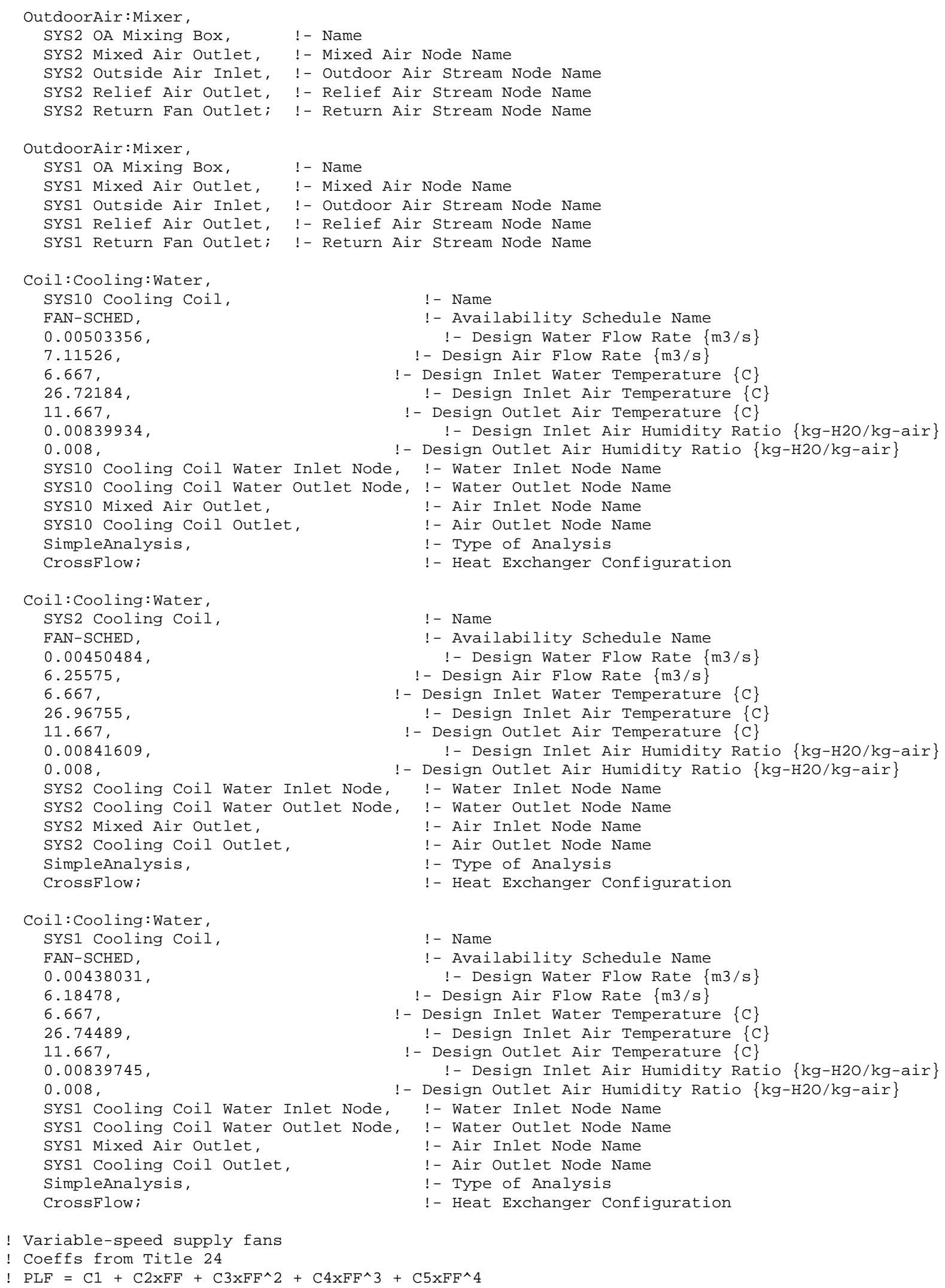




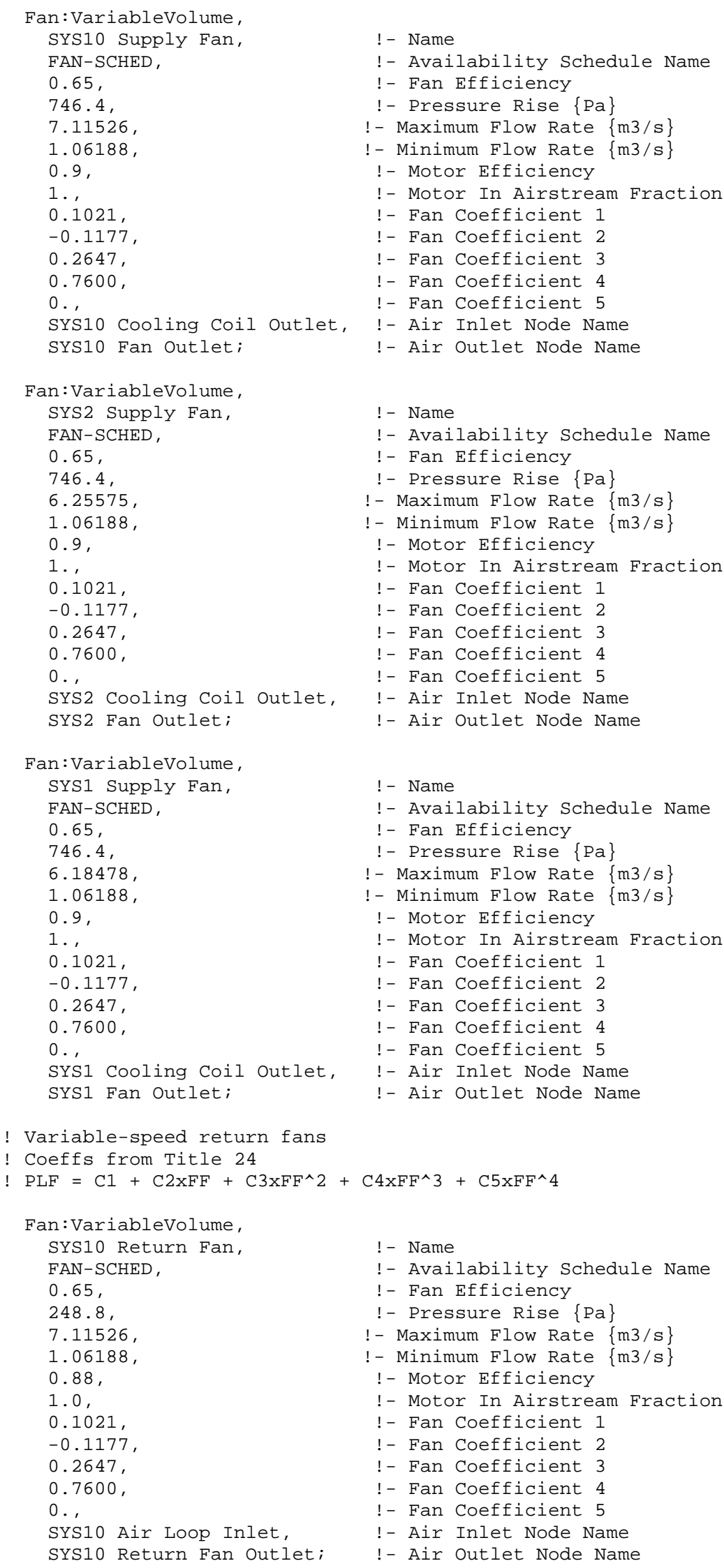




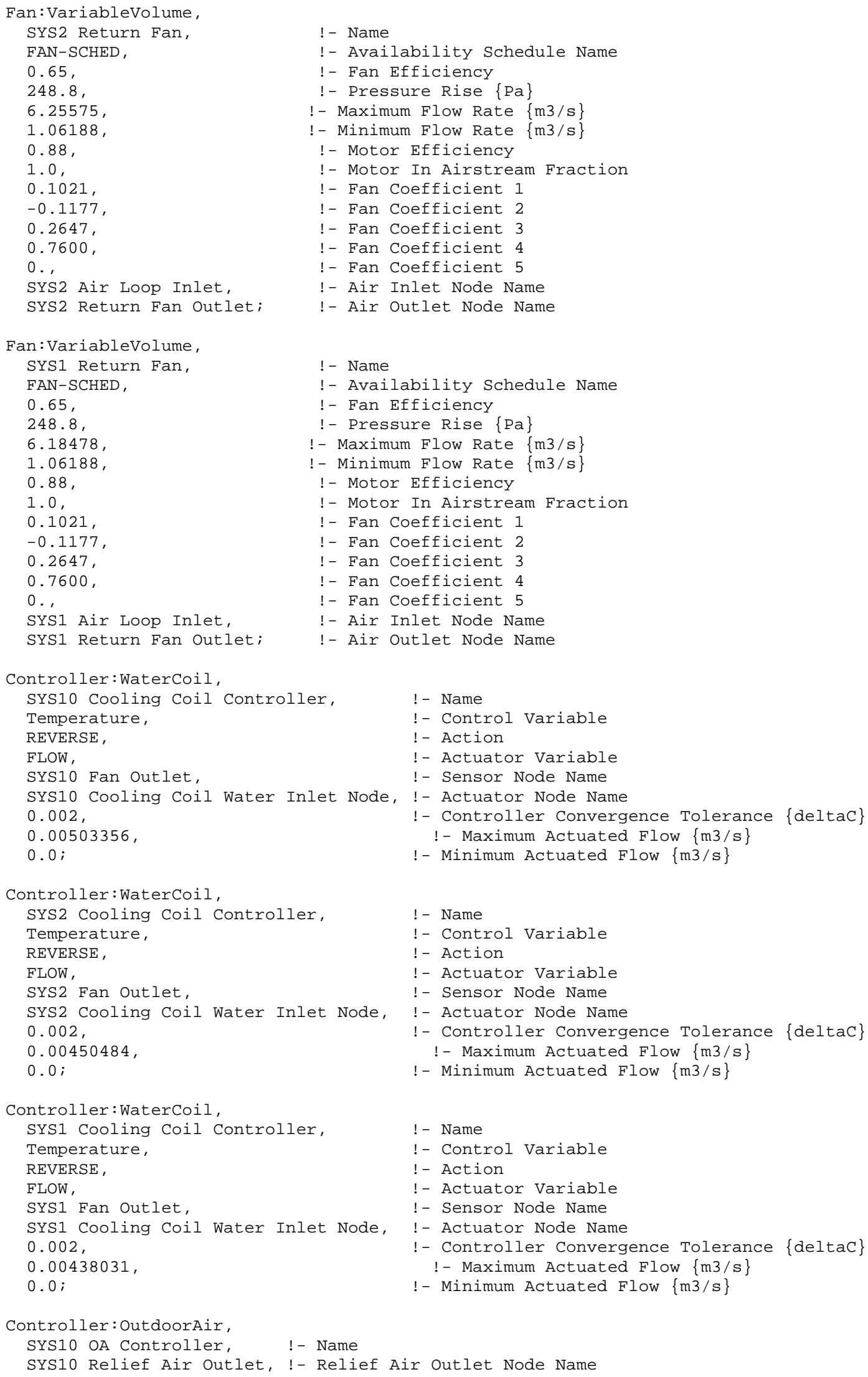

Controller: OutdoorAir, SYS10 OA Controller, ! - Name SYS10 Relief Air Outlet, !- Relief Air Outlet Node Name 
SYS10 Return Fan Outlet, !- Return Air Node Name

SYS10 Mixed Air outlet, !- Mixed Air Node Name

SYS10 Outside Air Inlet, !- Actuator Node Name

1.06185, !- Minimum Outdoor Air Flow Rate $\{\mathrm{m} 3 / \mathrm{s}\}$

7.11526, !- Maximum Outdoor Air Flow Rate $\{\mathrm{m} 3 / \mathrm{s}\}$

DifferentialDryBulb, !- Economizer Control Type (OAmin for Toa, $d b>T r a, d b$ )

ModulateFlow, !- Economizer Control Action Type

21.111,

Toa, $\mathrm{db}>\lim )$

'́loLockout

FixedMinimum,

!- Economizer Maximum Limit Dry-Bulb Temperature 70F

$\{C\}$ (OAmin for

FAN-SCHED ;

! - Economizer Maximum Limit Enthalpy $\{\mathrm{J} / \mathrm{kg}\}$

!- Economizer Maximum Limit Dewpoint Temperature $\{\mathrm{C}\}$

! - Electronic Enthalpy Limit Curve Name

!- Economizer Minimum Limit Dry-Bulb Temperature $\{\mathrm{C}\}$

! - Lockout Type

! - Minimum Limit Type

! - Minimum Outdoor Air Schedule Name

Controller: OutdoorAir,

SYS2 OA Controller, ! - Name

SYS2 Relief Air Outlet, !- Relief Air outlet Node Name

SYS2 Return Fan Outlet, !- Return Air Node Name

SYS2 Mixed Air outlet, !- Mixed Air Node Name

SYS2 Outside Air Inlet, !- Actuator Node Name

1.06185, ! - Minimum Outdoor Air Flow Rate $\{\mathrm{m} 3 / \mathrm{s}\}$

6.25575, !- Maximum Outdoor Air Flow Rate $\{\mathrm{m} 3 / \mathrm{s}\}$

DifferentialDryBulb, !- Economizer Control Type (OAmin for Toa, db>Tra, db)

ModulateFlow, !- Economizer Control Action Type

21.111,

Toa, $d b>\lim$ )

,

'́locockout

FixedMinimum,

!- Economizer Maximum Limit Dry-Bulb Temperature 70F

$\{C\}$ (OAmin for

FAN-SCHED

!- Economizer Maximum Limit Enthalpy $\{\mathrm{J} / \mathrm{kg}\}$

!- Economizer Maximum Limit Dewpoint Temperature $\{\mathrm{C}\}$

! - Electronic Enthalpy Limit Curve Name

!- Economizer Minimum Limit Dry-Bulb Temperature $\{\mathrm{C}\}$

! - Lockout Type

! - Minimum Limit Type

! - Minimum Outdoor Air Schedule Name

Controller:OutdoorAir,

SYS1 OA Controller, ! - Name

SYS1 Relief Air Outlet, !- Relief Air outlet Node Name

SYS1 Return Fan Outlet, !- Return Air Node Name

SYS1 Mixed Air outlet, !- Mixed Air Node Name

SYS1 Outside Air Inlet, !- Actuator Node Name

1.06185,

6.18478

- Minimum Outdoor Air Flow Rate $\{\mathrm{m} 3 / \mathrm{s}\}$

! - Maximum Outdoor Air Flow Rate $\{\mathrm{m} 3 / \mathrm{s}\}$

DifferentialdryBulb, Modulateflow,

21.111,

Toa, $d b>\lim$ )

,

'́loLockout

FixedMinimum,

!- Economizer Control Type (OAmin for Toa, $d b>T r a, d b$ )

! - Economizer Control Action Type

! - Economizer Maximum Limit Dry-Bulb Temperature 70F $\{\mathrm{C}\}$ (OAmin for

FAN-SCHED;

!- Economizer Maximum Limit Enthalpy $\{\mathrm{J} / \mathrm{kg}\}$

! - Economizer Maximum Limit Dewpoint Temperature $\{\mathrm{C}\}$

! - Electronic Enthalpy Limit Curve Name

!- Economizer Minimum Limit Dry-Bulb Temperature $\{\mathrm{C}\}$

! - Lockout Type

! - Minimum Limit Type

! - Minimum Outdoor Air Schedule Name

! No main heating coil so no associated main heating coil controller

SetpointManager: Scheduled,

SYS10 Setpoint Manager 1, ! Name

Temperature, ! - Control Variable

ConstSetSched11.7, !- Schedule Name

SYS10 Sup Air Temp Nodes; !- Setpoint Node or NodeList Name

SetpointManager: Scheduled,

SYS2 Setpoint Manager 1, ! - Name

Temperature

ConstSetSched11.7, !- Schedule Name

SYS2 Sup Air Temp Nodes; !- Setpoint Node or NodeList Name 


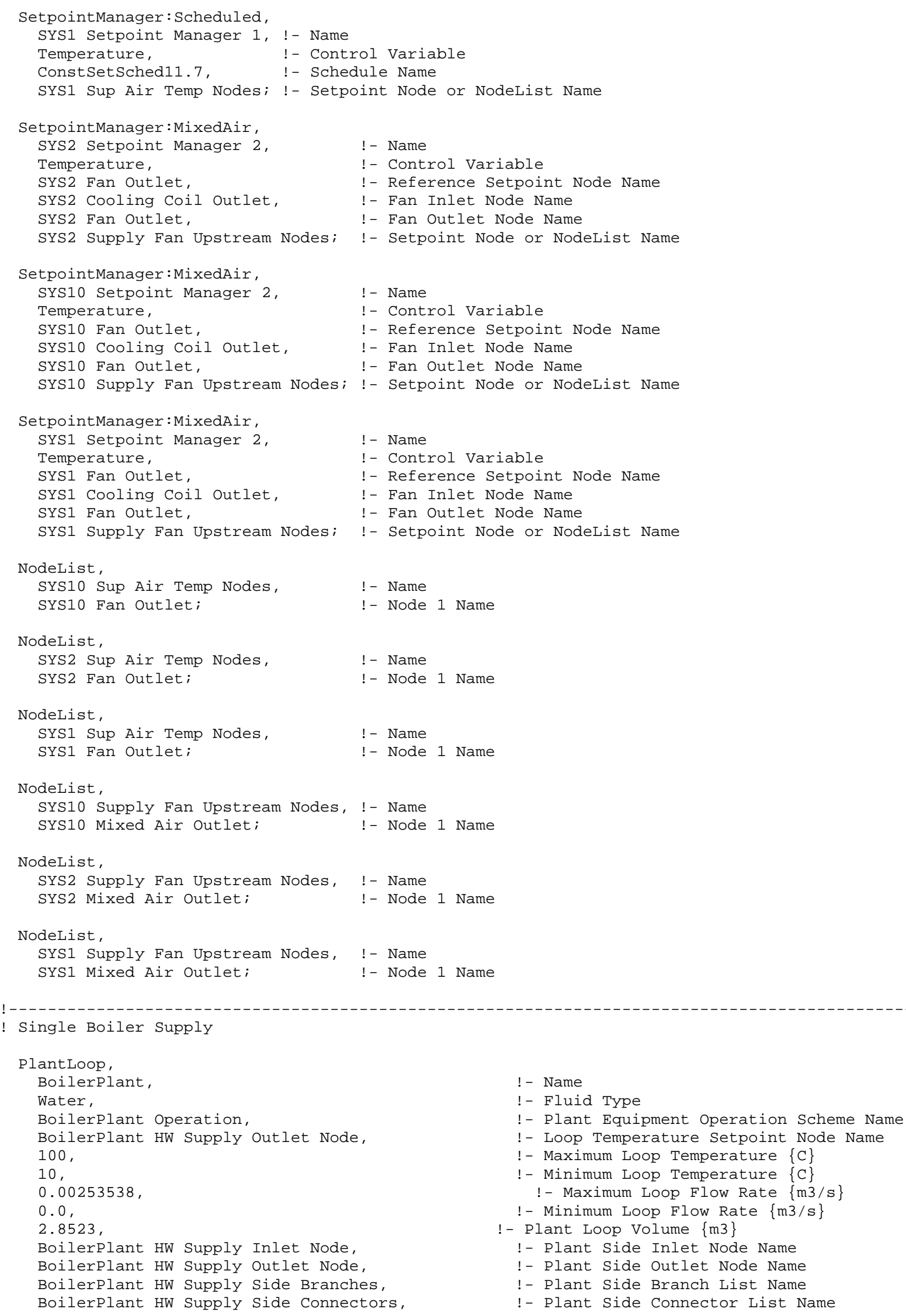


HWdemand1 HW Demand Inlet Node, HWdemand1 HW Demand Outlet Node, HWdemand1 HW Demand Side Branches, HWdemand1 HW Demand Side Connectors, Optimal;

SetpointManager: Scheduled, BoilerPlant HW Temp Manager, Temperature, ConstSetSched82.2, BoilerPlant HW Supply Outlet Node;

BranchList, BoilerPlant HW Supply Side Branches, BoilerPlant HW Supply Inlet Branch, BoilerPlant Boiler Branch, BoilerPlant HW Supply Bypass Branch, BoilerPlant HW Supply outlet Branch;

ConnectorList, BoilerPlant HW Supply Side Connectors, Connector:Splitter, BoilerPlant HW Supply Splitter, Connector:Mixer, BoilerPlant HW Supply Mixer;

! Use variable speed pump

Branch, BoilerPlant HW Supply Inlet Branch, Pump : Variablespeed, BoilerPlant HW Circ Pump, BoilerPlant HW Supply Inlet Node, BoilerPlant HW Pump Outlet Node, Active;

Branch,

BoilerPlant Boiler Branch,

Boiler:Hotwater,

BoilerPlant Boiler,

BoilerPlant Boiler Inlet Node,

BoilerPlant Boiler Outlet Node, Active;

Branch,

BoilerPlant HW Supply Bypass Branch,

Pipe: Adiabatic,

BoilerPlant HW Supply Side Bypass,

BoilerPlant HW Supply Bypass Inlet Node,

BoilerPlant HW Supply Bypass Outlet Node, Bypass;

Pipe:Adiabatic,

BoilerPlant HW Supply Side Bypass, BoilerPlant HW Supply Bypass Inlet Node, BoilerPlant HW Supply Bypass Outlet Node;

Branch, BoilerPlant HW Supply Outlet Branch,

Pipe:Adiabatic BoilerPlant HW Supply outlet, BoilerPlant HW Supply Exit Pipe Inlet Node, BoilerPlant HW Supply Outlet Node, Passive;

Pipe: Adiabatic BoilerPlant HW Supply outlet,
! - Demand Side Inlet Node Name

! - Demand Side Outlet Node Name

! - Demand Side Branch List Name

! - Demand Side Connector List Name

! - Load Distribution Scheme

! - Name

! - Control Variable

! - Schedule Name

! - Setpoint Node or NodeList Name

! - Name

! - Branch 1 Name

! - Branch 2 Name

! - Branch 3 Name

!- Branch 4 Name

! - Name

! - Connector 1 Object Type

! - Connector 1 Name

!- Connector 2 Object Type

! - Connector 2 Name
! - Name

! - Maximum Flow Rate $\{\mathrm{m} 3 / \mathrm{s}\}$

! - Component 1 Object Type

! - Component 1 Name

! - Component 1 Inlet Node Name

! - Component 1 Outlet Node Name

!- Component 1 Branch Control Type

! - Name

! - Maximum Flow Rate $\{\mathrm{m} 3 / \mathrm{s}\}$

! - Component 1 object Type

! - Component 1 Name

! - Component 1 Inlet Node Name

! - Component 1 Outlet Node Name

!- Component 1 Branch Control Type

! - Name

! - Maximum Flow Rate $\{\mathrm{m} 3 / \mathrm{s}\}$

! - Component 1 object Type

! - Component 1 Name

! - Component 1 Inlet Node Name

! - Component 1 outlet Node Name

!- Component 1 Branch Control Type

! - Name

! - Inlet Node Name

! - Outlet Node Name

! - Name

! - Maximum Flow Rate $\{\mathrm{m} 3 / \mathrm{s}\}$

! - Component 1 object Type

! - Component 1 Name

! - Component 1 Inlet Node Name

! - Component 1 Outlet Node Name

!- Component 1 Branch Control Type

! - Name 
BoilerPlant HW Supply Exit Pipe Inlet Node, BoilerPlant HW Supply Outlet Node;

BranchList,

HWdemand1 HW Demand Side Branches,

HWdemand1 HW Inlet Branch,

PER-1T HW-Branch,

PER-2T HW-Branch,

PER-3T HW-Branch,

PER-4T HW-Branch,

COR-1T HW-Branch,

PER-1I HW-Branch,

PER-2I HW-Branch,

PER-3I HW-Branch,

PER-4I HW-Branch,

COR-1I HW-Branch,

PER-1F HW-Branch,

PER-2F HW-Branch,

PER-3F HW-Branch,

PER-4F HW-Branch,

COR-1F HW-Branch,

HWdemand1 HW Bypass Branch,

HWdemand1 HW Outlet Branch;

ConnectorList,

HWdemand1 HW Demand Side Connectors,

Connector:Splitter,

HWdemand1 HW Splitter,

Connector:Mixer,

HWdemand1 HW Mixer;

Branch,

HWdemand1 HW Inlet Branch,

Pipe:Adiabatic

HWdemand1 HW Inlet Pipe,

HWdemand1 HW Demand Inlet Node,

HWdemand1 HW Demand Entrance Pipe outlet Node, Passive;

Pipe: Adiabatic

HWdemand1 HW Inlet Pipe,

HWdemand1 HW Demand Inlet Node,

HWdemand1 HW Demand Entrance Pipe Outlet Node;

Branch,

HWdemand1 HW Outlet Branch,

Pipe: Adiabatic,

HWdemand1 HW Outlet Pipe,

HWdemand1 HW Demand Exit Pipe Inlet Node,

HWdemand1 HW Demand Outlet Node,

Passive;

Pipe:Adiabatic

HWdemand1 HW Outlet Pipe,

HWdemand1 HW Demand Exit Pipe Inlet Node, HWdemand1 HW Demand Outlet Node;

Branch,

PER-1T HW-Branch,

Coil: Heating:Water

PER-1T Reheat Coil,

PER-1T Reheat Coil HW Inlet,

PER-1T Reheat Coil HW Outlet,

Active;

Branch,

PER-2T HW-Branch,

,
! - Inlet Node Name

! - Outlet Node Name

! - Name

! - Branch 1 Name

! - Branch 2 Name

! - Branch 3 Name

! - Branch 4 Name

! - Branch 5 Name

! - Branch 6 Name

! - Branch 7 Name

! - Branch 8 Name

! - Branch 9 Name

! - Branch 10 Name

! - Branch 11 Name

! - Branch 12 Name

! - Branch 13 Name

! - Branch 14 Name

! - Branch 15 Name

! - Branch 16 Name

! - Branch 17 Name

! - Branch 18 Name

! - Name

! - Connector 1 object Type

! - Connector 1 Name

! - Connector 2 object Type

!- Connector 2 Name

! - Name

! - Maximum Flow Rate $\{\mathrm{m} 3 / \mathrm{s}\}$

! - Component 1 Object Type

! - Component 1 Name

!- Component 1 Inlet Node Name

! - Component 1 outlet Node Name

!- Component 1 Branch Control Type

! - Name

! - Inlet Node Name

! - Outlet Node Name

! - Name

! - Maximum Flow Rate $\{\mathrm{m} 3 / \mathrm{s}\}$

! - Component 1 Object Type

! - Component 1 Name

! - Component 1 Inlet Node Name

! - Component 1 Outlet Node Name

!- Component 1 Branch Control Type

! - Name

! - Inlet Node Name

! - Outlet Node Name

! - Name

! - Maximum Flow Rate $\{\mathrm{m} 3 / \mathrm{s}\}$

! - Component 1 object Type

! - Component 1 Name

! - Component 1 Inlet Node Name

! - Component 1 Outlet Node Name

!- Component 1 Branch Control Type

! - Name

!- Maximum Flow Rate $\{\mathrm{m} 3 / \mathrm{s}\}$ 
Coil: Heating:Water, PER-2T Reheat Coil, PER-2T Reheat Coil HW Inlet, PER-2T Reheat coil HW Outlet, Active;

Branch,

PER-3T HW-Branch,

,

Coil: Heating:Water,

PER-3T Reheat Coil,

PER-3T Reheat Coil HW Inlet, PER-3T Reheat Coil HW Outlet, Active;

Branch,

PER-4T HW-Branch,

,

Coil: Heating:Water,

PER-4T Reheat Coil,

PER-4T Reheat Coil HW Inlet,

PER-4T Reheat Coil HW Outlet, Active;

Branch,

COR-1T HW-Branch,

'

Coil: Heating:Water,

COR-1T Reheat Coil,

COR-1T Reheat Coil HW Inlet,

COR-1T Reheat Coil HW Outlet, Active;

Branch,

PER-1I HW-Branch,

'

Coil: Heating:Water, PER-1I Reheat Coil,

PER-1I Reheat Coil HW Inlet, PER-1I Reheat Coil HW Outlet, Active;

Branch,

PER-2I HW-Branch,

'́oil: Heating: Water,

PER-2I Reheat Coil,

PER-2I Reheat Coil HW Inlet, PER-2I Reheat Coil HW Outlet, Active;

Branch,

PER-3I HW-Branch,

Coil: Heating:Water,

PER-3I Reheat Coil,

PER-3I Reheat Coil HW Inlet, PER-3I Reheat Coil HW Outlet, Active;

Branch,

PER-4I HW-Branch,

Coil: Heating: Water,

PER-4I Reheat Coil,

PER-4I Reheat Coil HW Inlet, PER-4I Reheat Coil HW Outlet, Active;

Branch,

COR-1I HW-Branch,
! - Component 1 object Type

! - Component 1 Name

! - Component 1 Inlet Node Name

! - Component 1 Outlet Node Name

!- Component 1 Branch Control Type

! - Name

!- Maximum Flow Rate $\{\mathrm{m} 3 / \mathrm{s}\}$

! - Component 1 object Type

! - Component 1 Name

! - Component 1 Inlet Node Name

! - Component 1 Outlet Node Name

!- Component 1 Branch Control Type

! - Name

! - Maximum Flow Rate $\{\mathrm{m} 3 / \mathrm{s}\}$

! - Component 1 Object Type

! - Component 1 Name

! - Component 1 Inlet Node Name

! - Component 1 Outlet Node Name

! - Component 1 Branch Control Type

! - Name

! - Maximum Flow Rate $\{\mathrm{m} 3 / \mathrm{s}\}$

! - Component 1 Object Type

! - Component 1 Name

! - Component 1 Inlet Node Name

!- Component 1 Outlet Node Name

!- Component 1 Branch Control Type

! - Name

! - Maximum Flow Rate $\{\mathrm{m} 3 / \mathrm{s}\}$

! - Component 1 Object Type

! - Component 1 Name

!- Component 1 Inlet Node Name

!- Component 1 Outlet Node Name

!- Component 1 Branch Control Type

! - Name

! - Maximum Flow Rate $\{\mathrm{m} 3 / \mathrm{s}\}$

! - Component 1 Object Type

! - Component 1 Name

! - Component 1 Inlet Node Name

! - Component 1 Outlet Node Name

! - Component 1 Branch Control Type

! - Name

! - Maximum Flow Rate $\{\mathrm{m} 3 / \mathrm{s}\}$

!- Component 1 Object Type

! - Component 1 Name

!- Component 1 Inlet Node Name

! - Component 1 Outlet Node Name

!- Component 1 Branch Control Type

! - Name

! - Maximum Flow Rate $\{\mathrm{m} 3 / \mathrm{s}\}$

!- Component 1 Object Type

! - Component 1 Name

! - Component 1 Inlet Node Name

! - Component 1 outlet Node Name

!- Component 1 Branch Control Type

! - Name 
Coil: Heating:Water,

COR-1I Reheat Coil,

COR-1I Reheat Coil HW Inlet,

COR-1I Reheat Coil HW Outlet, Active;

Branch,

PER-1F HW-Branch,

Coil: Heating: Water,

PER-1F Reheat Coil,

PER-1F Reheat Coil HW Inlet,

PER-1F Reheat Coil HW Outlet, Active;

Branch,

PER-2F HW-Branch,

Coil: Heating:Water,

PER-2F Reheat Coil,

PER-2F Reheat Coil HW Inlet,

PER-2F Reheat Coil HW Outlet, Active;

Branch,

PER-3F HW-Branch,

Coil: Heating: Water,

PER-3F Reheat Coil,

PER-3F Reheat Coil HW Inlet,

PER-3F Reheat Coil HW Outlet,

Active;

Branch,

PER-4F HW-Branch,

Coil: Heating:Water,

PER-4F Reheat Coil,

PER-4F Reheat Coil HW Inlet,

PER-4F Reheat Coil HW Outlet,

Active;

Branch,

COR-1F HW-Branch,

Coil: Heating:Water,

COR-1F Reheat Coil,

COR-1F Reheat Coil HW Inlet,

COR-1F Reheat Coil HW Outlet,

Active;
! - Maximum Flow Rate $\{\mathrm{m} 3 / \mathrm{s}\}$

! - Component 1 Object Type

! - Component 1 Name

!- Component 1 Inlet Node Name

! - Component 1 Outlet Node Name

!- Component 1 Branch Control Type

! - Name

! - Maximum Flow Rate $\{\mathrm{m} 3 / \mathrm{s}\}$

!- Component 1 Object Type

! - Component 1 Name

! - Component 1 Inlet Node Name

! - Component 1 Outlet Node Name

!- Component 1 Branch Control Type

! - Name

! - Maximum Flow Rate $\{\mathrm{m} 3 / \mathrm{s}\}$

! - Component 1 Object Type

! - Component 1 Name

! - Component 1 Inlet Node Name

! - Component 1 Outlet Node Name

!- Component 1 Branch Control Type

! - Name

! - Maximum Flow Rate $\{\mathrm{m} 3 / \mathrm{s}\}$

! - Component 1 Object Type

! - Component 1 Name

!- Component 1 Inlet Node Name

! - Component 1 Outlet Node Name

!- Component 1 Branch Control Type

! - Name

! - Maximum Flow Rate $\{\mathrm{m} 3 / \mathrm{s}\}$

!- Component 1 Object Type

! - Component 1 Name

!- Component 1 Inlet Node Name

!- Component 1 Outlet Node Name

!- Component 1 Branch Control Type

! - Name

! - Maximum Flow Rate $\{\mathrm{m} 3 / \mathrm{s}\}$

! - Component 1 Object Type

! - Component 1 Name

! - Component 1 Inlet Node Name

! - Component 1 Outlet Node Name

!- Component 1 Branch Control Type

! no main heating coil (so no associated coil branch)

Branch, HWdemand1 HW Bypass Branch,

'Pipe:Adiabatic,

HWdemand1 HW Bypass Pipe,

HWdemand1 HW Bypass Inlet Node,

HWdemand1 HW Bypass Outlet Node,

Bypass;

! - Name

! - Maximum Flow Rate $\{\mathrm{m} 3 / \mathrm{s}\}$

! - Component 1 Object Type

! - Component 1 Name

! - Component 1 Inlet Node Name

! - Component 1 Outlet Node Name

!- Component 1 Branch Control Type

Pipe: Adiabatic

HWdemand1 HW Bypass Pipe,

HWdemand1 HW Bypass Inlet Node,

HWdemand1 HW Bypass Outlet Node;

! - Name

! - Inlet Node Name

! - Outlet Node Name

Connector: Splitter

HWdemand1 HW Splitter,

HWdemand1 HW Inlet Branch,

! - Name

! - Inlet Branch Name 
PER-1T HW-Branch, PER-2T HW-Branch, PER-3T HW-Branch, PER-4T HW-Branch, COR-1T HW-Branch, PER-1I HW-Branch, PER-2I HW-Branch, PER-3I HW-Branch, PER-4I HW-Branch, COR-1I HW-Branch, PER-1F HW-Branch, PER-2F HW-Branch, PER-3F HW-Branch, PER-4F HW-Branch, COR-1F HW-Branch, HWdemand1 HW Bypass Branch;

Connector:Mixer,

HWdemand1 HW Mixer

HWdemand1 HW Outlet Branch, PER-1T HW-Branch,

PER-2T HW-Branch, PER-3T HW-Branch, PER-4T HW-Branch, COR-1T HW-Branch, PER-1I HW-Branch, PER-2I HW-Branch, PER-3I HW-Branch, PER-4I HW-Branch, COR-1I HW-Branch, PER-1F HW-Branch, PER-2F HW-Branch, PER-3F HW-Branch, PER-4F HW-Branch, COR-1F HW-Branch, HWdemand1 HW Bypass Branch;

Connector:splitter

BoilerPlant HW Supply splitter, BoilerPlant HW Supply Inlet Branch, BoilerPlant Boiler Branch,

BoilerPlant HW Supply Bypass Branch;

Connector:Mixer,

BoilerPlant HW Supply Mixer,

BoilerPlant HW Supply Outlet Branch, BoilerPlant Boiler Branch,

BoilerPlant HW Supply Bypass Branch;

PlantEquipmentoperationschemes, BoilerPlant operation, PlantEquipmentoperation: HeatingLoad, BoilerPlant Heat Supply, FAN - SCHED;

PlantEquipmentoperation: HeatingLoad, BoilerPlant Heat Supply, $\odot$, 1000000000000000 , BoilerPlant heating plant;

PlantEquipmentList, BoilerPlant heating plant, Boiler:Hotwater, BoilerPlant Boiler;
! - Outlet Branch 1 Name

! - Outlet Branch 2 Name

! - Outlet Branch 3 Name

! - outlet Branch 4 Name

! - Outlet Branch 5 Name

! - Outlet Branch 6 Name

! - Outlet Branch 7 Name

! - Outlet Branch 8 Name

! - Outlet Branch 9 Name

! - Outlet Branch 10 Name

! - Outlet Branch 11 Name

! - Outlet Branch 12 Name

! - Outlet Branch 13 Name

! - Outlet Branch 14 Name

! - Outlet Branch 15 Name

! - Outlet Branch 16 Name

! - Name

! - Outlet Branch Name

! - Inlet Branch 1 Name

! - Inlet Branch 2 Name

! - Inlet Branch 3 Name

! - Inlet Branch 4 Name

! - Inlet Branch 5 Name

! - Inlet Branch 6 Name

! - Inlet Branch 7 Name

! - Inlet Branch 8 Name

! - Inlet Branch 9 Name

! - Inlet Branch 10 Name

! - Inlet Branch 11 Name

! - Inlet Branch 12 Name

! - Inlet Branch 13 Name

! - Inlet Branch 14 Name

! - Inlet Branch 15 Name

! - Inlet Branch 16 Name

! - Name

! - Inlet Branch Name

! - Outlet Branch 1 Name

! - Outlet Branch 2 Name

! - Name

! - Outlet Branch Name

! - Inlet Branch 1 Name

! - Inlet Branch 2 Name

! - Name

! - Control Scheme 1 object Type

! - Control Scheme 1 Name

! - Control Scheme 1 Schedule Name

! - Name

! - Load Range 1 Lower Limit $\{W\}$

! - Load Range 1 Upper Limit $\{W\}$

! - Priority Control 1 Equipment List Name

! - Name

! - Equipment 1 object Type

! - Equipment 1 Name

! Coefficients below are curve fit to DOE-2 fuel use vs PLR default curve for HW boiler

Boiler:Hotwater, BoilerPlant Boiler, ! - Name NaturalGas, 
176634.73428 ,

0.79 ,

Boilerplant Boiler Efficiency Curve,

82.222 ,

0.00253538,

0.0,

1. 2,

1.0,

BoilerPlant Boiler Inlet Node,

BoilerPlant Boiler Outlet Node,

100.0 ,

VariableFlow;

Curve: Quadratic,

BoilerPlant Boiler Efficiency Curve,

$\odot .5887682$,

$\odot .7888184$

-0.3862498 ,

$\odot$,

1 ;

Pump: Variablespeed,

BoilerPlant HW Circ Pump,

BoilerPlant HW Supply Inlet Node,

BoilerPlant HW Pump Outlet Node,

0.00253538 ,

179344 . ,

647.72702 ,

0.9 ,

$\odot .$,

Stream

$\odot .$,

Performance Curve

$1 .$,

Performance Curve

$0 .$,

Performance Curve

O. ,

Performance Curve

$\odot$,

Intermittent;

\author{
! - Nominal Capacity $\{W\}$ \\ ! - Nominal Thermal Efficiency \\ ! - Normalized Boiler Efficiency Curve Name \\ ! - Design Water outlet Temperature $\{\mathrm{C}\}$ \\ ! - Design water Flow Rate $\{\mathrm{m} 3 / \mathrm{s}\}$ \\ I - Minimum Part Load Ratio \\ ! - Maximum Part Load Ratio \\ ! - optimum Part Load Ratio \\ ! - Boiler Water Inlet Node Name \\ ! - Boiler Water Outlet Node Name \\ ! - Water Outlet Upper Temperature Limit $\{\mathrm{C}\}$ \\ ! - Boiler Flow Mode
}

! - Name

! - Coefficient1 Constant

! - Coefficient2 $x$

! - Coefficient $3 x^{* *} 2$

! - Minimum Value of $x$

! - Maximum Value of $x$

! - Name

! - Inlet Node Name

! - Outlet Node Name

! - Rated Flow Rate $\{\mathrm{m} 3 / \mathrm{s}\}$

! - Rated Pump Head $\{\mathrm{Pa}\}$

! - Rated Power Consumption $\{W\}$

! - Motor Efficiency

! - Fraction of Motor Inefficiencies to Fluid

! - Coefficient 1 of the Part Load

! - Coefficient 2 of the Part Load

! - Coefficient 3 of the Part Load

! - Coefficient 4 of the Part Load

! - Minimum Flow Rate $\{\mathrm{m} 3 / \mathrm{s}\}$

! - Pump Control Type

! Chilled Water Demand Side

! Single Chiller Supply

PlantLoop,

CHWPlant

Water,

CHWPlant operation

CHWPlant ChW Supply outlet Node, 98 ,

1

$\odot .0139187$

0.0 ,

15.65855

CHWPlant ChW Supply Inlet Node

CHWPlant ChW Supply outlet Node,

CHWPlant ChW Supply Side Branches,

CHWPlant ChW Supply Side Connectors,

CHWdemand1 ChW Demand Inlet Node,

CHWdemand1 ChW Demand Outlet Node

CHWdemand1 ChW Demand Side Branches,

CHWdemand1 ChW Demand Side Connectors,

optimal;

SetpointManager: Scheduled,

CHWPlant ChW Temp Manager,

Temperature,

CHWPlant ChW Temp Schedule,

CHWPlant ChW Supply outlet Node;
! - Name

! - Fluid Type

! - Plant Equipment Operation Scheme Name

! - Loop Temperature Setpoint Node Name

! - Maximum Loop Temperature $\{\mathrm{C}\}$

! - Minimum Loop Temperature $\{\mathrm{C}\}$

! - Maximum Loop Flow Rate $\{\mathrm{m} 3 / \mathrm{s}\}$

! - Minimum Loop Flow Rate $\{\mathrm{m} 3 / \mathrm{s}\}$

! - Plant Loop Volume $\{\mathrm{m} 3\}$

! - Plant Side Inlet Node Name

! - Plant Side Outlet Node Name

! - Plant Side Branch List Name

! - Plant Side Connector List Name

! - Demand Side Inlet Node Name

! - Demand Side Outlet Node Name

! - Demand Side Branch List Name

! - Demand Side Connector List Name

! - Load Distribution Scheme

! - Name

! - Control Variable

! - Schedule Name

! - Setpoint Node or NodeList Name 


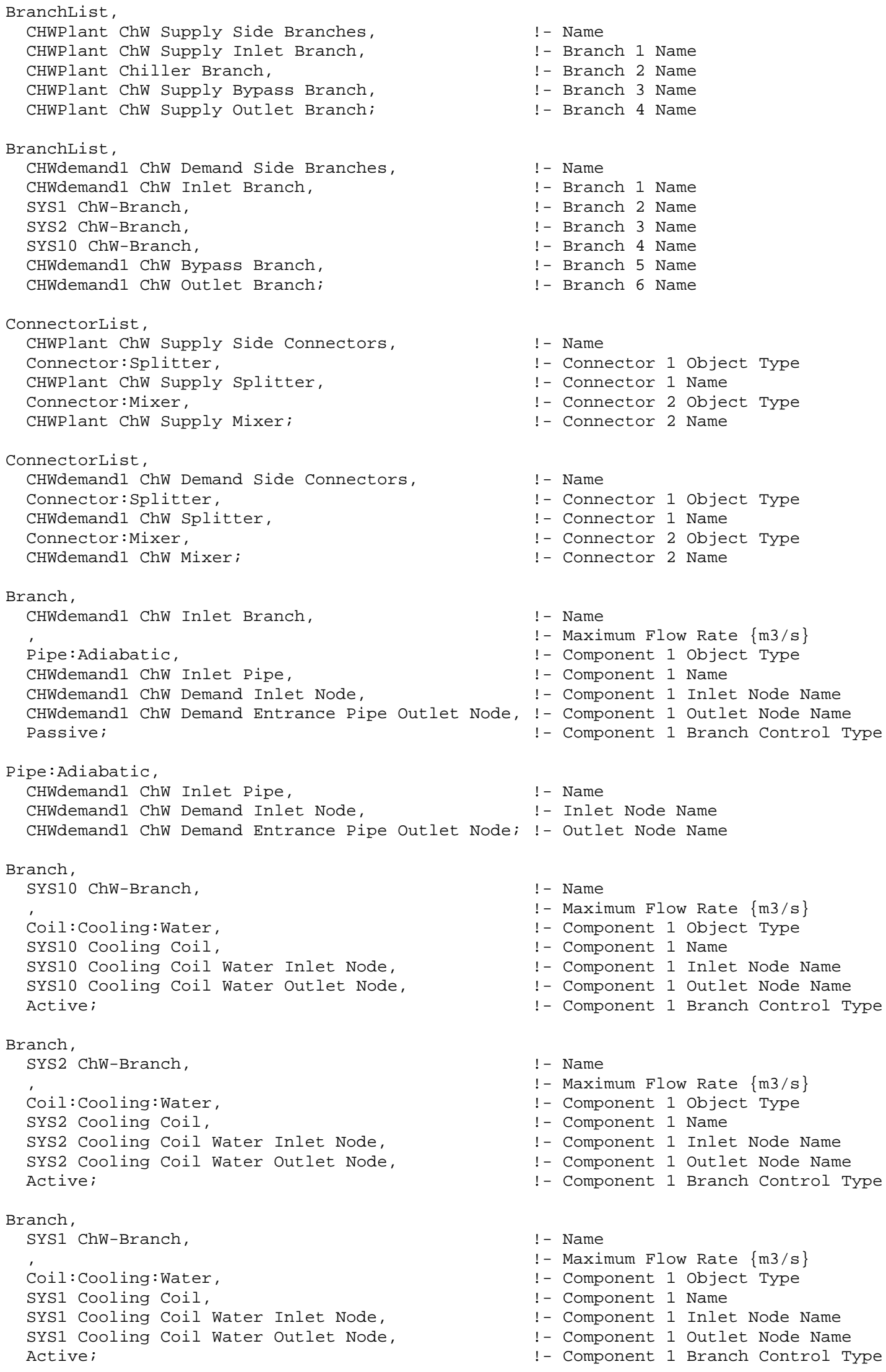


Branch,

CHWdemand1 ChW Bypass Branch,

Pipe: Adiabatic,

CHWdemand1 ChW Bypass Pipe,

CHWdemand1 ChW Bypass Inlet Node,

CHWdemand1 ChW Bypass outlet Node,

Bypass;

Pipe:Adiabatic,

CHWdemand1 ChW Bypass Pipe,

CHWdemand1 ChW Bypass Inlet Node,

CHWdemand1 ChW Bypass Outlet Node;

Branch,

CHWdemand1 ChW Outlet Branch,

Pipe: Adiabatic,

CHWdemand1 ChW Outlet Pipe,

CHWdemand1 ChW Demand Exit Pipe Inlet Node

CHWdemand1 ChW Demand Outlet Node,

Passive;

Pipe:Adiabatic

CHWdemand1 ChW Outlet Pipe,

CHWdemand1 ChW Demand Exit Pipe Inlet Node, CHWdemand1 ChW Demand Outlet Node;

Branch,

CHWPlant ChW Supply Outlet Branch,

'Pipe: Adiabatic,

CHWPlant ChW Supply outlet,

CHWPlant ChW Supply Exit Pipe Inlet Node,

CHWPlant ChW Supply Outlet Node,

Passive;

Pipe:Adiabatic,

CHWPlant ChW Supply outlet,

CHWPlant ChW Supply Exit Pipe Inlet Node,

CHWPlant ChW Supply Outlet Node;

Branch,

CHWPlant ChW Supply Inlet Branch,

Pump:Variablespeed,

CHWPlant ChW Circ Pump,

CHWPlant ChW Supply Inlet Node,

CHWPlant ChW Pump Outlet Node,

Active;

Branch,

CHWPlant Chiller Branch,

Chiller:Electric:EIR,

CHWPlant Chiller,

CHWPlant Chiller Inlet Node,

CHWPlant Chiller outlet Node,

Active;

Branch,

CHWPlant ChW Supply Bypass Branch,

Pipe:Adiabatic,

CHWPlant ChW Supply Side Bypass,

CHWPlant ChW Supply Bypass Inlet Node,

CHWPlant ChW Supply Bypass Outlet Node, Bypass ;

Pipe:Adiabatic,

\author{
! - Name \\ ! - Maximum Flow Rate $\{\mathrm{m} 3 / \mathrm{s}\}$ \\ ! - Component 1 object Type \\ ! - Component 1 Name \\ !- Component 1 Inlet Node Name \\ ! - Component 1 Outlet Node Name \\ !- Component 1 Branch Control Type
}

! - Name

! - Inlet Node Name

! - Outlet Node Name

! - Name

! - Maximum Flow Rate $\{\mathrm{m} 3 / \mathrm{s}\}$

!- Component 1 object Type

! - Component 1 Name

!- Component 1 Inlet Node Name

! - Component 1 outlet Node Name

! - Component 1 Branch Control Type

! - Name

! - Inlet Node Name

! - Outlet Node Name

! - Name

! - Maximum Flow Rate $\{\mathrm{m} 3 / \mathrm{s}\}$

! - Component 1 Object Type

! - Component 1 Name

! - Component 1 Inlet Node Name

! - Component 1 outlet Node Name

!- Component 1 Branch Control Type

! - Name

! - Inlet Node Name

! - Outlet Node Name

! - Name

! - Maximum Flow Rate $\{\mathrm{m} 3 / \mathrm{s}\}$

! - Component 1 Object Type

! - Component 1 Name

!- Component 1 Inlet Node Name

! - Component 1 Outlet Node Name

!- Component 1 Branch Control Type

! - Name

! - Maximum Flow Rate $\{\mathrm{m} 3 / \mathrm{s}\}$

! - Component 1 Object Type

! - Component 1 Name

! - Component 1 Inlet Node Name

! - Component 1 Outlet Node Name

!- Component 1 Branch Control Type

! - Name

! - Maximum Flow Rate $\{\mathrm{m} 3 / \mathrm{s}\}$

! - Component 1 object Type

! - Component 1 Name

! - Component 1 Inlet Node Name

! - Component 1 Outlet Node Name

!- Component 1 Branch Control Type 
CHWPlant ChW Supply Side Bypass,

CHWPlant ChW Supply Bypass Inlet Node,

CHWPlant ChW Supply Bypass Outlet Node;

Connector:Splitter,

CHWPlant ChW Supply Splitter,

CHWPlant ChW Supply Inlet Branch,

CHWPlant Chiller Branch,

CHWPlant ChW Supply Bypass Branch;

Connector:Mixer

CHWPlant ChW Supply Mixer,

CHWPlant ChW Supply outlet Branch,

CHWPlant Chiller Branch,

CHWPlant ChW Supply Bypass Branch;

Connector:Splitter,

CHWdemand1 ChW Splitter,

CHWdemand1 ChW Inlet Branch,

SYS10 ChW-Branch,

SYS2 ChW-Branch,

SYS1 ChW-Branch,

CHWdemand1 ChW Bypass Branch;

Connector:Mixer,

CHWdemand1 ChW Mixer,

CHWdemand1 ChW Outlet Branch,

SYS10 ChW-Branch,

SYS2 ChW-Branch,

SYS1 ChW-Branch,

CHWdemand1 ChW Bypass Branch;

PlantEquipmentoperationschemes, CHWPlant Operation,

PlantEquipmentoperation: CoolingLoad, CHWPlant ChW Supply,

FAN-SCHED ;

PlantEquipmentoperation: CoolingLoad CHWPlant ChW Supply,

$\odot$,

1000000000000000 ,

CHWPlant ChW Plant;

PlantEquipmentList,

CHWPlant ChW Plant,

Chiller:Electric:EIR,

CHWPlant Chiller;
! - Name

! - Inlet Node Name

! - Outlet Node Name

! - Name

! - Inlet Branch Name

! - Outlet Branch 1 Name

! - Outlet Branch 2 Name

! - Name

! - Outlet Branch Name

! - Inlet Branch 1 Name

! - Inlet Branch 2 Name

! - Name

! - Inlet Branch Name

! - Outlet Branch 1 Name

! - Outlet Branch 2 Name

! - Outlet Branch 3 Name

! - Outlet Branch 4 Name

! - Name

! - Outlet Branch Name

! - Inlet Branch 1 Name

! - Inlet Branch 2 Name

! - Inlet Branch 3 Name

!- Inlet Branch 4 Name

! - Name

! - Control Scheme 1 Object Type

! - Control Scheme 1 Name

! - Control Scheme 1 Schedule Name

! - Name

! - Load Range 1 Lower Limit $\{W\}$

! - Load Range 1 Upper Limit $\{W\}$

!- Priority Control 1 Equipment List Name

! - Name

!- Equipment 1 Object Type

!- Equipment 1 Name

! Generic hermetic centrifugal chiller from DOE-2.1E

Chiller:Electric:EIR, CHWPlant Chiller, 387887.48643 ,

5.5

6.667 ,

Temperature $(44 \mathrm{~F})\{\mathrm{C}\}$

29.444,

Temperature $(85 \mathrm{~F})\{\mathrm{C}\}$

0.0139187 ,

$\{\mathrm{m} 3 / \mathrm{s}\}$

$\odot .0197387$

HERM - CENT - CAP - FT

Curve Name HERM-CENT-EIR-FT,

Temperature Curve Name HERM-CENT-EIR-FP,

PLR Curve Name

0.1 ,

1.0

1.0 ,
! - Name

! - Reference Capacity $\{W\}$

! - Reference COP $\{W / W\}$

! - Reference Leaving Chilled Water

! - Reference Entering Condenser Fluid

! - Reference Chilled water Flow Rate $\{\mathrm{m} 3 / \mathrm{s}\}$

! - Reference Condenser Water Flow Rate

! - Cooling Capacity Function of Temperature

! - Electric Input/Cooling Output Function of

! - Electric Input/Cooling Output Function of

! - Minimum Part Load Ratio

! - Maximum Part Load Ratio

! - optimum Part Load Ratio 
0.2 ,

CHWPlant Chiller Inlet Node,

CHWPlant Chiller outlet Node,

CHWPlant Chiller Cond Inlet Node,

CHWPlant Chiller Cond Outlet Node, Watercooled,

1. $\odot$

2. 0 ,

Limit $\{\mathrm{C}\}$

Variableflow;

Pump:Variablespeed,

CHWPlant ChW Circ Pump,

CHWPlant ChW Supply Inlet Node,

CHWPlant ChW Pump Outlet Node,

0.0139187,

179344 . ,

3555.89277 ,

0.9 ,

$0 .$,

Stream

$0 .$,

Performance Curve

$1 .$,

Performance Curve

$0 .$,

Performance Curve

$0 .$,

Performance Curve

$\odot$,

Intermittent;
! - Minimum Unloading Ratio

! - Chilled Water Inlet Node Name

! - Chilled Water Outlet Node Name

!- Condenser Inlet Node Name

! - Condenser Outlet Node Name

! - Condenser Type

! - Condenser Fan Power Ratio $\{W / W\}$

! - Compressor Motor Efficiency

!- Leaving Chilled Water Lower Temperature

! - Chiller Flow Mode

! - Name

! - Inlet Node Name

! - Outlet Node Name

! - Rated Flow Rate $\{\mathrm{m} 3 / \mathrm{s}\}$

! - Rated Pump Head $\{\mathrm{Pa}\}$

! - Rated Power Consumption $\{W\}$

! - Motor Efficiency

! - Fraction of Motor Inefficiencies to Fluid

! - Coefficient 1 of the Part Load

!- Coefficient 2 of the Part Load

!- Coefficient 3 of the Part Load

! - Coefficient 4 of the Part Load

!- Minimum Flow Rate $\{\mathrm{m} 3 / \mathrm{s}\}$

!- Pump Control Type

! Single Tower Supply

CondenserLoop,

CHWPlant Condenser Loop,

Water,

CHWPlant Condenser Loop Operation, AIR,

Name/Ref

80 ,

5,

0.0197387

0.0

22. 206,

CHWPlant Cnd Supply Inlet Node

CHWPlant Cnd Supply outlet Node,

CHWPlant Condenser Supply Side Branches,

CHWPlant Condenser Supply Side Connectors,

CHWPlant Cnd Demand Inlet Node,

CHWPlant Cnd Demand Outlet Node,

CHWPlant Cnd Demand Side Branches,

CHWPlant Cnd Demand Side Connectors,

Sequential;

BranchList,

CHWPlant Condenser Supply Side Branches,

CHWPlant Condenser Supply Inlet Branch,

CHWPlant Tower Branch,

CHWPlant Condenser Supply Bypass Branch,

CHWPlant Condenser Supply Outlet Branch;

ConnectorList,

CHWPlant Condenser Supply Side Connectors,

Connector:Splitter,

CHWPlant Condenser Supply Splitter,

Connector:Mixer,

CHWPlant Condenser Supply Mixer;

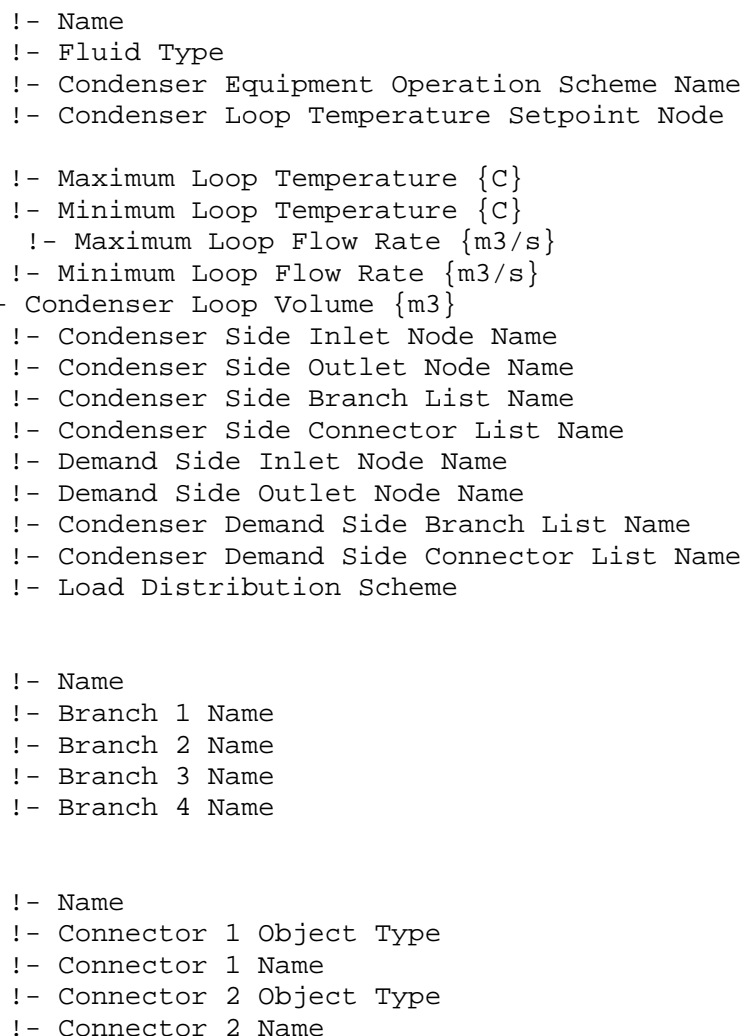

! - Name

! - Fluid Type

! - Condenser Equipment Operation Scheme Name

- Condenser Loop Temperature Setpoint Node

- Condenser Loop Volume $\{\mathrm{m} 3\}$

- Condenser Side Inlet Node

1 - Condenser Side Branch List Name

! - Condenser Side Connector List Name

- Demand Side Inlet Node Name

! - Condenser Demand Side Connector List Name

! - Load Distribution Scheme

! - Name

- Branch 3 Name

! - Name

! - Connector 1 Name

! - Connector 2 Name 
Branch,

CHWPlant Condenser Supply Inlet Branch, !- Name

Pump:Variablespeed,

CHWPlant Cnd Circ Pump,

CHWPlant Cnd Supply Inlet Node,

CHWPlant Cnd Pump Outlet Node,

Active;

! - Maximum Flow Rate $\{\mathrm{m} 3 / \mathrm{s}\}$

!- Component 1 Object Type

! - Component 1 Name

!- Component 1 Inlet Node Name

! - Component 1 outlet Node Name

!- Component 1 Branch Control Type

Branch,

CHWPlant Tower Branch,

CoolingTower: Singlespeed,

CHWPlant Tower,

CHWPlant Tower Inlet Node,

CHWPlant Tower Outlet Node,

Active;

! - Name

! - Maximum Flow Rate $\{\mathrm{m} 3 / \mathrm{s}\}$

! - Component 1 Object Type

! - Component 1 Name

! - Component 1 Inlet Node Name

! - Component 1 Outlet Node Name

!- Component 1 Branch Control Type

Branch

CHWPlant Condenser Supply Bypass Branch,

'Pipe:Adiabatic,

CHWPlant Condenser Supply Side Bypass,

! - Name

! - Maximum Flow Rate $\{\mathrm{m} 3 / \mathrm{s}\}$

!- Component 1 Object Type

CHWPlant Condenser Supply Bypass Inlet Node,

CHWPlant Condenser Supply Bypass Outlet Node,

! - Component 1 Name

! - Component 1 Inlet Node Name

Bypass；

! - Component 1 Outlet Node Name

!- Component 1 Branch Control Type

Pipe: Adiabatic,

CHWPlant Condenser Supply Side Bypass,

CHWPlant Condenser Supply Bypass Inlet Node,

! - Name

CHWPlant Condenser Supply Bypass Outlet Node;

! - Inlet Node Name

! - Outlet Node Name

Branch,

CHWPlant Condenser Supply Outlet Branch, !- Name

Pipe:Adiabatic,

CHWPlant Condenser Supply outlet,

! - Maximum Flow Rate $\{\mathrm{m} 3 / \mathrm{s}\}$

! - Component 1 object Type

! - Component 1 Name

CHWPlant Condenser Supply Exit Pipe Inlet Node,

CHWPlant Cnd Supply outlet Node,

!- Component 1 Inlet Node Name

! - Component 1 Outlet Node Name

Passive;

!- Component 1 Branch Control Type

Pipe:Adiabatic

CHWPlant Condenser Supply outlet,

! - Name

CHWPlant Condenser Supply Exit Pipe Inlet Node, !- Inlet Node Name

CHWPlant Cnd Supply outlet Node;

! - Outlet Node Name

BranchList,

CHWPlant Cnd Demand Side Branches,

CHWPlant Condenser Demand Inlet Branch,

CHWPlant Chiller Condenser Branch,

CHWPlant Condenser Demand Bypass Branch,

CHWPlant Condenser Demand Outlet Branch

! - Name

! - Branch 1 Name

! - Branch 2 Name

! - Branch 3 Name

! - Branch 4 Name

Connectorlist,

CHWPlant Cnd Demand Side Connectors,

Connector:Splitter,

CHWPlant Condenser Demand Splitter,

Connector:Mixer,

CHWPlant Condenser Demand Mixer:

! - Name

! - Connector 1 Object Type

! - Connector 1 Name

! - Connector 2 object Type

!- Connector 2 Name

Branch,

CHWPlant Condenser Demand Inlet Branch,

'Pipe: Adiabatic,

CHWPlant Cnd Demand Inlet Pipe,

CHWPlant Cnd Demand Inlet Node,

CHWPlant Cnd Demand In Pipe Outlet Node,

Passive;

! - Name

! - Maximum Flow Rate $\{\mathrm{m} 3 / \mathrm{s}\}$

! - Component 1 Object Type

! - Component 1 Name

!- Component 1 Inlet Node Name

!- Component 1 Outlet Node Name

!- Component 1 Branch Control Type

Pipe:Adiabatic

CHWPlant Cnd Demand Inlet Pipe,

! - Name 
CHWPlant Cnd Demand Inlet Node, CHWPlant Cnd Demand In Pipe Outlet Node;

Branch, CHWPlant Chiller Condenser Branch,

Chiller:Electric:EIR,

CHWPlant Chiller,

CHWPlant Chiller Cond Inlet Node,

CHWPlant Chiller Cond Outlet Node, Active;

Branch,

CHWPlant Condenser Demand Bypass Branch,

Pipe: Adiabatic,

CHWPlant Condenser Demand Side Bypass,

CHWPlant Condenser Demand Bypass Inlet Node,

CHWPlant Condenser Demand Bypass Outlet Node, Bypass;

Pipe:Adiabatic

CHWPlant Condenser Demand Side Bypass,

CHWPlant Condenser Demand Bypass Inlet Node,

CHWPlant Condenser Demand Bypass Outlet Node;

Branch,

CHWPlant Condenser Demand Outlet Branch,

Pipe: Adiabatic,

CHWPlant Condenser Demand Outlet,

CHWPlant Condenser Demand Exit Pipe Inlet Node,

CHWPlant Cnd Demand Outlet Node,

Passive;

Pipe: Adiabatic,

CHWPlant Condenser Demand outlet,

CHWPlant Condenser Demand Exit Pipe Inlet Node, CHWPlant Cnd Demand Outlet Node;

Connector:Splitter,

CHWPlant Condenser Demand Splitter,

CHWPlant Condenser Demand Inlet Branch, CHWPlant Chiller Condenser Branch,

CHWPlant Condenser Demand Bypass Branch;

Connector:Mixer,

CHWPlant Condenser Demand Mixer

CHWPlant Condenser Demand Outlet Branch,

CHWPlant Chiller Condenser Branch,

CHWPlant Condenser Demand Bypass Branch;

Connector:Splitter

CHWPlant Condenser Supply Splitter,

CHWPlant Condenser Supply Inlet Branch,

CHWPlant Tower Branch,

CHWPlant Condenser Supply Bypass Branch;

Connector:Mixer,

CHWPlant Condenser Supply Mixer,

CHWPlant Condenser Supply Outlet Branch,

CHWPlant Tower Branch,

CHWPlant Condenser Supply Bypass Branch;

CondenserEquipmentoperationschemes,

CHWPlant Condenser Loop Operation,

PlantEquipmentoperation: CoolingLoad,

CHWPlant Condenser Only,

FAN-SCHED;

PlantEquipmentoperation:CoolingLoad,
! - Inlet Node Name

! - Outlet Node Name

! - Name

! - Maximum Flow Rate $\{\mathrm{m} 3 / \mathrm{s}\}$

!- Component 1 Object Type

! - Component 1 Name

! - Component 1 Inlet Node Name

! - Component 1 Outlet Node Name

!- Component 1 Branch Control Type

! - Name

! - Maximum Flow Rate $\{\mathrm{m} 3 / \mathrm{s}\}$

! - Component 1 Object Type

! - Component 1 Name

!- Component 1 Inlet Node Name

! - Component 1 Outlet Node Name

!- Component 1 Branch Control Type

! - Name

! - Inlet Node Name

! - Outlet Node Name

! - Name

! - Maximum Flow Rate $\{\mathrm{m} 3 / \mathrm{s}\}$

! - Component 1 Object Type

! - Component 1 Name

!- Component 1 Inlet Node Name

! - Component 1 Outlet Node Name

!- Component 1 Branch Control Type

! - Name

! - Inlet Node Name

! - Outlet Node Name

! - Name

! - Inlet Branch Name

! - Outlet Branch 1 Name

! - Outlet Branch 2 Name

! - Name

! - Outlet Branch Name

! - Inlet Branch 1 Name

!- Inlet Branch 2 Name

! - Name

! - Inlet Branch Name

! - Outlet Branch 1 Name

! - Outlet Branch 2 Name

! - Name

! - Outlet Branch Name

! - Inlet Branch 1 Name

!- Inlet Branch 2 Name

! - Name

! - Control Scheme 1 object Type

! - Control Scheme 1 Name

! - Control Scheme 1 Schedule Name 


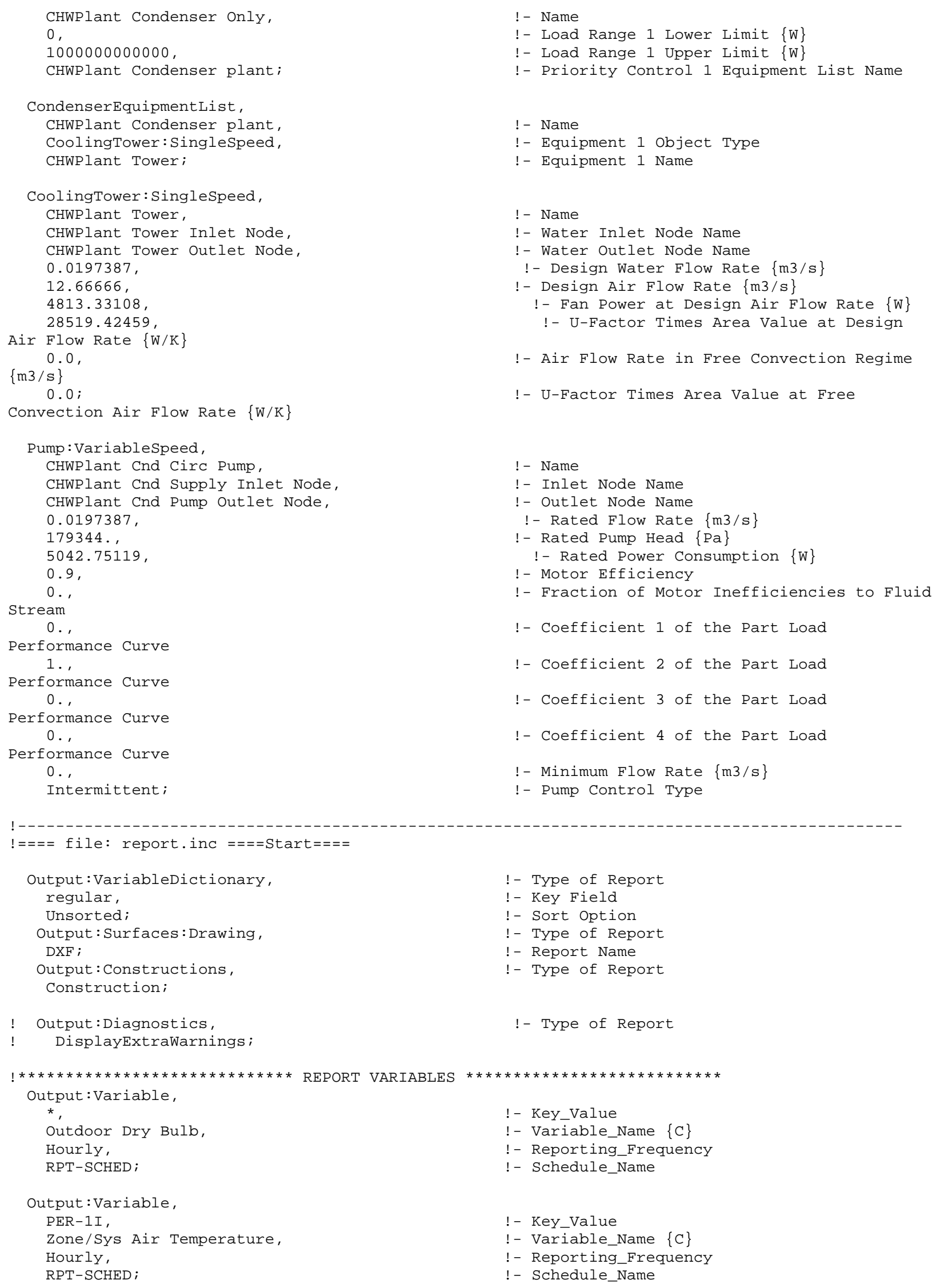




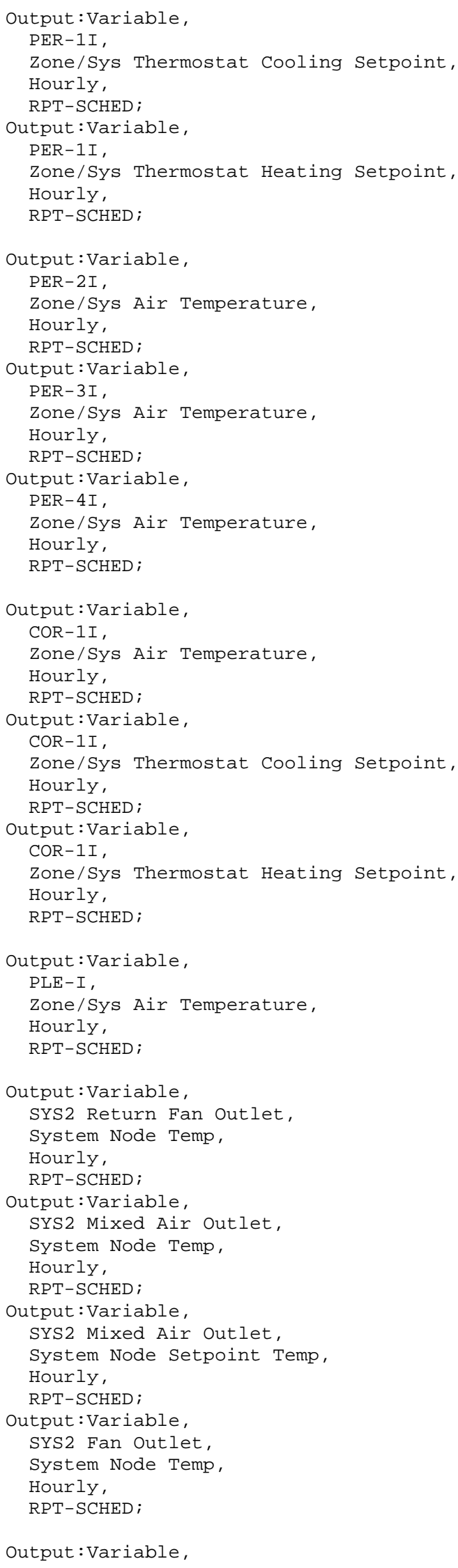

Output:Variable, 
PER-1I SUPPLY INLET, System Node Temp, Hourly, RPT - SCHED;

Output:Variable, PER-2I SUPPLY INLET, System Node Temp, Hourly, RPT -SCHED;

Output:Variable PER-3I SUPPLY INLET, System Node Temp, Hourly, RPT -SCHED;

Output: Variable, PER-4I SUPPLY INLET, System Node Temp, Hourly, RPT - SCHED;

Output:Variable, COR-1I SUPPLY INLET, System Node Temp, Hourly, RPT-SCHED;
! - Key_Value

! - Variable_Name $\{C\}$

! - Reporting_Frequency

! - Schedule_Name

! - Key Value

! - Variable_Name $\{C\}$

! - Reporting_Frequency

! - Schedule_Name

! - Key_Value

! - Variable_Name $\{c\}$

! - Reporting_Frequency

! - Schedule_Name

! - Key_Value

! - Variable_Name $\{\mathrm{C}\}$

! - Reporting_Frequency

!- Schedule_Name

! - Key_Value

! - Variable_Name $\{c\}$

! - Reporting_Frequency

! - Schedule_Name

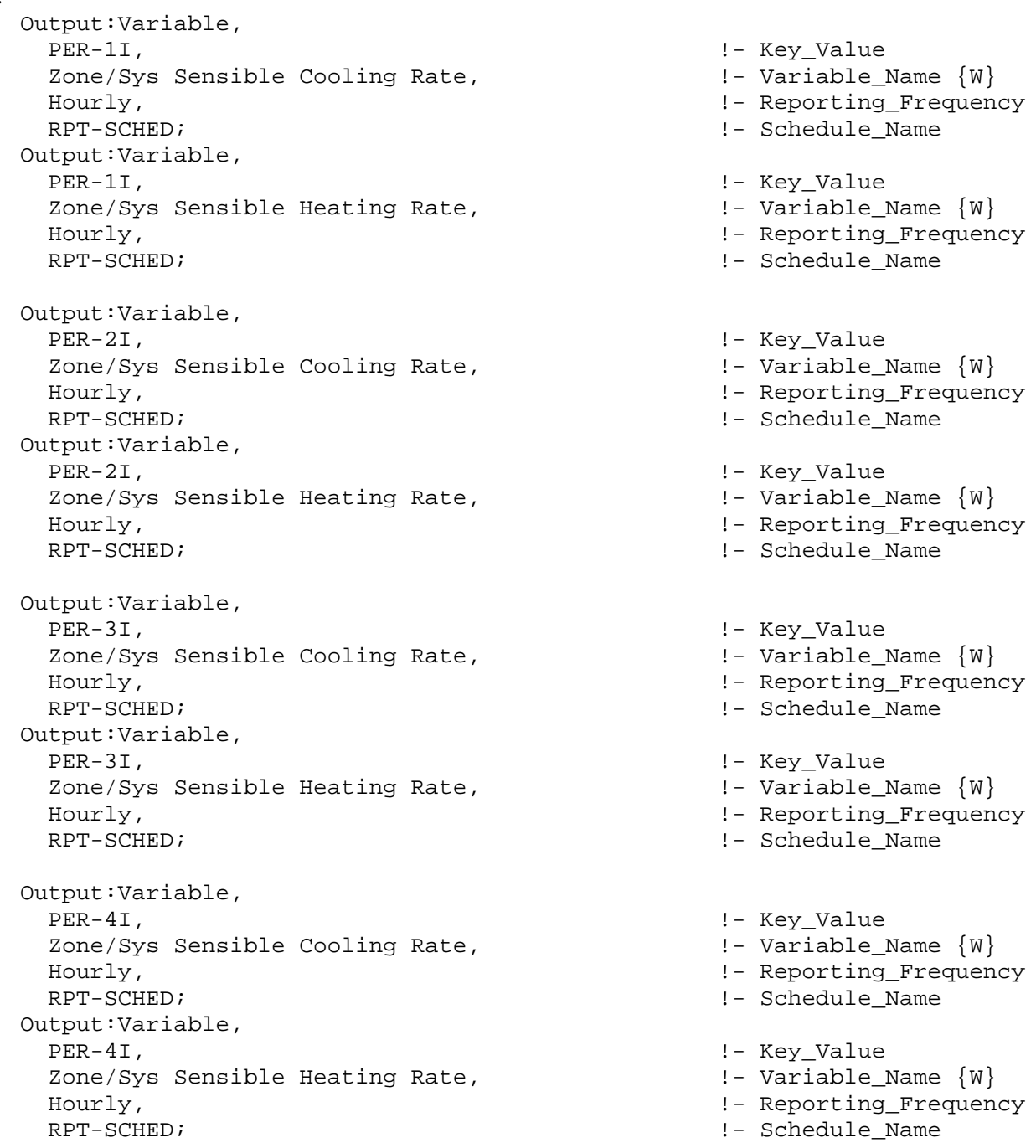

Output:Variable, 
COR-1I,

Zone/Sys Sensible Cooling Rate, Hourly, RPT - SCHED;

output: Variable,

COR-1I,

Zone/Sys Sensible Heating Rate, Hourly,

RPT - SCHED;

Output: Variable

PER-1I REHEAT COIL,

Total Water Heating Coil Rate,

Hourly,

RPT - SCHED;

Output:Variable,

PER-2I REHEAT COIL

Total water Heating Coil Rate,

Hourly,

RPT - SCHED ;

Output: Variable,

PER-3I REHEAT COIL,

Total water Heating Coil Rate,

Hourly,

RPT - SCHED;

Output:Variable,

PER-4I REHEAT COIL,

Total Water Heating Coil Rate,

Hourly,

RPT - SCHED :

Output: Variable,

COR-1I REHEAT COIL

Total Water Heating Coil Rate,

Hourly,

RPT - SCHED;

Output:Variable,

SYS2 COOLING COIL,

Total water Cooling coil Rate,

Hourly,

RPT - SCHED :

Output:Variable,

SYS2 COOLING COIL,

Sensible water Cooling Coil Rate,

Hourly,

RPT - SCHED ;

$* * * * * * * * * * * * * * * * * *$
Output: Variable

PER-1I,

Zone Total Internal Total Heat Gain,

Hourly,

RPT - SCHED :

Output:Variable,

PER-1I,

Zone People Number of Occupants,

Hourly,

RPT - SCHED;

Output: Variable,

PER-1I,

Zone People Total Heat Gain,

Hourly,

RPT - SCHED;

Output: Variable,

PER-1I,

Zone Lights Electric Power,

to return

Hourly,

RPT - SCHED;

Output: Variable,

PER-1I,

Zone Electric Equipment Electric Power,
! - Key_Value

! - Variable_Name $\{W\}$

! - Reporting_Frequency

! - Schedule_Name

! - Key Value

! - Variable_Name $\{W\}$

! - Reporting_Frequency

! - Schedule_Name

! - Key_Value

! - Variable_Name $\{W\}$

! - Reporting_Frequency

! - Schedule_Name

! - Key_Value

! - Variable_Name $\{W\}$

! - Reporting_Frequency

! - Schedule_Name

! - Key_Value

! - Variable_Name $\{W\}$

! - Reporting_Frequency

! - Schedule_Name

! - Key_Value

! - Variable_Name $\{W\}$

! - Reporting_Frequency

! - Schedule_Name

! - Key_Value

! - Variable_Name $\{W\}$

! - Reporting_Frequency

! - Schedule Name

! - Key_Value

! - Variable Name $\{W\}$

! - Reporting_Frequency

! - Schedule Name

! - Key_Value

! - Variable_Name $\{W\}$

! - Reporting_Frequency

! - Schedule Name

! - Key_Value

! - Variable Name $\{\mathrm{J}\}$

! - Reporting_Frequency

! - Schedule_Name

! - Key_Value

! - Variable_Name \{\}

! - Reporting_Frequency

! - Schedule_Name

! - Key_Value

! - Variable_Name $\{\mathrm{J}\}$

! - Reporting_Frequency

! - Schedule_Name

! - Key_Value

! - Variable_Name $\{W\}$ total including fraction

! - Reporting_Frequency

! - Schedule_Name

! - Key_Value

! - Variable_Name $\{W\}$ 


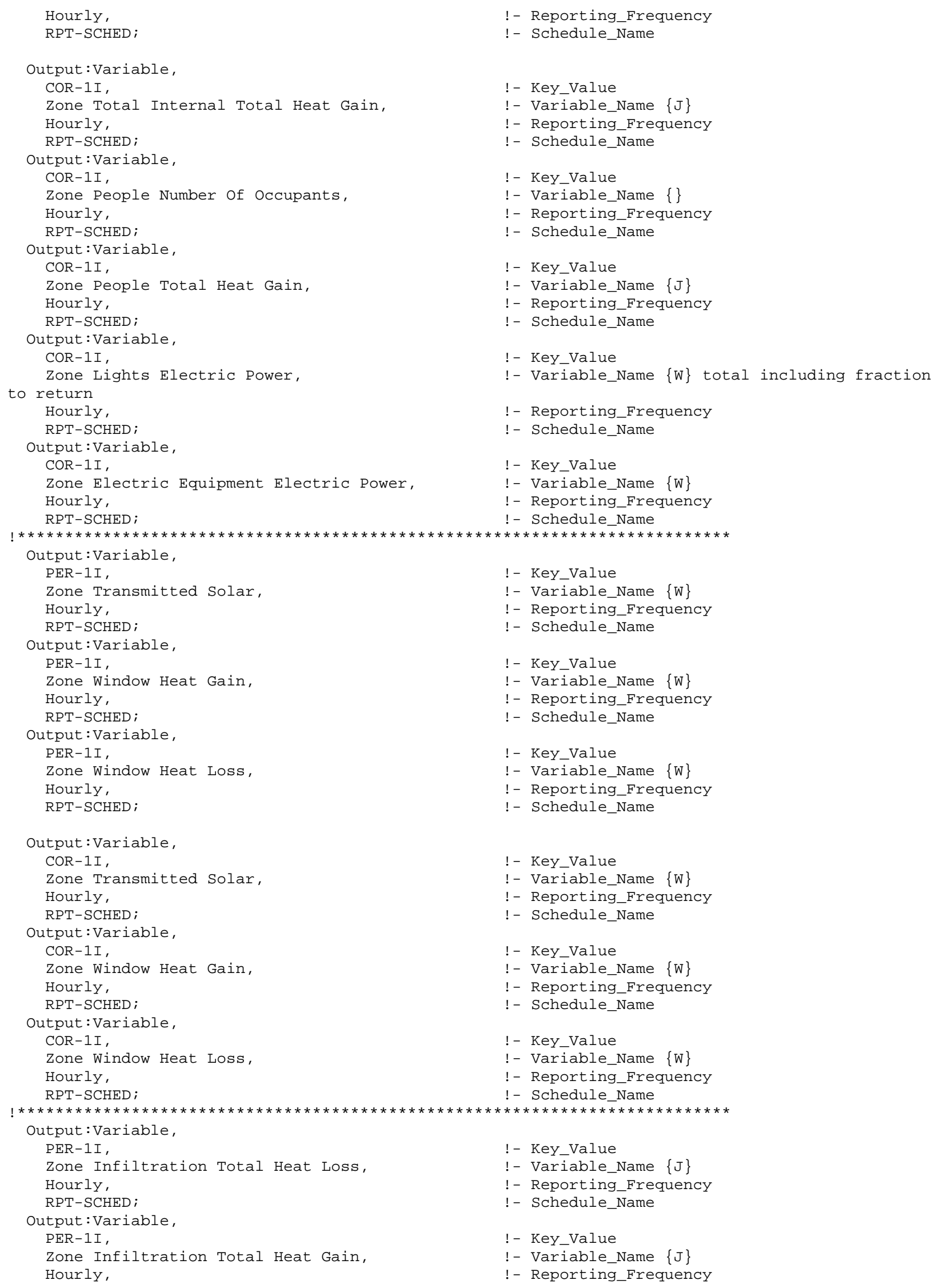




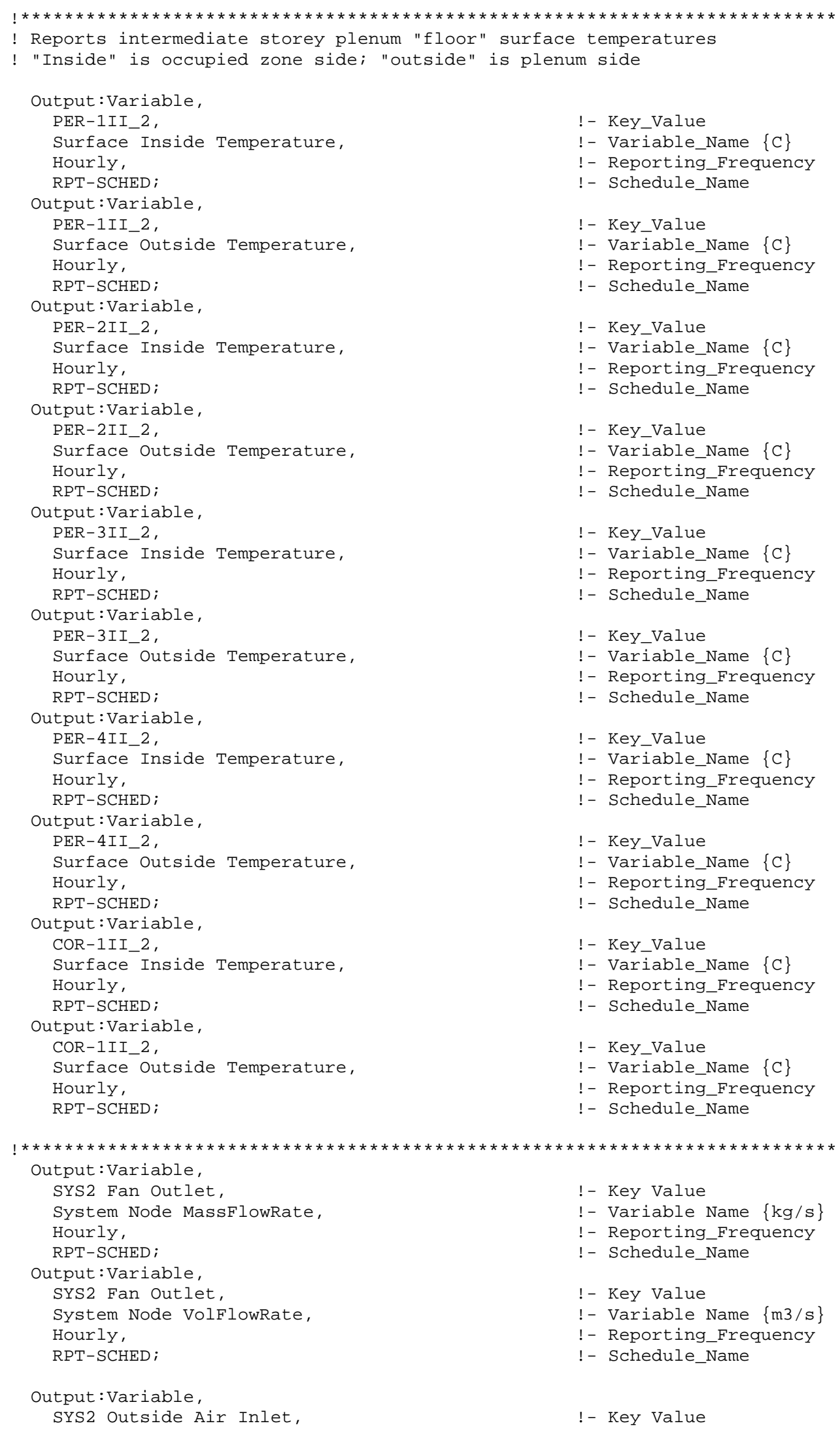


System Node MassFlowRate,

! - Variable Name $\{\mathrm{kg} / \mathrm{s}\}$

Hourly,

! - Reporting_Frequency

RPT - SCHED :

! - Schedule_Name

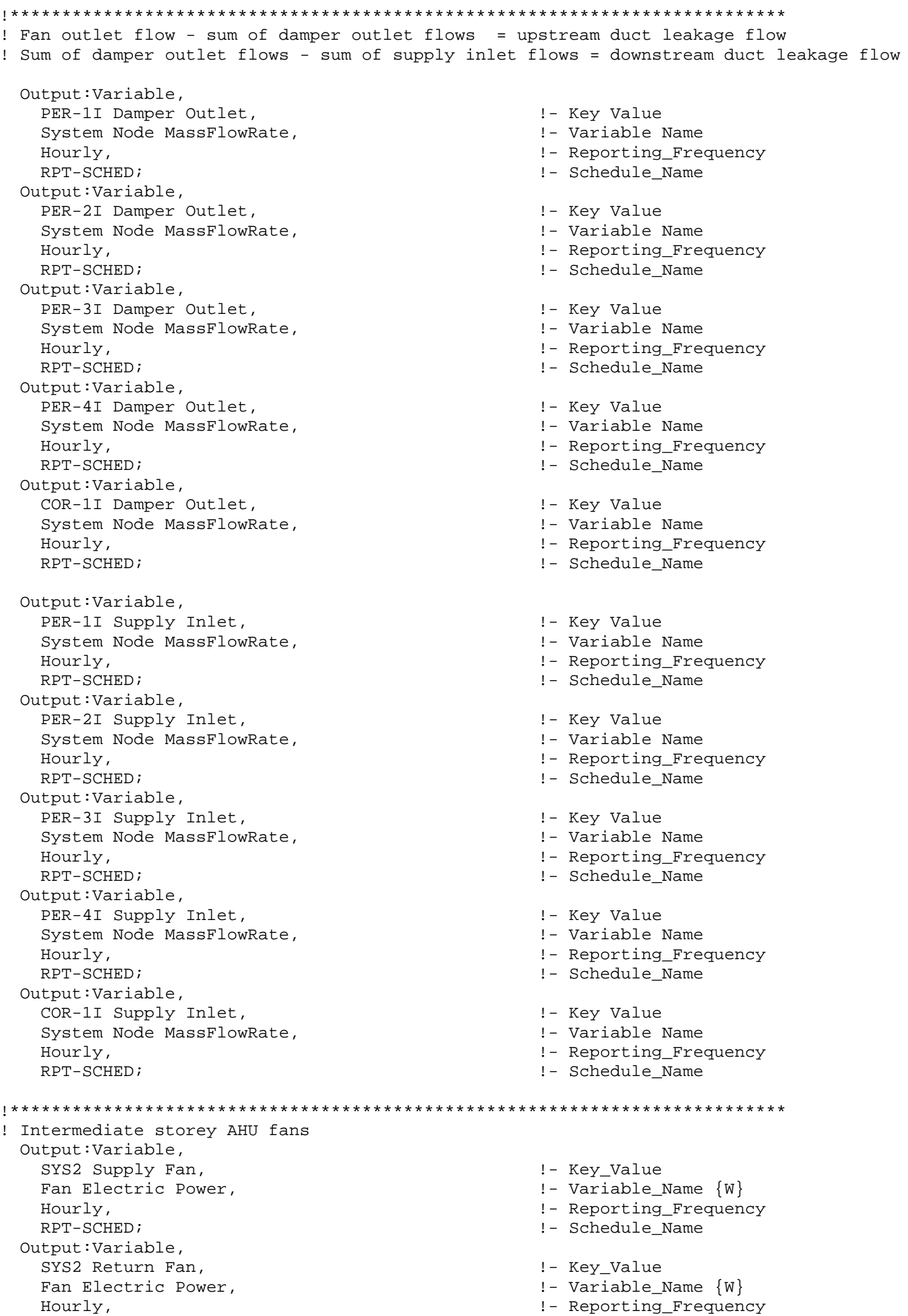


! Chilled water circ, condenser water circ, and hot water circ pumps Output:Variable,

*,

Pump Electric Power, Hourly, RPT - SCHED ;

Output:Variable,<smiles>[3H]</smiles>
Chiller Electric Power Hourly, RPT - SCHED;

Output:Variable, *, Tower Fan Electric Power, Hourly, RPT - SCHED ;

Output:Variable, *, Boiler Gas Consumption Rate, Hourly, RPT - SCHED ;

Output: Variable, *, Total HVAC Electric Demand, Hourly, RPT - SCHED :

Output:Variable, *, Total Building Electric Demand, Hourly, RPT - SCHED
! - Key_Value

! - Variable_Name $\{W\}$

! - Reporting_Frequency

! - Schedule_Name

! - Key_Value

! - Variable_Name $\{W\}$

! - Reporting_Frequency

! - Schedule_Name

I - Key_Value

! - Variable_Name $\{W\}$

! - Reporting_Frequency

! - Schedule_Name

! - Key_Value

! - Variable_Name $\{W\}$

! - Reporting_Frequency

! - Schedule Name

! - Key_Value

! - Variable_Name $\{W\}$

! - Reporting_Frequency

! - Schedule_Name

! - Key_Value

! - Variable_Name $\{W\}$

! - Reporting_Frequency

! - Schedule Name

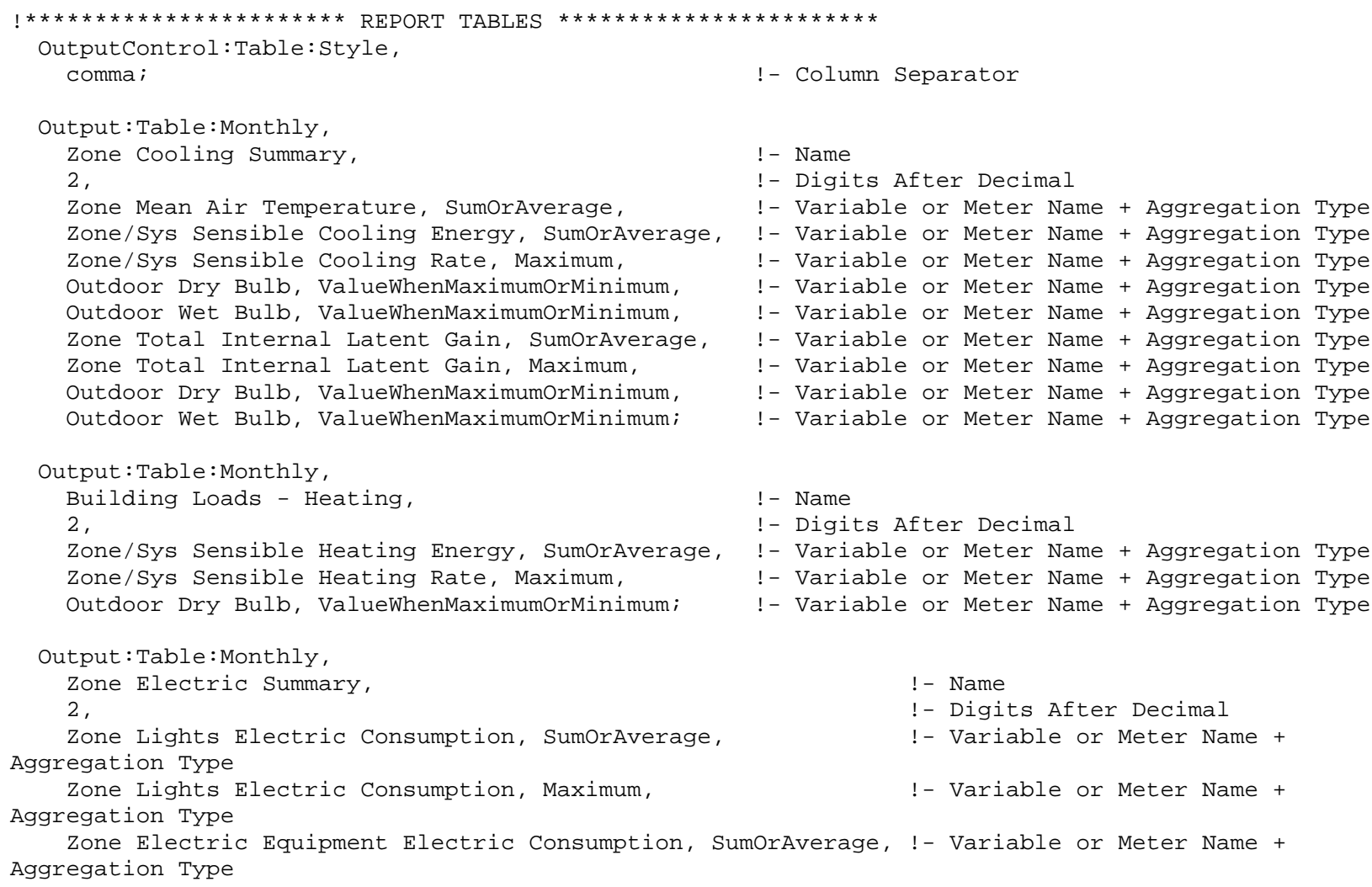


Zone Electric Equipment Electric Consumption, Maximum;

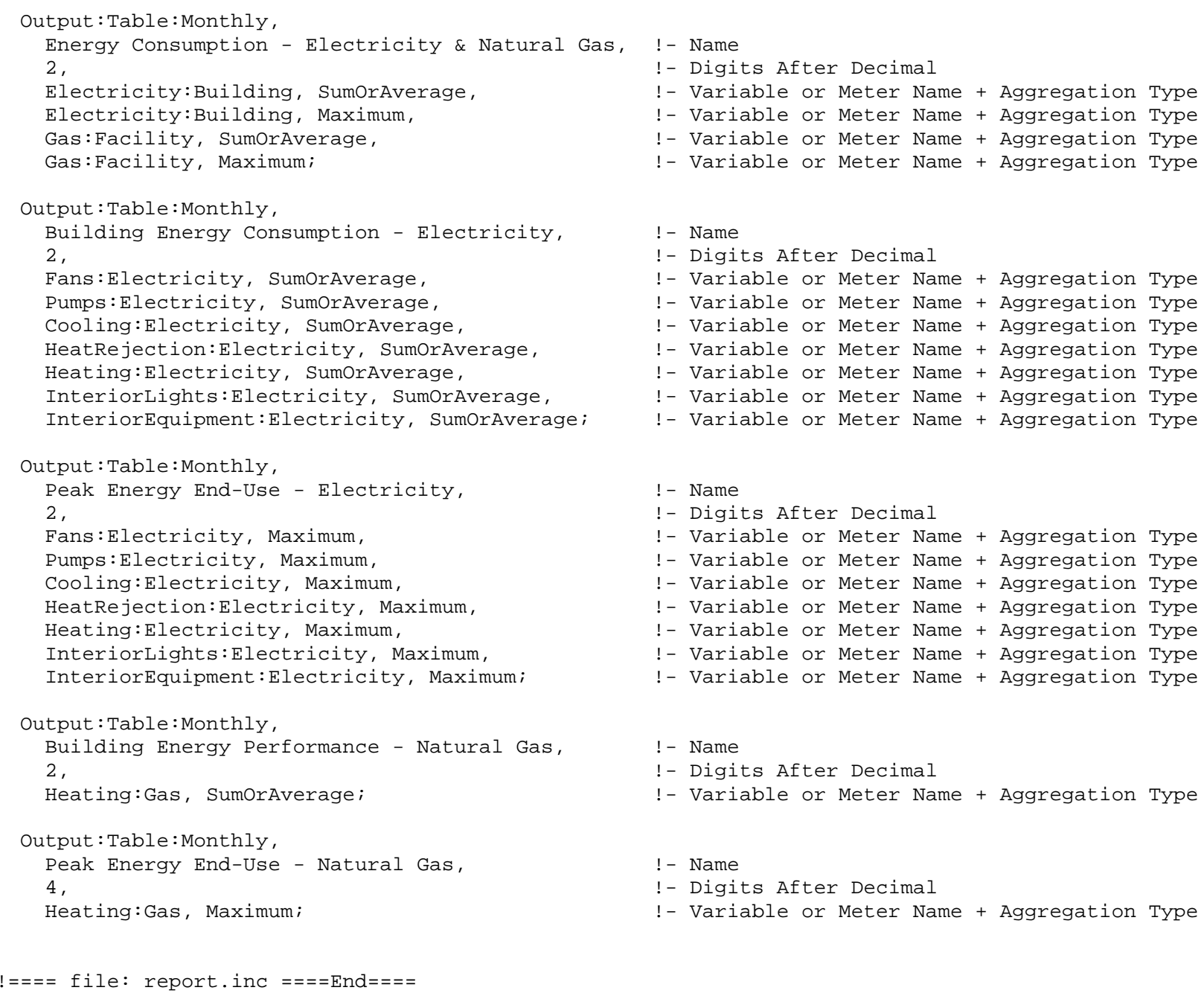

